\title{
Patterns of post-translational histone modifications, chromatin condensation and DNA fragmentation during apoptosis
}

\author{
Dissertation \\ zur Erlangung des Doktorgrades \\ der Mathematisch-Naturwissenschaftlichen Fakultäten \\ der Georg-August-Universität zu Göttingen
}

vorgelegt von

Nadine Beisel

aus Göttingen

Göttingen 2005 
D7

Referent: Prof. Dr. D. Doenecke

Korreferent: Prof. Dr. R. Hardeland

Tag der mündlichen Prüfung: 03.11.2005 
Die vorliegende Arbeit wurde in der Zeit von Oktober 2002 bis Oktober 2005 in der Abteilung Molekularbiologie unter Anleitung von Prof. Dr. D. Doenecke am Institut für Biochemie und Molekulare Zellbiologie der Georg-August-Universität zu Göttingen angefertigt. 


\section{Meinen Eltern}

I do not know what I may appear to the world, but to myself I seem to have been only like a boy playing on the sea-shore, and diverting myself in now and then finding a smoother pebble or a prettier shell than ordinary, whilst the great ocean of truth lay all undiscovered before me.

Sir Isaac Newton 


\section{Contents}

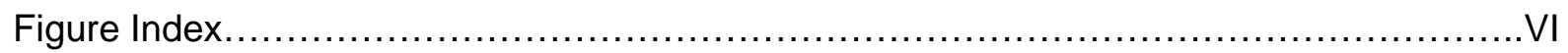

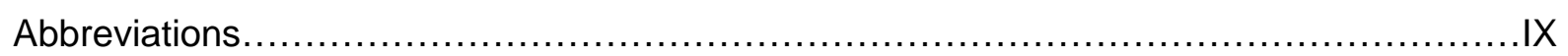

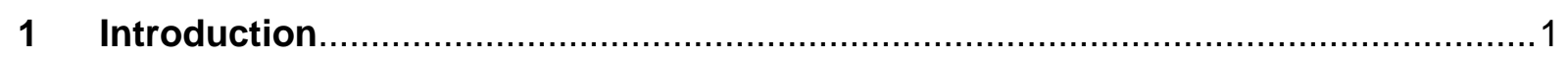

1.1 From nucleosome to chromosome: higher order chromatin structure ....................1

1.2 Histones and histone modifications .......................................................... 5

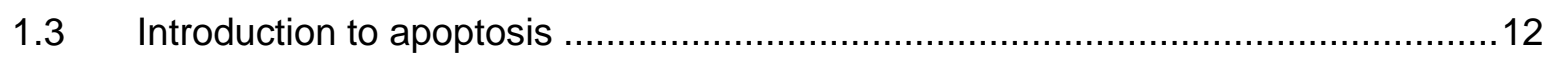

1.3.1 Biological significance and morphological / biochemical features .................12

1.3.2 Signalling pathways of apoptosis: molecular mechanisms ...........................14

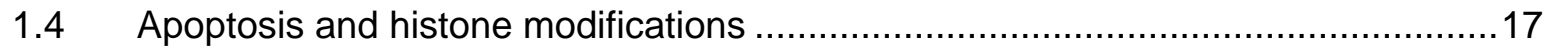

1.5 Present state of research and main aims of this project.................................19

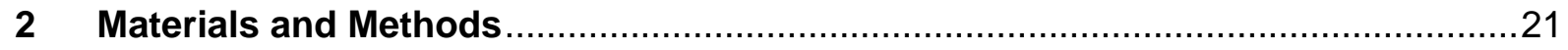

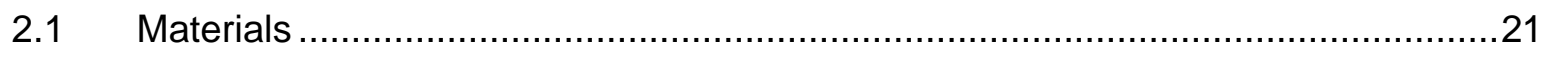

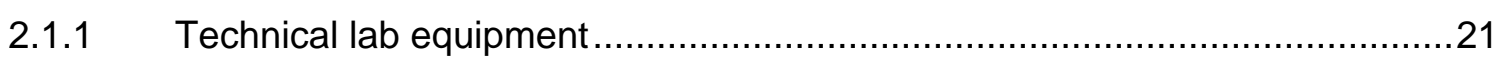

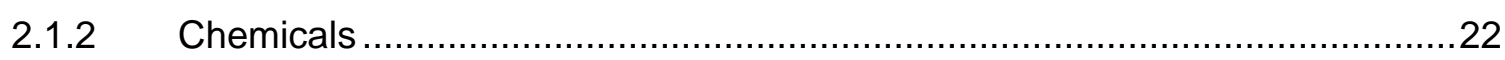

2.1.3 Standard buffers, media and solutions ............................................... 24

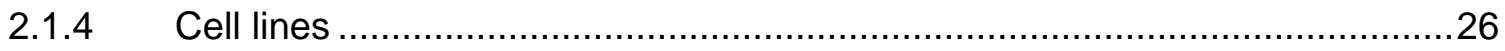

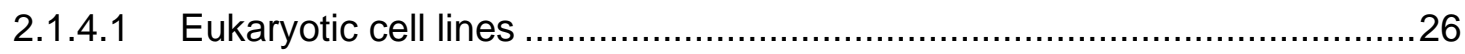

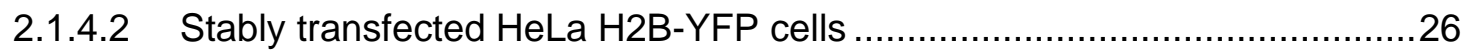

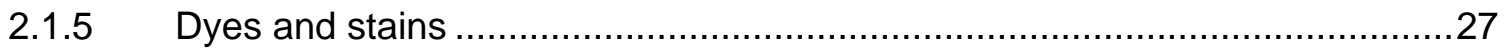

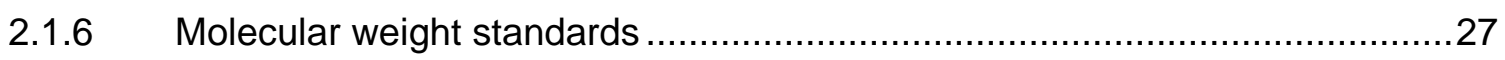

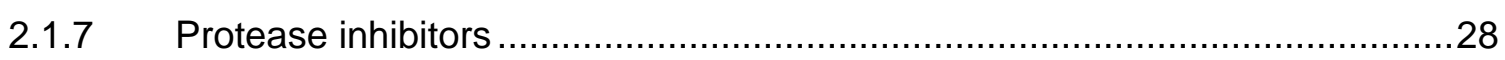

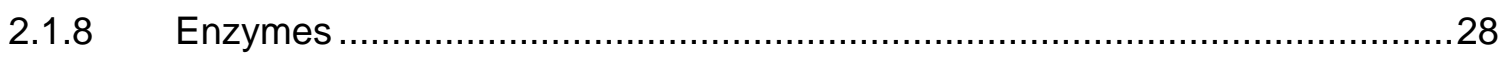

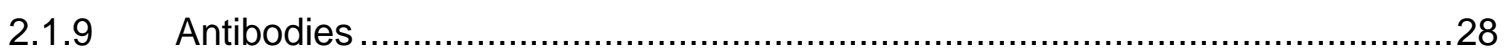

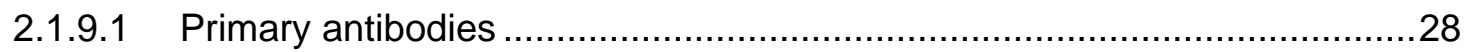

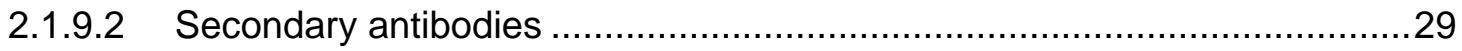

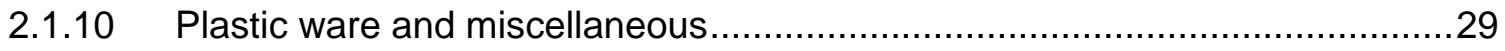

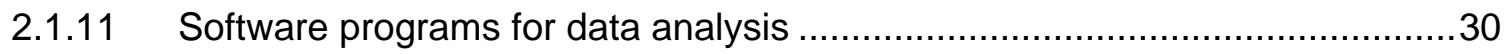

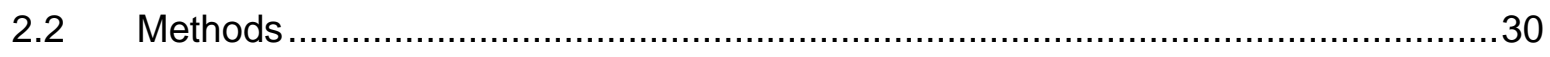

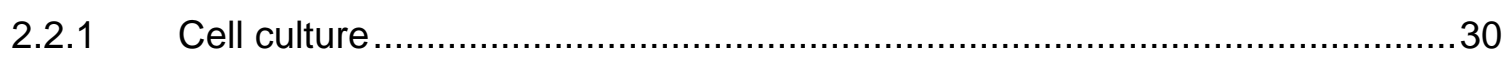

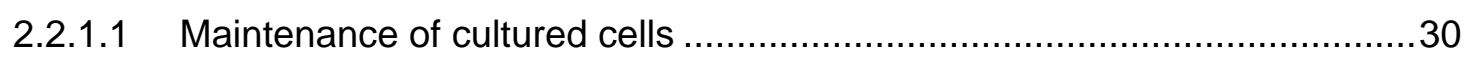

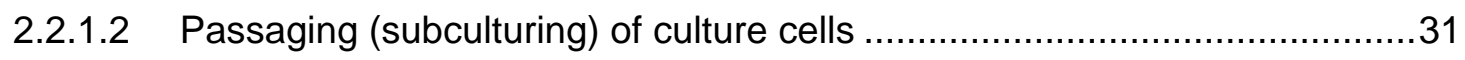

2.2.1.3 Freezing and thawing of cells for storage and cultivation .........................31

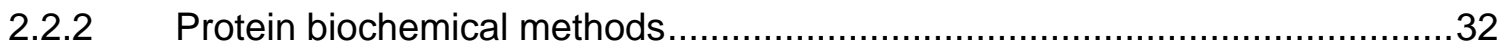

2.2.2.1 Protein extraction with TCA (trichloroacetic acid) ..................................32 
2.2.2.2 Preparation of core histones from eukaryotic cells .................................. 32

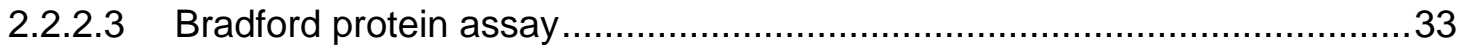

2.2.2.4 SDS polyacrylamide gel electrophoresis (SDS-PAGE) .............................33

2.2.2.5 Two-dimensional AUT/AUC-gel electrophoresis...........................................

2.2.2.5.1 Western blotting and immuno-detection .........................................39

2.2.2.5.2 Methods for protein detection .................................................... 40

2.2.2.5.2.1 Enhanced chemiluminescence (ECL) .....................................40

2.2.2.5.2.2 Colour detection: alkaline phosphatase with NBT/BCIP ….........41

2.2.2.5.2.3 Colour detection with diaminobenzidine (DAB) ..........................42

2.2.2.5.2.4 Stripping and re-probing ECL membranes................................. 42

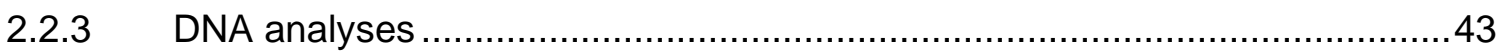

2.2.3.1 Phenol/chloroform extraction of DNA ................................................ 43

2.2.3.2 Agarose gel electrophoresis ............................................................... 43

2.2.4 Monitoring the process of apoptosis .................................................. 44

2.2.4.1 Preparation of apoptotic nucleosomal DNA (DNA ladder) .......................44

2.2.4.2 PARP (poly-ADP-ribose-polymerase) cleavage assay ............................45

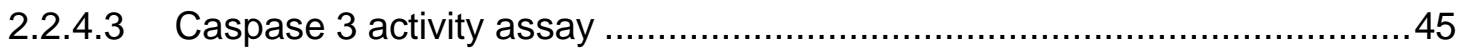

2.2.5 Nuclei-cytosol preparation techniques ..................................................... 46

2.2.5.1 Nuclei-cytosol preparations: different protocols .....................................46

2.2.5.2 Nuclei-cytosol preparations for comparative analysis of histone release into the cytosol during apoptosis...........................................48

2.2.6 Separation of apoptotic oligonucleosomes ................................................49

2.2.6.1 Sucrose gradients: size fractionation of apoptotic nucleosomal DNA fragments ................................................................ 49

2.2.6.2 Histone extraction from sucrose gradient pellet....................................50

2.2.7 Purification and preparation techniques for single

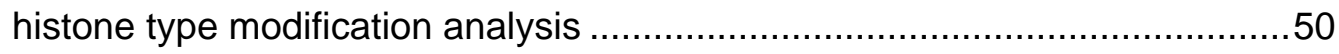

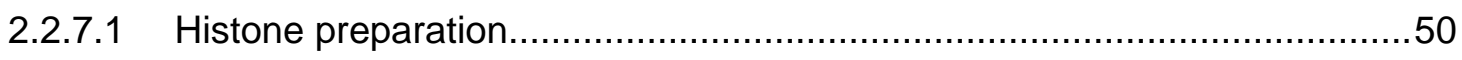

2.2.7.2 Preparation of a Bio-Gel ${ }^{\circledR}$ P60 polyacrylamide gel column .......................51

2.2.7.3 Separation and crude purification of core histones on Bio-Gel ${ }^{\circledR}$ P60 columns .52

2.2.7.4 Separation and purification of single core histone types on high performance liquid chromatography (HPLC) ............................52

2.2.7.5 Analysis of core histones via capillary zone electrophoresis (CZE) ............53

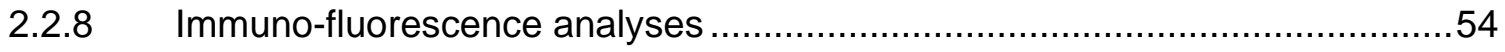

2.2.9 Fluorescence activated cell sorting (FACS) and TUNEL-assay .....................55 
3 Results.

3.1 Monitoring the ongoing process of apoptosis:

apoptosis markers for HL-60 cells

3.2 Monitoring the ongoing process of apoptosis:

apoptosis markers for HeLa H2B-YFP cells

3.3 Analysis of putative short-term dependent changes in

core histone modifications after induction of apoptosis 63

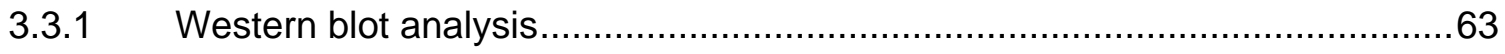

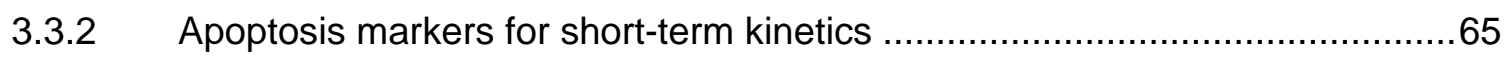

3.4 Analysis of putative long-term dependent changes in

core histone modifications after induction of apoptosis ..................................6 67

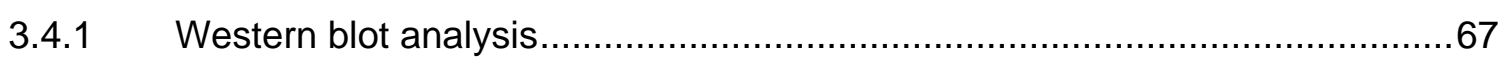

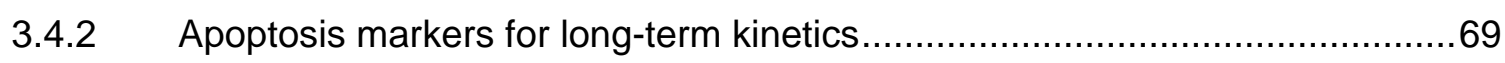

3.5 Purification and separation of core histones from HL-60

control and apoptotic cells ................................................................. 71

3.5.1 P60 Bio-gel ${ }^{\circledR}$ size exclusion chromatography (P60 column) ........................ 71

3.5.2 High performance liquid chromatography (HPLC) .................................. 73

3.6 Apoptosis-related changes of histone modifications in $\mathrm{HL}-60$.............................77

3.6.1 AUT-2D gel electrophoresis: $1^{\text {st }}$ dimension ........................................... 77

3.6.2 AUT-2D gel electrophoresis: $2^{\text {nd }}$ dimension ......................................... 80

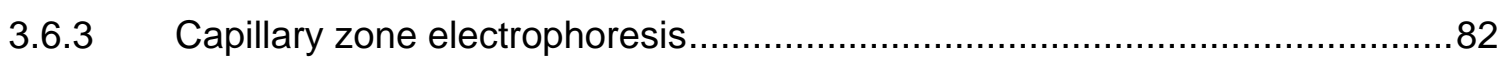

3.7 Nucleus-cytosol preparations - a question of techniques ................................ 86

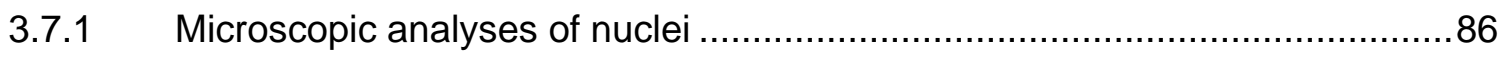

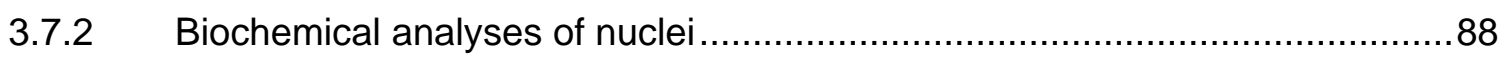

3.8 Apoptosis-related nucleosomal cleavage and nuclear

release of specifically modified core histones from HL-60 cells .............................90

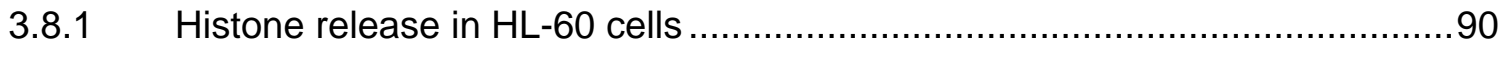

3.8.2 Histone release in HeLa H2B-YFP cells ................................................ 94

3.8.3 Comparative analysis of nuclear histone release ....................................99

3.9 Microscopic analyses of an apoptosis-related nuclear

release of core histones in stably transfected HeLa H2B-YFP cells. 104

3.9.1 Microscopic analysis of the nuclear lamina (lamin A/C) in HeLa H2B-YFP cells after induction of apoptosis. 104

3.9.2 Analysis of the nuclear lamina in HeLa H2B-YFP cells after induction of apoptosis via laser-scan microscopy. 106 
3.9.3 Microscopic analysis of the nuclear membrane via N-gycosylated nuclear pore complex proteins (anti-N-acetylglucosamine) in HeLa H2B-YFP cells after induction of apoptosis.

3.9.4 Analysis of the nuclear envelope in HeLa H2B-YFP cells via laser-scan microscopy after induction of apoptosis

3.9.5 Microscopic analysis of cytosolic structures (tubulin- $\alpha$ ) in HeLa H2B-YFP cells after induction of apoptosis.

3.9.6 Analysis of cytosolic structures (tubulin- $\alpha$ ) in HeLa H2B-YFP

cells after induction of apoptosis via laser-scan microscopy

3.10 Analysis of different histone modifications in nucleosomes

of fragmented chromatin after induction of apoptosis

compared to modifications in unfragmented chromatin

3.10.1 Accumulation of specific modifications in fragmented chromatin .................116

3.10.2 Depletion of specific modifications in fragmented chromatin ........................120

3.10.3 Histone modifications showing no specific distribution

in fragmented or bulk chromatin regions

3.10.4 Specific techniques for the extraction of

histone proteins from nuclear pellets

3.10.5 Analysis of a putative accumulation of heterochromatin

protein HP1- $\alpha$ in regions of fragmented chromatin .

3.11 Quantitative analysis of apoptosis-related DNA fragmentation

via FACS (fluorescence activated cell sorting)

4 Discussion

4.1 The role of post translational histone modifications

for chromatin structure during apotosis

4.2 Topotecan $^{\circledR}$ and etoposide induce apoptosis

in human cell lines HL-60 and HeLa.

4.3 Linking changes in histone modifications with apoptosis.

4.3.1 Overall time-dependent changes in histone

modifications linked with apoptosis.

4.3.2 Overall time-dependent changes in histone

modifications and histone variants linked with apoptosis

4.3.2.1 Purification and separation of histones via HPLC ................................... 138

4.3.2.2 Separation of histones via AUT/AUC- $2^{\text {nd }}$ dimension gel electrophoresis.

4.3.2.3 Separation of core histones via capillary zone electrophoresis 142 
4.4 Linking apoptosis-related cleavage and release of nucleosomal

DNA with specifically modified core histones: cell signalling

mechanism or pathological condition?

4.4.1 Analysing the release of unmodified and post-translationally

modified core histones into the nucleoplams / cytoplasm

after induction of apoptosis

4.5 Differences in histone modification composition of histones

from fragmented chromatin compared to histones from

non-fragmented chromatin after induction of apoptosis.

4.6 Future prospects

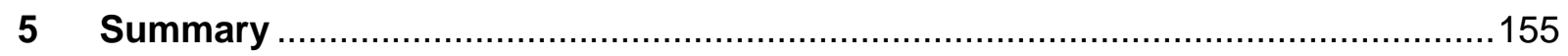

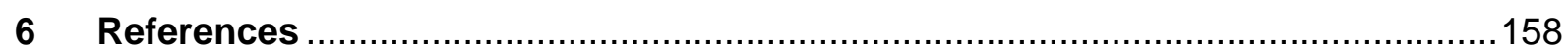




\section{Figure Index}

Fig. 1.1.1 From nucleosome to higher order chromatin structure: different stages of DNA packaging.....

Fig. 1.1.2 Model of the $30 \mathrm{~nm}$ fiber structure. Zigzag model of alternating

nucleosomes (a) versus a solenoid of adjacent nucleosomes (b) ......................... 4

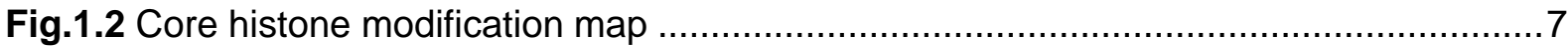

Fig. 1.3.2.1 Receptor-mediated caspase activation

via the DISC death-inducing signalling complex

Fig. 1.3.2.2 Mitochondria-mediated formation and activation of the apoptosome 16

Fig. 1.3.2.3 Apoptosis signalling pathways (extrinsic I+II; intrinsic) .....

Fig. 2.2. 2. 2.1 HRP driven chemiluminescent reaction of Lumigen PS-3.

Fig. 2.2.2.5.2.2 Chemical reaction initiated by alkaline phosphatase 42

Fig. 2.2.2.6.2.3 3,3'-diaminobenzidine.

Fig. 3.1 Markers for monitoring the ongoing process of apoptosis

in HL-60 cells: cleavage of nucleosomal DNA and PARP, caspase 3 assay.

Fig. 3.2 Markers for monitoring the ongoing process of apoptosis in

HeLa H2B-YFP cells: cleavage of nucleosomal DNA.

Fig. 3.2 (cont. 1) Markers for monitoring the ongoing process of apoptosis

in HeLa H2B-YFP cells: PARP cleavage and caspase 3 assay.

Fig. 3.3.1 Short-term kinetics for analyses of changes in histone modifications in HL-60 cells after induction of apoptosis with topotecan $\AA$. 65

Fig. 3.3.2 Monitoring the ongoing process of apoptosis during

short-term kinetics: cleavage of nucleosomal DNA.

Fig. 3.3.2 (cont. 1) Monitoring the ongoing process of apoptosis during

short-term kinetics: PARP cleavage and caspase 3 assay.

Fig. 3.4.1 Long-term kinetics for changes in histone modifications in

HL-60 cells after induction of apoptosis with topotecan ${ }^{\circledR}$.

Fig. 3.4.2 Monitoring the ongoing process of apoptosis during long-term

kinetics: cleavage of nucleosomal DNA and PARP and caspase 3 assay....

Fig. 3.5.1 Purification and separation of core histones from HL-60

control and apoptotic cells via P60 Biogel $₫$ size exclusion chromatography.

Fig. 3.5.2.1 HPLC retention times of all four core histones from HL-60 control cells.

Fig. 3.5.2.2 HPLC retention times of all four core histones

from topotecan ${ }^{\circledR}$ treated $\mathrm{HL}-60$ cells.

Fig. 3.5.2.3 Separation of core histones via HPLC and

assignment of peaks to specific histone types. 76

Fig. 3.6.1 AUT-1st dimension gel electrophoresis of single histone types. 
Fig. 3.6.2 AUT-2nd dimension gel electrophoresis of single histone subtypes....................81

Fig. 3.6.3 Capillary zone electrophoresis analyses of core histones. ............................... 83

Fig. 3.6.3 (cont. 1) Capillary zone electrophoresis analyses of core histones. .....................85

Fig. 3.7.1 Fluorescence microscopy of DAPI stained from HL-60 nuclei from four different nucleus-cytosol preparations

Fig. 3.7.2 Analysis of cytosolic fractions and nuclear fractions

for the cytosolic marker protein lactate dehydrogenase and the nuclear marker proteins PARP and RNA polymerase II.

Fig. 3.8.1 Western blot analyses of apoptosis-related

nucleosomal cleavage and release of unmodified core histones

from bulk chromatin into the nucleus and cytosol.

Fig. 3.8.1 (cont. 1) Western blot analyses of apoptosis-related

nucleosomal cleavage and release of specifically modified

core histones from bulk chromatin into the nucleus and cytosol.

Fig. 3.8.1 (cont. 2) Western blot analyses of apoptosis-related

nucleosomal cleavage and release of specifically modified

core histones from bulk chromatin into the nucleus and cytosol.

Fig. 3.8.2 Western blot analyses of apoptosis-related nucleosomal

cleavage and release of unmodified core histones from bulk

chromatin into the nucleus and cytosol.

Fig. 3.8.2 (cont. 1) Western blot analyses of apoptosis-related

nucleosomal cleavage and release of specifically modified

core histones from bulk chromatin into the nucleus and cytosol.

Fig. 3.8.2 (cont. 2) Western blot analyses of apoptosis-related

nucleosomal cleavage and release of specifically modified core

histones from bulk chromatin into the nucleus and cytosol.

Fig. 3.8.3 Monitoring the ongoing process of apoptosis with reference

to the nucleus-cytosol preparation protocol according to Radic et al. (2004).......101

Fig. 3.8.3 (cont. 1) Monitoring the ongoing process of apoptosis

with reference to the nucleus-cytosol preparation protocol

according to Radic et al. (2004). 102

Fig. 3.8.3 (cont. 2) Western blot analyses of apoptosis-related nucleosomal cleavage and release of core histones from bulk chromatin into the nucleus and cytosol with reference to a nucleus-cytosol preparation protocol by Radic et al. (2004). 103

Fig. 3.9.1 Immuno-fluorescence microscopic analysis of histone $\mathrm{H} 2 \mathrm{~B}$ release in comparison with lamin A/C $36 \mathrm{~h}$ after induction of apoptosis (100×magnification). 105 
Fig. 3.9.2 Laser-scan microscopic analysis of histone

$\mathrm{H} 2 \mathrm{~B}$ release in comparison with the nuclear marker

protein lamin A after treatment with etoposide (100×magnification).

Fig. 3.9.2 (cont. 1) Western blots of apoptosis-related

lamin A cleavage and release into the cytosol. 108

Fig. 3.9.3 Immuno-fluorescence microscopic analysis of

histone $\mathrm{H} 2 \mathrm{~B}$ release in comparison with $\mathrm{N}$-acetylglucosamine

after treatment with etoposide (40×magnification).

Fig. 3.9.4 Laser-scan microscopic analysis of histone H2B release

in comparison with the nuclear marker protein $\mathrm{N}$-acetylglucosamine

after treatment with etoposide (100×magnification).

Fig. 3.9.5 Immuno-fluorescence microscopic analysis of

histone $\mathrm{H} 2 \mathrm{~B}$ release in comparison with tubulin- $\alpha$

after treatment with etoposide (40×magnification).

Fig. 3.9.6 Laser-scan microscopic analysis of histone H2B release in comparison

with tubulin- $\alpha$ after treatment with etoposide (100×magnification).

Fig. 3.10.1 Accumulation of specific histone modifications

in apoptotic nucleosomes of fragmented chromatin.

Fig. 3.10.1 (cont. 1) Accumulation of specific histone modifications

in apoptotic nucleosomes of fragmented chromatin

Fig. 3.10.2 Depletion of specific histone modifications in apoptotic

nucleosomes of fragmented chromatin.

Fig. 3.10.2 (cont. 1) Depletion of specific histone modifications

in apoptotic nucleosomes of fragmented chromatin.

Fig. 3.10.3 No changes of specific histone modifications in apoptotic

nucleosomes of fragmented chromatin.

Fig. 3.10.3 (cont. 1) No changes of specific histone modifications in apoptotic nucleosomes of fragmented chromatin.

Fig. 3.10.4 Extraction of core histones from insoluble nuclear bulk chromatin pellets taken from sucrose gradient fractions

Fig. 3.10.5 Analysis of a putative accumulation of heterochromatin

protein HP1- $\alpha$ in regions of fragmented chromatin.

Fig. 3.11 Quantitative analysis of apoptosis-related DNA fragmentation in connection with accumulation of histone H2AX-phosphate S139 via FACS.

Fig. 4.2.1 Chemical structure of the camptothecin derivative topotecan®

Fig. 4.2.2 Chemical structure of etoposide 133 


\section{Abbreviations}

\begin{tabular}{|c|c|}
\hline A & \\
\hline A1 & adenosine receptor $\mathrm{A} 1$ \\
\hline $\mathrm{ad}$ & add up to \\
\hline AP & alkaline phosphatase \\
\hline Apaf-1 & apoptotic protease activating factor 1 \\
\hline APS & ammonium peroxosulfate \\
\hline AUT/AUC-gel & acetic acid-urea-triton gel / acetic acid-urea-CTAB gel \\
\hline \multicolumn{2}{|l|}{ B } \\
\hline $\mathrm{BCIP}$ & 5-bromo-4-chloro-3-indoylphosphate p-toluidine salt \\
\hline $\mathrm{Bcl}-2, \mathrm{Bcl}-\mathrm{X}_{\mathrm{L}}, \mathrm{Bcl}-\mathrm{W}$ & human proto-oncogenes from B-cell lymphoma \\
\hline Bid & Bcl-2 interacting domain \\
\hline BSA & bovine serum albumin \\
\hline \multicolumn{2}{|l|}{ C } \\
\hline CAF-1 & chromatin assembly factor 1 \\
\hline CAD & caspase-activated DNase \\
\hline CE & capillary electrophoresis \\
\hline CHAPS & $\begin{array}{l}\text { (3-[(3-Cholamidopropyl)-dimethyl-ammonio]-1-propane sulfonate } \\
\text { (a non-denaturing zwitterionic detergent) }\end{array}$ \\
\hline $\mathrm{CHO}$ & Chinese hamster ovary cells \\
\hline CTAB & acetyltrimethylammoniumbromide \\
\hline CZE (FSCE) & capillary zone electrophoresis/free-solution capillary electrophoresis \\
\hline \multicolumn{2}{|l|}{$\mathbf{D}$} \\
\hline DAB & diaminobenzidine \\
\hline DAPI & 4'-6-diamino-2-phenylindol-dihydrochlorid \\
\hline DD & death domain \\
\hline DED & death effector domain \\
\hline DEVD- AFC & $\begin{array}{l}\text { Caspase } 3 \text { substrate labelled with a fluorophore: } \\
\text { N-acetyl-Asp-Glu-Val-Asp-7-amino-4-trifluoromethyl coumarin }\end{array}$ \\
\hline DFF40 & DNA fragmentation factor with a molecular weight of $40 \mathrm{kDa}$ \\
\hline DISC & death-inducing signalling complex \\
\hline CHAPS & 3-[(3-cholamidopropyl) dimethylammonio]-1-propansulfonat] \\
\hline DMF & dimethylformamide \\
\hline DMSO & dimethyl sulfoxid \\
\hline DNA & deoxyribonucleic acid \\
\hline
\end{tabular}




\begin{tabular}{|c|c|}
\hline DR5 & death receptor 5 / belongs to TRAIL receptor family \\
\hline DTT & dithiothreitol \\
\hline \multicolumn{2}{|l|}{$\mathbf{E}$} \\
\hline ECL & enhanced chemiluminescence \\
\hline EDTA & ethylenediaminetetraacetate \\
\hline EGTA & ethylene-bis(oxyethylenenitrilo) tetraacetic acid \\
\hline \multicolumn{2}{|l|}{$\mathbf{F}$} \\
\hline FACS & fluorescence activated cell sorting \\
\hline FCS & fetal calf serum \\
\hline $\begin{array}{l}\text { FAS/CD95/ } \\
\text { Fas-ligand /APO-1 }\end{array}$ & fibroblast associated ligand \\
\hline FADD & Fas-associated death domain protein \\
\hline FITC & fluorescein isothiocyanate \\
\hline \multicolumn{2}{|l|}{$\mathbf{H}$} \\
\hline HAT & histone acetyl transferase \\
\hline HBSS & Hanks' balanced salt solutions \\
\hline HDAC & histone deacetylase \\
\hline HEPES & N-2-hydroxyethylpiperazine-N'-2-ethanesulfonic acid \\
\hline HIRA & Histone Regulator A (a histone chaperone) \\
\hline HMG & high mobility group proteins \\
\hline HMGN1 & high mobility group $(\mathrm{N})$ nucleosomal binding protein \\
\hline HPCE & high performance capillary electrophoresis \\
\hline HPLC & high performance liquid chromatography \\
\hline $\mathrm{HPLC} \mathrm{H}_{2} \mathrm{O}$ & $\mathrm{H}_{2} \mathrm{O}$ with $\mathrm{HPLC}$ grade \\
\hline HPMC & hydroxypropylmethylcellulose \\
\hline HP1- $\alpha$ & Heterochromatin Protein 1- $\alpha$ \\
\hline hPRC12 & E3 ubiquitin ligase complex \\
\hline HRP & horseradish peroxidase \\
\hline HMTase & histone methyltransferase \\
\hline \multicolumn{2}{|l|}{$\mathbf{I}$} \\
\hline ICE & Interleukin-1- $\beta$-converting enzyme \\
\hline \multicolumn{2}{|l|}{$\mathbf{L}$} \\
\hline $\mathrm{LDH}$ & lactate dehydrogenase \\
\hline \multicolumn{2}{|l|}{$\mathbf{M}$} \\
\hline Mcl-1 & $\begin{array}{l}\text { human proto-oncogene from human myeloid cell leukaemia-1 } \\
\text { (belongs to } \mathrm{Bcl}-2 \text { family) }\end{array}$ \\
\hline
\end{tabular}




\begin{tabular}{|c|c|}
\hline $\mathbf{N}$ & \\
\hline NBT & p-nitro blue tetrazolium chloride \\
\hline NPC & nuclear pore complex \\
\hline \multicolumn{2}{|l|}{$\mathbf{P}$} \\
\hline PARP & poly-ADP-ribose polymerase \\
\hline PAGE & polyacrylamide gel electrophoresis \\
\hline PBS & phosphate buffered saline \\
\hline PK & protein kinase \\
\hline PMSF & phenylmethylsulfonyl fluoride \\
\hline \multicolumn{2}{|l|}{$\mathbf{R}$} \\
\hline RPMI & $\begin{array}{l}\text { cell culture medium developed by Moore et al. at Roswell Park } \\
\text { Memorial Institute }\end{array}$ \\
\hline \multicolumn{2}{|l|}{$\mathbf{S}$} \\
\hline SAXS & X-ray scattering studies \\
\hline SDS & sodium dodecyl sulfate \\
\hline SUMO & small ubiquitin modifyer \\
\hline Suvar39H1 & $\begin{array}{l}\text { mammalian histone methyltransferase, named after Drosophila gene } \\
\text { locus suvar }\end{array}$ \\
\hline \multicolumn{2}{|l|}{$\mathbf{T}$} \\
\hline TBE & tris-boric acid-EDTA buffer \\
\hline TBS & tris buffered saline \\
\hline TBST & tris buffered saline Tween-20 \\
\hline TCA & trichloroacetic acid \\
\hline TdT & terminal deoxynucleotidyltransferase \\
\hline TE & tris-EDTA buffer \\
\hline TEMED & $\mathrm{N}, \mathrm{N}, \mathrm{N}$ ',N'-tetramethylethylenediamine \\
\hline TFA & trifluoroacetic acid \\
\hline TSA & trichostatin A \\
\hline TNF- $\alpha$ & tumor necrosis factor alpha \\
\hline TNFR & TNF- $\alpha$ receptor \\
\hline TRADD & TNF-receptor associated death domain protein \\
\hline TRAIL & TNF-related apoptosis-inducing ligand \\
\hline Tris & tris(hydroxymethyl)aminomethane \\
\hline TRITC & tetramethylrhodamine isothiocyanate \\
\hline Triton $^{\circledR}$ X-100 & t-octylphenoxypolyethoxyethanol \\
\hline
\end{tabular}




\begin{tabular}{|l|l|}
\hline Tween-20 & polyoxyethylenesorbitan monolaurate \\
\hline $\mathbf{U}$ & \\
\hline uH2A & ubiquitylated histone H2A \\
\hline $\mathbf{Y}$ & \\
\hline YFP & yellow fluorescent protein \\
\hline $\mathbf{Z}$ & \\
\hline Z-VAD-(OMe)-fmk & caspase 3 inhibitor: Z-Val-Ala-Asp(OMe)-fluormethylketone \\
\hline
\end{tabular}




\section{Introduction}

\subsection{From nucleosome to chromosome: higher order chromatin structure}

Eukaryotic chromosomes are large molecule complexes, which show a far more complex degree of structural organisation than the genetic material of prokaryotes. Prokaryotic DNA is packaged into a circular, tightly folded molecule, the so-called nucleoid. In contrast to that, the diploid human genome with its $6 \times 10^{9}$ base pairs, which corresponds to a DNA strand of about 1-2 metres, has to be tightly packaged into a nucleus of about $10 \mu \mathrm{m}$ in diameter. This sort of packaging to a state of eukaryotic chromosomes is achieved by organising DNA in arrays of nucleosomes, the basic repeating unit of chromatin, and to condense these into higher order chromatin fibres. Eukaryotic chromatin consists of proteins, the majority of which are histones and DNA in equal amounts. Only a very small part of it consists of non-histone proteins (e.g. HMG protein).

Chromatin provides the substrate for basic cellular processes such as DNA replication, genetic recombination, transcription and DNA damage repair. Although the structure of the nucleosome core particle has already been elucidated at almost atomic resolution (Davey and Richmond, 2002; Davey et al., 2002), the remaining fundamental question of how the nucleosome is organised within the chromatin fibre, is still controversially discussed. The nucleosome provides the basic unit on the first level of chromatin organisation. DNA of around 146 base pairs is wrapped around a disk-shaped protein assembly in 1 3/4 tight, lefthanded superhelical turns. This structure is termed nucleosome core particle (Arents et al., 1991; Finch et al., 1977; Klug et al., 1980; Kornberg and Thomas, 1974). Elucidation of the detailed core histone structure turned out to be a gradual developing process over the years, involving mostly crystallisation and X-ray experiments. The very first steps were taken by Finch (Finch et al., 1977), who got the first crystal structure of the core particle at a resolution of $7 \AA$ by diffraction of X-rays. Subsequently, researchers worked hard on higher resolutions to define elements of the nucleosome in more detail. Arents and co-workers (Arents et al., 1991) took further steps into that direction, reaching resolutions of $3.1 \AA$. Luger et al. (Luger et al., 1997) used crystallisation techniques combined with a unique DNA sequence and purified recombinant proteins to obtain a resolution at $2.8 \AA$. Firstly, they managed to reveal the distortion of DNA that is wound around the octamer. Secondly, they could prove that only by histone-DNA and histone-histone interactions through their 'histone fold motif', the typical configuration resembling that of a 'hand shake' was formed. This structural information brought a kind of breakthrough, as it facilitated experimental approaches used to study functions of specific regions in the histone protein sequence. However, this does not count for the histone N-terminal tails, as until now it has not been possible to visualise these in the crystal. Finally, in more recent works, Davey and Richmond managed to increase the amount 
of structural information on binding properties of histones and DNA within the nucleosome. They managed an unprecedented resolution of $1.9 \AA$ by using reconstituted nucleosomes from recombinant Xenopus laevis histones, in addition to a 'symmetric' DNA fragment of 147 base pairs, derived from human $\alpha$-satellite DNA (Davey and Richmond, 2002; Davey et al., 2002; Richmond et al., 1993).

The nucleosome core particle, which is $1 \mathrm{~nm}$ in diameter, consists of altogether eight core histone proteins, two copies each of the following histones $\mathrm{H} 2 \mathrm{~B} \cdot \mathrm{H} 2 \mathrm{~A}$ and $\mathrm{H} 3$ - $\mathrm{H}$ 4, (Kornberg and Thomas, 1974). In a first step, which leads to its formation, newly synthesised $\mathrm{H} 3$ and $\mathrm{H} 4$ are bound by their chaperone CAF-1 (chromatin assembly factor 1; (Smith and Rill, 1989; Smith and Stillman, 1989), a protein complex consisting of three polypeptide units p150, p60 and p48 (Carruthers et al., 1998; Kaufman et al., 1995). Both histones are preferentially deposited and assembled at sites of DNA replication, once both molecules $\mathrm{H} 3$ • $\mathrm{H} 4$ have formed a tetramer. Subsequently, the $\mathrm{H} 3 \bullet \mathrm{H} 4$ tetramer is incorporated into the DNA to build a sub-nucleosomal particle. In the following two $\mathrm{H} 2 \mathrm{~A} \cdot \mathrm{H} 2 \mathrm{~B}$ dimers, which are attached to their chaperone NAP-1, are then additionally bound to the already existing H3 • $\mathrm{H} 4$ tetramer, to form the actual core particle. The following organisation of nucleosomes into uniformly spaced arrays requires hydrolysis of ATP and can be catalysed in vitro by a number of distinct proteins (Cremisi et al., 1977; Ito et al., 1997; Senshu et al., 1978; VargaWeisz et al., 1997; Worcel, 1978; Worcel et al., 1978). Up to quite recently this model of nucleosome assembly was well accepted. However, in a very recent study Tagami et al. (Tagami et al., 2004) found strong evidence that histone variants H3.1 and H3.3 mediate nucleosome pathways which are in the first case dependent or as in the second case independent of DNA synthesis. This group purified deposition machineries for these two histone variants and found out that the purified complexes contained pre-deposited forms of $\mathrm{H} 3.1 / \mathrm{H} 3.3$ and H4 histones. Moreover it was observed that the H3.1 complex contains the CAF-1 chaperone, whereas the H3.3 complex contains the HIRA chaperone. As CAF-1 and HIRA mediate DNA-synthesis-dependent and -independent histone deposition it was suggested that major and variant histone depositions are driven by distinct pathways. In addition it was observed that both histones $\mathrm{H} 3$ and $\mathrm{H} 4$ exist as heterodimers within the complex. This fact proposes that $\mathrm{H} 3$ and $\mathrm{H} 4$ are deposited as a dimeric rather than a compact tetrameric unit. In a semi-conservative model for nucleosome assembly Tagami and co-workers suggest: after disruption of parental $(\mathrm{H} 3 \bullet \mathrm{H} 4)_{2}$ tetramers, $(\mathrm{H} 3 \bullet \mathrm{H} 4)$ dimers are paired with de novo synthesised $(\mathrm{H} 3 \cdot \mathrm{H} 4)$ dimers and are subsequently segregated onto daughter DNA strands via interaction of the H3.1 complex. Only then will the tetramer be completed. The semi-conservative model thereby allows deposition of mixed parental and newly synthesised in the same nucleosome core particle. 
With the help of more elaborate preparation techniques, by which (Olins and Olins, 1974) and (Oudet et al., 1975) had removed linker histones from the DNA, the improved quality of their electron microscopy pictures showed nucleosomes as a $1 \mathrm{~nm}$ 'beads-on-a-string' like structure (Thoma and Koller, 1977). H1 linker histones fix the DNA, which is wrapped around the histone octamer. This was assumed to play a key role in the formation of the next level of higher order structure and with it, the tighter packaging and condensation of chromatin (Carruthers et al., 1998; Kornberg, 1977; Thoma et al., 1979). Linker histones serve as a bridge between adjacent nucleosomes. $\mathrm{H} 1$ is located on the outside of the nucleosome, where it is bound to linker DNA and where it also interacts with $\mathrm{H} 2 \mathrm{~A}$ subunits from the core particle. The $\mathrm{C}$ - and $\mathrm{N}$-terminal tails of the linker histones bind both the DNA, which is directly attached to the nucleosome core particle and to the linker DNA between the nuclear core particles (Crane-Robinson and Ptitsyn, 1989; Pruss et al., 1996; Thoma et al., 1979; Zhou et al., 1998). As the C- and N-terminal tails of core histones contain very basic amino acid sequences, these tend to neutralise the negatively charged backbone of the DNA so that the formation of the nuclear core particle to higher chromatin structures is facilitated (Clark and Kimura, 1990).
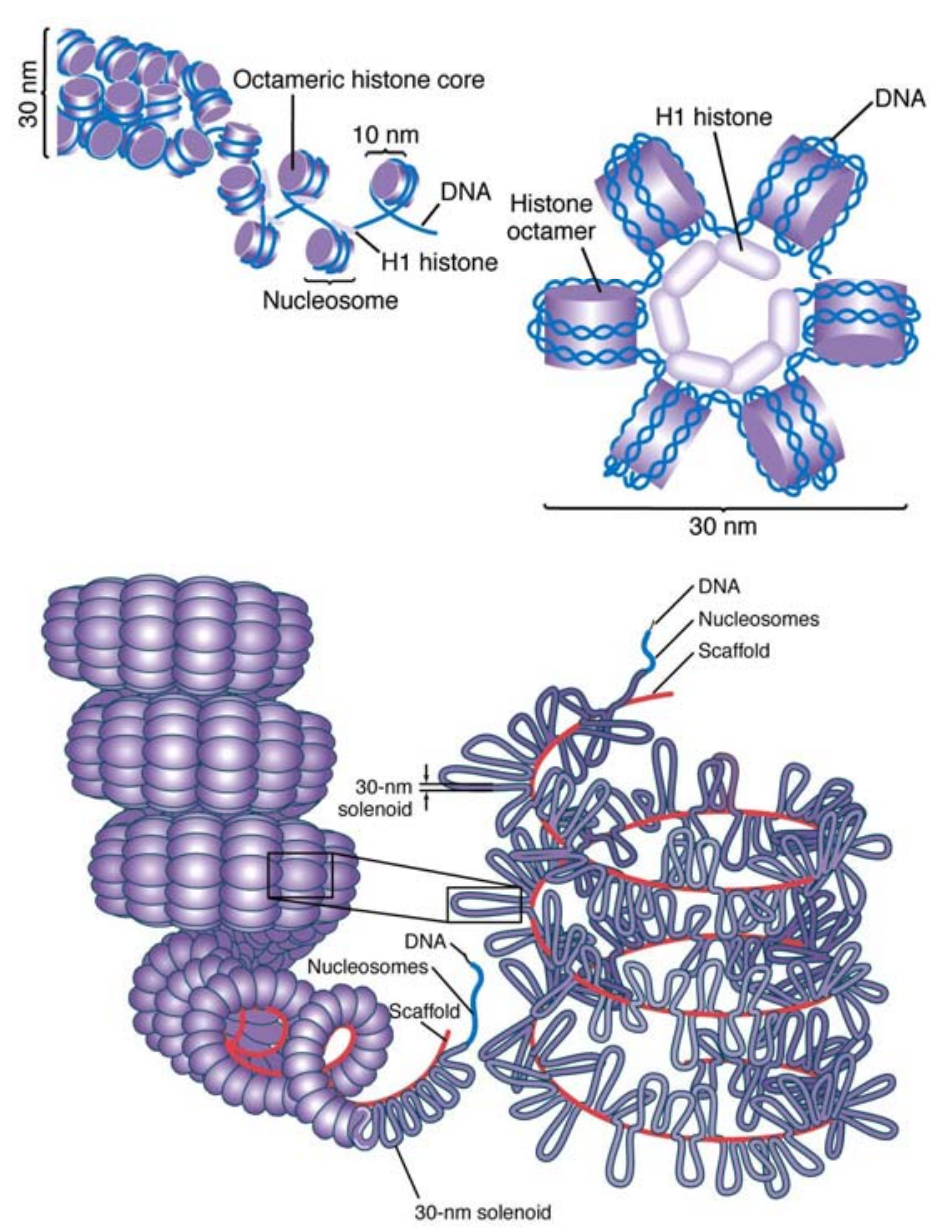

Fig. 1.1.1 From nucleosome to higher order chromatin structure: different stages of DNA packaging (http://www.bio.miami.edu/dana/104/solenoid.jpg). 
However, some groups like Dasso et al. (Dasso et al., 1994) and Shen et al. (Shen et al., 1995) claimed that linker histones might not be essential for the formation of higher order structure chromatin.

Following the addition of salt in vitro (Arents et al., 1991; Klug et al., 1980; Thoma et al., 1979) or when observed in situ the next level of chromatin compaction is achieved by formation of a $30 \mathrm{~nm}$ fibre. According to electron microscopy and X-ray scattering studies (SAXS), two different models for the $30 \mathrm{~nm}$ chromatin fiber emerged and have ever since been discussed controversially: firstly, a one-start solenoidal helix (solenoid), in which a linear array of nucleosomes is coiled (Finch and Klug, 1976) and secondly, a two-start helix, in which nucleosomes are re-assembled in shape of a zigzag ribbon that twists or supercoils (Woodcock et al., 1984; Woodcock and Frank, 1984).

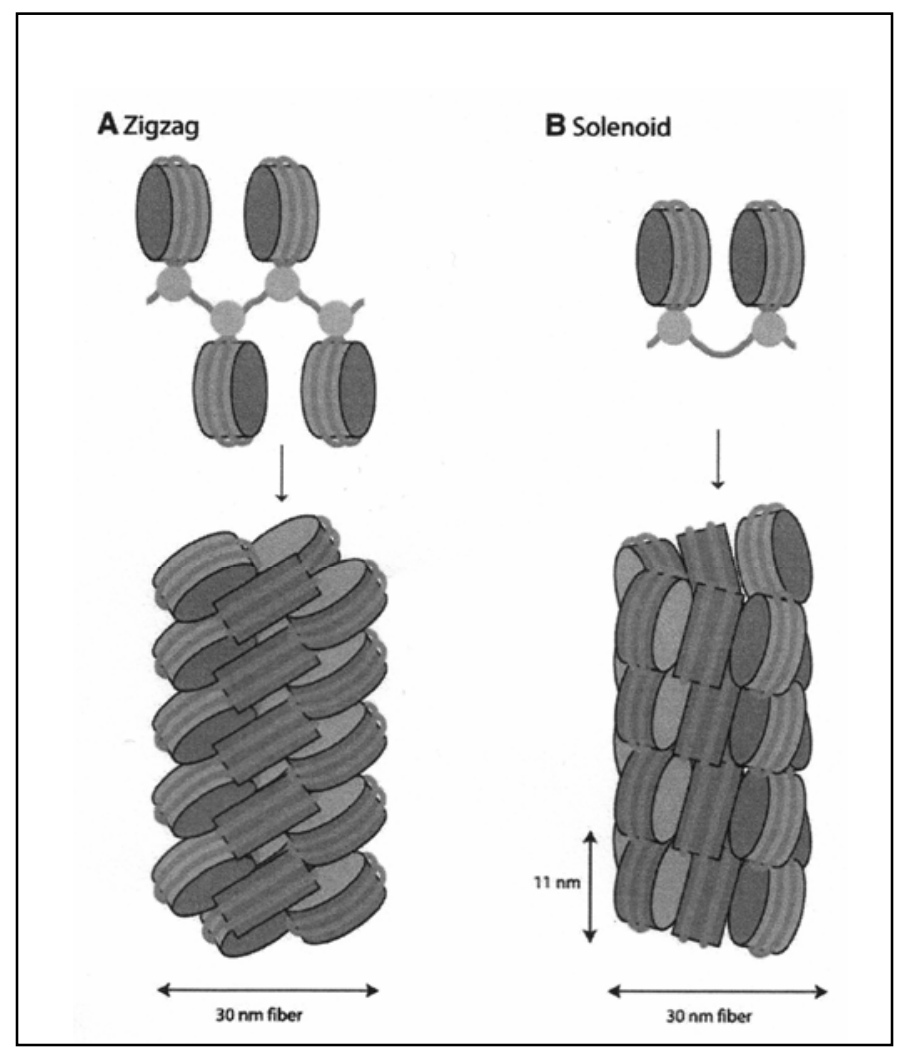

Fig. 1.1.2 Model of the $30 \mathrm{~nm}$ fiber structure. Zigzag model of alternating nucleosomes (a) versus a solenoid of adjacent nucleosomes (b) (Khorasanizadeh, 2004).

Evidence supporting the traditional solenoid model included observations like the invariant diameter with respect to DNA linker length (Carruthers et al., 1998; Thoma et al., 1979; Widom et al., 1985; Woodcock et al., 1984; Woodcock and Frank, 1984) increased compaction of fibres with six or more nucleosomes (Butler and Thomas, 1980) and a possible requirement for supercoiled linker DNA (Felsenfeld, 1992; McGhee et al., 1983). Evidence giving support to the zigzag model turns out to be completely the opposite, such as variation of the fibre diameter with reference to DNA linker length (Athey et al., 1990), a 
zigzag path of nucleosomes perceived in tomographic reconstruction in situ (Horowitz et al., 1994) and linker DNA which is not tightly bent (Pehrson, 1989). Results of most recent studies in which the structure of a tetranucleosome was analysed via X-ray, further supports the zigzag model. Schalch et al. (2005) argue that substantial linker length deviations would even further facilitate a higher-level folding in an otherwise tightly compacted fibre.

Although the exact nature of further chromatin compaction is still not quite clear, one popular model proposes that DNA is arranged in loops of 50-30 kilo base pairs, which is formed once AT-rich DNA sequences bind to the nuclear matrix (Laemmli, 1978; Saitoh and Laemmli, 1993). These loops are held together by the so-called nuclear scaffold. Two classes of proteins that contribute to the formation of the nuclear scaffold have been identified so far. One of them is the topoisomerase II (Chen et al., 1984), a main component of the nuclear matrix, which is responsible for the supercoiling of the DNA. The DNA in itself is most important in altering the architecture and accessibility of the chromatin during cell cycle replication or transcription. In this way the $30 \mathrm{~nm}$ chromatin fibre reaches its final stage of compaction (Thoma et al., 1979; Widom et al., 1985; Widom and Klug, 1985).

\subsection{Histones and histone modifications}

Core histones $\mathrm{H} 2 \mathrm{~A}, \mathrm{H} 2 \mathrm{~B}, \mathrm{H} 3, \mathrm{H} 4$ and the linker histone $\mathrm{H} 1$ together form the major protein component in chromatin. The core histones build a group of small basic proteins found in all eukaryotes and which are highly conserved in evolution (Mardian and Isenberg, 1978). Two out of four core histone types have highly conserved variants, namely $\mathrm{H} 3$ with $\mathrm{H} 3.1$ and $\mathrm{H} 3.3$ and $\mathrm{H} 2 \mathrm{~A}$ with $\mathrm{H} 2 \mathrm{AX}$ and $\mathrm{H} 2 \mathrm{AZ}$ with specialised functions (Redon et al., 2002). The most conserved region in the histone's tripartite structure is its central globular domain, structurally composed of the 'histone fold domain'. In this domain three $\alpha$-helices are connected by two loops (Arents et al., 1991). These regions interact to form the wedge-shaped heterodimers $\mathrm{H} 2 \mathrm{~A} \bullet \mathrm{H} 2 \mathrm{~B}$ and $\mathrm{H} 3 \bullet \mathrm{H} 4$, each in turn binding $2 \frac{1}{2} 2$ turns of DNA. The binding occurs at the DNA phosphodiester backbone to ensure DNA package irrespective of any sequence pattern (Clark and Kimura, 1990).

In contrast to the globular domains, the $\mathrm{N}$-terminal tails of core histones are much more variable and rather unstructured. They are particularly rich in lysine and arginine residues, which is why they are extremely basic (Bradbury et al., 1975; Stedman, 1950). The Nterminal histone tails are sites for numerous post-translational modifications that are proposed to modify its charge, thereby altering the accessibility of the DNA as well as protein-protein interactions with the nucleosome. In this respect they play a key role in DNAdependent processes like replication, transcription and genetic recombination (Strahl and Allis, 2000). Apart from the N-terminal tails, histone modifications have also been detected on the C-terminal tails and in the globular domain, however, this section has only recently 
become more popular (Cosgrove et al., 2004; Felsenfeld and Groudine, 2003; Peterson and Laniel, 2004).

Apart from core histones, the group of linker histones $\mathrm{H} 1$ and its subtypes is equally important, as they build the final link in the formation of the smallest repeating unit in chromatin, namely the nucleosome. $\mathrm{H} 1$ is located on the outside of the nucleosome, where it binds linker DNA and interacts with $\mathrm{H} 2 \mathrm{~A}$ subunits of the nucleosomal core, to further tighten the association of DNA with the nucleosome. These smaller chromatin units are called chromatosomes (Simpson, 1978). Unlike core histones, linker histones are not well conserved between species (Pruss et al., 1996; Richmond et al., 1993; Thoma et al., 1979). In higher eukaryotes they are, like core histones, composed of three domains, a globular, non-polar central domain, which is essential for $\mathrm{H} 1$ interactions with the DNA and the two non-structured $\mathrm{C}$-and $\mathrm{N}$-terminal tails. These, too, are sites for post-translational modifications. In mammals $\mathrm{H} 1$ histones seven subtypes have been classified, namely H1.1H1.5 (Albig et al., 1993; Albig et al., 1991; Doenecke et al., 1994; Eick et al., 1989; Pruss et al., 1996; Richmond et al., 1993; Thoma et al., 1979) and two special replication independent subtypes, $\mathrm{H}^{\circ}{ }^{\circ}$ (Doenecke and Tonjes, 1986) and H1t (Drabent et al., 1991).

In general, core histones are subjected to large numbers of post-translational modifications, such as acetylation, methylation (especially at lysine and arinine), phosphorylation (especially at serine and threonine), ubiquitylation, ADP-ribosylation, sumoylation (especially at lysine) and even deimination (Carruthers et al., 1998; Jenuwein and Allis, 2001; van Holde and Zlatanova, 1995). Adding to the complexity of this matter is the fact that each lysine residue can accept up to three methyl groups (Rice et al., 2003; Santos-Rosa et al., 2002; Sarg et al., 2004) and each arginine can either be mono-, or dimethylated (Seligson et al., 2005). The majority of post-translational modifications have been found on the N-terminal tail and less on the C-terminal tail, however, more and more evidence is gathered for modifications in the globular domain of core histones (Cosgrove et al., 2004). Their association with specific biological processes has led to the proposed hypothesis of the 'language of covalent histone modifications', referred to as the 'histone code' (Strahl and Allis, 2000). It is assumed that histones by means of their covalent modification might contribute to different mechanisms which can alter the chromatin structure. In a way this might subsequently lead to inherited differences in transcriptional 'on-off' states, which push forward stable formation of chromosomes by defining a specialised higher order chromatin structure. Therefore it was proposed that the histone code might considerably extend the information potential of the genetic DNA code (Jenuwein and Allis, 2001). 


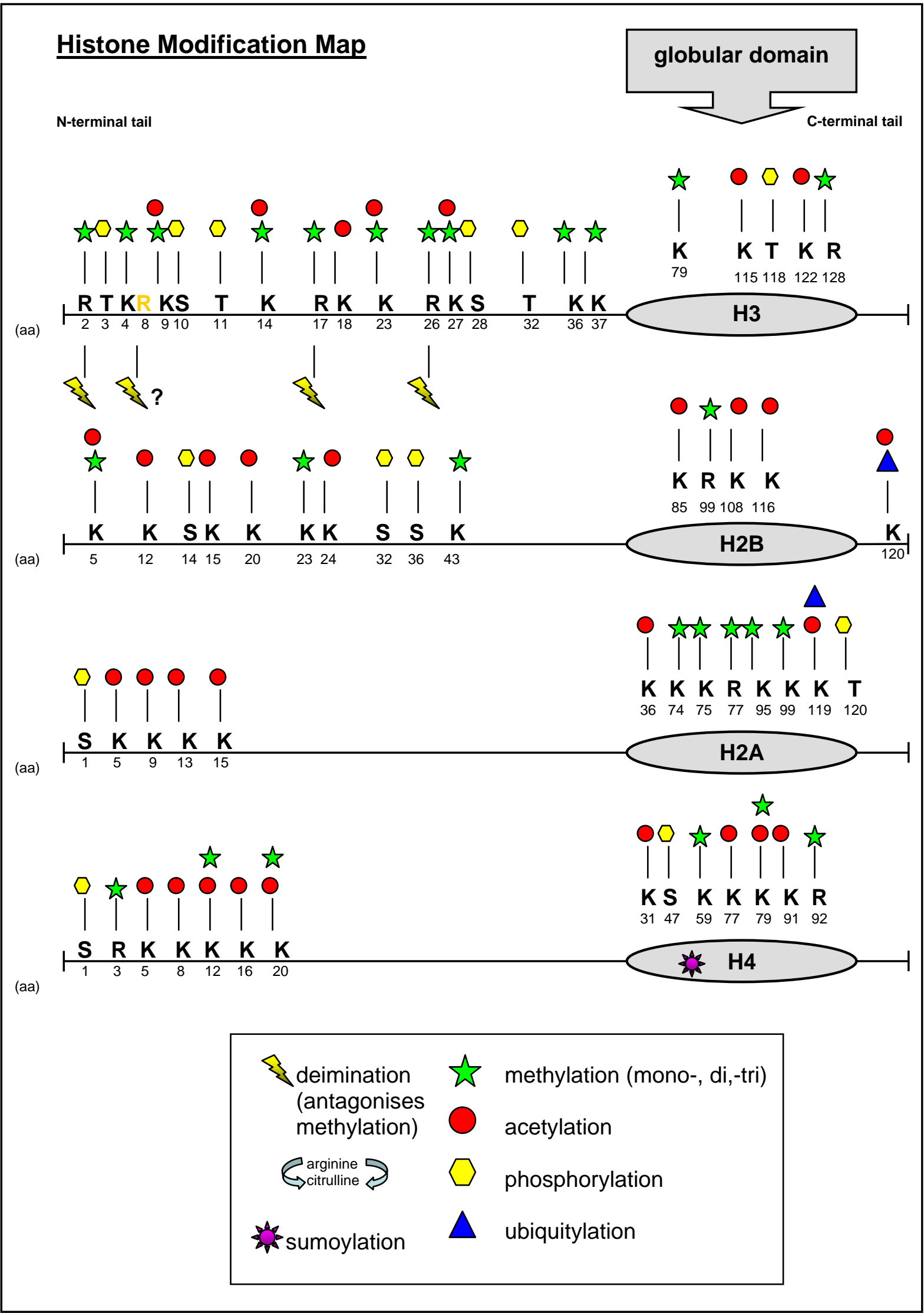

Fig.1.2 Core histone modification map, summarised according to (Cosgrove et al., 2004; Felsenfeld and Groudine, 2003; Peterson and Laniel, 2004). 
Within the last few years many core histone modifications have been detected, mostly on the $\mathrm{N}$-terminal tail of core histones, and their numbers are constantly increasing. The following figure should just give an overview of this most complex matter (Fig. 1.2).

As already mentioned briefly, an increasing body of evidence suggests that post-translational modifications are suggested to have a major influence on chromatin folding, with clear functional consequences (van Holde and Zlatanova, 1995; Wolffe and Hayes, 1999). It is assumed that distinct patterns of covalently modified histones in a way of the so-called 'histone code', serve as a signalling platform to recruit and bind other nuclear factors, which mediate downstream functions by not yet fully understood mechanisms (Cheung et al., 2000; Strahl and Allis, 2000; Turner, 2000). Up to this point research groups managed to somehow categorise the 'jungle' of all these newly detected histone modifications with respect to their possible biological functions. The following table gives an overview.

\begin{tabular}{|l|l|}
\hline \multicolumn{1}{|c|}{ biological function of modification } & \multicolumn{1}{|c|}{ type of histone modification } \\
\hline transcriptional repression / gene & H3 trimethyl K9 \\
silencing & H2A phosphate S1 \\
& H4 sumoylated \\
& H4 acetyl K12 (telomeric silencing) \\
& H4 monomethyl K20 \\
& H4 trimethyl K20 (heterochromatin regions) \\
& H4 methyl K59 \\
\hline transcriptional activation & H3 acetyl K4, K9, K14; K18, K23, K27 \\
& H4 acetyl K5, K8, K12, K16 \\
& (only H4 ac K16 specific for activation?) \\
& H2A acetyl K4, K5, K7 \\
& H2B acetyl k5, K11, K12, K15, K16, K20 \\
& H3 di-, and trimethyl K4, K36 \\
\hline chromatin assembly & H4 acteyl K5, K12 (?) \\
& H4 acetyl K91 \\
\hline DNA repair & H2AX phosphate S139 \\
& H2A phosphate S129 \\
& H3 acetyl K14, K18, K23 \\
& H4 acetyl K5, K8, K12 \\
\hline cell cycle (mitosis / meiosis) & H2A phosphate S1, T119 \\
& H3 phosphate T3, T11, S10, S28 \\
& H4 phosphate S1 \\
& H2B ubiquitylated K120 \\
\hline apoptosis-related DNA fragmentation & H2B phosphate S32 \\
and chromatin condensation & dephosphorylated H1 and subtypes \\
& hyperphosphorylated H2AX \\
& phosphorylated H3 \\
\hline
\end{tabular}

Table 1.2 Overview of core histone modifications and their possible biological functions (data was summarised from recent publications including Peterson and Laniel (Peterson and Laniel, 2004). Most of the core histone modifications analysed, were found in yeast. Up to now only a few of them have been detected in mammals.

Recent studies have shown that particular combinations of site-specific histone modifications can already be well correlated with distinct biological functions. Some key examples shall be given in the following section. Nakayama and co-workers (Nakayama et al., 2001) analysed the role of histone $\mathrm{H} 3$ lysine 9 methylation with reference to epigenetic control of 
heterochromatin assembly. They found out that H3 lysine 9 in the fission yeast strain Schizosaccharomyces pombe is preferably methylated by the protein Clr4 at heterochromatin-associated regions according to the following step-wise model for heterochromatin formation: acetylated $\mathrm{H} 3$ at lysine 9 and 14 gets deacetylated by two different HDACs in the first place. Subsequently, the modification site at $\mathrm{H} 3$ lysine 9 is vacant to be methylated by the HTMase complex Clr4/Rik1. Finally, binding of the protein Swi6 will then result in self-propagating heterochromatin assembly. The process that has been described for the fission yeast strain S. pombe, was previously analysed in the mammalian cell type U2OS with HP-1 $1 \alpha$, which is the mammalian homolog to Swi6 in yeast. This also refers to the yeast HTMase Clr4/Rik1, which is a homolog to the mammalian SUVAR 39H1 HTMase (Bannister et al., 2001). Another example for correlating histone modifications with the biological function of transcriptional activation is the acetylation of histone $\mathrm{H} 4$ at lysines 5 , 8, 12 and 16, acetylation of histone $\mathrm{H} 3$ at lysine 14 as well as histone $\mathrm{H} 3$ phosphorylation at serine 10. Whereas Sabet et al. (Sabet et al., 2004) suggested a general, transcriptional regulatory potential for the $\mathrm{N}$-terminal tails of histones $\mathrm{H} 3$ and $\mathrm{H} 4$, Dion and co-workers (Dion et al., 2005) were able to define the specific sites of acetylation for this particular function. They observed that only acetylation of $\mathrm{H} 4$ at lysine 16 is specific for the activation of gene transcription, whereas the other sites, although acetylated, turned out to be only non-specific, cumulative effects in terms of function going along with H4 acetyl K16. Furthermore, several groups proposed that the doubly-modified H3, which gets phosphorylated at serine 10 and at the same time acetylated at lysine 14, the levels of which are modified by the chromosomal protein HMGN1 (Lim et al., 2005), is closely connected with transcriptional activation (Lo et al., 2001). Phosphorylation of histone $\mathrm{H} 3$ at serine 10 is even proposed to have an augmenting effect on further acetylation of H3 lysine 14 (Lo et al., 2000).

In contrast to the modifications just mentioned, two more research groups, Schotta et al. (Schotta et al., 2004b) and Peters et al. (Peters et al., 2003), discovered specific histone modifications exclusively restricted to heterochromatin regions and associated only with gene silencing. Schotta and co-workers declared trimethylated histone $\mathrm{H} 3$ at lysine 9 and trimethylated histone $\mathrm{H} 4$ at lysine 20 as hallmarks for pericentric chromatin. It was demonstrated that $\mathrm{H} 3$ trimethyl $\mathrm{K} 9$ is without exceptions required for subsequent induction of $\mathrm{H} 4$ trimethyl K20. Peters and co-workers evidenced that apart from $\mathrm{H} 3$ trimethyl K9, nonmethylated $\mathrm{H} 3$ at lysine 27 appeared to be a selective marker for pericentric chromatin. However, statements of other groups suggest factors other than hypermethylation of $\mathrm{H} 3$ and hypoacetylation of the $\mathrm{N}$-terminal tail of histone $\mathrm{H} 4$ to play an important role in whether a chromatin sequence is constitutively eu- or heterochromatic (Jiang et al., 2004).

In addition to all that particular patterns of histone modifications have throughout the last years repeatedly been correlated with global chromatin dynamics, such as $\mathrm{H} 4$ acetyl $\mathrm{K} 5$ and 
$\mathrm{K} 12$, which were particularly associated with the deposition of newly synthesised histones during S-phase (Verreault et al., 1998). Histones H3 and H4 exhibit a heterogenic pattern of post-translational modifications (Verreault et al., 1996). Newly synthesised H4 is especially acetylated at lysines 5 and 12 and various residues of histone H3 have also been observed to be acetylated at several sites (Sobel et al., 1995). It was first thought that prior to formation of nucleosomal arrays, H4 needed to be acetylated by HAT1 acetyltransferase (Adams and Kamakaka, 1999). However, recent results confirmed that the $\mathrm{N}$-terminal tails of both $\mathrm{H} 3$ and $\mathrm{H} 4$ are dispensable for preferential assembly of nucleosomes onto replicated DNA by CAF-1 (Shibahara et al., 2000). This group later verified their results and proclaimed that neither acetylated histone $\mathrm{H} 4$ at lysines 5 and 12, nor any acetylated residues of histone $\mathrm{H} 3$ were necessary for CAF-1 dependent nucleosome assembly onto replicated DNA. In experiments with recombinantly expressed $(\mathrm{H} 3 \bullet \mathrm{H} 4)_{2}$ tetramers, CAF-1 and each of its individual subunits still bound to the tetramer, although the $\mathrm{N}$-terminal tails of both $\mathrm{H} 3$ and $\mathrm{H} 4$ were either truncated or their modifications were triple point mutated. Most recently Ye and co-workers (Ye et al., 2005) stated that acetylated lysine 91 in the globular domain of histone $\mathrm{H} 4$ is most important for chromatin assembly. Besides its function in chromatin assembly, it is also supposed to play a key role in transcriptional silencing and DNA repair.

Basic biological processes such as chromatin condensation and mitosis have also been linked to specific post-translational histone modifications by several research groups. Whereas $\mathrm{H} 2 \mathrm{~A}$ threonine 119 was found to be exclusively phosphorylated during cell cycle $\mathrm{M}$ phase (definitely not S-phase) (Aihara et al., 2004), enhancement of histone $\mathrm{H} 4$ and $\mathrm{H} 2 \mathrm{~A}$ serine 1 phosphorylation was confirmed to be evolutionary conserved during M-phase and in lightly lower concentrations during S-phase of the cell cycle (Barber et al., 2004).

These findings could be related to $\mathrm{H} 3$ phosphorylation at serines 10 and 28 and also to phosphorylated threonine 11 in plants (Houben et al., 2005) in more or less the same way (Ajiro et al., 1996; Gernand et al., 2003; Nowak and Corces, 2000; Nowak and Corces, 2004; Prigent and Dimitrov, 2003). Moreover, phosphorylation of $\mathrm{H} 3$ at threonines 3 and 11 was observed during mitosis and meiosis (Polioudaki et al., 2004).

Quite a series of more exclusive histone modifications have after all only quite recently been a matter of investigation, such as histone arginine deimination, sumoylation and in a way (a kind of revival of this research area) histone ubiquitylation. Histone arginine deimination was described by Cuthbert and co-workers (Cuthbert et al., 2004). This group confirmed that deimination of arginines 2, 8, 17 and 26 to citrulline in the N-terminal tail of histone $\mathrm{H} 3$ antagonises arginine methylation in general, which is supposed to propel transcriptional activation (Bauer et al., 2002; Ma et al., 2001; Wang et al., 2001b).

Histone sumoylation has only recently been discovered on histone $\mathrm{H} 4$. $\mathrm{H} 4$, which is usually found acetylated in regions of transcriptionally active genes, can by means of its acetylated 
state, potentially recruit the SUMO-conjugating enzymes E2 and E3, which are capable of modifying either histones or activators, to achieve an attenuation of transcription. Subsequently, a co-repressor could then be recruited in combination with initiation of HDAC activity. This is achieved by recruiting a DNA-bound repressor (SUMO might even contribute to it). Both processes will then lead to histone deacetylation, making way for the addition of repression-specific histone methylation, such as $\mathrm{H} 3$ trimethyl $\mathrm{K} 9$ with subsequent binding of HP1. In this way, histone sumoylation finally leads to gene silencing (Nathan et al., 2003; Shi et al., 2003).

Histone ubiquitylation, was originally detected on histone $\mathrm{H} 2 \mathrm{~A}(\mathrm{uH} 2 \mathrm{~A})$ by Goldknopf and coworkers (Goldknopf et al., 1980). Later on H2B was found to be ubiquitylated in the budding yeast strain S. cerevisiae. It turned out that ubiquitylated H2B (uH2B) plays an important role in methylation of histone $\mathrm{H} 3$. There it was supposed to function as a mark for gene transcription repression (Kao et al., 2004; Osley, 2004; Sun and Allis, 2002). However, Wyce et al. (Wyce et al., 2004) claimed that due to their investigations of the transcriptional role of H2B C-terminal tail ubiquitylation/deubiquitylation in S. cerevisiae, both processes are rather required for gene activation. These findings are supported by the works of Baarends et al. (Baarends et al., 1999a; Baarends et al., 1999b) and Wang et al. (Wang et al., 2004). Baarends and co-workers investigated $\mathrm{H} 2 \mathrm{~A}$ ubiquitylation in correlation with chromatin remodelling during mouse spermatogenesis. They found high concentrations of $\mathrm{uH}_{2} \mathrm{~A}$ in pachytene spermatocytes. Concentrations were even increased during a relatively short developmental period in elongating spermatids. In contrast to this, Wang and his colleagues found evidence for linking monoubiquitylated H2A at lysine 119 (in mammals), a residue which accepts its modification from the E3 ubiquitin ligase complex hPRC12, to Polycomb gene silencing.

All these observations in changing histone modifications have actually led to the idea of the 'histone code' (Strahl and Allis, 2000). Meanwhile, according to up to date research results on histone modifications in general, this term has been extended to 'histone or chromatin cross-talk'. This idea has come up as more and more evidence has been accumulated pointing into the direction that a particular modification mark or rather a set of marks will not always inevitably carry the same biological function but can rather have different or even opposing consequences. That means combination patterns of histone marks can be distinctly recognised and interpreted by cellular factors, depending on the genetic background and the cellular context. The interplay of different types of modifications e.g. acetylation with phosphorylation or acetylation with methylation, which finally lead to a defined biological process, is therefore more and more often referred to as chromatin or histone cross-talk (Cheung et al., 2000; Fischle et al., 2003). 
The following two examples will explain this in more detail. As already mentioned with reference to histone methylation in general, this matter is getting even more complex as e.g. lysine methylation in vivo occurs in three different states: mono-, di- and trimethylation. Histone H3 dimethyl K4 was found both in active and inactive euchromatic genes (Kim et al., 2003), whereas trimethylated $\mathrm{H} 3$ at lysine 4 was exclusively found in active genes. Therefore it can be assumed that the presence of $\mathrm{H} 3$ trimethyl $\mathrm{K} 4$ defines an active state of gene expression (Nishioka et al., 2002; Santos-Rosa et al., 2002; Schneider et al., 2004). The same functional pattern was discussed by Bannister et al. (Bannister et al., 2005) for di- and trimethylation of histone $\mathrm{H} 3$ at lysine 36 . Both methylation states were reported to be useful markers of active genes, although spatially different distributed. This fact suggests different roles in transcriptional termination and early RNA processing.

However, dimethylated $\mathrm{H} 3$ at lysine 4 has recently been found to be required for maintenance of gene silencing at telomeres, rDNA and HML locus in S. cerevisiae (SantosRosa et al., 2004). Santos-Rosa and colleagues reported that euchromatic methylation of $\mathrm{H} 3$ lysine 4 was necessary to maintain gene silencing at specific heterochromatic sites.

Another example for histone modification marks showing opposing biological consequences is given by Vakoc et al. (Vakoc et al., 2005). Methylation of H3 at lysines 9 and 27 together with $\mathrm{H} 4$ methylation at lysine 20 has been associated with heterochromatin formation and some repressed euchromatic genes. $\mathrm{H} 3$ di-and trimethylation at lysine 9 together with HP1 binding which were actually thought to occur in heterochromatic regions and which were supposed to be associated with transcriptional repression, were now also detected in actively transcribed gene regions in mammalian chromatin. The presence of both HP-1 $\gamma$ and H3 trimethyl K9 thereby being dependent upon elongation by RNA polymerase II.

Generally speaking, all examples given clearly point into the direction of a very dynamic functional pattern which is taken over by specific histone modifications, depending on the different cellular contexts.

\subsection{Introduction to apoptosis}

\subsubsection{Biological significance and morphological / biochemical features}

The term 'programmed cell death' was originally introduced in 1964, proposing that cell death during development is not of accidental nature but follows a sequence of controlled steps, leading to locally and temporally defined self-destruction of cells (Lockshin and Williams, 1964). Subsequently, the term 'apoptosis', a word of Greek origin meaning 'falling off or dropping off' in analogy to autumn leaves falling off trees, was used to describe the morphological and biochemical processes, which lead to controlled cellular self-destruction. It was first introduced by Kerr, Wyllie and Currie (Kerr et al., 1972). In general, the process of 
apoptosis is of great importance in the development of multi-cellular organisms, as well as in the regulation and maintenance of cell populations in different tissues upon both physiological and pathological conditions. Although apoptosis is by far the most frequent way of programmed cell death, non-apoptotic types of programmed cell death have already been described (Leist and Jaattela, 2001a; Leist and Jaattela, 2001b). The biological significance of apoptosis is highlighted by the following examples: during early development an excess of different cell types is produced, most of which eventually undergo programmed cell death, thereby contributing to the final formation of organs and tissues (Meier et al., 2000). Another example is given by the formation of human limbs. Here separate digits evolve by apoptosis of interdigital mesenchymal tissue (Zuzarte-Luis and Hurle, 2002). Two more examples can be found in brain development, in which one half of all neurons initially created, is disposed of by the organism during the differentiation of neurons and adult brain formation (Hutchins and Barger, 1998) and not to forget the formation of reproductive organs (Meier et al., 2000). As all cells of an adult organism undergo physiological cell death during its lifetime, this must be balanced with cell proliferation rates in order to maintain homeostasis in terms of constant cell numbers. With reference to the human immune system, apoptosis is of major importance when it comes down to regulation and function. The majority of developing lymphocytes either die during genetic rearrangement events or in formation of the antigen receptor during negative selection or in the periphery. By these means, the pool of highly efficient, non-selfreactive immune cells is strictly controlled. Moreover, lymphocyte numbers are kept relatively constant (Fadeel et al., 1999a; Fadeel et al., 1999b; Rathmell and Thompson, 2002). A last few most important points in terms of biological function of apoptosis are the elimination of damaged, dangerous cells, e.g. cells containing severely damaged DNA that is beyond repair; inappropriate mitogen signalling that stays in conflict with the homeostasis of the cell and might either result in cell cycle arrest or even in apoptosis; elimination of infected cells by microorganisms (Vaux et al., 1988; Vaux and Korsmeyer, 1999).

Taking together all these regulatory functions of apoptosis it becomes clear, what disastrous or even lethal effect a dysfunction or dysregulation has on the organism. Defects in apoptosis are tightly connected with a variety of pathological conditions. While, e.g. by mutation of genes which code for proteins involved in initiation or execution of the signalling cascade (Mullauer et al., 2001), repressed apoptosis might lead to cancer, autoimmune diseases and spreading of viral infections, excessive apoptosis can result in AIDS and iscaemic diseases as well as neurodegenerative disorders, such as Alzheimers' disease, Parkinson's disease, Huntington's disease and amyotrophic lateral sclerosis (Reed, 2002).

Cells undergoing apoptosis always show some characteristic morphological and biochemical features (Cohen, 1993b). Two of them are actually seen as biological hallmarks of apoptosis, namely chromatin condensation and DNA fragmentation. The latter is achieved by activation 
of endonucleases like CAD (caspase-activated DNAse) (Reed, 1998; Wyllie et al., 1981; Wyllie et al., 1984). Moreover, despite cell shrinking and loss of cell-cell contacts, all cell organelles and membranes remain intact. However, apoptotic cells cease to maintain phospholipid asymmetry in their membrane structure. Phosphatidylserine flips to the outer leaflet (Callahan et al., 2000). Even the mitochondrial membrane is subject to apoptosis related changes, including a loss of its electrochemical gradient by formation of pores. Substances like cytochrome c leak from the mitochrondria into the cytoplasm. In later stages of apoptosis the cell is formed into apoptotic bodies, which are finally phagocytosed by macrophages or adjacent epithelial cells (Cohen, 1993a; Cohen, 1993b; Savill et al., 1989). This is another crucial step during apoptosis, as it prevents an inactivation of inflammatory processes (Saraste and Pulkki, 2000).

In contrast to apoptosis, we find a second rather uncontrolled process of cell death that is necrosis (Dive et al., 1992). Necrosis occurs, when cells are exposed to an extreme variance of physiological conditions, such as hypothermia and hypoxia, which both cause plasma membrane damage. It is initiated by disturbance of the cell's ability to keep up its homeostasis. Agents like complement or lytic viruses can cause direct damage to the plasma membrane under physiological conditions. In the following this leads to an uncontrolled influx of water and extracellular ions and finally results in the disruption of organelles and the whole cell. Due to uncontrolled release of cellular contents including lysosomal enzymes into the surrounding extracellular fluid, necrotic cell death is most often associated with extensive tissue damage and initiation of excessive inflammatory responses (Vermes and Haanen, 1994).

\subsubsection{Signalling pathways of apoptosis: molecular mechanisms}

Apoptosis can be triggered by various stimuli either from outside the cell i.e. binding of cell surface death receptor ligands such as Fas (Nagata, 1994; Nagata and Golstein, 1995), TNFR1 and DR5 with their ligands FasL, TNF- $\alpha$ and TRAIL (Ashkenazi, 2002) (extrinsic pathway) or from within the cell, via direct DNA damage by cytotoxic drugs or irradiation (Achenbach et al., 2000; Rich et al., 2000).

The extrinsic pathway further distinguishes between type I and type II, depending on the actual cell type. Apoptosis induced via the extrinsic signalling pathway type I is mediated by activation of 'death receptors', protein complexes which belong to the tumor necrosis factor receptor (TNFR) gene superfamily (Ashkenazi, 2002; Ashkenazi and Dixit, 1998; Nagata, 1994; Nagata and Golstein, 1995; Vandenabeele et al., 1995a; Vandenabeele et al., 1995b). After binding of their ligands FasL (synonyms APO-1; CD95), TNF- $\alpha$ or TRAIL, which the receptor recognises by their cysteine rich extracellular subdomain, the receptors trimerise and get activated (Naismith and Sprang, 1998). Subsequently, the cytoplasmic part of the 
receptor, termed 'death domain' (DD) initiates the following steps in the signalling cascade. Adapter molecules like FADD (Fas-associated death domain protein) and TRADD (TNFreceptor associated death domain) possess their own death domains, by which they are recruited to the activated DD of the receptor. In this way the death-inducing signalling complex (DISC) is formed (Sartorius et al., 2001). Besides its DD, FADD also possesses a death effector domain (DED), which by interacting with the receptor, DED, recruits procaspase 8 to the DISC. Once bound to the DISC, several procaspase 8 molecules are brought into close proximity. They are assumed to activate each other via autoproteolysis (Denault and Salvesen, 2002), releasing activated caspase 8 molecules. Activated caspase 8 then cleaves and thereby activates several downstream effector caspases, which finally cleave specific substrates consequently causing cell death. One of the most crucial substrates is the endonuclease CAD (caspase-activated DNAase), which is responsible for DNA fragmentation within the nucleus (Scaffidi et al., 1998).

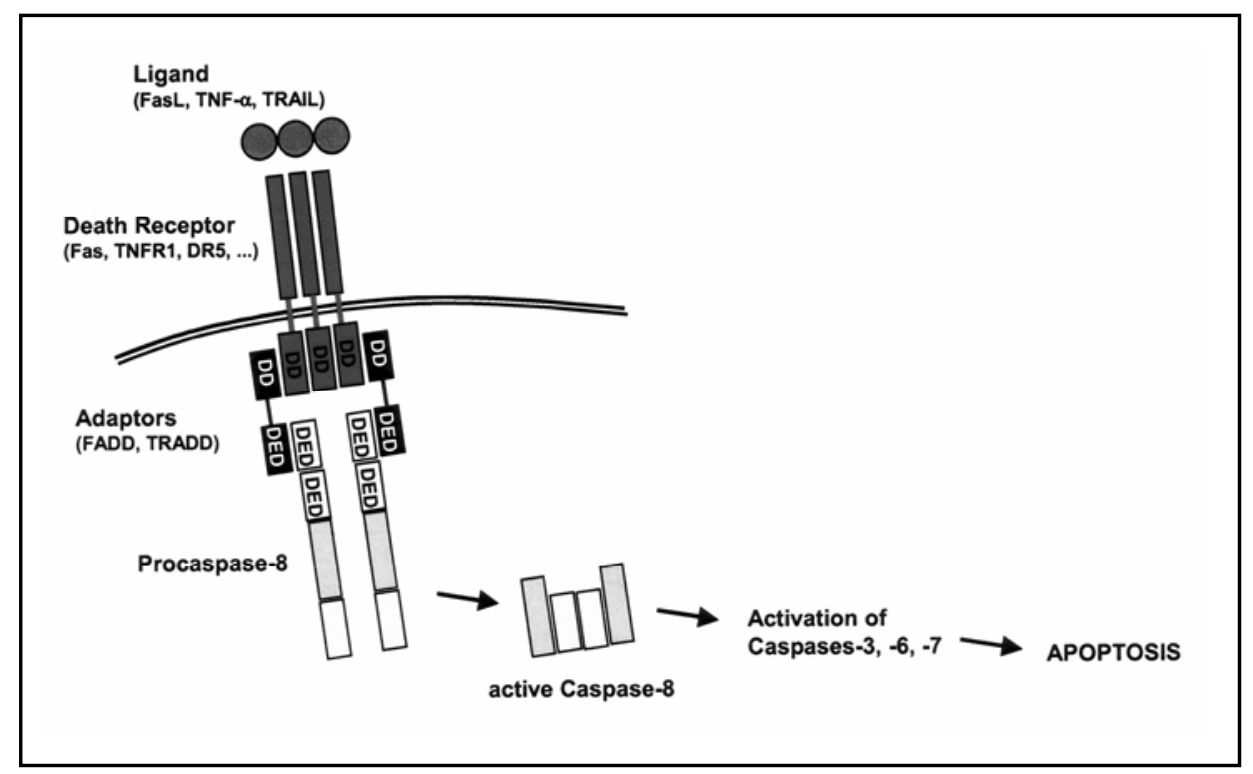

Fig. 1.3.2.1 Receptor-mediated caspase activation via the DISC death-inducing signalling complex (Gewies, 2003 / www.celldeath.de/encyclo/aporev/aporev/htm).

In contrast to the extrinsic type I pathway, the signal generated via the extrinsic type II pathway is not strong enough to start off the above described process on its own. The signal needs to be amplified with the help of the mitochondrial pathway. The pro-apoptotic Bcl-2 family member Bid provides the link in the chain to connect the receptor-mediated caspase activation via the DISC with the mitochondrial pathway. Bid is one of several substrates of the activated caspase 8 . Once Bid is cleaved into action, its truncated brother translocates into the mitochondria, where it co-operates with other pro-apoptotic Bcl-2 family proteins like Bax and Bak (Bernardi et al., 1999). Together these proteins initiate the release of cytochrom c and other pro-apoptotic mitochondrial factors into the cytosol (Luo et al., 1998). Of course, 
theses processes can be gradually attenuated and counter-acted, when anti-apoptotic proteins interfere, proteins such as Bcl-2, Bcl-X $\mathrm{L}, \mathrm{Bcl}-\mathrm{W}, \mathrm{A} 1$ and $\mathrm{Mcl}-1$ (Borner, 2003; Vaux et al., 1988). In this way at certain stages of apoptosis, the fate of a cell can still be tilted towards pro-survival.

When cytochrome $\mathrm{c}$ is released into the cytosol, it subsequently binds to the monomeric Apaf-1 in the presence of dATP. This binding causes a conformational change in Apaf-1, leading to an oligomerisation of several Apaf-1 molecules, which finally assemble to form the apoptosome (Salvesen and Renatus, 2002). The apoptosome is a heptameric protein complex with a wheel-like structure. It triggers the activation of initiator pro-caspase 9 (Acehan et al., 2002). Thus activated caspase 9 switches on the caspase cascade, including caspases 3, 6 and 7. Finally, this leads to cleavage of a specific set of substrates, resulting in mediation and amplification of the actual death signal, including all morphological and biochemical features usually observed (Earnshaw et al., 1999; Slee et al., 1999).

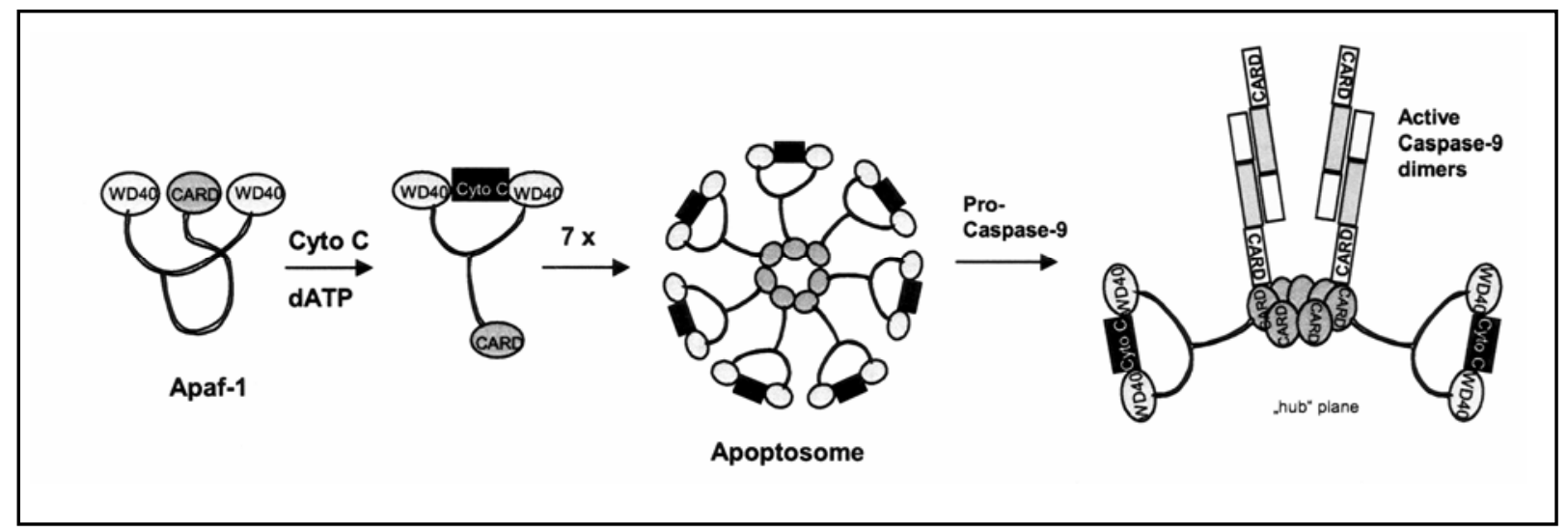

Fig. 1.3.2.2 Mitochondria-mediated formation and activation of the apoptosome (Gewies, 2003/ www.celldeath.de/encyclo/aporev/aporev/htm).

Apart from functioning as an amplifier for the extrinsic apoptosis pathway type II, the mitochondrial intrinsic apoptosis pathway also plays a key role in integrating and propagating death signals coming from inside the cell. 


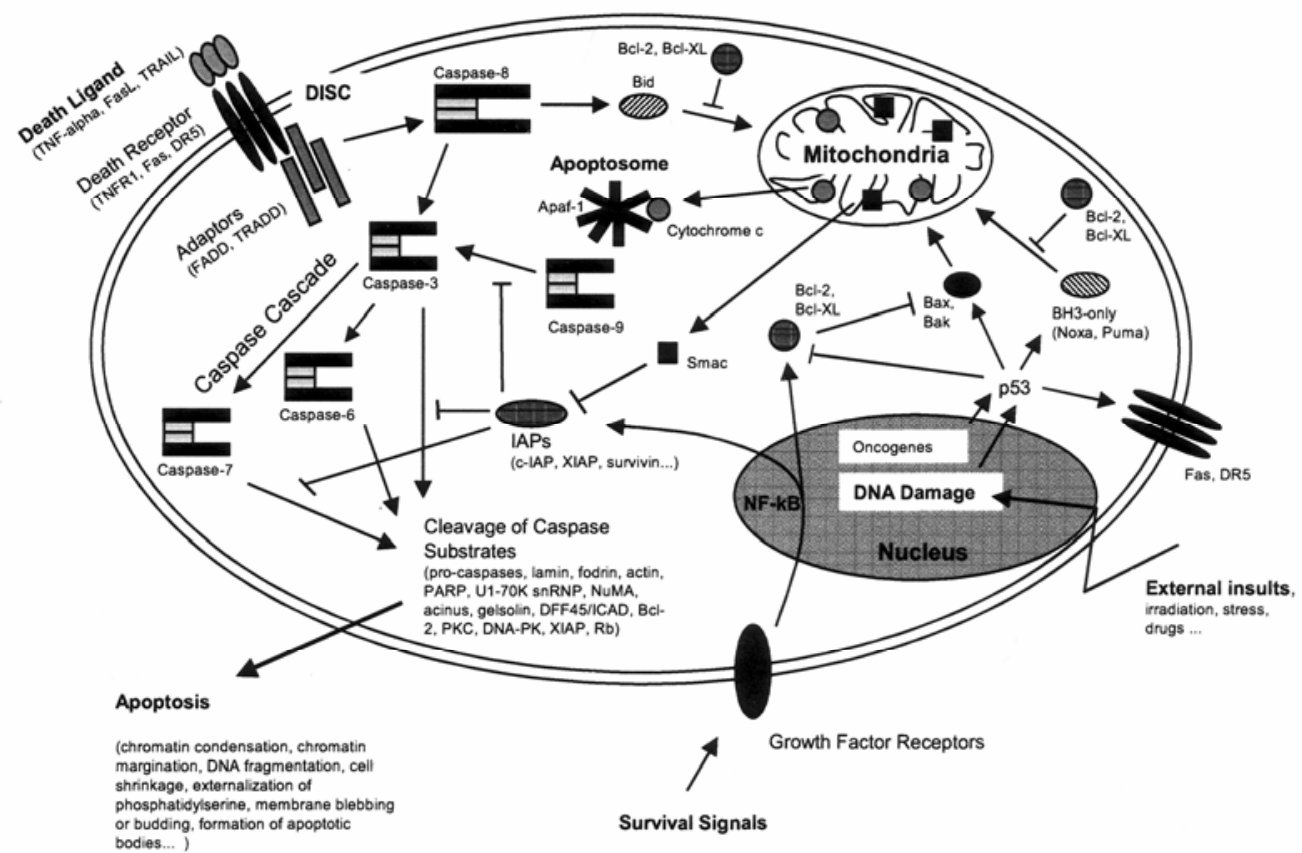

Fig. 1.3.2.3 Apoptosis signalling pathways (extrinsic I+Il; intrinsic), (Gewies, 2003 www.celldeath.de/encyclo/aporev/aporev/htm).

These stimuli include DNA damage, oxidative stress, mitogen starvation, radiation, in addition to those changes induced by cytotoxic drugs (Kaufmann and Earnshaw, 2000; Wang, 2001). In biological terms, induction and propagation of pro-apoptotic signals are run in the same way as described for the extrinsic apoptosis pathway.

\subsection{Apoptosis and histone modifications}

Taking together all the data mentioned in the previous section on histone modifications, an increasing body of evidence suggests that these have great influences on chromatin folding, DNA repair, transcription repression and activation with functional consequence (Peterson and Laniel, 2004; Strahl and Allis, 2000; Turner, 2000; van Holde and Zlatanova, 1995; Wolffe and Hayes, 1999). Moreover, given the drastic changes in the integrity of DNA and the state of chromatin compaction with the onset of apoptosis, it was assumed that different histone modifications might play a pivotal role in promoting cleavage of nucleosomal DNA and chromatin condensation, which are said to be hallmarks of apoptosis (Wyllie et al., 1981; Wyllie et al., 1980; Wyllie et al., 1984). Several groups have already proposed that special histone modifications like $\mathrm{H} 2 \mathrm{~B}$ phosphorylation (Ajiro, 2000) and $\mathrm{H} 1$ dephosphorylation (Talasz et al., 2002) are marks for apoptosis-related DNA fragmentation and chromatin condensation. In their most recent work on the $\mathrm{H} 1 \mathrm{C}$-terminal domain binding to the apoptotic nuclease DFF40/CAD, which subsequently results in DNA cleavage, Widlak et al. (Widlak et 
al., 2005) proposed a strong interaction of histone $\mathrm{H} 1$ with DFF40/CAD, which target and activate linker DNA cleavage during the final stages of apoptosis.

Apart from these findings, it has not yet been possible to clearly define specific core histone modifications, which are exclusively induced during apoptosis, with just one or two exceptions to this rule (Cheung et al., 2000; Jason et al., 2001; Th'ng, 2001). Phosphorylation of histone $\mathrm{H} 3$ at serines 10 and 28 as well as phosphorylation of $\mathrm{H} 2 \mathrm{AX}$ at serine 139 in particular (Rogakou et al., 1998) were first thought to react as direct markers for apoptosis. But these results had to be revised: phosphorylation of histone $\mathrm{H} 3$ at serines 10 and 28 has consistently been reported to be associated with mitotic chromatin condensation and cell cycle events (Cheung et al., 2000; Happel et al., 2005; Hendzel et al., 1998b). A direct connection of these modifications with apoptosis could not be confirmed. Although phosphorylation of the histone $\mathrm{H} 2 \mathrm{~A}$ variant $\mathrm{H} 2 \mathrm{AX}$ at serine 139 was repeatedly correlated with DNA double-strand breaks, induced by various stimuli (Hendzel et al., 1998a; Rogakou et al., 1999; Rogakou et al., 2000a; Rogakou et al., 1998; Thiriet and Hayes, 2005), this mark was found out to act more in a sense of a general DNA-damage sensor than a marker for the onset of apoptosis (Wang et al., 2003). This phenomenon was particularly observed with phosphorylation of histones at specific sites, which was either associated with cell cycle events (mitosis / meiosis) e.g. H3 phosphate S 10; S 28, T 3; T11; H2A S 1; T 119 H4 S 1 or with DNA repair e.g. H2AX-phosphate S 139.

Cheung and co-workers (Cheung et al., 2003) presented one of two exceptional modifications out of a large pool of known modifications, namely histone H2B phosphorylated at serine 14 , which could be directly linked with apoptosis. Combined with these findings a similar observation was made by Ahn and co-workers (Ahn et al., 2005a; Ahn et al., 2005b) in the yeast strain S. cerevisiae. The only difference in the phosphorylation pattern was found in a site specific change from serine 14 in mammals to serine 10 in yeast.

Mimnaugh and colleagues (Mimnaugh et al., 2001) reported about a caspase-dependent deubiquitylation of monoubiquitylated lysine residues in histone $\mathrm{H} 2 \mathrm{~A}$, which was induced by various stimuli. However, this group concluded that this modification was a downstream consequence of procaspase activation and was seen as a consistent feature of the execution phase of apoptosis rather than a determining or initiating event.

All in all this data clearly points out the complex matter of linking histone site specific modifications to an even more complex story of the signalling pathway in apoptosis. The greatest difficulties must be seen in the fact that it is almost impossible to clearly separate cell cycle events and with it processes of mitosis, meiosis and chromatin condensation from the process of apoptosis in correlation with DNA condensation and fragmentation. As it is, a kind of fluid transition seems to exist between these two processes, even more so with 
reference to DNA repair mechanisms. So it still remains a real challenge in research to clearly assign molecular changes to one or the other.

\subsection{Present state of research and main aims of this project}

The main features of apoptotic cells have been investigated extensively by means of morphological, biochemical, and cytological methods. The process of apoptosis is characterised by morphological features like cell shrinkage and formation of apoptotic bodies and biochemical features such as cleavage of nucleosomal DNA into large (Brown et al., 1993) and finally nucleosomal fragment sizes (Wyllie et al., 1984) and chromatin condensation (Hale et al., 1996; Harmon and Allan, 1997; Kerr et al., 1972; Wyllie et al., 1980). The activity of different caspases (Herrera et al., 2001; Thornberry and Lazebnik, 1998) and the endogenous nuclease CAD/DFF40 (Arends et al., 1990; Khodarev et al., 1998) were confirmed to play a crucial role in chromatin fragmentation. Moreover, with respect to chromatin condensation and packaging more and more evidence has come up which suggests that post-translational histone modifications such as acetylation, methylation, phosphorylation and others greatly influence the formation of chromatin structures with defined functional consequences (van Holde and Zlatanova, 1995; Wolffe and Hayes, 1999). However, it has not yet been fully elucidated, whether specific histone modifications determine a preferential cleavage of nucleosomal DNA. In their quite recent publication by Widlak et al. (Widlak et al., 2005), this group confirmed that the linker histone interacts with the endogenous nuclease CAD/DFF40 and thereby mediates apoptosis-related DNA cleavage.

Due to all these findings, the main aim of this work was to analyse cause and effects of apoptosis-related changes in histone modifications in particular, as well as their influence on chromatin condensation and fragmentation during apoptosis. To tackle this question, possible overall changes in histone modification patterns after induction of apoptosis were examined by western blotting, using antibodies raised against specific histone modifications. These analyses were to be supplemented by more detailed investigations of changes in histone modifications on single histone type level, including the histone variants of $\mathrm{H} 2 \mathrm{~A}$ and H3. For this purpose core histones were purified and separated via HPLC and analysed on AUT/AUC $2^{\text {nd }}$ dimension gels as well as by CZE.

Cleavage of nucleosomal DNA is a pivotal point in later stages of apoptosis. Moreover, recent publications by $\mathrm{Wu}$ et al. (Wu et al., 2002) and Radic et al. (Radic et al., 2004) proposed a functional release of apoptotic nucleosome and histones respectively into the cytosol. Konishi and co-workers described the apoptosis-related release of the histone variant H1.2 into the cytosol (Konishi et al., 2003), which is assumed to function as a 
transmitter for apoptotic signals from the nucleus to mitochondria induced by DNA double strand breaks.

On the basis of these previous results, a further aim of this project was on the one hand the analysis of a putative nuclear release of specifically modified histones into the cytosol, on the other hand the study of different histone modifications in nucleosomes of fragmented chromatin after induction of apoptosis compared to modifications in non-fragmented chromatin. Methods that should be applied for the analyses of a histone release included Western blotting and laser-scan microscopy. Investigations of histone modifications in fragmented versus non-fragmented chromatin involved isopycnic ultracentrifugation of sucrose gradients and subsequent western blotting. 


\section{Materials and Methods}

\subsection{Materials}

\subsubsection{Technical lab equipment}

\begin{tabular}{|c|c|}
\hline agarose gel electrophoresis chambers & precision workshop (Göttingen University) \\
\hline PIACE MDQ capillary zone electrophoresis & Beckman Coulter (CA, USA) \\
\hline cell counting unit CASY 1 TT & Schärfe System (Reutlingen) \\
\hline centrifuge 5415 & Eppendorf (Hamburg) \\
\hline centrifuge: Biofuge pico & Heraeus (Hanau) \\
\hline centrifuge: Megafuge 1.0 & Heraeus (Hanau) \\
\hline centrifuge: Sorvall RCB (cooling) & Kendro (Hanau) \\
\hline centrifuge: Varifuge 3.0R & Heraeus (Hanau) \\
\hline cooling trap RVT 100 & Savant (Holbrook NY, USA) \\
\hline cytospin system & Heraeus Sepatech (Osterode) \\
\hline digital sonifier & Branson (Schwäbisch Gmünd) \\
\hline Duomax 1030 shaker & Heidolph (Schwabach) \\
\hline FACScalibur & BECTON DICKINSON (Heidelberg) \\
\hline $\begin{array}{l}\text { fluorescent plate reader: } \\
\text { Fluoroskan Ascent FL }\end{array}$ & $\begin{array}{l}\text { Thermo Labsystems Oy, } \\
\text { Electron Corporation }\end{array}$ \\
\hline fraction collector FRAC 10 & Pharmacia (Freiburg) \\
\hline HPLC unit & Kontron Instruments (CA, USA) \\
\hline $\begin{array}{l}\text { immuno-fluorescence microscope: } \\
\text { Axioscope } 20\end{array}$ & Zeiss (Göttingen) \\
\hline $\begin{array}{l}\text { horizontal laminar flow hood } \\
\text { HERAsafe Typ 18/2 }\end{array}$ & Heraeus (Hanau) \\
\hline incubator: Cytoperm 2 & Heraeus (Hanau) \\
\hline incubator: Model CO24 & $\begin{array}{l}\text { New Brunswick Scientific Co. Inc. (Edson, } \\
\text { New Jersey, USA) }\end{array}$ \\
\hline incubator: type B5050 & Heraeus (Hanau) \\
\hline Intas Gel Jet Image & INTAS (Göttingen) \\
\hline $\begin{array}{l}\text { Jupiter C4 column (150×4.6 mm inner } \\
\text { diameter; } 5 \mu \mathrm{m} \text { particle size, } 300 \AA \text { pore size) }\end{array}$ & Phenomenex (Aschaffenburg) \\
\hline liquid nitrogen storage container & (Air liquide Kryotechnik, Düsseldorf) \\
\hline $\begin{array}{l}\text { laser scanning microscope: } \\
\text { Zeiss LSM } 410 \text { invert }\end{array}$ & Zeiss (Göttingen) \\
\hline
\end{tabular}




\begin{tabular}{|c|c|}
\hline magnetic stirrer IKAMAG ${ }^{\circledR}$ RET & Janke und Kunkel (Staufen) \\
\hline perfusor Secura & B. Braun (Melsungen) \\
\hline pH-meter CG820 & Schott (Mainz) \\
\hline photometer Ultrospec 4050 & Amersham (Freiburg) \\
\hline photometric RNA/DNA calculator Genequant II & Amersham Pharmacia (Freiburg) \\
\hline power supply pack 1000 & BioRad (München) \\
\hline quartz glass distilling apparatus Destamat & Heraeus (Hanau) \\
\hline refractometer & Carl Zeiss (Göttigen) \\
\hline rotor types: SS34, HB 4, HB 6 & Kendro (Hanau) \\
\hline SW28, TLA-100 & Beckman Coulter (CA, USA) \\
\hline scales & Sartorius (Göttingen) \\
\hline SDS-gel electrophoresis chambers & precision workshop (Göttingen) \\
\hline semi-dry blotting unit & precision workshop (Göttingen) \\
\hline Speed vac SC100 & Savant (Holbrook NY, USA) \\
\hline standard power supply P25 & Biometra (Göttingen) \\
\hline thermocycler TC 2 & Perkin Elmer (Weiterstadt) \\
\hline ultracentrifuge Optima $^{\text {TM }}$ TLX 120 CE & Beckman Coulter (CA, USA) \\
\hline ultracentrifuge L7 5S & Beckman Instruments (München) \\
\hline vacuum pump & Millipore (Schwalbach) \\
\hline
\end{tabular}

\subsubsection{Chemicals}

All chemicals exhibit analytical grade unless stated otherwise.

\begin{tabular}{|l|l|}
\hline acetone & Roth (Karlsruhe) \\
\hline acetonitrile & Roth (Karlsruhe) \\
\hline acrylamide/bisacrylamide 30/08 & Roth (Karlsruhe) \\
\hline activated carbon & Roth (Karlsruhe) \\
\hline agarose & Roth (Karlsruhe) \\
\hline ammonia & Merck (Darmstadt) \\
\hline ammonium persulfate & Serva (Heidelberg) \\
\hline APO-DIRECT'TM KIT & BECTON DICKINSON (Heidelberg) \\
\hline 2-mercaptoethylamine/HCl & Sigma (Steinheim) \\
\hline Bio-Gel ${ }^{\circledR}$ P60 polyacrylamide & BioRad (München) \\
\hline boric acid & Roth (Karlsruhe) \\
\hline bovine serum albumin & Roth (Karlsruhe) \\
\hline calcium chloride $^{\text {Merck (Darmstadt) }}$ \\
\hline
\end{tabular}




\begin{tabular}{|c|c|}
\hline CHAPS & Sigma (Steinheim) \\
\hline chloroform & Roth (Karlsruhe) \\
\hline CTAB & Roth (Karlsruhe) \\
\hline $\mathrm{D}(+)$ glucose & Sigma (Steinheim) \\
\hline diaminobenzidine (DAB) & Serva (Heidelberg) \\
\hline dipotassium hydrogen phosphate & Roth (Karlsruhe) \\
\hline disodium hydrogen phosphate & Roth (Karlsruhe) \\
\hline DMSO & Sigma (Steinheim) \\
\hline DTT & Applichem (Darmstadt) \\
\hline EDTA disodium salt & Serva (Heidelberg) \\
\hline EGTA & Serva (Heidelberg) \\
\hline ethanol & Roth (Karlsruhe) \\
\hline etoposide & Sigma (Steinheim) \\
\hline FCS (fetal calf serum) for HeLa H2B-YFP & PAA (Cölbe) \\
\hline FCS (fetal calf serum) for HL-60 cells & Biochrom (Berlin) \\
\hline Ficoll & Gibco RBL (Karlsruhe) \\
\hline Gentamycin & Biochrom (Berlin) / PAA (Cölbe) \\
\hline glacial acetic acid & Roth (Karlsruhe) \\
\hline glycerol & Roth (Karlsruhe) \\
\hline glycine & Roth (Karlsruhe) \\
\hline HEPES & Roth (Karlsruhe) \\
\hline HPMC & Roth (Karlsruhe) \\
\hline $\mathrm{HPLC} \mathrm{H}_{2} \mathrm{O}$ & Roth (Karlsruhe) \\
\hline hydrochloric acid $32 \%$ & Roth (Karlsruhe) \\
\hline IGEPAL (formerly Nonidet P-40) & Sigma (Steinheim) \\
\hline isoamyl alcohol & Roth (Karlsruhe) \\
\hline isopropanol & Roth (Karlsruhe) \\
\hline Isoton ${ }^{\circledR}$ buffer & Beckman Coulter (CA, USA) \\
\hline magnesium chloride hexahydrate & Merck (Darmstadt) \\
\hline magnesium sulfate & Merck (Darmstadt) \\
\hline methanol & Roth (Karlsruhe) \\
\hline (non-fat) dry milk & Applichem (Darmstadt) \\
\hline $\mathrm{N},-\mathrm{N}$-dimethyl formamide & Roth (Karlsruhe) \\
\hline ortho-phosphoric acid 85\% & Roth (Karlsruhe) \\
\hline phenol equilibrated & BioRad (München) / Roth (Karlsruhe) \\
\hline polyoxyethylene sorbitane monolaureate & Roth (Karlsruhe) \\
\hline
\end{tabular}




\begin{tabular}{|l|l|}
\hline (Tween 20) & \\
\hline Ponceau red & Roth (Karlsruhe) \\
\hline phosphoric acid & Roth (Karlruhe) \\
\hline potassium chloride & Merck (Darmstadt) \\
\hline potassium dihydrogen phosphate & Roth (Karlsruhe) \\
\hline Pyronin Y & Serva (Heidelberg) \\
\hline RPMI medium & $\begin{array}{l}\text { PAA Laboratories (Cölbe) and } \\
\text { Biochrom (Berlin) }\end{array}$ \\
\hline SDS & Serva (Heidelberg) \\
\hline sodium acide & Merck (Darmstadt) \\
\hline sodium chloride & Roth (Karlsruhe) \\
\hline sodium dihydrogen phosphate monohydrate & Merck (Darmstadt) \\
\hline sodium hydrogen carbonate & Roth (Karlruhe) \\
\hline sucrose & Serva (Heidelberg) \\
\hline sulphuric acid & Roth (Karlruhe) \\
\hline TEMED & Serva (Heidelberg) \\
\hline topotecan ${ }^{\circledR}$ (topoisomerase I inhibitor) & SmithKline Beecham (Munich) \\
\hline trichloroacetic acid & Applichem (Darmstadt) \\
\hline trichostatin A & Sigma (Steinheim) \\
\hline trifluoroacetic acid & Sigma (Steinheim) \\
\hline tris base & Roth (Karlsruhe) \\
\hline Triton ${ }^{\circledR}$ X-100 & Sigma (Steinheim) \\
\hline urea & Sigma (Steinheim) \\
\hline -mercaptoethanol & Boehringer (Ingelheim) \\
\hline z-VAD-(OMe)-fmk (caspase 3 inhibitor) & Calbiochem / Merck (Schwalbach) \\
\hline
\end{tabular}

\subsubsection{Standard buffers, media and solutions}

alkaline phosphatase buffer:

$100 \mathrm{mM}$ Tris/ $\mathrm{HCl}, \mathrm{pH}$ 9.5, $100 \mathrm{mM} \mathrm{NaCl}, 5 \mathrm{mM} \mathrm{MgCl} 2$

alkaline phosphatase reaction solution:

$100 \mathrm{mM}$ Tris/ $\mathrm{HCl}, 100 \mathrm{mM} \mathrm{NaCl}, 5 \mathrm{mM} \mathrm{MgCl}$, 0.0175\% (w/v) BCIP, 0.02625\% (w/v) NBT, $0.67 \%(v / v)$ DMF

DNA loading buffer(10x)

20\% (w/v) Ficoll, 0.1 M EDTA, 1\% (w/v) SDS, 0.25\% (w/v) bromophenol blue 


\section{DAPI mounting shield (embedding medium)}

10\% (v/v) PBS, 90\% (v/v) glycerol, $1 \mathrm{mg} / \mathrm{ml}$ phenylenediamin, $1 \mu \mathrm{g} / \mathrm{ml}$ 4,6-diamino-2phenylindol (DAPI)

ethidium bromide (Sharp et al., 1973)

stock solution: $10 \mathrm{mg} / \mathrm{ml}$; working dilution: $2 \mu \mathrm{g} / \mathrm{ml}$

etoposide stock solution

$50 \mathrm{mM}$ etoposide in $100 \%$ DMSO (working dilution: $50 \mu \mathrm{M}$ ), aliquots were stored at $-20^{\circ} \mathrm{C}$

nuclear preparation buffer (III,1)

$10 \mathrm{mM}$ Tris/ $\mathrm{HCl}, \mathrm{pH} 7.4,2 \mathrm{mM} \mathrm{MgCl} 2,0.14 \mathrm{M} \mathrm{NaCl}$

nuclear preparation buffer (III,2)

nuclear preparation buffer (III,1) with 2\% (v/v) Tween 20

nuclear preparation buffer (III,3)

nuclear preparation buffer (III,1) with $50 \%$ (w/v) sucrose

PBS (10x)

$1.4 \mathrm{M} \mathrm{NaCl}, 27 \mathrm{mM} \mathrm{KCl}, 15 \mathrm{mM} \mathrm{KH}_{2} \mathrm{PO}_{4}, 90 \mathrm{mM} \mathrm{Na}_{2} \mathrm{HPO}_{4}, \mathrm{pH} 7.4$

\section{RPMI medium}

RPMI instant powder, $2 \mathrm{~g} / \mathrm{l} \mathrm{NaHCO}_{3}$ (24 mM), $3.576 \mathrm{~g} / \mathrm{HEPES}(15 \mathrm{mM}), \mathrm{pH} 7.3$; the medium was sterilised by filtration $\left(0.2 \mu \mathrm{M}\right.$ pore size); storage at $4^{\circ} \mathrm{C}$;

$10 \%(\mathrm{v} / \mathrm{v})$ FCS and $50 \mu \mathrm{g} / \mathrm{ml}$ gentamycin were added prior to use

\section{$\underline{\text { RPMI freezing medium }}$}

RPMI medium with 20\% (v/v) FCS and 10\% (v/v) DMSO

SDS-PAGE chamber buffer (5x) (Laemmli et al., 1976)

$0.25 \mathrm{M}$ Tris/ $\mathrm{HCl}, \mathrm{pH}$ 8.7, 10 mM EDTA, $1.9 \mathrm{M}$ glycine, 0.5\% (w/v) SDS

SDS-PAGE 'Laemmli' loading buffer (3x)

9\% (w/v) SDS, 300 mM Tris/HCl, pH 6.8, 22.5\% (w/v) glycerol, 0.1\% (w/v) bromophenol blue, 10\% (v/v) $\beta$-mercaptoethanol 


\section{$\underline{\text { TBE buffer (10x) }}$}

$0.9 \mathrm{M}$ Tris/ $\mathrm{HCl}, \mathrm{pH}$ 8.3, $0.9 \mathrm{M}$ boric acid, $0.025 \mathrm{M}$ EDTA

$\underline{\operatorname{TBS}(1 \times)}$

$20 \mathrm{mM}$ Tris/ $\mathrm{HCl}, \mathrm{pH} 7.6,137 \mathrm{mM} \mathrm{NaCl}$

\section{$\underline{\operatorname{TBST}(1 \times)}$}

$20 \mathrm{mM}$ Tris/HCl, pH 7.6, $137 \mathrm{mM} \mathrm{NaCl}, 0.5 \%$ (v/v) Tween-20

\section{$\underline{\text { TE buffer }}$}

10 mM Tris/HCl, pH 8.0, 1 mM EDTA, pH 8.0

\section{Topotecan stock solution}

$1 \mathrm{mg} / \mathrm{ml}$ in $\mathrm{H}_{2} \mathrm{O}$ bidest., aliquots were stored at $-20^{\circ} \mathrm{C} /$ working dilution: $150 \mathrm{ng} / \mathrm{ml}$

transfer buffer (10x) (modified after Towbin and Gordon, 1984)

25 mM Tris/HCl, pH 8.3, 192 mM glycine, 0.037\% (w/v) SDS, 20\% (v/v) methanol

\subsubsection{Cell lines}

\subsubsection{Eukaryotic cell lines}

HL-60: is a promyelocytic cell line, which derives from a 36-year-old Caucasien female who was suffering from acute promyelocytic leukaemia. They were first described by Collins et al. (Collins et al., 1977) and further characterised by Gallagher et al. (Gallagher et al., 1979). These relatively small cells grow in suspension. In the presence of certain chemical compounds or cytokines, such as DMSO or TNF- $\alpha$ these cells may differentiate to fully functional monocytes or even macrophages.

HeLa: is an epithelial cervix carcinoma cell line, which derived from a 31-year-old female African American, Henrietta Lacks (1951), who was suffering from a malignant cervix adenocarcinoma. This cell line was first characterised by Gey et al. (Gey et al., 1952).

\subsubsection{Stably transfected HeLa H2B-YFP cells}

Stably transfected HeLa H2B-YFP cells (American Type Culture Collection (ATCC), No. CCL-2) were kindly provided by Prof. Dr. J. Langowski ${ }^{2}$. To establish stable transfectants, a

\footnotetext{
${ }^{2}$ DKFZ Deutsches Krebsforschungszentrum, Dept. Biophysics of Macromolecules B040,
} 
HeLa clone expressing the core histone $\mathrm{H} 2 \mathrm{~B}$ fused to the yellow fluorescent protein $(\mathrm{H} 2 \mathrm{~B}$ YFP) was used. The vector (pSV HIII H2B-YFP), which is selective for the antibiotics kanamycin and neomycin, is optimised for stable transfection in mammalian cell lines and was obtained from BD Biosciences Clontech (Heidelberg, Germany).

The transfectants were generated by a protocol developed by Knoch (2002) ${ }^{3}$. Transfections were carried out using lipofectamin. HeLa cells were grown in $5 \% \mathrm{CO}_{2}$ atmosphere at $37^{\circ} \mathrm{C}$. The cells were cultured in RPMI medium (PAA (Cölbe)) and supplemented with 10\% (w/v) FCS but without phenol red, to avoid a possible colour interference with YFP.

\subsubsection{Dyes and stains}

\begin{tabular}{|l|l|}
\hline BCIP & Applichem (Darmstadt) \\
\hline bromophenol blue & Merck (Darmstadt) \\
\hline Coomassie brilliant blue G250 (Serva blue) & Serva (Heidelberg) \\
\hline Coomassie brilliant blue R250 & Fluka (Taufkirchen) \\
\hline DAB & Serva (Heidelberg) \\
\hline DAPI (Vectashield) in mounting medium & Vector Laboratories (Burlingame, USA) \\
\hline DEVD-afc & BioSource (Camarillo, USA) \\
\hline ethidium bromide & Sigma (Steinheim) \\
\hline luminol (ECL) & Amersham (Freiburg) \\
\hline NBT & Applichem (Darmstadt) \\
\hline Ponceau S concentrate & Sigma (Steinheim) \\
\hline
\end{tabular}

\subsubsection{Molecular weight standards}

\begin{tabular}{|l|l|}
\hline 2-log DNA ladder 0.1-10.0 kb & New England Biolabs (Schwalbach) \\
\hline $\begin{array}{l}\text { DNA Standard } \lambda \text {-DNA cleaved with } \\
\text { Eco RI / Hind III }\end{array}$ & MBI Fermentas (St. Leon-Roth) \\
\hline prestained protein ladder, $\sim 10-180 \mathrm{kDa}$ & MBI Fermentas (St. Leon-Roth) \\
\hline prestained protein standard Seeblue plus 2 & Invitrogen (Karlsruhe) \\
\hline
\end{tabular}

Im Neuenheimer Feld 580, 69120 Heidelberg, Germany

${ }^{3}$ T.A. Knoch, Approaching the three-dimensional organisation of the human genome (Mannheim, 2002), pp. 222-226. 


\subsubsection{Protease inhibitors}

\begin{tabular}{|l|l|}
\hline aprotinin & Roche (Mannheim) \\
\hline Complete $®$ & Roche (Mannheim) \\
\hline leupeptin & Roche (Mannheim) \\
\hline pepstatin & Roche (Mannheim) \\
\hline phenylmethylsulfonyl fluoride (PMSF) & Serva (Heidelberg) \\
\hline
\end{tabular}

\subsubsection{Enzymes}

\begin{tabular}{|l|l|}
\hline proteinase K & Boehringer (Mannheim) \\
\hline RNAse A & Roche (Mannheim) \\
\hline trypsin & Biochrom (Berlin) \\
\hline
\end{tabular}

\subsubsection{Antibodies}

\subsubsection{Primary antibodies}

\begin{tabular}{|c|c|c|}
\hline $\begin{array}{l}\text { primary antibody } \\
\text { raised against: }\end{array}$ & $\begin{array}{c}\text { dilution in } \\
5 \%(w / v) \mathrm{BSA}^{\prime} \\
0.02 \%(\mathrm{w} / \mathrm{v}) \mathrm{NaN}_{3}\end{array}$ & company \\
\hline $\begin{array}{l}\text { poly-ADP-ribose polymerase } \\
\text { (PARP) (polyclonal) }\end{array}$ & $1: 1,000$ & $\begin{array}{l}\text { Cell Signaling Technology } \\
\text { (Beverly, USA) }\end{array}$ \\
\hline rabbit histone $\mathrm{H} 3$ (polyclonal) & $1: 1,000$ & $\begin{array}{l}\text { Cell Signaling Technology } \\
\text { (Beverly, USA) }\end{array}$ \\
\hline histone H2B (polyclonal) & $1: 1,000$ & $\begin{array}{l}\text { Cell Signaling Technology } \\
\text { (Beverly, USA) }\end{array}$ \\
\hline histone $\mathrm{H} 2 \mathrm{~A}$ (polyclonal) & $1: 1,000$ & $\begin{array}{l}\text { Cell Signaling Technology } \\
\text { (Beverly, USA) }\end{array}$ \\
\hline histone H4 (polyclonal) & $1: 1,000$ & $\begin{array}{l}\text { Cell Signaling Technology } \\
\text { (Beverly, USA) }\end{array}$ \\
\hline $\begin{array}{l}\text { histone H3 di-methyl lysine } 4 \\
\text { (polyclonal) }\end{array}$ & $1: 5,000$ & Upstate (New York, USA) \\
\hline $\begin{array}{l}\text { histone H3 di-methyl lysine } 9 \\
\text { (polyclonal) }\end{array}$ & $1: 2,000$ & Upstate (New York, USA) \\
\hline $\begin{array}{l}\text { histone H3 di-methyl lysine } \\
36 \text { (polyclonal) }\end{array}$ & $1: 5,000$ & Upstate (New York, USA) \\
\hline $\begin{array}{l}\text { histone H3 tri-methyl lysine } 4 \\
\text { (polyclonal) }\end{array}$ & $1: 2,000$ & abcam (Cambridge, UK) \\
\hline $\begin{array}{l}\text { histone H3 tri-methyl lysine } 9 \\
\text { polyclonal rabbit }\end{array}$ & $1: 500$ & abcam (Cambridge, UK) \\
\hline $\begin{array}{l}\text { histone } \mathrm{H} 2 \mathrm{~A} \text { ubiquityl } \\
\text { (monoclonal) }\end{array}$ & $1: 1,000$ & Upstate (New York, USA) \\
\hline $\begin{array}{l}\text { histone H2A.X phospho } \\
\text { serine } 139 \text { (monoclonal) }\end{array}$ & $0.1 \mu \mathrm{g} / \mathrm{ml}$ & Upstate (New York, USA) \\
\hline $\begin{array}{l}\text { lactate dehydrogenase } \\
\text { (LDH) (polyclonal) }\end{array}$ & $1: 500$ & Rockland (Gilbertsville, PA) \\
\hline $\begin{array}{l}\text { RNA polymerase II } \\
\text { (polyclonal) }\end{array}$ & $1: 500$ & Santa Cruz (California, USA) \\
\hline HP1- $\alpha$ (Heterochromatin & $1: 1,000$ & Upstate (New York, USA) \\
\hline
\end{tabular}




\begin{tabular}{|l|c|l|}
\hline Protein 1- $\alpha$ ) (polyclonal) & $1: 100$ & $\begin{array}{l}\text { Cell Signaling Technology } \\
\text { (Beverly, USA) }\end{array}$ \\
\hline lamin A/C (polyclonal) & $1: 1,000$ & $\begin{array}{l}\text { Alexis Biochemicals } \\
\text { (Grünberg) }\end{array}$ \\
\hline $\begin{array}{l}\text { N-acetylglucosamine } \\
\text { (monoclonal) }\end{array}$ & $1: 1,000$ & Sigma (Steinheim) \\
\hline tubulin- $\alpha$ (monoclonal) & & \\
\hline
\end{tabular}

\subsubsection{Secondary antibodies}

\begin{tabular}{|l|c|l|}
\hline $\begin{array}{l}\text { secondary antibody } \\
\text { raised against }\end{array}$ & $\begin{array}{c}\text { dilution in } \\
\text { (w/v) non-fat dry milk / } \\
\text { TBST }\end{array}$ & company \\
\hline $\begin{array}{l}\text { anti-rabbit alkaline } \\
\text { phosphatase }\end{array}$ & $1: 2,500$ & Dianova (Hamburg) \\
\hline $\begin{array}{l}\text { anti-mouse IgG alkaline } \\
\text { phosphatase }\end{array}$ & $1: 5,000$ & Sigma (Steinheim) \\
\hline anti-mouse IgG HRP & $1: 50,000$ & Sigma (Steinheim) \\
\hline anti-goat IgG HRP & $1: 5,000$ & Sigma (Steinheim) \\
\hline AlexaFluor488 anti-mouse & $1: 1,000$ & $\begin{array}{l}\text { Molecular Probes } \\
\text { (Eugene, USA) }\end{array}$ \\
\hline AlexaFluor488 anti-goat & $1: 1,000$ & $\begin{array}{l}\text { Molecular Probes } \\
\text { (Eugene, USA) }\end{array}$ \\
\hline AlexaFluor555 anti-mouse & $1: 1,000$ & $\begin{array}{l}\text { Molecular Probes } \\
\text { (Eugene, USA) }\end{array}$ \\
\hline
\end{tabular}

\subsubsection{Plastic ware and miscellaneous}

\begin{tabular}{|l|l|}
\hline 96-well microtiter plates & Sarstedt Inc. (Newton, USA) \\
\hline blotting paper type 2668 & Schleicher \& Schuell (Dassel) \\
\hline cell culture dishes & Sarstedt Inc. (Newton, USA) \\
\hline cell culture flasks & Sarstedt Inc. (Newton, USA) \\
\hline developer Kodak LX24 & Kodak (Paris, France) \\
\hline dialysis tubing MWCO 5,000 kDa & Roth (Karlsruhe) \\
\hline exposure cassette & AGS GmbH (Heidelberg) \\
\hline folded filters ( $\varnothing 12.5 \mathrm{~cm})$ & Macherey-Nagel (Düren) \\
\hline Hyperfilm ${ }^{\text {TM }} \mathrm{ECL}$ & Amersham Biosciences (Frankfurt) \\
\hline $\begin{array}{l}\text { nitrocellulose membrane Optitran } \\
(0.2 \mu \mathrm{m} \text { pore size) }\end{array}$ & Schleicher \& Schuell (Dassel) \\
\hline Parafilm & American Chicago National Can \\
\hline sterile filter (cell culture $0.5 \mu \mathrm{m}$ pore size) & Sarstedt Inc. (Newton, USA) \\
\hline sterile filter (general $0.22 \mu \mathrm{m}$ pore size) & Sartorius (Göttingen) \\
\hline $\begin{array}{l}\text { Vivaspin concentrators }(20 \mathrm{ml} ; 6 \mathrm{ml}) \\
\text { MWCO 5,000 }\end{array}$ & Viva Science Sartorius Group (Göttingen) \\
\hline
\end{tabular}




\subsubsection{Software programs for data analysis}

\begin{tabular}{|l|}
\hline Adobe Photoshop and Reader \\
\hline Corel Draw 11.0 \\
\hline Endnote (Bibliography) \\
\hline Geminyx version 1.91 \\
\hline Karat ${ }^{\mathrm{T}} 32$ version 7.0 \\
\hline Microsoft Word 2003 \\
\hline Microsoft Excel 2003 \\
\hline Microsoft PowerPoint 2003 \\
\hline 1DscanEx 3.0 evaluation program \\
\hline Spot (fluorescence microscopy) \\
\hline Windows XP \\
\hline
\end{tabular}

\subsection{Methods}

\subsubsection{Cell culture}

\subsubsection{Maintenance of cultured cells}

For the experiments described, two cell lines, the human promyeloid cell line HL-60 and the human cervix carcinoma cell line HeLa (stable transfectants) were used. Both cell lines were cultured in RPMI medium (RPMI for stably transfected HeLa H2B-YFP did not contain phenol red, to avoid a possible colour interference with YFP), which was stored at $4^{\circ} \mathrm{C}$ before use. For optimised growth conditions, the cells were kept in incubators at $37^{\circ} \mathrm{C}$ in a humid atmosphere with $5 \% \mathrm{CO}_{2}$ concentration. To keep the cells in culture, it was most important to add a certain amount of minerals and nutrients. For this purpose 10\% (v/v) FCS (fetal calf serum) was always added to the RPMI culture medium. One great advantage of using FCS is that due to the very low concentrations of antibodies, cell growth is not affected by crossreactions. Moreover, FCS provides culture cells with all necessary minerals and growth factors. Possible interference of complement factors with cell growth was counteracted by inactivating the $\mathrm{FCS}$ at $56^{\circ} \mathrm{C}$ for $45 \mathrm{~min}$ before use. To minimise contaminations of the medium during cell culturing, antibiotics such as gentamycin $(50 \mu \mathrm{g} / \mathrm{ml})$ were added. To avoid microbial contaminations from the air, all works connected to the culturing of cells were carried out under a sterile laminar flow hood. All used plastic ware and culture medium were disposed off by autoclaving the material. 


\subsubsection{Passaging (subculturing) of culture cells}

Cells maintained under the above mentioned conditions show a distinct growth pattern. Shortly after a new culture has been set up, the cells go through a quiescent, the lag phase. During this time there is almost no increase in cell growth. Once recovered from their storage in liquid nitrogen, the cells progress through an exponential log phase. In this phase they generally show the highest metabolic activity, and this state will be kept up as long as the nutrition concentration keeps up with constantly increasing cell numbers. Eventually, the cell population enters the stationary or plateau phase, where growth stops and their number is maintained. This confluent cell population then needs to be passaged (subcultured) to clear all toxic metabolites, otherwise this culture will die.

Confluent HeLa H2B-YFP cell populations were split up 1:5 once in three days. This process could be repeated up to 25 times for one single culture. As HeLa cells are an adherently growing cell line, the cells needed to be removed from the culture flask by a short proteolytic digestion with trypsin, only to detach them from the flask surface. For this purpose the culture medium was removed, the cells were washed with PBS to remove all traces of FCS and the digestion was started with $5 \mathrm{ml}$ trypsin-EDTA solution $(0.05 \%(\mathrm{w} / \mathrm{v})$ trypsin, $0.02 \%(\mathrm{w} / \mathrm{v})$ EDTA in PBS). After 2-3 min incubation at $37^{\circ} \mathrm{C}$, the cells were detached by tapping and swirling the flask. Proteolytic digestion was stopped by adding 5 volumes of RPMI medium containing $10 \%(\mathrm{v} / \mathrm{v})$ FCS. The cell suspension was transferred to centrifuge tubes (Sarstedt) and pelleted at $1,200 \mathrm{rpm}$ for $5 \mathrm{~min}$. The trypsin containing supernatant was carefully discarded and the cells were suspended and washed in $10 \mathrm{ml} \mathrm{PBS}$. To determine the cell number for proper seeding, usually cells were counted using a CASY 1 TT electronic cell counter. For cell counting, Casy vials were filled with $10 \mathrm{ml}$ Isoton ${ }^{\circledR}$ buffer (Beckman Coulter) and mixed with $100 \mu \mathrm{l}$ cell suspension. Besides calculating cell numbers, this device also determines cell sizes and their distribution within a cell population, which can be used as a means to evaluate the viability of a cell population. After the cell number had been determined, an appropriate number of cells was suspended in fresh medium and seeded in new flasks.

\subsubsection{Freezing and thawing of cells for storage and cultivation}

For long term preservation and storage of cell populations, liquid nitrogen $\left(\mathrm{N}_{2}\right)$ proved to be the method of choice, as the formation of ice crystals in cells is slowed down at temperatures below $-130^{\circ} \mathrm{C}$. Besides the damage through ice crystals, factors such as dehydration and changes in $\mathrm{pH}$ are to a certain extent lethal to frozen cell populations. For this reason the cryoprotective agent DMSO (similar in use to glycerol) was added to the freezing medium to lower the freezing point. To avoid any damage, the cells were wrapped up in a styrofoam box 
to be cooled down very slowly from $25^{\circ} \mathrm{C}$ to $-80^{\circ} \mathrm{C}$. This process allows the remaining water to be drained from the cells before freezing.

For long term storage $5-6 \times 10^{6}$ cells were suspended in $1.5 \mathrm{ml}$ freezing medium $(20 \%(\mathrm{v} / \mathrm{v})$ FCS, 10\% (v/v) DMSO in RPMI medium) and transferred to $1.8 \mathrm{ml}$ cryo tubes. These were stored in the box in the freezer $\left(-80^{\circ} \mathrm{C}\right)$ for at least $24 \mathrm{~h}$. After that the cells were cryoconserved in liquid nitrogen tanks.

To maximise the yield of intact cells, the thawing process was proceeded with very quickly. The cryo-tube with the cell culture was immersed completely in methanol to inactivate mycoplasms. After that the cells were kept in a $37^{\circ} \mathrm{C}$ hot water bath to accelerate the melting process of ice crystals. To avoid a critical toxic concentration of DMSO, the cell culture aliquot was immediately transferred into a culture flask with $50 \mathrm{ml}$ (HeLa H2B-YFP cells) or $100 \mathrm{ml}\left(\mathrm{HL}-60\right.$ cells) pre-warmed $\left(37^{\circ} \mathrm{C}\right)$ medium once the cell pellet came loose from the tube. This transfer allowed a quick dilution of DMSO from the freezing medium. As soon as the cells had recovered from the thawing process and taken on with exponential growth, the medium was changed on a regular basis to remove all traces of remaining DMSO (especially with HL-60 cells).

\subsubsection{Protein biochemical methods}

\subsubsection{Protein extraction with TCA (trichloroacetic acid)}

To $1 \mathrm{ml}$ sucrose gradient fraction $240 \mu \mathrm{l}$ 100\% (v/v) TCA (final concentration 20\% TCA) were added. The samples were stored on ice for $1 \mathrm{~h}$ to allow complete protein precipitation. The samples were centrifuged at $13,000 \mathrm{rpm}$ (micro-centrifuge) for $30 \mathrm{~min}$ at $4^{\circ} \mathrm{C}$. The resulting precipitate was washed with $1 \mathrm{ml}$ acetone and centrifuged once again for 10 min under the above mentioned conditions. The supernatant was carefully discarded and the precipitate was allowed to air dry until all acetone had evaporated. The sample was dissolved in $60 \mu \mathrm{l}$ $30 \mathrm{mM} \mathrm{HCl}$, as this turned out to be the optimised concentration for histones. For the analysis of histone modifications, $20 \mu \mathrm{l}$ of each fraction were mixed with $7 \mu$ Laemmli sample buffer and loaded onto an SDS-gel for separation. Subsequently, the proteins from all sucrose gradient fractions were transferred to nitrocellulose membranes and probed with modification specific antibodies.

\subsubsection{Preparation of core histones from eukaryotic cells}

For the analysis of histone modifications from whole cell lysates, $3-4 \times 10^{7}$ cells per sample were harvested, washed with $5 \mathrm{ml}$ PBS and pelleted at 1,200 rpm for $5 \mathrm{~min}$ (Heraeus). The cells were then suspended in $1 \mathrm{ml} 0.4 \mathrm{~N} \mathrm{H}_{2} \mathrm{SO}_{4}$ and kept on ice for $1 \mathrm{~h}$ to dissolve the basic 
histones in the acid. After that the samples were centrifuged for $10 \mathrm{~min}$ at $13,000 \mathrm{rpm}$ in a microcentrifuge at $4^{\circ} \mathrm{C}$. At this step most non-histone proteins were lost, as these do not dissolve under the acidic conditions. $800 \mu$ of the supernatant were carefully transferred to a new tube and $200 \mu \mathrm{l}$ TCA were added to precipitate all histones from the solution. The samples were kept on ice for $1 \mathrm{~h}$. The precipitate was centrifuged at 13,000 rpm for $30 \mathrm{~min}$ at $4^{\circ} \mathrm{C}$. The pellet was washed once with $1 \mathrm{ml}$ acetone and centrifuged once again for $10 \mathrm{~min}$ under the above mentioned conditions. The supernatant was carefully discarded and the precipitate was allowed to air dry until all acetone had evaporated. The histones were dissolved in $100 \mu \mathrm{l} 30 \mathrm{mM} \mathrm{HCl}$. About $15 \mu \mathrm{l}-20 \mu \mathrm{l}$ of the sample were mixed with $7 \mu \mathrm{l}$ Laemmli sample buffer, electrophoresed on SDS-gels, transferred to nitrocellulose membranes, and treated with modification specific antibodies.

\subsubsection{Bradford protein assay}

The Bradford assay is a rapid and fairly accurate method to determine total protein contents of a sample (Bradford, 1976). The assay's principle is based on the fact that the absorbance maximum for an acidic solution of Coomassie Brilliant Blue G-250 shifts from $465 \mathrm{~nm}$ to $595 \mathrm{~nm}$ when it binds to proteins. Hydrophobic as well as ionic interactions stabilize the anionic form of the dye, which causes a visible change in colour. The intensity in the change of colour increases with the amount of bound protein, which can easily be measured at 595 $\mathrm{nm}$ in a photometer. This assay is fairly reliable as the extinction coefficient of a dye-albumin complex solution is constant over a 10 -fold concentration range.

The Bradford protein assay was used to determine the protein concentration in cell lysates for the caspase 3 activity assay. For this purpose the Bradford reagent was prepared as follows: Bradford stock solution: $100 \mathrm{ml}$ 95\% ethanol, $200 \mathrm{ml} 88 \%$ phosphoric acid, $350 \mathrm{mg}$ Coomassie Brilliant Blue G-250; final Bradford reagent: $425 \mathrm{ml}$ bidest. $\mathrm{H}_{2} \mathrm{O}, 15 \mathrm{ml}$ 95\% ethanol, $30 \mathrm{ml} 88 \%$ phosphoric acid and $30 \mathrm{ml}$ Bradford stock solution.

BSA was generally used as protein standard. The protein concentrations in the standard samples ranged from $10 \mu \mathrm{g}$ to $0.2 \mathrm{mg}$ and were set up in duplicates in the same buffer as used for the actual samples. These were diluted to a concentration between $20 \mu \mathrm{g}$ and 30 $\mu \mathrm{g} / \mathrm{ml}$. For the Bradford assay $1 \mathrm{ml}$ Bradford reagent was added to each sample. After 10 min the absorbance was measured at $595 \mathrm{~nm}$. A standard curve was calculated from these results using linear regression (processed with Microsoft Excel).

\subsubsection{SDS polyacrylamide gel electrophoresis (SDS-PAGE)}

SDS (sodium dodecyl sulphate) is an anionic detergent whose molecules, when dissolved, have a net negative charge within a wide $\mathrm{pH}$ range. All polypeptide chains of the proteins 
separated bind high amounts of SDS in proportion to their relative molecular mass. SDS denatures the proteins by wrapping the hydrophobic tail around the polypeptide backbone, conferring a net negative charge to it in proportion to its length. This is why in SDS-PAGE separations protein migration is no longer determined by intrinsic electric polypeptide charges but by its molecular weight only. Differences in the proteins molecular shape, meaning secondary and tertiary protein structure, are eliminated by SDS, too, as it disrupts hydrogen bonds and blocks off hydrophobic interactions. The samples can be totally unfolded, when a reducing agent such as $\beta$-mercaptoethanol is added, which destroys any disulphide bond between cysteine residues.

Two possible types of buffer systems can be used for SDS-PAGEs, continuous (first developed by Ornstein (Ornstein, 1964) and Davis (Davis, 1964)) or discontinuous denaturing modification of Ornstein and Davis; (Laemmli et al., 1970a; Laemmli et al., 1970b)), depending on whether only one or two buffers are used for the gel and chambers. In this case the discontinuous system was used for protein separation. At the beginning of the electrophoresis chloride ions in the sample and stacking gel form the leading edge of the moving boundary, whereas the trailing edge is composed of glycine molecules. A zone of lower conductivity and steeper voltage gradient forms up between leading and trailing edge of the moving boundary, which withdraws the polypeptides from the sample and deposits them on the surface of the separating gel. The higher $\mathrm{pH}$ of the separating gel $(\mathrm{pH}$ 8.8) initiates the ionisation of glycine. The ions migrate through the stacked polypeptides and follow up the chloride ions through the separating gel. Once released from the moving boundary, the SDS-polypeptide complexes migrate through the separating gel in a zone of uniform voltage and $\mathrm{pH}$. Within this area their separation progresses according to size by sieving.

The sieving properties of an SDS-PAGE matrix are dependent on the size of the pores. It is a function of absolute concentrations of acrylamide and bisacrylamide that are used to cast the gels. Acrylamide:bisacrylamide concentrations of 10\%-15\% used here, generally allowed the separation of protein sizes ranging from $80 \mathrm{kDa}-10 \mathrm{kDa}$.

The process of polymerisation of acrylamide gels requires a cross-linking agent such as $\mathrm{N}, \mathrm{N}$ '-methylenbisacrylamide to form up a meshwork of defined porosity. The reaction is initiated in the presence of free radicals, which are generated when $N, N, N^{\prime}, N^{\prime}-$ tetramethylethylenediamine (TEMED) and ammonium persulfate are added. TEMED accelerates the polymerisation by forming free radicals from ammonium persulfate.

The following buffers and components were used to cast the gels for protein separation: $\underline{3 x}$ Laemmli sample buffer: 9\% (w/v) SDS, $300 \mathrm{mM}$ Tris/HCl, pH 6.8, 22.5\% (w/v) glycerol, 0.1\% (w/v) bromophenol blue, 10\% (v/v) $\beta$-mercaptoethanol; stacking gel: $0.125 \mathrm{M} \mathrm{Tris} / \mathrm{HCl}, \mathrm{pH}$ $6.8,0.1 \%(w / v)$ SDS, $5 \%$ acrylamide/bisacrylamide (30:0.8), 0.15\% (w/v) ammonium 
persulfate, $0.1 \%(\mathrm{v} / \mathrm{v})$ TEMED; separating gel: $0.375 \mathrm{M} \mathrm{Tris} / \mathrm{HCl}, \mathrm{pH} 8.8,0.1 \%(\mathrm{w} / \mathrm{v}) \mathrm{SDS}$, $10-15 \%$ acrylamide/bisacrylamide (30:0.8), $0.15 \%(\mathrm{w} / \mathrm{v})$ ammonium persulfate, $0.1 \%(\mathrm{v} / \mathrm{v})$ TEMED; $5 \times$ chamber buffer: (this buffer was used for both the upper and lower reservoir) $0.25 \mathrm{M}$ Tris/HCl, pH 8.7, $10 \mathrm{mM}$ EDTA, 1.9 M glycine, 0.5\% (w/v) SDS.

Before the samples were loaded onto the gel, they were mixed with $7 \mu$ Laemmli sample buffer and boiled for $5 \mathrm{~min}$ to destroy remaining secondary and tertiary structures. The electrophoresis was run for $2.5 \mathrm{~h}$ (small size gels $8.4 \mathrm{~cm} \times 6.5 \mathrm{~cm}$ ) or $3.5-4 \mathrm{~h}$ (for large size gels $6.5 \mathrm{~cm} \times 13.5 \mathrm{~cm}$ ), using vertical mini-gel-chambers (manufactured by the precision workshop, Göttingen University). A current of $15 \mathrm{~mA}$ was applied until the samples had migrated through the stacking gel. Once the samples had reached the separating gel, the current was turned up to $20 \mathrm{~mA}$ per gel. The run of the samples could easily be traced as the loading buffer contained bromophenol blue. A protein standard (prestained protein ladder, 10-180 kDa, MBI Fermentas) of a suitable molecular size was run on the same gel as the samples. Once the bromophenol blue band had reached the end of the separating gel, the electrophoresis was stopped. After that the gel was either fixed and stained for 15 min to 30 min with Coomassie brilliant blue (Coomassie R250 0.15\% (w/v), 50\% methanol, 10\% glacial acetic acid, $40 \% \mathrm{H}_{2} \mathrm{O}$ bidest.), which is an aminotriarylmethane dye that forms strong, noncovalent protein complexes by a combination of van der Waals forces and electrostatic interactions with $\mathrm{NH}_{3}{ }^{+}$groups or it was used for western blotting and antibody treatment. When stained with Coomassie, excess dye was then allowed to diffuse from the gel during a prolonged period of destaining in decreasing concentrations of methanol:glacial acetic acid solution. The results were documented by scanning the gel with a conventional computer scan system.

\subsubsection{Two-dimensional AUTIAUC-gel electrophoresis}

The AUT-gel (Panyim and Chalkley, 1969a; Panyim and Chalkley, 1969b) electrophoresis (acetic acid-urea-triton) is a fine working alternative method for the separation of specifically modified single core histones and their subtypes. As histones tend to aggregate in conventional SDS-PAGE, a change in detergent from SDS to Triton ${ }^{\circledR}$ X-100 (Zweidler, 1978) brings about higher resolutions of histone extracts into their variants. Using a discontinuous buffer system with CTAB (Bonner et al., 1980) in the cathode buffer and subsequent analysis of the samples on 2-D electrophoresis makes it possible to further separate histone variants. It is even possible to distinguish between phosphorylated and acetylated histones compared to their unmodified forms (Pantazis and Bonner, 1982), as their migration rates differ in both dimensions.

The separation of modified core histones and their variants was carried out according to the protocol by Pilch et al. (Pilch et al., 2004). 
The preparation of histones on 2D-AUT/AUC-gels is done basically in the same way according to the preparation of SDS-gels, described earlier. The fundamental difference lies in the chemical composition of the gels.

The following buffers and solutions were used to cast and run AUT-1D gels.

AUT-stacking gel ( $1^{\text {st }}$ dimension only) $(1 \times)$

\begin{tabular}{|l|l|}
\hline component & quantity \\
\hline urea & $1.6 \mathrm{~g}$ \\
\hline acrylamide $(60 \%(\mathrm{w} / \mathrm{v})$ stock sol. $)$ & $266 \mu \mathrm{l}$ \\
\hline bisacrylamide $(2 \%(\mathrm{w} / \mathrm{v})$ stock sol.) & $266 \mu \mathrm{l}$ \\
\hline glacial acetic acid & $200 \mu \mathrm{l}$ \\
\hline ammonia (25\% (v/v) stock sol.) & $14.46 \mu \mathrm{l}$ \\
\hline APS (10\% (w/v) stock sol.) & $33.3 \mu \mathrm{l}$ \\
\hline TEMED & $8.33 \mu \mathrm{l}$ \\
\hline $\mathrm{H}_{2} \mathrm{O}$ bidest. & ad $6 \mathrm{ml}$ \\
\hline
\end{tabular}

1D-AUT-separating gel $(1 \times)$

\begin{tabular}{|c|c|}
\hline component & quantity \\
\hline \multicolumn{2}{|c|}{$18 \%$ acrylamide/bisacrylamide meshwork } \\
\hline urea $(53.3 \%(w / v)$ final conc.) & $6.4 \mathrm{~g}$ \\
\hline acrylamide (60\% (w/v) stock sol.) & $4 \mathrm{ml}$ \\
\hline bisacrylamide (2\% (w/v) stock sol.) & $800 \mu \mathrm{l}$ \\
\hline Triton $® X-100$ & $260 \mu \mathrm{l}$ \\
\hline glacial acetic acid & $800 \mu \mathrm{l}$ \\
\hline ammonia (25\% (v/v) stock sol.) & $57.8 \mu \mathrm{l}$ \\
\hline APS (10\% (w/v) stock sol.) & $133.3 \mu \mathrm{l}$ \\
\hline TEMED & $33.3 \mu \mathrm{l}$ \\
\hline $\mathrm{H}_{2} \mathrm{O}$ bidest. & ad $12 \mathrm{ml}$ \\
\hline
\end{tabular}

AUT sample buffer

\begin{tabular}{|l|l|}
\hline component & quantity \\
\hline urea & $4.8 \mathrm{~g}$ \\
\hline acetic acid & $600 \mu \mathrm{l}$ \\
\hline ammonia (25\% (v/v) stock sol.) & $43.4 \mu \mathrm{l}$ \\
\hline methylene blue & $0.00125 \%(\mathrm{w} / \mathrm{v})$ \\
\hline $\mathrm{H}_{2} \mathrm{O}$ bidest. & ad $10 \mathrm{ml}$ \\
\hline
\end{tabular}


Pyronin Y $(0.1 \%(w / v)$ working dil.)

$0.01 \mathrm{~g}$

(additional colour reagent for sample tracing)

1D-AUT-chamber buffer

\begin{tabular}{|l|l|}
\hline component & quantity \\
\hline acetic acid & $60 \mathrm{ml}$ \\
\hline glycine & $8 \mathrm{~g}$ \\
\hline $\mathrm{H}_{2} \mathrm{O}$ bidest. & ad $1 \mathrm{l}$ \\
\hline
\end{tabular}

For polymerisation the gels were kept at $37^{\circ} \mathrm{C}$ to avoid crystallisation of urea. Before the samples were loaded onto the gel for separation, the gel was pre-run for $4 \mathrm{~h}$ at $7 \mathrm{~mA}$ to remove all traces of urea crystals. The samples were run for $18 \mathrm{~h}$ overnight at a constant current of $5 \mathrm{mM}$. After electrophoresis the gels were stained in Coomassie brilliant blue solution for about 20-30 min and destained in methanol:glacial acetic acid solution (compare chap. 2.2.2.4 SDS-PAGE). The results were documented with a computer scan system.

The samples which were to be analysed, were excised from the gel and soaked in 3 volumes of AUC-soaking solution overnight.

AUC-soaking solution

\begin{tabular}{|l|l|}
\hline component & quantity \\
\hline acetic acid & $15 \mathrm{ml}$ \\
\hline ammonia $(25 \%(\mathrm{v} / \mathrm{v})$ stock sol.) & $0.8 \mathrm{ml}$ \\
\hline 2-mercaptoethylamine/HCl & $2.5 \mathrm{~g}$ \\
\hline $\mathrm{H}_{2} \mathrm{O}$ bidest. & ad $250 \mathrm{ml}$ \\
\hline
\end{tabular}

2D-AUT-separating gel $(1 \times)$ :

\begin{tabular}{|c|c|}
\hline component & quantity \\
\hline \multicolumn{2}{|c|}{ 18\% acrylamide/bisacrylamide meshwork } \\
\hline urea $(10 \%(w / v)$ final conc.) & $1.2 \mathrm{~g}$ \\
\hline acrylamide (60\% (w/v) stock sol.) & $4 \mathrm{ml}$ \\
\hline bisacrylamide (2\% (w/v) stock sol.) & $800 \mu \mathrm{l}$ \\
\hline glacial acetic acid & $800 \mu \mathrm{l}$ \\
\hline ammonia (25\% (v/v) stock sol.) & $57.8 \mu \mathrm{l}$ \\
\hline APS (10\% (w/v) stock sol.) & $133.3 \mu \mathrm{l}$ \\
\hline TEMED & $33.3 \mu \mathrm{l}$ \\
\hline $\mathrm{H}_{2} \mathrm{O}$ bidest. & ad $12 \mathrm{ml}$ \\
\hline
\end{tabular}


Embedding solution

\begin{tabular}{|c|c|}
\hline component & quantity \\
\hline \multicolumn{2}{|l|}{$2 \times$ gel prep solution } \\
\hline acetic acid & $60 \mathrm{ml}$ \\
\hline ammonia (25\% (v/v) stock sol.) & $3 \mathrm{ml}$ \\
\hline $\mathrm{H}_{2} \mathrm{O}$ bidest. & ad $500 \mathrm{ml}$ \\
\hline \multicolumn{2}{|l|}{$2 \times$ agarose solution } \\
\hline agarose & $2 \mathrm{~g}$ \\
\hline glycerol & $40 \mathrm{ml}$ \\
\hline $\mathrm{H}_{2} \mathrm{O}$ bidest. & $100 \mathrm{ml}$ \\
\hline
\end{tabular}

For the final embedding solution $10 \mathrm{ml} 2 \underline{2 x}$ gel prep solution were mixed with $\underline{2 x}$ agarose solution and melted in the microwave. The excised, soaked 1D-gel pieces were placed in the gel cast cassette into the stacking gel pockets. Remaining spaces were filled up with embedding solution so that the gel pieces were pushed down towards the stacking gel. After the embedding solution had solidified, the same electrophoresis settings (5 mA current for 18h overnight) were applied. For the second dimension the following discontinuous buffer system was used:

Upper chamber buffer

\begin{tabular}{|l|l|}
\hline component & quantity \\
\hline acetic acid & $60 \mathrm{ml}$ \\
\hline glycine & $8 \mathrm{~g}$ \\
\hline CTAB (5\% (w/v) stock sol.) & $30 \mathrm{ml}$ \\
\hline $\mathrm{H}_{2} \mathrm{O}$ bidest. & ad $1 \mathrm{l}$ \\
\hline
\end{tabular}

Lower chamber buffer

\begin{tabular}{|l|l|}
\hline component & quantity \\
\hline acetic acid & $60 \mathrm{ml}$ \\
\hline glycine & $8 \mathrm{~g}$ \\
\hline $\mathrm{H}_{2} \mathrm{O}$ bidest. & ad $1 \mathrm{l}$ \\
\hline
\end{tabular}

After electrophoresis the gels were stained again in Coomassie brilliant blue solution for about 20-30 min and destained in methanol:glacial acetic acid solution (compare chap. 2.2.2.4 SDS-PAGE). The results were documented with a computer scan system. 


\subsection{Western blotting and immuno-detection}

Protein samples which were separated in single bands via SDS-PAGE, were transferred to nitrocellulose membranes by Western blotting for further analysis via immuno-detection. The protein transfer was run in a semi-dry blotting unit. For this purpose six filter papers (three on each side of the 'sandwich') were soaked in transfer buffer (modified according to Towbin and Gordon, 1984) (10x buffer $25 \mathrm{mM}$ Tris/HCl, pH 8.3, $192 \mathrm{mM}$ glycine, 0.037\% (w/v) SDS, $20 \%(\mathrm{v} / \mathrm{v})$ methanol, added just prior to transfer). Before transfer the gel was equilibrated in transfer buffer for $2 \mathrm{~min}$, to facilitate the blotting of proteins, especially histones in this case. The blotting stack was prepared as follows:

\begin{tabular}{|c|}
\hline cathode \\
\hline three layers of filter papers soaked in transfer buffer \\
\hline SDS-gel, equilibrated in transfer buffer \\
\hline nitrocellulose membrane soaked in $\mathrm{H}_{2} \mathrm{O}$ bidest. \\
\hline three layers of filter papers soaked in transfer buffer \\
\hline anode \\
\hline
\end{tabular}

The proteins were blotted at a constant current of $1 \mathrm{~mA} / \mathrm{cm}^{2}$, according to the size of the stack for 105 min.

To confirm that all proteins had been blotted in equal amounts, the membrane was stained in Ponceau $\mathrm{S}$ dye $(0.5 \%(\mathrm{w} / \mathrm{v})$ Ponceau $\mathrm{S}$ red in $1 \%(\mathrm{v} / \mathrm{v})$ acetic acid) for $3-5 \mathrm{~min}$. The membrane was rinsed shortly to remove excess dye. Total protein amounts were documented by scanning of the membrane with a conventional computer scan system.

The remaining Ponceau $S$ dye was removed completely with TBST (Tris buffered saline Iween 20: $20 \mathrm{mM}$ Tris/ $\mathrm{HCl}, \mathrm{pH}$ 7.6, $137 \mathrm{mM} \mathrm{NaCl}, 0.5 \%$ (v/v) Tween-20). The membrane was blocked with $5 \%(\mathrm{w} / \mathrm{v})$ nonfat dry milk in TBST for $30 \mathrm{~min}$ at room temperature. For the complete immuno-detection protocol see scheme below.

\begin{tabular}{|l|l|}
\hline $\begin{array}{l}\text { membrane washing I } \\
\text { cleans off remaining non-fat milk }\end{array}$ & $\begin{array}{l}\text { membranes were rinsed with TBS for about } \\
15 \text { min, with changing buffers every } 5 \mathrm{~min}\end{array}$ \\
\hline $\begin{array}{l}\text { primary antibody, diluted in TBS with 5\% } \\
(\mathrm{w} / \mathrm{v}) \mathrm{BSA}, 0.02 \%(\mathrm{w} / \mathrm{v}) \mathrm{NaN}_{3}\end{array}$ & $\begin{array}{l}\text { membranes were incubated with } 10 \mathrm{ml} \\
\text { primary antibody overnight at } 4^{\circ} \mathrm{C}\end{array}$ \\
\hline $\begin{array}{l}\text { membrane washing II } \\
\text { cleans off remaining antibody residues }\end{array}$ & $\begin{array}{l}\text { membranes were rinsed with TBST for about } \\
15 \text { min, with changing buffers every } 5 \mathrm{~min}\end{array}$ \\
\hline $\begin{array}{l}\text { secondary antibody, diluted in blocking } \\
\text { buffer (5\% (w/v) nonfat dry milk in TBST) }\end{array}$ & $\begin{array}{l}\text { membranes were incubated with } 10 \mathrm{ml} \\
\text { secondary antibody for 2h at room } \\
\text { temperature }\end{array}$ \\
\hline
\end{tabular}




\begin{tabular}{|l|l|}
\hline $\begin{array}{l}\text { membrane washing III } \\
\text { cleans off remaining antibody residues }\end{array}$ & $\begin{array}{l}\text { membranes were rinsed with TBST for about } \\
15 \mathrm{~min} \text {, with changing buffers every } 5 \text { min }\end{array}$ \\
\hline detection & $\begin{array}{l}\text { either via enhanced chemiluminescence } \\
\text { (ECL) or alkaline phosphatase with } \\
\text { NBT/BCIP }\end{array}$ \\
\hline
\end{tabular}

\subsection{Methods for protein detection}

\subsection{Enhanced chemiluminescence (ECL)}

The ECL Plus Western blotting detection method provides an improved, very sensitive nonradioactive method for the detection of immobilised specific antigens, which are conjugated to Horseradish Peroxidase (HRP) labelled secondary antibodies.

The ECL Plus reaction is based on the enzymatic generation of an acridinium ester, which produces a very intense light emission of long duration (Joss and Towbin, 1994; Rongen et al., 1994; Woodhead, 1995). A combined HRP and peroxide catalysed oxidation of the substrate Lumigen PS-3 Acridan synthesises myriads of acridinium ester intermediates per minute (Fig. 2.2.2.5.2.1). Under slightly alkaline conditions the intermediates react with peroxide to produce a sustained, high intensity chemiluminescent signal with maximum emission at $\lambda 430 \mathrm{~nm}$ (Weeks et al., 1983). The resulting signals can be detected on autoradiography films e.g. Hyperfilm ${ }^{\mathrm{TM}} \mathrm{ECL}$, which were used in this case.

After the last washing step, excess TBST was drained from the membrane, which was then placed protein side up on a piece of cling film. The two detection solutions $A$ and $B$ were mixed in a ratio of $40: 1$ ( $2 \mathrm{ml}$ solution $A$ and $50 \mu \mathrm{l}$ solution $B)$. The final volume of detection reagent required was $0.1 \mathrm{ml} / \mathrm{cm}^{2}$, adjusted to the size of the membranes. The membrane was incubated with the detecting reagent for $5 \mathrm{~min}$ at room temperature. After that excess reagent was drained off and the membrane was fully wrapped up in cling film: to avoid a trapping of air bubbles, these were gently smoothed out before the actual detecting process. The wrapped blot was placed protein side up in an X-ray film cassette. All following steps were performed in a dark room. A sheet of autoradiography film was placed on top of the membrane and the cassette was closed to avoid any exposure of the film to daylight. The exposure time lay between $30 \mathrm{~s}$ to $5 \mathrm{~min}$ depending on the signal intensity. Subsequently, the films were immediately immersed in developer solution until the bands were visible. After a short wash in water, the film was kept in a fixing bath for 2 min. Excess fixing solution was rinsed away with water and the film was completely dried before the results were documented using a conventional computer scan system. 


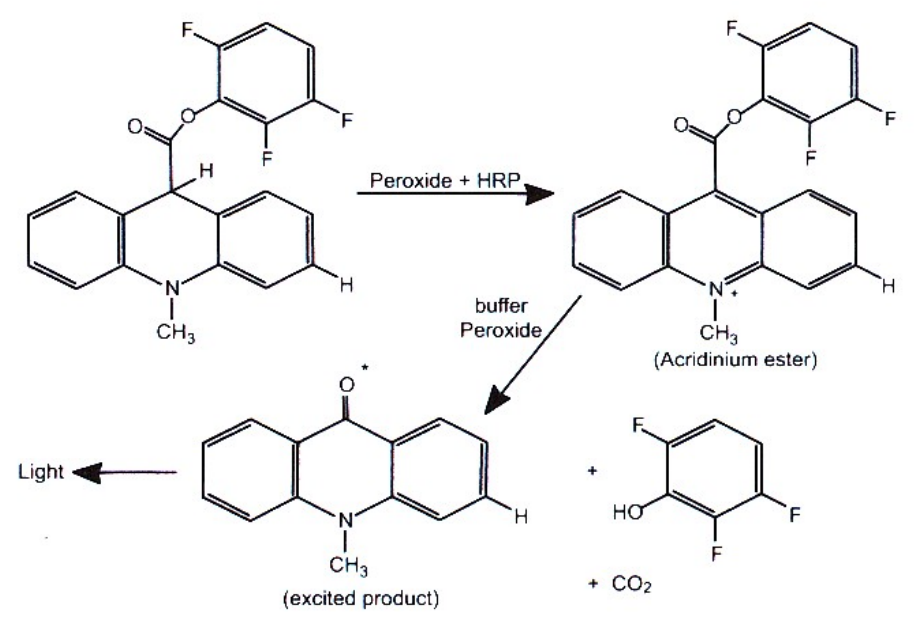

Fig. 2.2.2.5.1 HRP driven chemiluminescent reaction of Lumigen PS-3.

\subsection{Colour detection: alkaline phosphatase with NBT/BCIP ${ }^{456}$}

The alkaline phosphatase colour development reagents, 5-bromo-4-chloro-3indoylphosphate p-toluidine salt (BCIP) and p-nitro blue tetrazolium chloride (NBT) are used to detect antigens immobilised on nitrocellulose or nylon membranes. These colour substrates taken together, develop an insoluble purple precipitate on the membrane surface in the presence of alkaline phosphatase conjugated antibodies. In the reaction NBT is reduced and BCIP is oxidised, which leads to the formation of the coloured precipitate at sites of specific antibody binding.

The following dyes and buffers for the colorimetric reaction were prepared: $\underline{\text { NBT stock }}$ solution: $7.5 \%(\mathrm{w} / \mathrm{v}) \mathrm{NBT}$ in $70 \%(\mathrm{v} / \mathrm{v})$ dimethylformamide (DMF), stored at $-20^{\circ} \mathrm{C}$; BCIP stock solution: $5 \%(\mathrm{w} / \mathrm{V} \mathrm{BCIP})$ in $100 \% \mathrm{DMF}$, stored at $-20^{\circ} \mathrm{C}$; alkaline phosphatase buffer: $100 \mathrm{mM}$ Tris/ $\mathrm{HCl}, \mathrm{pH} 9.5,100 \mathrm{mM} \mathrm{NaCl}, 5 \mathrm{mM} \mathrm{MgCl}_{2}$, stored at $4^{\circ} \mathrm{C}$ to prevent precipitation; alkaline phosphatase reaction solution: $100 \mathrm{mM}$ Tris/ $\mathrm{HCl}, 100 \mathrm{mM} \mathrm{NaCl}, 5 \mathrm{mM} \mathrm{MgCl}, 0.0175 \%$ (w/v) BCIP, $0.02625 \%(\mathrm{w} / \mathrm{v}) \mathrm{NBT}, 0.67 \%$ (v/v) DMF, prepared immediately prior to use; reaction stop solution: $20 \mathrm{mM}$ EDTA in bidest. $\mathrm{H}_{2} \mathrm{O}, \mathrm{pH}$ 8.0.

The membrane was immersed in alkaline phosphatase reaction solution and kept in the dark until the precipitates were visible. To avoid over-intensified signals, the reaction was stopped with 20 mM EDTA solution. Results were documented using a computer scan system before the membrane was dried for storage.

\footnotetext{
${ }^{4}$ Horwitz, J.P. et al. (1966), J. Med. Chem. 9, p. 447.

${ }^{5}$ Michael, G. et al. in: Methods of Enzymatic Analysis (Bergmeyer, H.U. ed.) $3^{\text {rd }}$ edition 1983, Vol I, p. 197.

${ }^{6}$ Wolf, P.L. et al. (1968), Enzymologia (Enzyas) 35, p. 154.
} 


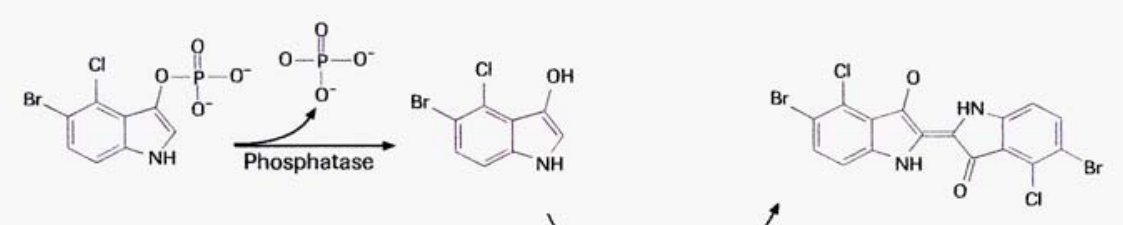

$$
\begin{aligned}
& \text { BCIP } \\
& \text { colorless, soluble }
\end{aligned}
$$
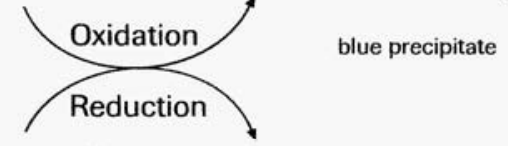

blue precipitate

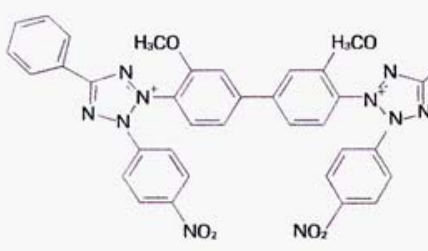

NBT

yellowish, soluble

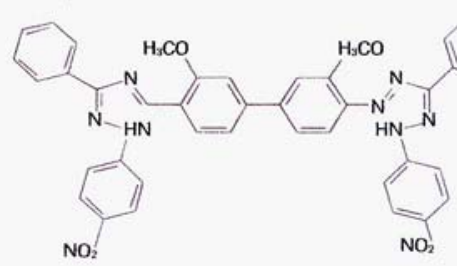

blue precipitate

Fig. 2.2.2.5.2 Chemical reaction initiated by alkaline phosphatase (manual Roche, Mannheim).

\subsection{Colour detection with diaminobenzidine (DAB)}

DAB is a similar colour development reagent compared to the NBT/BCIP system but here colour development is driven by the secondary antibody conjugate HRP.<smiles>Nc1ccc(-c2ccc(N)c(N)c2)cc1N</smiles>

Fig. 2.2.2.6.2.3 3,3'-diaminobenzidine.

\subsection{Stripping and re-probing ECL membranes}

In cases where ECL probed membranes had to be incubated with a second set of antibodies for comparative analyses, the first set of antibodies used, had to be removed. The following protocol was used to strip ECL membranes: the membrane was submerged in stripping buffer (62.5 mM Tris/HCl, pH 6.7, $100 \mathrm{mM} \beta$-mercaptoethanol, 2\% (w/v) SDS) and incubated at $50^{\circ} \mathrm{C}$ for $30 \mathrm{~min}-1 \mathrm{~h}$ under occasional agitation. After that the membrane was washed twice for $10 \mathrm{~min}$ in TBST at room temperature, using large volumes of wash buffer. Subsequently, the membrane was blocked with 5\% (w/v) non-fat dried milk in TBST for $30 \mathrm{~min}$ at room temperature. The immuno-detection protocol was repeated as described above. 


\subsubsection{DNA analyses}

\subsubsection{Phenol/chloroform extraction of DNA}

The phenol extraction is a common technique used to purify a DNA sample. An equal volume of each TE-saturated phenol (TE prevents the DNA from getting dissolved in the phenol phase) and chloroform/isoamyl alcohol (premixed in a 24:1 ratio) were added to an aqueous DNA sample. The mixture was shaken vigorously to destroy and precipitate the protein. Whereas chloroform stabilizes the two phases once the suspension was centrifuged for 1 min at 13,000 rpm, the addition of isoamyl alcohol inhibits foaming of the sample. The upper aqueous phase contains DNA, the lower phase contains the contaminating denatured proteins.

The upper aqueous phase was carefully removed and re-extracted once again by adding an equal volume of chloroform/isoamyl alcohol. The sample was vortexed vigorously and centrifuged once again at 13,000 rpm for $1 \mathrm{~min}$. The upper layer was transferred to a new tube and mixed with $1 / 10$ volume of $3 \mathrm{M}$ sodium acetate, $\mathrm{pH} 4.8$, to acidify the solution and facilitate DNA precipitation. Three volumes of ice cold $100 \%$ ethanol (kept at $-20^{\circ} \mathrm{C}$ ) were added to precipitate the DNA, and the sample was kept on ice for $1 \mathrm{~h}$. After that the probe was centrifuged at $13,000 \mathrm{rpm}$ for $20 \mathrm{~min}$ at $4^{\circ} \mathrm{C}$ to pellet the DNA. The supernatant was discarded and the DNA was washed with $500 \mu \mathrm{l}$ of $70 \%(\mathrm{v} / \mathrm{v})$ ethanol. Samples were kept at room temperature for $10 \mathrm{~min}$, before the DNA was pelleted in a final centrifugation step at $13,000 \mathrm{rpm}$ for $15 \mathrm{~min}$. The ethanol was removed and the pellet was air dried before the DNA was dissolved in $60 \mu \mathrm{l}$ TE buffer.

Apoptotic nucleosomal DNA fragments were analysed on a 1.5\% (w/v) agarose gel. The samples were electrophoresed for 4-5 h at constant voltage of $100 \mathrm{~V}$.

\subsubsection{Agarose gel electrophoresis}

Agarose gel electrophoresis was mainly used to separate and analyse nucleosomal DNA fragments of different sizes. As fragment sizes of isolated DNA from apoptotic cells reach from $200 \mathrm{bp}$ (mono-nucleosomes) to more than 10,000 bp (high molecular weight DNA), $1.5 \%(\mathrm{w} / \mathrm{v})$ agarose gels in TBE buffer (gel preparation and running buffer) $(90 \mathrm{mM} \mathrm{Tris} / \mathrm{HCl}$, $\mathrm{pH}$ 8.3, $90 \mathrm{mM}$ boric acid, $2.5 \mathrm{mM}$ EDTA) were used for the electrophoresis. For this purpose the required amount of agarose was mixed with $1 \times$ TBE buffer and boiled in a microwave until fully dissolved. The agarose was cooled down to about $50^{\circ} \mathrm{C}$ in a water bath, before it was poured into a gel casting tray. A comb of appropriate size was fixed to the tray, to generate wells for the DNA samples. Before the samples were loaded onto the gel, they were mixed with 1/10 of DNA loading buffer (10x concentrated: 20\% (w/v) Ficoll, 0.1 M EDTA, 1\% (w/v) SDS, $0.25 \%(\mathrm{w} / \mathrm{v})$ bromophenol blue) containing bromophenol blue as tracking dye. This was 
done to increase their density and simplify the loading of the gel even more so when apoptotic high molecular weight DNA was present in the samples. The electrophoresis was run for 3-4 $\mathrm{h}$ at constant voltage (100V) and a suitable molecular size standard (2-log DNA ladder 0.1-10.0 kb, New England Biolabs) was run on the same gel as the actual samples. After that the agarose gels were stained with ethidium bromide (Sharp et al., 1973) (stock solution: $10 \mathrm{mg} / \mathrm{ml}$; working dilution: $2 \mu \mathrm{g} / \mathrm{ml}$ ) for about 10-20 min. Ethidium bromide (Sigma Aldrich) with its tricyclic planar group is a fluorescent dye, which intercalates between the stacked DNA base pairs and binds to DNA with almost no sequence preference.

The stained DNA was visualised under UV light (radiation at $302 \mathrm{~nm}$ ) and the results were documented with a camera.

\subsubsection{Monitoring the process of apoptosis}

\subsubsection{Preparation of apoptotic nucleosomal DNA (DNA ladder)}

This rapid method to isolate fragmented nucleosomal DNA was used as a qualitative but not quantitative marker to make sure that the cells underwent apoptosis after having been induced with different inducing chemicals such as etoposide (topoisomerase II inhibitor) or topotecan $^{\circledR}$ (topoisomerase I) inhibitor.

For the preparation $5 \times 10^{6}$ cells were harvested by centrifugation $(1,200 \mathrm{rpm}$ for $5 \mathrm{~min})$, washed with $5 \mathrm{ml}$ PBS, pelleted at 1,200 rpm for $5 \mathrm{~min}$ and resuspended in $200 \mu \mathrm{l}$ lysis buffer (10 mM Tris/HCl, pH 8.0, 1 mM EDTA, 0.2\% (v/v) Triton X-100) with $4 \mu$ RNAse A (stock solution $10 \mathrm{mg} / \mathrm{ml}$ ). The samples were incubated at $37^{\circ} \mathrm{C}$ for $30 \mathrm{~min}$. After that $200 \mu \mathrm{l}$ proteinase $\mathrm{K}$ buffer ( $2 \times$ concentrated: $200 \mathrm{mM}$ Tris/HCl, $\mathrm{pH} 8.5,10 \mathrm{mM}$ EDTA, $0.4 \mathrm{M} \mathrm{NaCl}$, $0.4 \%(\mathrm{w} / \mathrm{v}) \mathrm{SDS}$ ) and $4 \mu \mathrm{l}$ proteinase $\mathrm{K}$ (stock solution $20 \mathrm{mg} / \mathrm{ml}$ ) were added to each sample. A second incubation step at $56^{\circ} \mathrm{C}$ for $1 \mathrm{~h}$ followed. To precipitate the DNA from the solution $1 \mathrm{ml}$ isopropanol was added to each sample and the precipitation proceeded at room temperature for $1 \mathrm{~h}$. The DNA precipitates were centrifuged at $13,000 \mathrm{rpm}$ in a microcentrifuge for $30 \mathrm{~min}$ at room temperature to prevent precipitation of SDS in the solution. The supernatant was discarded. Precipitates were washed with $500 \mu \mathrm{l} 70 \%$ ethanol and centrifuged once again at $13,000 \mathrm{rpm}$ for another $15 \mathrm{~min}$. The supernatants were discarded and the pellets dried for 2 min in a Speed Vac centrifuge. The DNA was dissolved in $100 \mu \mathrm{l}$ TE buffer for $1 \mathrm{~h}$. After that the 'bulk' chromatin was removed and $40 \mu \mathrm{l}$ of the remaining solution containing both medium and small size nucleosomal DNA fragments were analysed on a $1.5 \%$ agarose gel. The electrophoresis was run for 3-4 $\mathrm{h}$ at constant voltage (100V). The agarose gel was stained with ethidium bromide $(2 \mu \mathrm{g} / \mathrm{ml})$ for $10-20 \mathrm{~min}$ and the DNA fragments were visualised under UV light. 


\subsubsection{PARP (poly-ADP-ribose-polymerase) cleavage assay}

This method was used to monitor the ongoing process of PARP cleavage, which was initiated once cells were treated with apoptosis inducing chemicals such as topotecan ${ }^{\circledR}$ or etoposide. For this purpose $5 \times 10^{6}$ cells were harvested, washed with $5 \mathrm{ml}$ PBS and centrifuged at 1,200 rpm for 5 min (Heraeus). The cell pellet was suspended in $600 \mu \mathrm{l}$ of the strongly denaturing PARP sample buffer $(62.5 \mathrm{mM}$ Tris/ $\mathrm{HCl}, \mathrm{pH} 6.8,6 \mathrm{M}$ urea, 10\% (v/v) glycerol, 2\% (w/v) SDS, 0.00125\% (w/v) bromophenolblue, 5\% (v/v) $\beta$-mercaptoethanol) (the last component was always added prior to use). In the following sonification step (15 $\mathrm{s}$ with intervals; 25\% amplitude; Branson digital sonifier), genomic DNA in the sample was sheared to ensure that all proteins were completely dissolved in PARP sample buffer. PARP, a protein that in vivo is tightly bound to the DNA by its smaller DNA binding unit, is detached from its substrate by the process. It can be easily detected in Western blots.

The samples were incubated for $15 \mathrm{~min}$ at $65^{\circ} \mathrm{C}$ in a water bath before they were loaded onto an SDS-gel for protein separation and Western blotting. PARP proteins were detected using the colorimetric NBT/BCIP detecting system.

\subsubsection{Caspase 3 activity assay}

With this method the activity of caspase 3 in whole cell lysates can be measured. The enzyme specifically cleaves after aspartate residues in particular peptide sequences which in this case is DEVD. This substrate ( $\mathrm{N}$-acetyl-Asp-Glu-Val-Asp-AFC) is labelled with the fluorescent molecule 7-amino-4-trifluoromethyl coumarin (AFC). When the fluorophore AFC is cleaved in the presence of caspase 3 , this reaction can be monitored by a fluorescence shift from blue to green. The data obtained is later expressed as a ratio of signal obtained from a treated sample to an untreated control sample after the appropriate buffer controls had been subtracted.

To determine the caspase 3 activity of our probes $5 \times 10^{6}$ cells were harvested by centrifugation (1,200 rpm for $5 \mathrm{~min}$ ), washed with $5 \mathrm{ml}$ phosphate buffered saline (PBS), pelleted at 1,200 rpm for 5 min and resuspended in $50 \mu \mathrm{l}$ (HL-60 cells) or $70 \mu \mathrm{l}$ (HeLa-H2BYFP cells) lysis buffer (50 mM HEPES, pH7.4, 0.1 mM EDTA, 1 mM DTT, 0.1\% (w/v) CHAPS). The lysates were kept on ice for $10 \mathrm{~min}$. After that they were centrifuged at $500 \times \mathrm{g}$ for $5 \mathrm{~min}$ at $4^{\circ} \mathrm{C}$ in a micro centrifuge. The supernatant was used for further analyses. The actual caspase activity assay was run in microtiter plates. Each experiment was processed in duplicates and two mock samples with buffer and fluorophore only were run in parallel. At first $10 \mu \mathrm{l}$ of cell lysate and then $90 \mu \mathrm{l}$ of reaction buffer II were added to the microtiter well (reaction buffer I: $50 \mathrm{mM}$ HEPES, 1\% (w/v) sucrose, 0.1\% (w/v) CHAPS; reaction buffer II: $50 \mu \mathrm{M}$ DEVD-AFC, $10 \mathrm{mM}$ DTT are dissolved in reaction buffer I). 
After that the microtiter plate was immediately put into a fluorescent plate reader (Fluoroskan Ascent FL, Thermo Labsystems Oy, Electron Corporation) measuring the excitation at 390 $\mathrm{nm}$ and the emission at $510 \mathrm{~nm}$ to get control values with caspase 3 activity at $\mathrm{t}_{0}$. The plate was then covered up and incubated at $37^{\circ} \mathrm{C}$ for $20 \mathrm{~min}$. After this time it was read once again and the data was presented as delta $\mathrm{t}_{20 \mathrm{~min}} / \mathrm{t}_{0 \mathrm{~min}}$, which produces relative fluorescence values with reference to the incubation time.

\subsubsection{Nuclei-cytosol preparation techniques}

\subsubsection{Nuclei-cytosol preparations: different protocols}

As the isolation of intact and fully functional nuclei from different cell types played a pivotal role for later assays and experiments, four different nuclei-cytosol preparations were tested for intact nuclei.

For all four protocols $3 \times 10^{7}$ cells per sample were harvested, washed with $10 \mathrm{ml}$ PBS and centrifuged at 1,200 rpm (Heraeus) for $5 \mathrm{~min}$. During the following procedures protease inhibitors used (Complete ${ }^{\circledR}$, pepstatin, PMSF) were always prepared prior to use.

The first protocol (I) tested, was originally used by Antalis and Godbolt (1991) to isolate nuclei from hematopoietic cell lines such as the pro-monocytoid cell line U937 and HL-60 cells, a promyelocytic leukaemia cell line. They modified a protocol which was developed by Nevins (Nevins, 1987).

For the following preparation only one lysis buffer (I) was used: $10 \mathrm{mM} \mathrm{Tris/HCl,} \mathrm{pH} \mathrm{7.5,} 10$ $\mathrm{mM} \mathrm{NaCl}, 3 \mathrm{mM} \mathrm{MgCl}$, $1 \mathrm{mM}$ PMSF, 0.05\% (v/v) IGEPAL; protease inhibitors: Complete ${ }^{\circledR}$ (EDTA free) 1 tablet in $1 \mathrm{ml} \mathrm{H}_{2} \mathrm{O}$ bidest. (stock solution/working dilution in $\mathrm{H}_{2} \mathrm{O}$ bidest. 1:100), pepstatin (stock solution $1 \mathrm{mg} / \mathrm{ml} /$ working dilution $1 \mu \mathrm{g} / \mathrm{ml}$ ).

After centrifugation, the supernatant was discarded leaving a small liquid aliquot to swirl the cell pellet to a loose suspension. Five volumes lysis buffer (min. $1.5 \mathrm{ml}$ ) were added and the suspension was mixed gently. The nuclei were centrifuged immediately at $700 \mathrm{rpm}$ (micro centrifuge) for $5 \mathrm{~min}$. The supernatant was taken as the cytosolic fraction. To reduce mechanical stress on the nuclear membrane the centrifugation of the nuclei was proceeded at very low speed. The supernatant was carefully removed and the nuclei were diluted immediately by adding 20 volumes of lysis buffer without IGEPAL.

The second protocol (II) tested, was originally used by Chen and co-workers (Chen et al., 2000), who isolated nuclei from human T-lymphocytes according to a modified method developed by Dyer and Herzog (Dyer and Herzog, 1995). 
This protocol involved three different buffers which were prepared as follows: sucrose buffer (II): $0.32 \mathrm{M}$ sucrose, $3 \mathrm{mM} \mathrm{CaCl}$, $2 \mathrm{mM}$ magnesium acetate, $0.1 \mathrm{mM}$ EDTA, $10 \mathrm{mM}$ Tris/ $\mathrm{HCl}$, pH 8, 1 mM DTT, 0.5\% (v/v) IGEPAL; cytoplasm extraction buffer (II): $150 \mathrm{mM}$ HEPES/ $\mathrm{NaOH}, \mathrm{pH} 7.9,0.7 \mathrm{M} \mathrm{KCl}, 15 \mathrm{mM} \mathrm{MgCl}_{2}$; low salt buffer (II): $20 \mathrm{mM} \mathrm{HEPES/NaOH}, \mathrm{pH} 7.9$, $1.5 \mathrm{mM} \mathrm{MgCl}_{2}, 20 \mathrm{mM} \mathrm{KCl}, 0.5 \mathrm{mM}$ DTT, 25\% (v/v) glycerol.

After centrifugation, the cells were lysed by suspending them in $100 \mu$ l sucrose buffer (II). The lysate was then centrifuged at $500 \times \mathrm{g}$ for $5 \mathrm{~min}$ to pellet the nuclei. Supernatants were transferred to a new reaction tube, mixed with 0.22 volumes of $5 \times$ cytoplasmic extraction buffer (II) and centrifuged a second time at $12,000 \times \mathrm{g}$ for $15 \mathrm{~min}$ at $4^{\circ} \mathrm{C}$. The supernatant equalled the cytosolic extract. For storage at $-70^{\circ} \mathrm{C}$ glycerol was added to a final concentration of $25 \%(\mathrm{v} / \mathrm{v})$. The nuclear pellet from the first centrifugation step was washed with sucrose buffer (II) without IGEPAL and was centrifuged once again at $500 \times \mathrm{g}$ for $5 \mathrm{~min}$ at $4^{\circ} \mathrm{C}$. The supernatant was discarded and the nuclei were resuspended in $20 \mu$ low salt buffer (II).

The third protocol (III) tested, was used by Bunce and co-workers (Bunce et al., 1988) as a rapid method to isolate hemopoietic cell nuclei from the following cell lines: HL-60 (human promyeloid cell line), RPMI 8226 and Daudi (human B-cell lines), HUT 78 (T-cell line) and the pro-monocytoid cell line $U$ 937. They used a modified protocol which was originally developed by Standring and Williams (Standring and Williams, 1978) as well as Brown and co-workers (Brown et al., 1985). Bunce's modification was based on accelerating the original preparation process altogether to avoid a possible loss of nuclear constituents. Compared with the original protocol preparation time was reduced from $90 \mathrm{~min}$ to $30 \mathrm{~min}$.

For this protocol only one standard buffer was used, which was supplied by two more components: nuclear preparation buffer (III,1): $10 \mathrm{mM} \mathrm{Tris/HCl,} \mathrm{pH} \mathrm{7.4,} 2 \mathrm{mM} \mathrm{MgCl}, 0.14 \mathrm{M}$ $\mathrm{NaCl}$; nuclear preparation buffer $(\mathrm{III}, 2)$ : nuclear preparation buffer $(\mathrm{III}, 1)$ with $2 \%(\mathrm{v} / \mathrm{v})$ Tween 20 (cell lysis); nuclear preparation buffer (III,3): nuclear preparation buffer (III,1) with 50\% (w/v) sucrose (purification of nuclei).

After having washed the cells in PBS, they were washed once again in nuclear preparation buffer (III,1). After centrifugation at 1,200 rpm for $5 \mathrm{~min}$, the cells were resuspended in $1 \mathrm{ml}$ cold nuclear preparation buffer $(\mathrm{III}, 2)$. The lysate was immediately transferred to a cryo tube and immersed in liquid nitrogen. The cells were thawed by incubating the tube in a $50^{\circ} \mathrm{C}$ hot water bath until the frozen pellet had thawed completely. The lysate was transferred to a glass Teflon homogenizer, which was kept on ice all the time during preparation. The nuclei were then released from the cell by twenty gentle strokes of the homogenizer. The resulting homogenate was layered onto a $250 \mu$ cushion of $50 \%(w / v)$ sucrose (nuclear preparation buffer (III,3)). The homogenate was centrifuged at 13,000 rpm for $1 \mathrm{~min}$ (micro- centrifuge) at 
room temperature to avoid viscosity changes of the sucrose cushion. The supernatant contained the cytosolic fraction. The nuclear pellet was suspended in $1 \mathrm{ml}$ nuclear preparation buffer $(I I I, 1)$ or phosphate-EDTA buffer and immediately used for further applications.

The fourth protocol (IV) tested, was developed by Thomas Meergans (Department of Biology, section: Biochemical Pharmacology, University of Konstanz), to isolate nuclei from adherent cells such as HeLa cells (cervix carcinoma cells).

For the preparation the following buffers and detergents were used: extraction buffer (VI): 20 $\mathrm{mM}$ HEPES/ $\mathrm{H}_{2} \mathrm{SO}_{4}, \mathrm{pH} 7.3,110 \mathrm{mM}$ potassium acetate, $5 \mathrm{mM}$ sodium acetate, $2 \mathrm{mM}$ magnesium acetate, $0.5 \mathrm{mM}$ EGTA, pepstatin, leupeptin, aprotinin all in the following concentration of $1 \mu \mathrm{g} / \mathrm{ml}$; digitonin solution (IV) (stock solution $20 \mathrm{mg} / \mathrm{ml}$ in DMSO/working dilution $160 \mu \mathrm{g} / \mathrm{ml}$ in extraction buffer (IV)); import assay buffer (IV): $20 \mathrm{mM} \mathrm{HEPES} / \mathrm{H}_{2} \mathrm{SO}_{4}$, pH 7.3, 110 mM potassium acetate, 1 mM EGTA, 2 mM magnesium acetate, 2 mM DTT.

The cells were resupended and washed in $1 \mathrm{ml}$ ice cold extraction buffer $(\mathrm{VI})$ and centrifuged for $15 \mathrm{~s}$ at 10,000 rpm at room temperature (micro centrifuge). After that all following steps were processed at $4^{\circ} \mathrm{C}$ or on ice. The supernatant was carefully discarded and the cells were lysed in $100 \mu \mathrm{l}$ digitonin solution. After $7 \mathrm{~min}$ on ice, the lysate was centrifuged for $30 \mathrm{~s}$ at $13,000 \mathrm{rpm}$. The supernatant corresponded to the cytosolic fraction, which was stored at $-75^{\circ} \mathrm{C}$. The nuclei were washed three times in $300 \mu \mathrm{l}$ import assay buffer (IV). Between each washing step the samples remained on ice for $7 \mathrm{~min}$. It was not recommended to minimise the washing steps, as each step reduced the chance of remaining cytosolic components within the nuclear fractions. The nuclear pellet was resuspended in $50 \mu \mathrm{l}$ import assay buffer (IV) and immediately used for further applications.

All nuclei isolated by the protocols just described were later analysed in terms of morphology and function under the fluorescence microscope and in Western blots with appropriate protein markers.

\subsubsection{Nuclei-cytosol preparations for comparative analysis of histone release into the cytosol during apoptosis}

The following protocol was developed and used by Radic and co-workers (Radic et al., 2004) to analyse the release of apoptotic nucleosomes into the cytosol. We used this protocol in parallel to our own to compare different approaches to an 'appropriate' nuclei-cytosol preparation. Radic et al. (Radic et al., 2004) treated their cells with camptothecin to induce apoptosis. Control cells were pre-incubated with the caspase 3 inhibitor z-VAD-(OMe)-fmk, before the inducer was added. $1 \times 10^{8}$ cells were harvested by centrifugation, washed in HBSS (Hanks' Balanced Salt Solutions) and incubated in hypotonic buffer (10 mM HEPES, 
$\mathrm{pH}$ 7.4, $10 \mathrm{mM} \mathrm{NaCl} 1 \mathrm{mM}$ EDTA, $1 \mathrm{mM} \mathrm{DTT}$ ) on ice for $15 \mathrm{~min}$. After that IGEPAL was added to a final concentration of $0.5 \%(\mathrm{v} / \mathrm{v})$, the cells were vigorously vortexed for $30 \mathrm{~s}$ and centrifuged at $13,000 \mathrm{rpm}$ for $5 \mathrm{~min}$. The supernatant was taken as the cytoplasmic fraction, whereas the pellet contained the nuclear fraction.

All nuclear and cytosolic fractions were analysed on SDS-PAGE and in Western blots.

\subsubsection{Separation of apoptotic oligonucleosomes}

\subsubsection{Sucrose gradients: size fractionation of apoptotic nucleosomal DNA fragments}

Running sucrose gradients has turned out to be the best method for size-fractionation of soluble nucleosomes and oligonucleosomes (Butler and Thomas, 1998) for a detailed analysis of histone modifications in apoptotic cells. For this purpose we used standard linear gradients (protocol Finch et al., 1975) with sucrose concentrations of 4\%-25\%.

Nuclei from $2-3 \times 10^{8} \mathrm{HL}-60$ cells (non-apoptotic control cells and apoptotic cells) were isolated using protocol (III) according to Bunce and co-workers (Bunce et al., 1988). After the last centrifugation step, instead of suspending them in nuclear preparation buffer (III,1), nuclei were lysed in 3-5 ml hypotonic phosphate-EDTA buffer ( $5 \mathrm{mM}$ sodium phosphate, $\mathrm{pH}$ 6.8, 0.2 mM EDTA; 1 mM PMSF was added just before use). The nuclear lysate was immediately layered onto the sucrose gradient (30 $\mathrm{ml}$ tubes, Beckman). Gradients were poured using a gradient former. The following two sucrose buffers were used to prepare the gradient: low sucrose concentration buffer ( $5 \%(\mathrm{w} / \mathrm{v})$ sucrose in phosphate-EDTA buffer) and high sucrose concentration buffer $(28.8 \%(\mathrm{w} / \mathrm{v})$ sucrose in phosphate-EDTA buffer). The sucrose concentrations within the gradient were determined by measuring the index of refraction with a refractometer. Overnight runs (Beckman Instruments Ultracentrifuge LZ, L7 5S) for approximately $16 \mathrm{~h}$, for which the centrifuge was set to switch off without using brakes, brought the best resolutions for the size fractionation of nucleosomal DNA fragments. The gradient was run at 22,000 rpm in an SW28 rotor (swing-out bucket). The gradient was fractionated in $2 \mathrm{ml}$ fractions, which resulted in 16 fractions altogether, including the nuclear pellet. To analyse the differently sized apoptotic nucleosomal fragments on protein level as well as on DNA level, $1 \mathrm{ml}$ of each fraction was used for histone preparation and $1 \mathrm{ml}$ for the preparation of nucleosomal DNA. 


\subsubsection{Histone extraction from sucrose gradient pellet}

To avoid selective analysis of the only partially soluble chromatin material during the isolation process of core histones from solid bulk chromatin fractions, four different approaches were taken to extract the core histones from the solid sucrose gradient pellet.

I: the pellet was suspended in $1 \mathrm{ml}$ phosphate-EDTA buffer $(5 \mathrm{mM}$ sodium phosphate, $\mathrm{pH}$ 6.8, 0.2 mM EDTA, $1 \mathrm{mM}$ PMSF) and nucleo-proteins were precipitated from the fraction using $240 \mu \mathrm{l} \mathrm{TCA} \mathrm{(20 \%} \mathrm{final} \mathrm{concentration).} \mathrm{After} \mathrm{a} \mathrm{centrifugation} \mathrm{step} \mathrm{at} 13,000 \mathrm{rpm}$ (micro centrifuge) for $30 \mathrm{~min}$, the protein was washed once with $1 \mathrm{ml}$ acetone and air dried. The resulting pellet was dissolved in $500 \mu \mathrm{l}$ Laemmli buffer. 10-15 $\mu \mathrm{l}$ were run on an SDS-PAGE.

II: the pellet was suspended in phosphate-EDTA buffer and aliquots of 10-15 $\mu$ l were taken, mixed with an appropriate volume of Laemmli buffer for analysis on an SDS-PAGE.

III: the pellet, which was at first suspended in phosphate-EDTA buffer, was mixed with sulphuric acid (final concentration $0.4 \mathrm{~N}$ ) and kept on ice for incubation for $1 \mathrm{~h}$. After that the fraction was centrifuged at $13,000 \mathrm{rpm}$ for $10 \mathrm{~min}$ to clear off all insoluble material. The next step involved protein precipitation with TCA. The following steps were proceeded with in the same way as mentioned in $\mathbf{I}$.

IV: for this protocol the pellet was again suspended in phosphate-EDTA buffer. To make sure that the bulky chromatin fraction is turned into an easy working homogenate, the suspension was transferred to a glass-teflon homogeniser. The material was homogenised with 20 up- and downward strokes. After that the nucleo-protein was precipitated with $20 \%$ TCA and an aliquot of 10-15 $\mu$ was analysed on SDS-Page.

\subsubsection{Purification and preparation techniques for single histone type modification analysis}

\subsubsection{Histone preparation}

The following protocol was used to isolate single core histone types from HL-60 cells, purify them via size exclusion chromatography (P60-column) and high performance liquid chromatography (HPLC), and to subsequently analyse them by using capillary zone electrophoresis.

For this purpose, $5-6 \times 10^{8}$ control HL-60 cells and apoptosis induced HL-60 (induction with $150 \mathrm{ng} / \mathrm{ml}$ topotecan ${ }^{\circledR}$ for $8 \mathrm{~h}$ ) cells were harvested, washed with PBS, and centrifuged at $1,200 \mathrm{rpm}$ for $5 \mathrm{~min}$. Aliquots of about $3 \times 10^{7}$ cells were taken to isolate the nuclei from which the histones were to be prepared later on. For the nucleus-cytosol preparation, the third protocol (III) by Bunce and co-workers (1988) was used (c.f. above). All nuclei-containing aliquots were then pooled and suspended in $8 \mathrm{ml}$ phosphate-EDTA buffer (5 mM sodium phosphate, $\mathrm{pH}$ 6.8, $0.2 \mathrm{mM}$ EDTA, $1 \mathrm{mM}$ PMSF). To make sure that all histones become 
detached from the genomic DNA, $1.92 \mathrm{ml}$ of a $5 \mathrm{M} \mathrm{NaCl}$ solution were added to the lysate to receive a final salt concentration of $1 \mathrm{M} \mathrm{NaCl}$. The sample was shortly vortexed and kept on ice for 10-15 min. After that, the samples were sonified twice for $15 \mathrm{~s}$ at $25 \%$ amplitude, to get rid of all genomic DNA, and centrifuged in an SS34 rotor (Sorvall centrifuge) at 15,000 rpm for $25 \mathrm{~min}$ at $4^{\circ} \mathrm{C}$. The supernatant was removed and dialysed overnight at $4^{\circ} \mathrm{C}$ in 30 $\mathrm{mM} \mathrm{HCl}$, with frequent changes of the buffer to the salt. A membrane with a molecular cut-off of 5,000 kDa was used, to ensure that no histones were lost during dialysis. Subsequently, precipitated unsoluble non-histone proteins were removed from the sample by centrifugation at $13,000 \mathrm{rpm}$ for $10 \mathrm{~min}$ at $4^{\circ} \mathrm{C}$. The supernatant was carefully removed and the pellet discarded. The clear histone lysate was immediately used for further purification and separation on a P60-column via size exclusion chromatography or stored on ice for a short time.

\subsubsection{Preparation of a Bio-Gel ${ }^{\circledR}$ P60 polyacrylamide gel column}

Size exclusion chromatography or gel filtration separates soluble proteins according to their size and is based on the molecules' different permeation properties into porous carrier matrices of defined pore size. Proteins larger than the pore size cannot enter the matrix. They are eluted together with the void volume. Smaller molecules migrate into the pores of the matrix and are therefore retarded in their elution process.

Bio-Gel P gels are porous polyacrylamide beads prepared by copolymerisation of acrylamide and N,N'-methylene-bis-acrylamide. The matrices are extremely hydrophilic, essentially free of charge and provide efficient, gentle gel filtration of sensitive compounds. A high resolution of protein samples is assured as these columns allow a consistent narrow distribution of bead diameters and excellent molecular weight discrimination.

For the separation of core histones a Bio-Gel P-60 (medium) matrix, which separates proteins with sizes below $60 \mathrm{kDa}$, was used with the following properties:

particle size range of hydrated beads $(\mu \mathrm{M}): 90-180$

hydrated bed volume $(\mathrm{ml} / \mathrm{g})$ of dry gel: 11

flow rate $(\mathrm{cm} / \mathrm{h}): 4.0-6.0$

fractionation rangel

nominal exclusion limit (Da): 3,000-60,000

column size: $\varnothing 1.5 \mathrm{~cm}$; cross length $50 \mathrm{~cm}$; max. sectional area $1.77 \mathrm{~cm}^{2}$; volume $89 \mathrm{ml}$

The Bio-Gel ${ }^{\circledR} \mathbf{P}-60$ was prepared by soaking the material in $30 \mathrm{mM} \mathrm{HCl}$ overnight. After that the beads were washed three times using large volumes of $30 \mathrm{mM} \mathrm{HCl}$. Once the hydration process was completed, excess volumes of the solution were decanted and the material was 
transferred to a filter flask. The flask was connected to a vacuum source to degas the material for $30 \mathrm{~min}$, occasionally swirling it. This was done to avoid trapping air bubbles in the matrix that might have led to an uneven packing of the column. Finally, the slurry was poured into the column in one single smooth movement, to avoid splashing and ensure even packing. Once a $2-5 \mathrm{~cm}$ bed had formed, the column outlet was opened to allow packing. Before actual use 2 bed volumes of buffer were passed through the column.

\subsubsection{Separation and crude purification of core histones on Bio-Gel ${ }^{\circledR}$ P60 columns}

The column flow was adjusted to $0.2-0.3 \mathrm{ml} / \mathrm{min}$. $4 \mathrm{ml}$ of histone extract were applied to the column. Once the sample had entered the gel bed completely, a further volume of $30 \mathrm{mM}$ $\mathrm{HCl}$ was added and the elution was started. The actual fractionation process did only start after about 5-7.5 $\mathrm{ml}$ of void volume had passed through the column. After that 75 fractions with $1 \mathrm{ml}$ per fraction were collected, using an automatic fraction collector (Amersham Pharmacia). For further analysis $40 \mu \mathrm{l}$ of each fraction were mixed with $14 \mu \mathrm{l}$ Laemmli sample buffer and boiled for $5 \mathrm{~min}$. All fractions were subsequently analysed on SDS-PAGE. After fractionation the column was rinsed with two column volumes $30 \mathrm{mM} \mathrm{HCl}$, sealed tightly with parafilm, to avoid dehydration and stored at room temperature until further use.

The column fractions were pooled in three main fractions with a) $\mathrm{H} 1$ linker histones and histone $\mathrm{H} 3, \mathrm{~b}$ ) histones $\mathrm{H} 2 \mathrm{~A} / \mathrm{H} 2 \mathrm{~B}$ and traces of histone $\mathrm{H} 3$ and c) mainly histone $\mathrm{H} 4$. To reduce the single fraction volumes for further analysis on high pressure liquid chromatography (HPLC), all three fractions were concentrated using Viva Spin concentrators with $20 \mathrm{ml}$ and $6 \mathrm{ml}$ volumes (Viva Science Sartorius group). These have a cut-off of 5,000 $\mathrm{Da}$, to ensure that no protein is lost during the process. All three fractions were concentrated from $20 \mathrm{ml} / 15 \mathrm{ml}$ to $1 \mathrm{ml}$ per fraction and further purified on an HPLC system.

\subsubsection{Separation and purification of single core histone types on high performance liquid chromatography (HPLC)}

To purify the histones for further single-histone type analysis via capillary zone electrophoresis (CZE), the samples were put through an HPLC system first.

The HPLC separation method for core histones was modified after a protocol originally used by Talasz et al. (Talasz et al., 1998) for the separation of $\mathrm{H} 1$ linker histone subtypes. The HPLC equipment used was a Kontron Instruments 450 MT2 system, including an M420 pump, an M425 gradient former, and an M 432 variable wavelength detector. For appropriate cooling of the pump, a perfusor (Perfusor secura, B. Braun, Melsungen) operating with isopropanol was used. 
Before loading a $150 \mu \mathrm{l}$ sample (approx. $100 \mu \mathrm{g}$ ) onto the column, the samples were centrifuged in a table ultracentrifuge (Optima ${ }^{\mathrm{TM}}$ TLX 120 CE ultracentrifuge, Beckman Coulter) at $100,000 \times \mathrm{g}$ for $15 \mathrm{~min}$ at $4^{\circ} \mathrm{C}$, using a TLA 100 rotor (Beckman Coulter) with carbonated tubes $(7 \times 20 \mathrm{~mm} ; 0.2 \mathrm{ml}$ volume). This step was necessary to remove any traces of insoluble material, which might disturb the separation. The histones, dissolved in $30 \mathrm{mM}$ $\mathrm{HCl}$, were separated on a Jupiter C4 column $(150 \times 4.6 \mathrm{~mm}$ inner diameter; $5 \mu \mathrm{m}$ particle size, $300 \AA$ A pore size; Phenomenex, Aschaffenburg). The samples were eluted at a constant flow rate of $1 \mathrm{ml} / \mathrm{min}$ and the absorbance of the effluent was monitored at $\lambda 210 \mathrm{~nm}$. The following solvents were used to form the gradient: solvent $\mathrm{A}$ with $0.1 \%(\mathrm{v} / \mathrm{v})$ trifluoroacetic acid (TFA), solvent B with $59.5 \%(\mathrm{v} / \mathrm{v})$ acetonitrile in water (HPLC grade) and $0.1 \%(\mathrm{v} / \mathrm{v})$ TFA. The column was generally rinsed with solvent C, 100\% (v/v) methanol (HPLC grade). For the actual separation of the core histones the following multi-step gradient program was used:

\begin{tabular}{|l|l|}
\hline time [min] & function \\
\hline rinsing of column & solvent C $100 \%$ \\
\hline $0-5.20$ & solvent A $100 \%$ / solvent B 0\% \\
\hline $5.20-10.20$ & solvent A $50 \%$ / solvent B $50 \%$ \\
\hline $10.20-76.20$ & solvent A 0\% / solvent B $90 \%$ \\
\hline
\end{tabular}

The peaks were recorded using the software program Geminyx version 1.91 (Flowspek $A G$ ). The manually collected samples were vacuum-dried overnight in a Speed Vac centrifuge (Speed Vac SC 100 , Savant) and stored at $-20^{\circ} \mathrm{C}$.

\subsubsection{Analysis of core histones via capillary zone electrophoresis (CZE)}

Capillary electrophoresis (CE) encompasses quite a range of different related separationtechniques that use narrow-bore fused-silica capillaries to separate complex arrays of differently sized molecules, proteins among others. High electric field strengths are used to separate proteins on the basis of differences in their charge, size and hydrophobicity. The samples are loaded onto the system by immersing one end of the capillary into a sample vial and applying high voltage. The proteins are detected by an on-column detector at a wavelength of $200 \mathrm{~nm}$.

One of these highly specified separation-techniques is the capillary zone electrophoresis (CZE), also known as free-solution CE (FSCE). Its great advantages compared with conventional electrophoresis techniques lie in the fact that only very small sample volumes and solvent volumes are needed. Besides the method allows short separation times and high resolutions. The separation mechanism is based on differences in the charge-to-mass ratio 
of the samples. Homogeneity of the buffer solution and constant field strength throughout the length of the capillary are essential for CZE. The separation itself principally relies on the $\mathrm{pH}-$ driven dissociation of acidic groups on the solute or alternatively on the protonation of basic functions on the solute, depending on the properties of the protein analysed.

A PIACE MDQ capillary electrophoresis system (Beckman Coulter) was used for the analysis of core histones. The conditions were modified and optimised after a method developed by Lindner et al. (Lindner et al., 1995). A fused-silica capillary was used for the separation. The following conditions were applied for separating core histones:

\begin{tabular}{|l|l|}
\hline property & condition \\
\hline cartridge temperature & $30^{\circ} \mathrm{C}$ \\
\hline voltage & $10 \mathrm{kV}$ \\
\hline current & approx. $39 \mu \mathrm{A}$ \\
\hline separation time & $120 \mathrm{~min}$ \\
\hline sample injection & by pressure \\
\hline injection time & $2 \mathrm{~s}$ \\
\hline protein concentration of the sample & approx. $0.5 \mathrm{mg} / \mathrm{ml}$ \\
\hline absorbance detection & $\lambda 200 \mathrm{~nm}$ \\
\hline length of capillary & $1.1 \mathrm{~m}$ \\
\hline separation buffer & $\begin{array}{l}30 \mathrm{mM} \mathrm{H}_{3} \mathrm{PO} \\
\text { hydroxypropylmethylcellulose }(\mathrm{HPMC}), \\
\text { pH } 2.0, \text { adjusted with triethylamine }\end{array}$ \\
\hline rinse buffers & $\begin{array}{l}1 \mathrm{~N} \mathrm{H}_{2} \mathrm{SO}_{4} ; 1 \mathrm{~N} \quad \mathrm{NaOH} ; 0.1 \mathrm{~N} \mathrm{NaOH;} \mathrm{H}_{2} \mathrm{O} \\
\text { bidest. }\left(\mathrm{HPLC}_{4} \text { grade) }\right.\end{array}$ \\
\hline
\end{tabular}

Table 2.2.7.5 CZE system properties and separation conditions for the analysis of core histones.

The vacuum-dried samples separated by HPLC were dissolved in $30 \mathrm{mM} \mathrm{HCl}$ for 15 min. During that time they were kept on ice to prevent protein degradation. In a final centrifugation step at $13,000 \mathrm{rpm}$ for $10 \mathrm{~min}$ at $4^{\circ} \mathrm{C}$ (microcentrifuge) all traces of insoluble material were removed which might otherwise block up the capillary. Subsequently, the samples were injected into the system. The absorbance data was recorded and analysed by a PC-based integration system (A P/ACE MDQ), operating with Karat 32 ${ }^{\mathrm{TM}}$ (version 7.0) software.

\subsubsection{Immuno-fluorescence analyses}

To localize a possible release of core histones into the cytosol after induction of apoptosis with different chemical inducers (those cells which became detached from the cover slip 
surface in the course of apoptosis were also analysed, taking the culture supernatant for cytospin at $500 \mathrm{rpm}$ for $3 \mathrm{~min}$ ), indirect immuno-fluorescence staining techniques were applied. Depending on the time kinetics, $6 \times 10^{5} \mathrm{HeLa}$ H2B-YFP cells were grown on cover slips, harvested at different times, washed twice with $3 \mathrm{ml} \underline{\text { PBS }}(140 \mathrm{mM} \mathrm{NaCl}, 2.7 \mathrm{mM} \mathrm{KCl}$, $1.5 \mathrm{mM} \mathrm{KH}_{2} \mathrm{PO}_{4}, 9 \mathrm{mM} \mathrm{Na} \mathrm{HPO}_{4}, \mathrm{pH}$ 7.4) per well and fixed in fixation buffer $(3 \%(\mathrm{w} / \mathrm{v})$ paraformaldehyde) in PBS for 15 min at room temperature. After that the cover slips were washed three times with PBS. The cells were then permeabilised with permeabilising buffer $(0.5 \%(\mathrm{v} / \mathrm{v})$ Triton $\mathrm{X}-100$ in $\mathrm{PBS})$ for $10 \mathrm{~min}$ at room temperature. To fully remove the detergent, the cells were washed again three times with PBS. To avoid unspecific antibody binding, the cells were blocked in blocking buffer (3\% (w/v) bovine serum albumin (BSA) in PBS for 10 min again at room temperature. After that depending on the primary antibody used, the cells were incubated with the antibody diluted in blocking buffer either at $37^{\circ} \mathrm{C}$ for $1 \mathrm{~h}$ or overnight at $4^{\circ} \mathrm{C}$ (cells were always kept in a humid box to avoid dehydration of the probes). To remove the primary antibody, the cells were washed three times in PBS and then incubated with the secondary antibody for $2 \mathrm{~h}$ at $37^{\circ} \mathrm{C}$ (for a detailed list of primary and secondary antibodies and the dilutions used compare table in chap. 2.1.9.1). After a final washing step, the nuclei were stained with the DNA-binding substrate diamino-2-phenylindol (DAPI, Sigma), which is one component of the embedding medium ( $90 \%(\mathrm{v} / \mathrm{v})$ glycerol, $10 \%$ (w/v) PBS, $1 \mathrm{mg} / \mathrm{ml}$ phenylenediamin, 1 $\mathrm{g} / \mathrm{ml}$ DAPI). Specific antibody binding was analysed with a Zeiss fluorescence microscope (Axioscope 20) and a Zeiss LSM 410 invert using 40x or 100x magnifying objective lenses (Plan Neofluar). Results were obtained through digital imaging, using Zeiss version 3.50 and SPOT software.

\subsubsection{Fluorescence activated cell sorting (FACS) and TUNEL-assay}

Flow cytometry or fluorescence-activated-cell-sorting (FACS) provides a highly sensitive method to analyse multiple characteristics of single cells. The information obtained is both qualitative and quantitative. Applications of FACS analyses and cell sorting in biochemical and biomedical fields are numerous. Conjugation of fluorescent dyes to ligands and to monoor polyclonal antibodies has facilitated the study of density and distribution of cell-surface and cytoplasmic determinants as well as receptors, but also the identification of certain subpopulations of cells. Moreover, a wide range of fluorescent probes, such as propidium iodide, phycoerythrin or flourescein, is available for directly measuring cellular parameters, such as nucleic acid content, $\mathrm{pH}$, intracellular calcium flux, enzyme activity or membrane potential (Carter and Ormerod, $2003^{7}$ ).

\footnotetext{
${ }^{7}$ N.P. Carter and M. G. Ormerod, "Introduction to the principles of flow cytometry", in Flow Cytometry, chap. 1, ed. M. G. Ormerod (Oxford, UK, 2003), pp. 1-22.
} 
Flow cytometry measures optical and fluorescence features on single cell level. Physical properties are measured in two different modi, firstly by the forward angle light scatter, with the help of which cell sizes can be determined, secondly by the right-angle scatter, through which granularity and internal complexity of a cell are displayed.

Cells labelled in any of the ways described above, are passed by a light source, where the bound fluorescent molecules are excited to a higher energy state. The fluorochromes, once they return to their resting state, emit light energy at higher wavelengths. The fact that numerous fluorochromes show similar excitation wavelengths but different emission wavelengths, allows several cell properties to be measured at the same time.

During the actual screening process inside a flow cytometer, cells in suspension are drawn into a stream which is caused by a surrounding sheath of isotonic fluid that generates a laminar flow. The flow guarantees that only single cells pass through the interrogation point, where via a beam of monochromatic light, usually generated by a laser, the cells are intersected. Excited fluorochromes then emit light into all directions, which is collected by optics. These direct the light to a series of filters and dichroic mirrors, which isolate particular wavelength bands. All light signals are then detected by a system of photomultiplier tubes and digitised for computer analysis (Brown and Wittwer, 2000). Results are generally presented in histograms and two-dimensional dot-plots.

Chromatin condensation and cleavage of apoptotic linker DNA between nucleosome core particles are biochemical hallmarks of apoptosis. Especially the latter is counted for one of the later processes in apoptosis, which is caused by the activation of DNA endonucleases. These cleave the higher order chromatin structure first into medium size fragments of $\sim 300$ $\mathrm{kb}$ and later on into small pieces of $50 \mathrm{bp}$ in length. A general, very efficient method to detect DNA fragmentation is the TUNEL-assay (terminal deoxynucleotidyltransferase dUTP nick end labelling), a reaction that is catalysed by exogenous TdT.

For the analysis of H2AX serine 139 phosphorylation in HL-60 cells after the onset of apoptosis with relation to DNA double strand breaks and fragmentation, $1 \times 10^{6}$ cells were treated with topotecan ${ }^{\circledR}$ and incubated for $8 \mathrm{~h}$. Untreated cells served as controls. After incubation, the cells were washed twice with $3 \mathrm{ml}$ sterile PBS and centrifuged for $5 \mathrm{~min}$ at $500 \times g$ in a Heraeus centrifuge $\left(4^{\circ} \mathrm{C}\right)$. The supernatant was carefully discarded and the cell pellet was suspended in the remaining fluid. The cell suspension was injected with a syringe (gauge $0.4 \mathrm{~mm}$ ) into a FACS tube containing $3 \mathrm{ml}$ of $100 \%$ ice-cold ethanol and stored overnight at $-20^{\circ} \mathrm{C}$. Next, the tubes were centrifuged at $500 \times \mathrm{g}$ for $5 \mathrm{~min}$. The ethanol was quickly discarded and the cells were washed twice in PBS/0.5\% BSA wash buffer and centrifuged once again at $500 \times \mathrm{g}$ for $5 \mathrm{~min}$ at $4^{\circ} \mathrm{C}$. Subsequently, the cells were incubated with $100 \mu \mathrm{l}$ of the primary antibody anti-H2AX-phosphate S139 $(2 \mu \mathrm{g} / \mathrm{ml})$ overnight with gentle agitation at 10 min intervals. Control cells were incubated in parallel in PBS/0.5\% BSA wash 
buffer. After that all samples were washed twice with PBS/0.5\% BSA wash buffer and centrifuged at $500 \times \mathrm{g}$ for $5 \mathrm{~min}\left(4^{\circ} \mathrm{C}\right)$. The supernatant was quickly removed and the cells were incubated with $100 \mu \mathrm{l}$ of the secondary antibody AlexaFluor488 anti-mouse antibody $(1: 1,000)$ for $1 \mathrm{~h}$ at $37^{\circ} \mathrm{C}$. In a last step the cells were washed and centrifuged twice again as described and finally suspended in $500 \mu$ sterile PBS.

For the TUNEL-assay $1 \times 10^{6}$ cells were harvested and washed as described. Afterwards the samples were stained according to the protocol of the APO-DIRECT ${ }^{\mathrm{TM}} \mathrm{KIT}$ from $\mathrm{BD}$ Bioscience. The following table shows the contents of the master mix for a single sample.

\begin{tabular}{|l|c|}
\hline staining solution & 1 assay $[\boldsymbol{\mu l}]$ \\
\hline reaction buffer & 10.00 \\
\hline TdT enzyme & 0.75 \\
\hline FITC-dUTP & 8.00 \\
\hline distilled $\mathrm{H}_{2} \mathrm{O}$ (HPLC grade) & 32.25 \\
\hline total volume & 51.00 \\
\hline
\end{tabular}

A volume of $51 \mu \mathrm{l}$ was added to the samples that were to be analysed via TUNEL assay. The cells were incubated for $1 \mathrm{~h}$ at $37^{\circ} \mathrm{C}$. In a following step, the suspension was centrifuged at $500 \times \mathrm{g}$ for $5 \min \left(4^{\circ} \mathrm{C}\right)$ and the supernatant was carefully removed. The cells were washed twice with $1 \mathrm{ml}$ rinse buffer provided from the KIT, centrifuged and finally suspended in $500 \mu \mathrm{l}$ PBS. Cells just treated with rinse buffer served as control cells. All samples were analysed in the flow cytometer. The following table gives a list of all samples prepared:

\begin{tabular}{|c|}
\hline FACS samples \\
\hline A) control cells \\
\hline $\begin{array}{l}\text { B) cells incubated with H2AX-phosphate S139 } \\
\text { antibody and AlexaFluor555 labelled } \\
\text { secondary antibody }\end{array}$ \\
\hline $\begin{array}{l}\text { C) cells stained with a FITC-labelled anti-BrdU } \\
\text { monoclonal antibody (TUNEL-assay) and } \\
\text { H2AX-phosphate S139 antibody with an } \\
\text { AlexaFluor555 labelled secondary antibody }\end{array}$ \\
\hline $\begin{array}{l}\text { D) cells stained with a FITC-labelled anti-BrdU } \\
\text { monoclonal antibody (TUNEL-assay) }\end{array}$ \\
\hline
\end{tabular}

The results were displayed in histograms and two-dimensional dot-plots. 


\section{Results}

The aim of this project was in the first place, to analyse the molecular basis and effects of the apoptosis-related chromatin condensation and fragmentation. To further elucidate this matter, putative apoptosis-related changes in core histone modifications, as well as histone modifications in fragmented and non-fragmented regions of the chromatin should be analysed. Moreover, the release of histones from fragmented chromatin was also investigated.

\subsection{Monitoring the ongoing process of apoptosis: apoptosis markers for HL-60 cells} Before the actual experiments were set about, it was necessary to characterise the cell lines HL-60 and HeLa H2B-YFP in terms of their apoptotic features. To ensure morphological and biochemical viability of control cells, as well as an efficient induction of apoptosis, markers of apoptosis such as PARP cleavage, caspase 3 activity and cleavage of nucleosomal DNA (DNA ladder) were monitored on a regular basis. Parameters for the induction of apoptosis, such as concentration of the inducer and duration of exposure of cultured cells to the specific chemical compound, were optimised by running dose-response curves. The following two chemical compounds were used throughout this work, the topoisomerase I inhibitor topotecan $^{\circledR}$ and the topoisomerase II inhibitor etoposide. For most experiments, if not indicated otherwise, the following induction times and concentrations of the inducers were applied: For the induction of HL-60 cells with topotecan ${ }^{\circledR} 150 \mathrm{ng} / \mathrm{ml}$ turned out to be the most efficient working concentration to induce apoptosis. With reference to the time of exposal of HL-60 cells to this inducer, cleavage of nucleosomal DNA (Fig. 3.1.1 lane 3), as well as PARP cleavage (Fig. 3.1.2 lane 3) were initiated between $2 \mathrm{~h}$ to $8 \mathrm{~h}$ after the induction of apoptosis. 
1

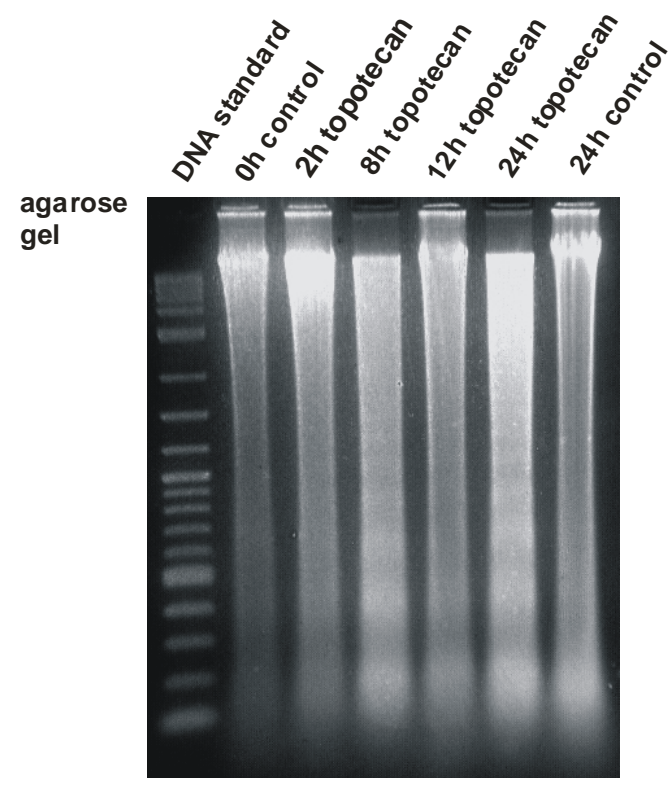

2 PARP cleavage

alkaline phosphatase immuno-detection

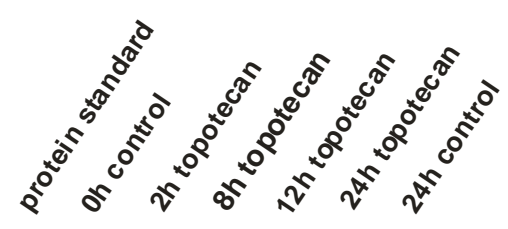

Ponceau stain
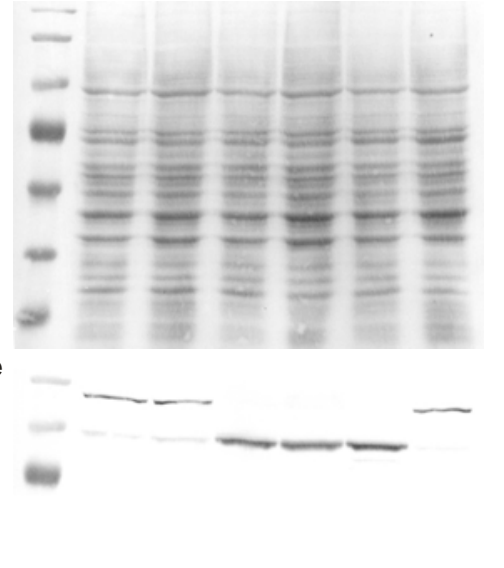

3

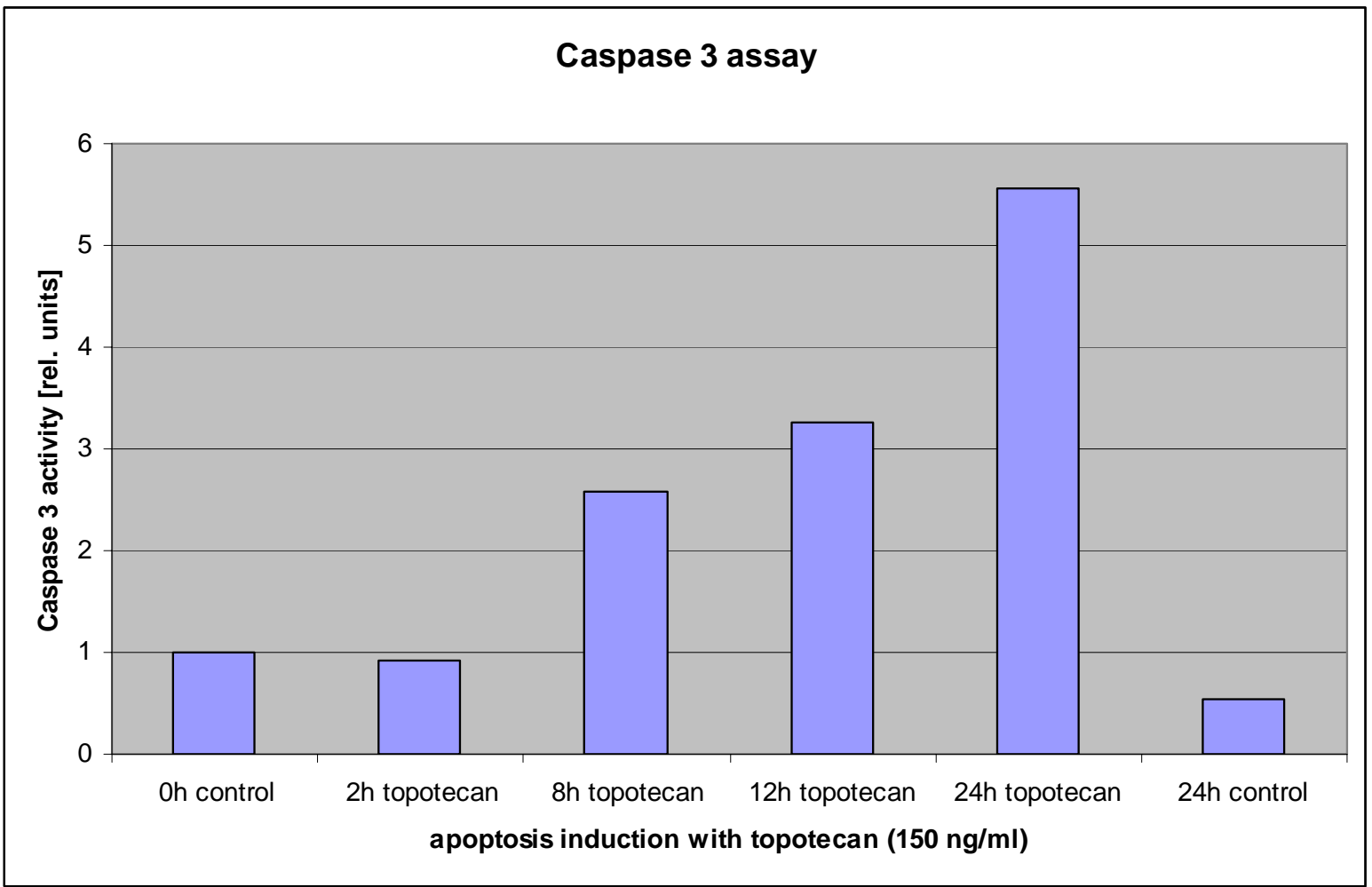

Fig. 3.1 Markers for monitoring the ongoing process of apoptosis in HL-60 cells: cleavage of nucleosomal DNA and PARP, caspase 3 assay. HL-60 cells were induced with topotecan ${ }^{\circledR}$ and harvested after 2 h, 8 $\mathrm{h}, 12 \mathrm{~h}$ and $24 \mathrm{~h}$ of induction. Untreated cells which were harvested shortly after seeding (0h), and after $24 \mathrm{~h}$ of incubation, served as control cells. Apoptotic nucleosomal DNA from all samples and proteins for PARP cleavage analyses were harvested and separated. Total protein lysates were subject to SDS-PAGE (15\%). Subsequently, Western blot analysis of PARP was carried out. Proteins for the caspase 3 assay were harvested at the same times and protein lysates were used for fluorometric measurement of caspase 3 activity. (1) Separation of control cell DNA and apoptotic nucleosomal DNA on a 1.5\% agarose gel. Cleavage of nucleosomal DNA was observed between $2 \mathrm{~h}$ 
to $8 \mathrm{~h}$ after induction. (2) Western blot, incubated with anti-PARP antibody. Approximately equal amounts of protein were loaded onto the gel, as shown by Ponceau staining. Cleavage of all PARP proteins was observed between $2 \mathrm{~h}$ to $8 \mathrm{~h}$ after induction of apoptosis. (3) Measurement of caspase 3 activity in HL-60 lysates. A gradual increase in the activity was observed $8 \mathrm{~h}$ after induction, which went on over the whole period of $24 \mathrm{~h}$.

In correlation with this, the caspase 3 activity in HL-60 cells also showed a clear increase after $8 \mathrm{~h}$ which went up until $24 \mathrm{~h}$ of incubation (Fig. 3.1.3). Nevertheless, for the analyses of different histone modifications in apoptotic nucleosomes of fragmented chromatin and changes in histone modifications during apoptosis, incubation times did not exceed 8h, as, according to our data here and phase contrast microscopy (data not shown), after $24 \mathrm{~h} \mathrm{a}$ majority of the cell population had shown signs of severe damage. In this respect, the inducing experiments in HL-60 cells with topotecan ${ }^{\circledR}$ and the above mentioned duration were carried out following previous experiments that have been pursued in our lab (Kratzmeier et al., 2000; Kratzmeier et al., 1999).

\subsection{Monitoring the ongoing process of apoptosis: apoptosis markers for HeLa H2B- YFP cells}

Besides the promyelocytic cell line HL-60 we used HeLa cells, which had been stably transfected with a histone $\mathrm{H} 2 \mathrm{~B}$ gene and which were later used for fluorescence analyses of nuclear histone release. Therefore this cell line had to be previously tested for the induction of apoptosis, by means of dose-response curve. HeLa H2B-YFP cells were induced with the topoisomerase II inhibitor etoposide, as this cell line did not respond to topotecan ${ }^{\circledR}$ (data not shown). To work out a proper working concentration for the induction of apoptosis in HeLa H2B-YFP cells with this inducer, the cells were exposed to a series of dilutions over a defined period of time. Etoposide concentrations of $25 \mu \mathrm{M}, 50 \mu \mathrm{M}$ and $100 \mu \mathrm{M}$ were used and the cells were exposed to this chemical compound up to $48 \mathrm{~h}$. The long incubation times of HeLa cells with this inducer might be explained by different modes of action of etoposide compared with topotecan ${ }^{\circledR}$.

To evaluate the efficiency of apoptotic features in these cells, parameters such as cleavage of nucleosomal DNA, PARP cleavage and measuring the caspase 3 activity were analysed. HeLa H2B-YFP cells in contrast to HL-60 cells did only show apoptosis-related cleavage of high molecular weight DNA but did not produce cleavage of DNA into oligonucleosomes which usually results in the pattern of a nucleosomal DNA ladder (Fig. 3.2 1). Moreover, it was observed that with the following concentrations and incubation times: $100 \mu \mathrm{M}$ etoposide / $36 \mathrm{~h} ; 25 \mu \mathrm{M}, 50 \mu \mathrm{M}, 100 \mu \mathrm{M}$ / $48 \mathrm{~h}$, the DNA showed signs of degradation visible through the DNA smear on the agarose gel (Fig. 3.21 lanes 7-10). 
PARP cleavage was monitored almost right from the start, 24h after induction of apoptosis with $25 \mu \mathrm{M}$ etoposide and showed a gradual increase with time and increasing concentrations of the inducer (Fig. 3.2 2). All PARP protein was cleaved after 48h, with an etoposide concentration of $100 \mu \mathrm{M}$ (Fig. 3.22 lane 10).

Similar results were confirmed by measuring the caspase 3 activity. A strong increase in the caspase 3 activity was observed, the higher the concentration of the inducer etoposide and the longer the cells were exposed to it (Fig. 3.2 3).

Taking together all results obtained from the dose-response curves, it was decided to use inducer concentrations and incubation times, which on the one hand cause efficient reactions in HeLa H2B-YFP cells with reference to apoptotic features but on the other hand avoid excess damage of the cells, i.e. causing secondary necrosis.

For all further apoptosis-related experiments with HeLa H2B-YFP cells, an etoposide concentration of $50 \mu \mathrm{M}$ was used and the cells were incubated over a period of $48 \mathrm{~h}$.

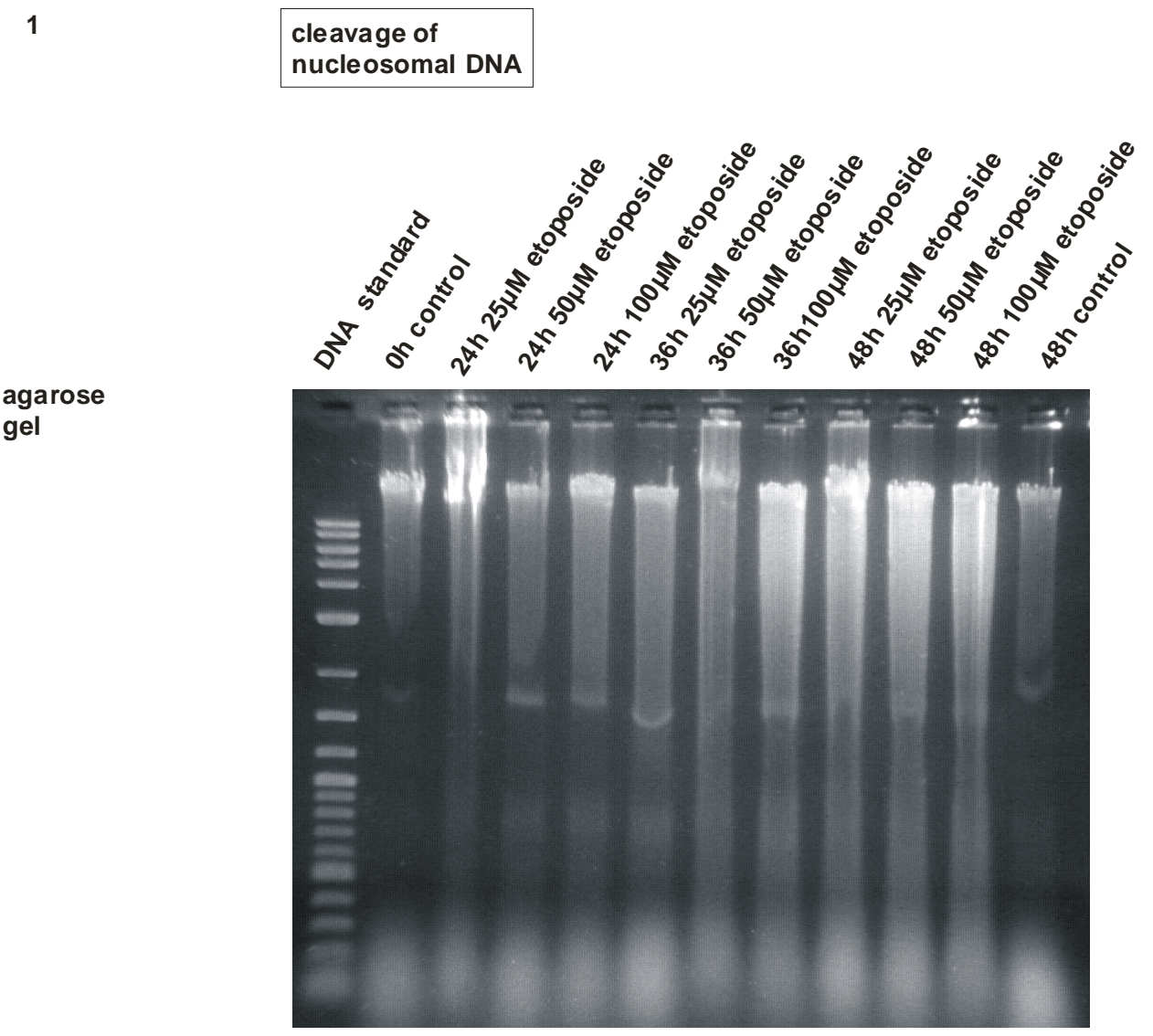

Fig. 3.2 Markers for monitoring the ongoing process of apoptosis in HeLa H2B-YFP cells: cleavage of nucleosomal DNA. HeLa H2B-YFP cells were induced with increasing concentrations of etoposide (25 $\mu \mathrm{M}-100 \mu \mathrm{M})$ and harvested after $24 \mathrm{~h}, 36 \mathrm{~h}$ and $48 \mathrm{~h}$. Cells harvested $24 \mathrm{~h}$ and $48 \mathrm{~h}$ after seeding served as control cells. Apoptotic nucleosomal DNA was prepared from all samples. (1) Separation of control cell DNA and apoptotic nucleosomal DNA on a 1.5\% agarose gel. Cleavage of high molecular weight DNA was observed from $24 \mathrm{~h}$ to $48 \mathrm{~h}$ after induction of apoptosis. 
Ponceau

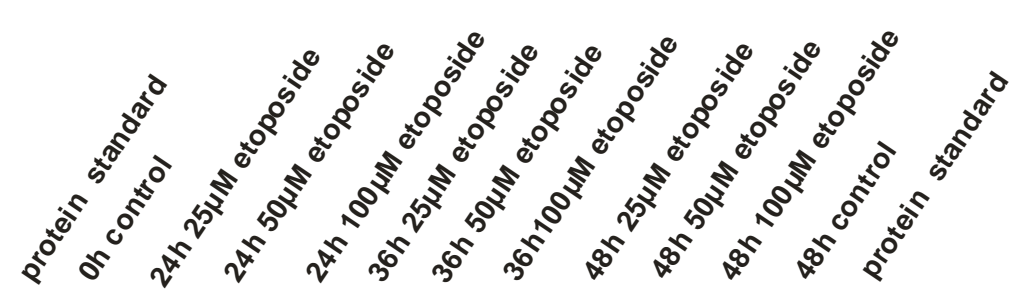

stain

alkaline phosphatase immuno-detection

$\begin{array}{lllllllllll}1 & 2 & 3 & 4 & 5 & 6 & 7 & 8 & 9 & 10 & 11\end{array}$

3

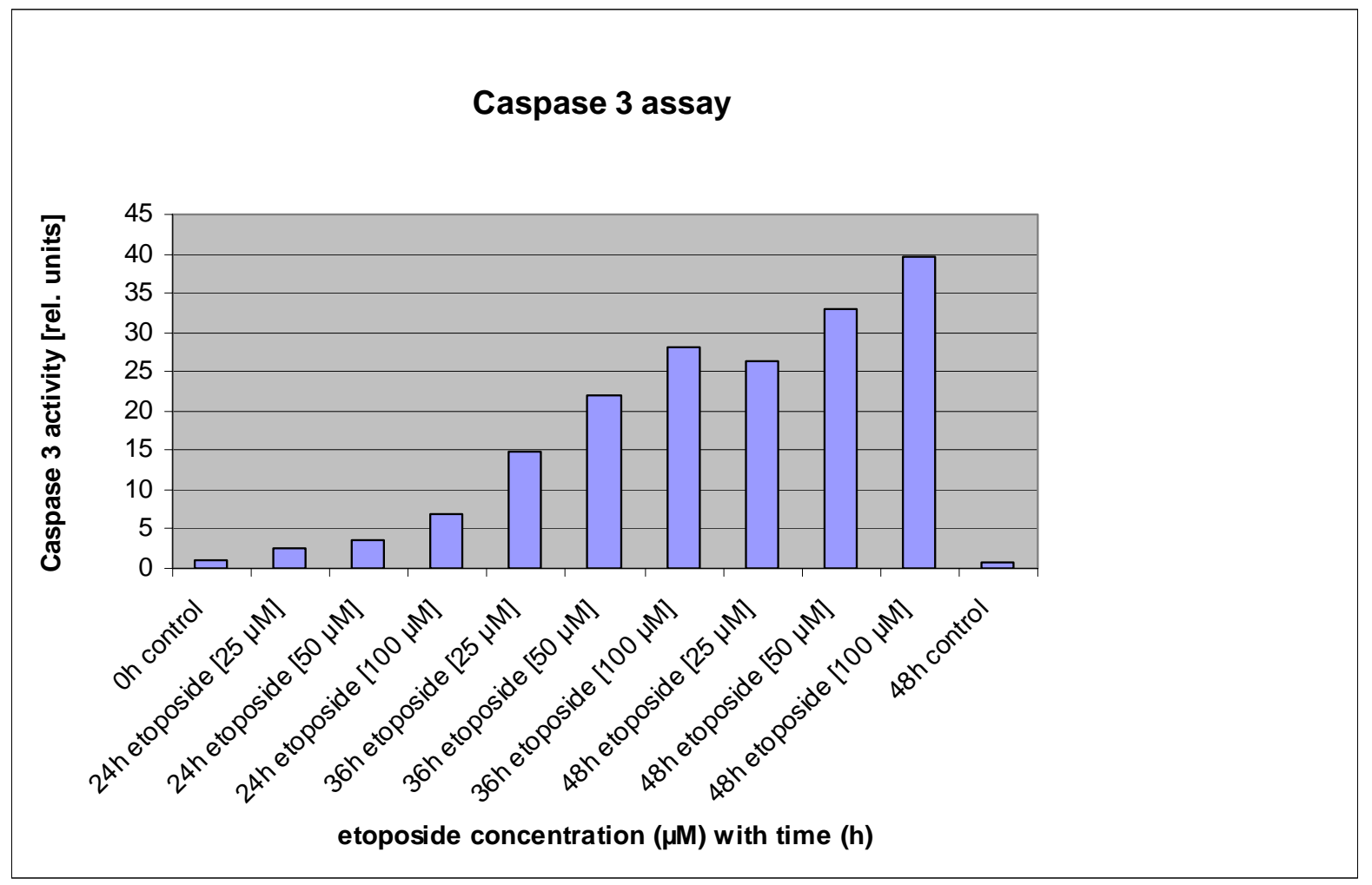

Fig. 3.2 (cont. 1) Markers for monitoring the ongoing process of apoptosis in HeLa H2B-YFP cells: PARP cleavage and caspase 3 assay. HeLa H2B-YFP cells were induced with increasing concentrations of etoposide $(25 \mu \mathrm{M}-100 \mu \mathrm{M})$ and harvested after $24 \mathrm{~h}, 36 \mathrm{~h}$ and $48 \mathrm{~h}$. Cells harvested $24 \mathrm{~h}$ and $48 \mathrm{~h}$ after seeding served as control cells. Apoptotic nucleosomal DNA was prepared from all samples and proteins for PARP cleavage analyses were isolated. Total protein lysates were subject to SDS-PAGE (15\%). Subsequently, Western blot analysis of PARP was carried out. Proteins for the caspase 3 assay were harvested at the same times and protein lysates were used for fluorometric measurement of caspase 3 activity (2). Cleavage of PARP protein started after $24 \mathrm{~h}$ with an etoposide concentration of $25 \mu \mathrm{M}$. PARP protein was cleaved $48 \mathrm{~h}$ after induction of apoptosis with an etoposide concentration 
of $100 \mu \mathrm{M}$. (3) Measurement of caspase 3 activity in HeLa H2B-YFP lysates. A gradual increase in the activity was observed from $24 \mathrm{~h}(25 \mu \mathrm{M}$ etoposide) after induction onwards over a period of $48 \mathrm{~h}$, with increasing etoposide concentrations.

\subsection{Analysis of putative short-term dependent changes in core histone modifications after induction of apoptosis}

\subsubsection{Western blot analysis}

Nucleosomal DNA fragmentation in association with chromatin condensation is one of the most important nuclear events occurring during apoptosis (Ajiro, 2000; Waring et al., 1997). Specific histone modifications have been proposed to affect chromatin structure and functions during both cell cycle events and apoptosis (Kratzmeier et al., 2000; Kratzmeier et al., 1999; Talasz et al., 2002; Widlak et al., 2005). Therefore we investigated possible changes of different histone modifications after induction of apoptosis.

As a first approach to get an overview of changes in core histone modifications during apoptosis on general terms, we ran short-term and long-term kinetics. For that purpose, apoptosis in HL-60 cells was induced using topotecan ${ }^{\circledR}(150 \mathrm{ng} / \mathrm{ml})$, a topoisomerase I inhibitor, which causes DNA double-strand breaks. For short-term kinetics, $3 \times 10^{7} \mathrm{HL}-60$ cells were harvested after $10 \mathrm{~min}, 20 \mathrm{~min}, 30 \mathrm{~min}, 1 \mathrm{~h}$ and $2 \mathrm{~h}$ of induction. Control cells were harvested immediately after seeding (corresponds to $0 \mathrm{~h}$ control). Core histones were extracted from whole cells. Core histones were separated with SDS-PAGE (15\%) and transferred to nitrocellulose membranes by Western blotting.

As to date publications point out the growing evidence that histone acetylation was mainly connected with transcriptional activation and gene expression, whereas histone methylation in general was mostly referred to transcriptional inactivation and gene silencing, our analyses of changes in histone modifications during apoptosis mainly focussed on histone $\mathrm{H} 3$ dimethylation of lysines 4, 9, 36 and on H3 trimethylation of lysines 4 and 9 in comparison with $\mathrm{H} 3$ acetylation at lysines 9, 18 and 23. Moreover, our experiments were extended to analysing the histone $\mathrm{H} 2 \mathrm{~A}$ variant $\mathrm{H} 2 \mathrm{AX}$ phosphorylated at serine 139 as well as ubiquitylated $\mathrm{H} 2 \mathrm{~A}$.

Within a short time after induction of apoptosis ( 0 h-2 h), neither changes in histone methylation at lysines 4, 9, 39, nor changes in histone acetylation at lysines 9, 18 and 23 were detected (Fig. 3.3.1 1-8). Neither did we perceive any changes in the ubiquitylation pattern of $\mathrm{H} 2 \mathrm{~A}$ during that time. The only exception to these findings was the quickly increasing state of serine 139 phosphorylation of the histone $\mathrm{H} 2 \mathrm{~A}$ variant $\mathrm{H} 2 \mathrm{AX}$, which was observed as early as 10 min after topotecan ${ }^{\circledR}$ treatment and which was still increasing up to the latest point of incubation (Fig. 3.3.1 9). 


\section{short-term kinetics}

1

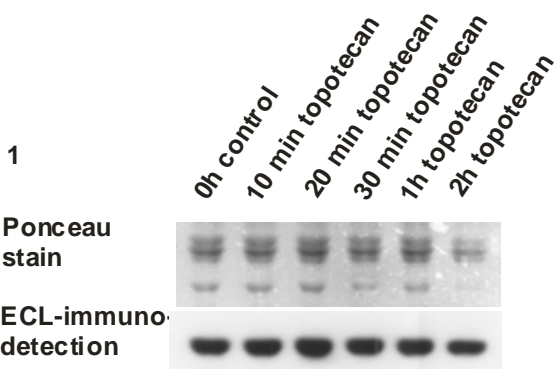

H3-dim ethyl K4

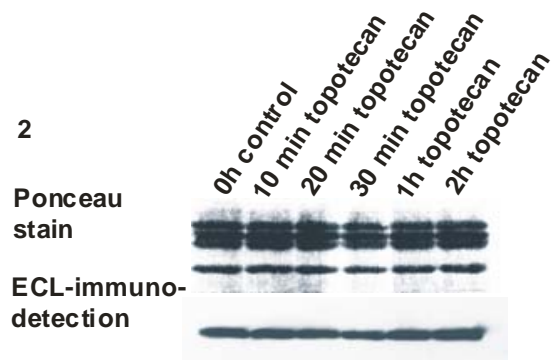

H3-dimethyl K9

3

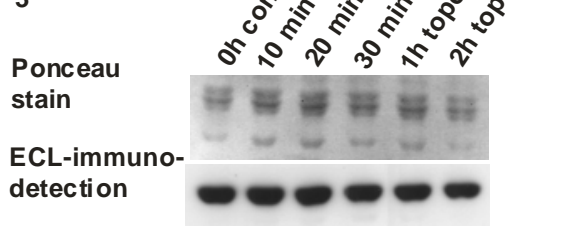

H3-dimethyl K36

4

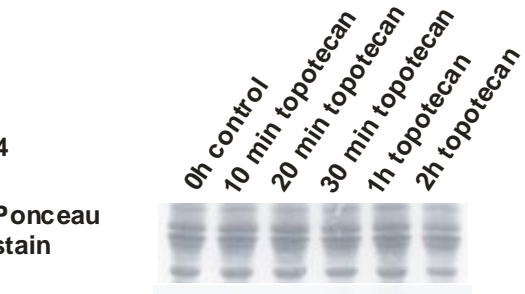

ECL-immunodetection

H3-trimethyl K4

5

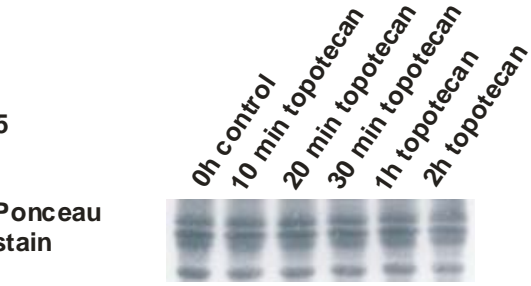

ECL-immunodetection

H3-trimethyl K9
Ponceau

stain

ECL-immunodetection

7

Ponceau

stain

ECL-immunodetection

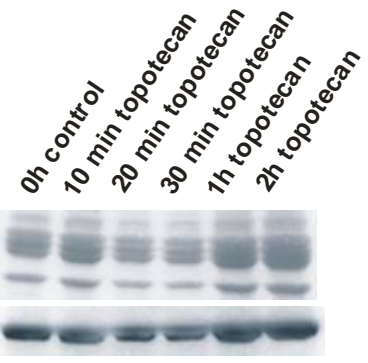

H3-acetyl K9

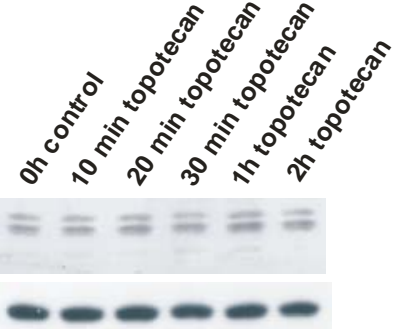

H3-acetyl K18

8

Ponceau

stain

ECL-immunodetection

\section{H3-acetyl K23}

9

Ponceau

stain

ECL-immunodetection

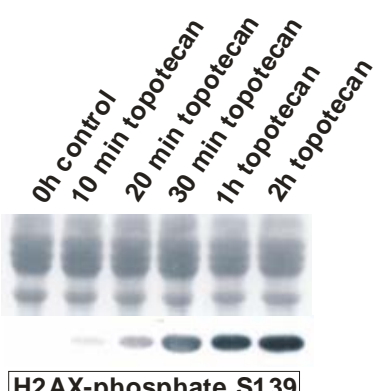

10

Ponceau stain

ECL-immunodetection

H2A-ubiquityl 
Fig. 3.3.1 Short-term kinetics for analyses of changes in histone modifications in HL-60 cells after induction of apoptosis with topotecan ${ }^{\circledR}$. HL-60 cells were treated with topotecan ${ }^{\circledR}$ to induce apoptosis. Cells were harvested at different times and histones were isolated (described in chapter 2.2.2.2). Core histones were separated with SDS-PAGE (15\%) and transferred to nitrocellulose membranes by Western blotting. All membranes were incubated with antibodies raised against the respective histone modifications. (1) Anti-H3-dimethyl K4. (2) Anti-H3-dimethyl K9. (3) Anti-H3-dimethyl K36. (4) Anti-H3trimethyl K4. (5) Anti-H3-trimethyl K9. (6) Anti-H3-acetyl K9. (7) Anti-H3 acetyl K18. (8) Anti-H3-acetyl K23. A sample treated with the HDAC inhibitor trichostatin A (400 ng/ml) for $16 \mathrm{~h}$ was used as a positive control to check for positive H3 acetylation. (9) Anti-H2AX-phospate S139. (10) Anti-H2Aubiquitylation. Except for H2AX phosphorylation at serine 139 as early as 10 min after induction of apoptosis, no changes in the methylation pattern or the acetylation pattern were observed.

\subsubsection{Apoptosis markers for short-term kinetics}

To ensure that the induction of apoptosis was successful and the HL-60 control cells were showing a defined grade of viability, apoptosis markers were run in parallel with the above described experiments. For this purpose the cells were checked for all three parameters, nucleosomal DNA cleavage, PARP cleavage and caspase 3 activity.

For a short period of time such as $2 \mathrm{~h}$, no changes could be observed in terms of cleavage of nucleosomal DNA (Fig. 3.3.2 1) or PARP (Fig. 3.3.2 2).
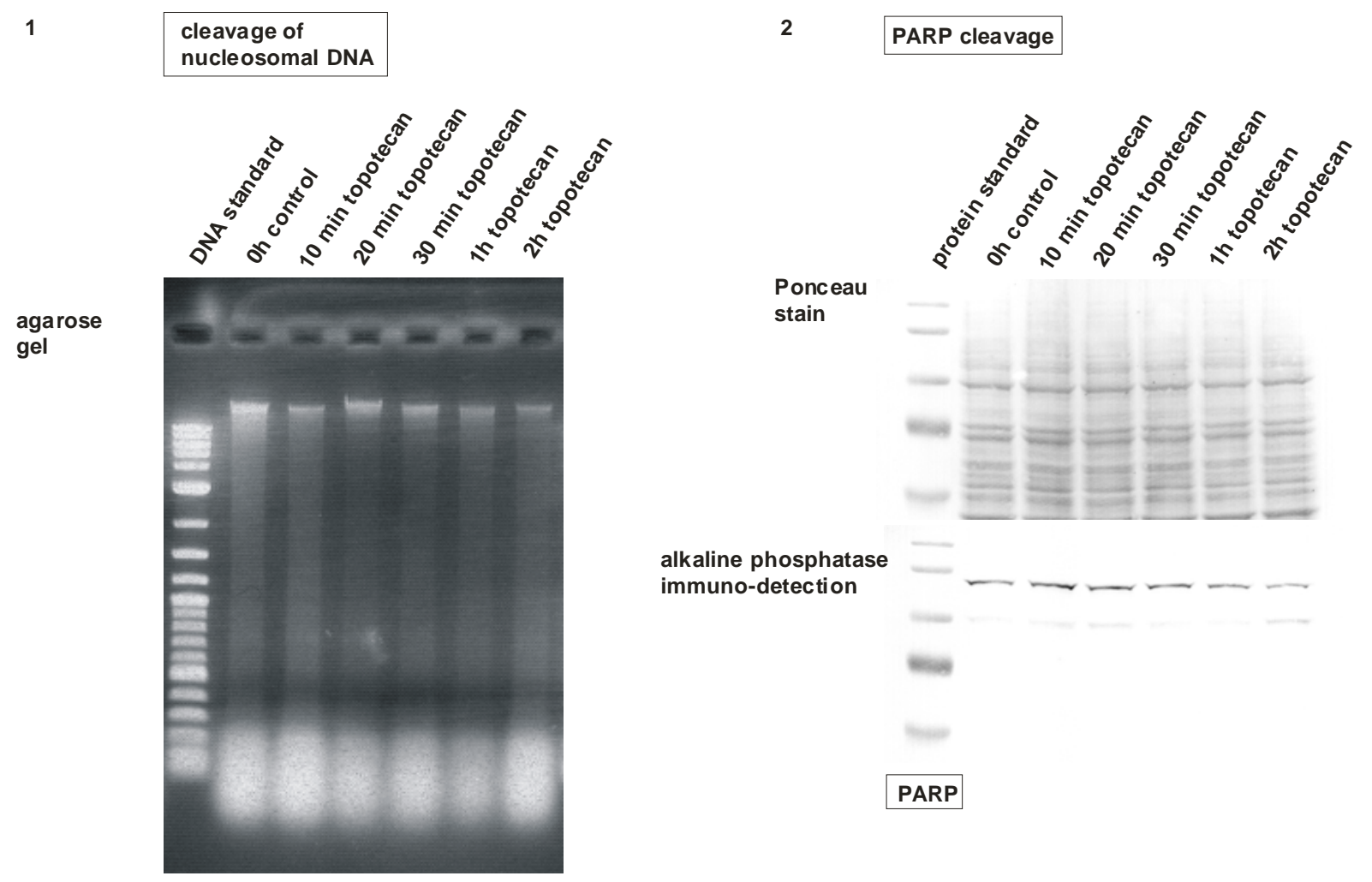

Fig. 3.3.2 Monitoring the ongoing process of apoptosis during short-term kinetics: cleavage of nucleosomal DNA. HL-60 cells were induced with topotecan ${ }^{\circledR}$ and harvested after $10 \mathrm{~min}, 20 \mathrm{~min} 30$ min, $1 \mathrm{~h}$ and $2 \mathrm{~h}$. Cells shortly harvested after seeding served as control cells. Apoptotic nucleosomal DNA was prepared from all samples. (1) Separation of control cell DNA and apoptotic nucleosomal DNA on a $1.5 \%$ agarose gel. Cleavage of high molecular weight nucleosomal DNA could not be observed within $2 \mathrm{~h}$ after induction. 
3

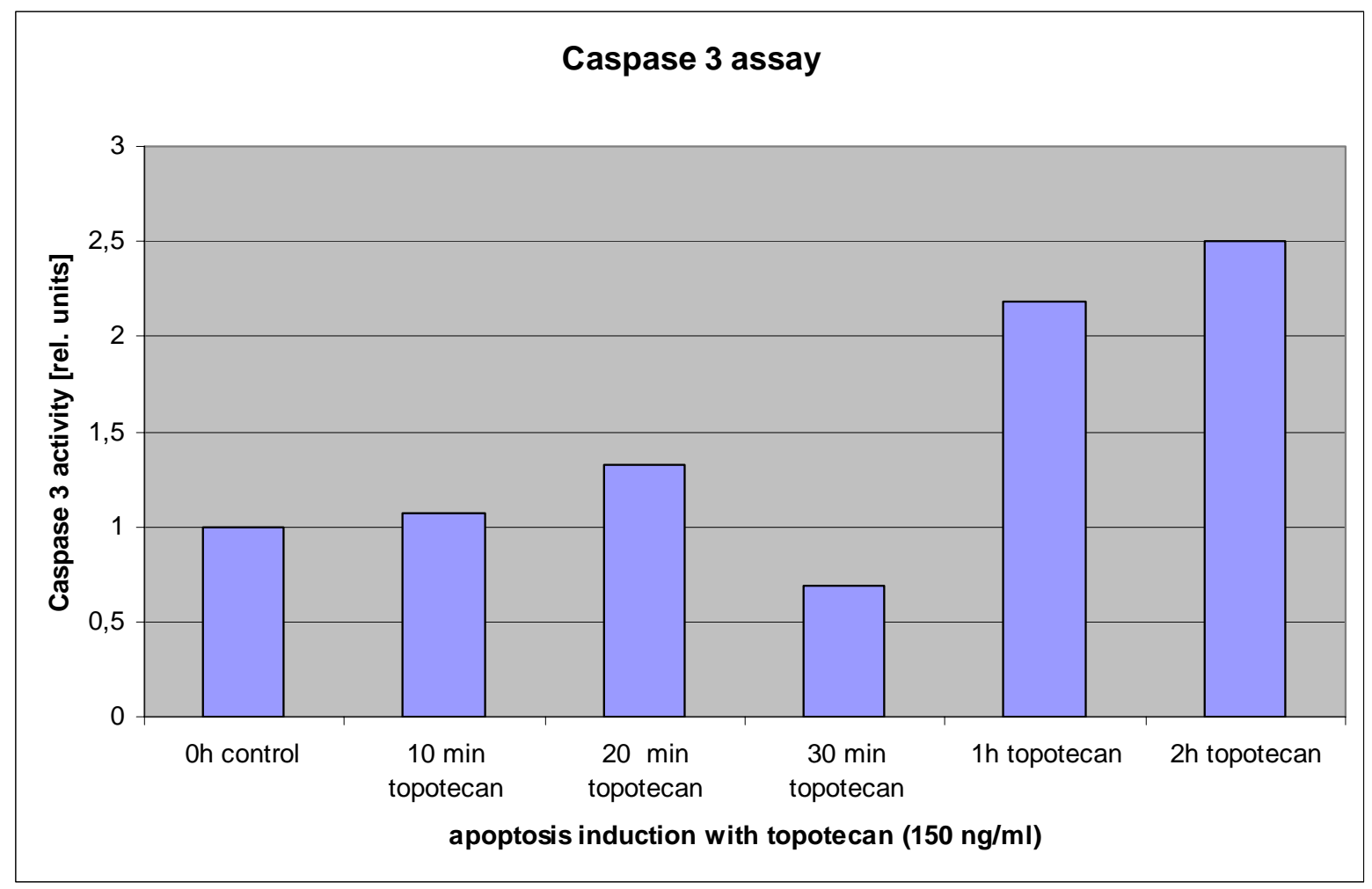

Fig. 3.3.2 (cont. 1) Monitoring the ongoing process of apoptosis during short-term kinetics: PARP cleavage and caspase 3 assay. HL-60 cells were induced with topotecan ${ }^{\circledR}$ and harvested after 10 min, $20 \mathrm{~min} 30 \mathrm{~min}, 1 \mathrm{~h}$ and $2 \mathrm{~h}$. Cells shortly harvested after seeding served as control cells. Apoptotic nucleosomal DNA was prepared from all samples and separated on 1.5\% agarose gels. Proteins for PARP cleavage analyses were isolated. Total protein lysates were subjected to SDS-PAGE (15\%). Subsequently, Western blot analysis of PARP was carried out. Proteins for the caspase 3 assay were harvested at the same times and protein lysates were used for fluorometric measurement of caspase 3 activity. (2). PARP cleavage assay. No cleavage of PARP proteins was perceived within 2h. (3) Measurement of caspase 3 activity in HL-60 lysates. Apart from slight basic differences in the caspase 3 activity, a remarkable increase of caspase 3 activity was observed 30 min-1 h post-induction.

The caspase 3 activity showed just slight basic changes within the first hour. A remarkable increase in the activity was measured $30 \mathrm{~min}-1 \mathrm{~h}$ after induction of apoptosis.

With reference to the apoptosis markers, it does not seem to be surprising that except for $\mathrm{H} 2 \mathrm{AX}$ phosphorylation at serine 139 , which is a general marker for DNA double strand breaks (Rogakou et al., 1999; Rogakou et al., 2000b), no changes in the methylation or acetylation pattern of histone $\mathrm{H} 3$ could be observed. The duration time we chose was seemingly too short for any overall changes. 


\subsection{Analysis of putative long-term dependent changes in core histone modifications after induction of apoptosis}

\subsubsection{Western blot analysis}

Compared to the analyses of short-term kinetics with relation to changes in histone modifications, our attempts to possibly detect any changes after longer periods of time were more successful. The same types of histone modification that were tested during short-term kinetics, were also tested in long-term kinetics. No parameters were changed in this experiment apart from the duration of incubation times from originally $2 \mathrm{~h}$ to $12 \mathrm{~h}$. Only one exception had to be made concerning the analysis of H2A ubiquitylation. Here we had to extent the duration of incubation to $24 \mathrm{~h}$, as changes were still perceived before that time.

In correlation with the results from the short-term kinetics, neither the methylation pattern of histone $\mathrm{H} 3$ at lysines 4, 9 and 36 nor the acetylation pattern of histone $\mathrm{H} 3$ at lysines 8, 18 and 23 changed within $12 \mathrm{~h}$ of induction (Fig. 3.4.1 1-8). However, besides the already mentioned increase in $\mathrm{H} 2 \mathrm{AX}$ serine 139 phosphorylation, which did even more increase throughout $12 \mathrm{~h}$ of incubation (Fig. 3.4.1 9), we perceived a remarkable decrease in the histone H2A ubiquitylation $6 \mathrm{~h}$ after induction of apoptosis. The H2A ubiquitin signal vanished completely $24 \mathrm{~h}$ after incubation (Fig. 3.4.1 10 lane 6). At this point it turned out that the first incubation times we chose for the short-term kinectics were just too short for some histone modifications like H2A ubiquitylation in this case. 


\section{long-term kinetics}

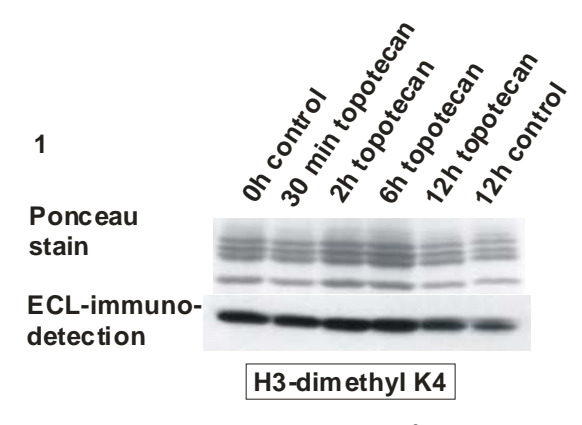

2

Ponceau

stain

ECL-immunodetection

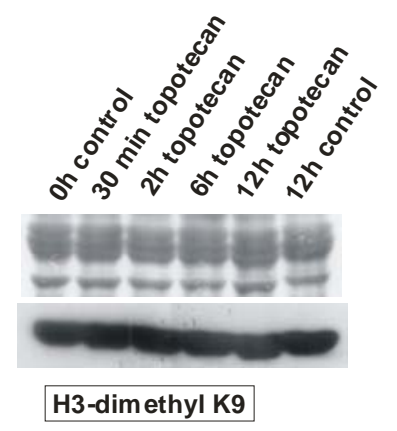

3

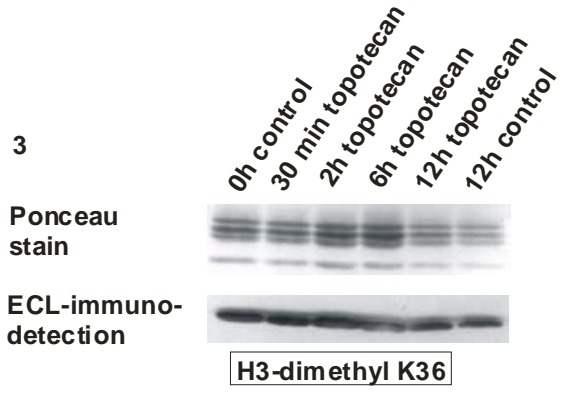

4

Ponceau

stain

ECL-immunodetection

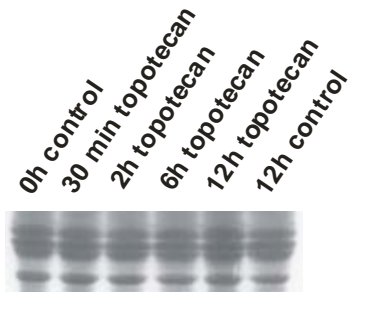

H3-trimethyl K4

5

Ponceau

stain

ECL-immunodetection

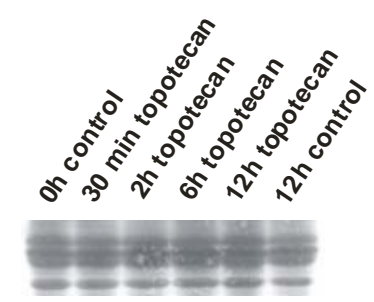

H3-trimethyl K9
6

Ponceau

stain

ECL-immunodetection

7

Ponceau

stain

ECL-immunodetection

8

Ponceau

stain

ECL-immunodetection

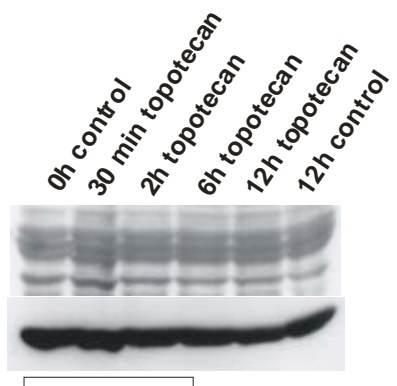

H3-acetyl K9
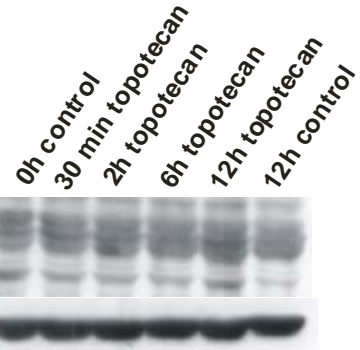

H3-acetyl K18
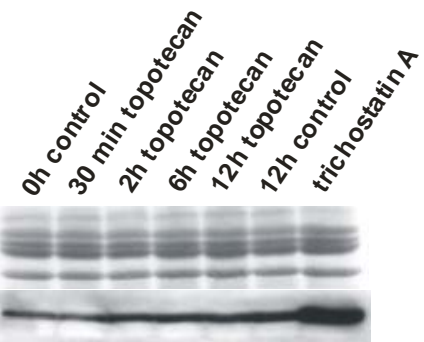

H3-acetyl K23

9

Ponceau stain

ECL-immunodetection

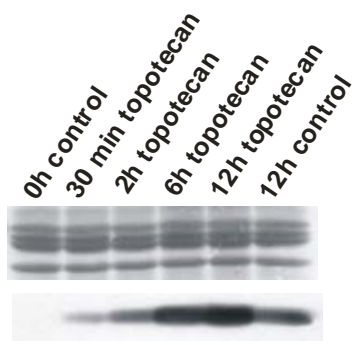

H2AX-phosphate S139

10

Ponceau

stain

ECL-immunodetection

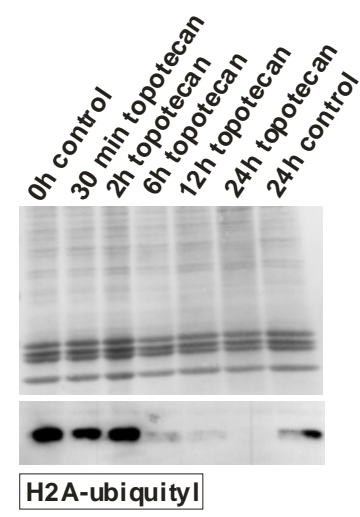




\subsubsection{Apoptosis markers for long-term kinetics}

Apoptosis markers were run in parallel with the above described experiments, to ensure that the induction of apoptosis was successful and the HL-60 control cells were showing a defined grade of viability at the beginning of the experiments. For this purpose the cells were checked for all three parameters, nucleosomal DNA cleavage, PARP cleavage and caspase 3 activity.

Compared to short-term kinetics, all markers of apoptosis changed remarkably during longterm kinetics. After HL-60 cells were incubated with topotecan ${ }^{\circledR}$ over a period of $12 \mathrm{~h}$, the cells were harvested $30 \mathrm{~min}, 2 \mathrm{~h}, 6 \mathrm{~h}$ and $12 \mathrm{~h}$ after induction of apoptosis. Cells shortly harvested after seeding and after $12 \mathrm{~h}$ of incubation served as control cells. Nucleosomal DNA and PARP cleavage, as well as caspase 3 activity were measured.

Cleavage of nucleosomal DNA was detected $2 \mathrm{~h}$ after treatment of the cells with topotecan ${ }^{\circledR}$ and was increasing up to $12 \mathrm{~h}$ hours of apoptosis induction. Control cells did not show any cleavage of nucleosomal DNA (Fig. 3.4.2 1).

The cleavage of PARP proteins started around $30 \mathrm{~min}$ to $2 \mathrm{~h}$. After $6 \mathrm{~h}$ all PARP protein appeared to be cleaved. Here, too, almost no cleaved proteins could be traced in the controls (Fig. 3.4.2 2).

The caspase 3 activity started to increase around $2 \mathrm{~h}$ after induction of apoptosis and went on over the whole period of $12 \mathrm{~h}$, whereas both $0 \mathrm{~h}$ and $12 \mathrm{~h}$ controls only showed a basic level of caspase 3 activity (Fig. 3.4.2 3 lanes 1 and 6).

All DNA, PARP and caspase 3 controls confirmed the viability of the cells at the beginning of the experiment. Moreover, these results emphasise the fact that induction of apoptosis was definitely successful. All in all, compared with the Western blot results from our long-term kinetics, it appears that incubation times from $2 \mathrm{~h}$ up to $12 \mathrm{~h}$ and even further, with reference to ubiquitylation of $\mathrm{H} 2 \mathrm{~A}$, seem to be a period of time when most apoptosis-related changes in the cell are going on.

Fig. 3.4.1 Long-term kinetics for changes in histone modifications in HL-60 cells after induction of apoptosis with topotecan ${ }^{\circledR}$. HL-60 cells were treated with topotecan ${ }^{\circledR}$ to induce apoptosis. Cells were harvested at different times and histones were isolated (described in chapter 2.2.2.2). Core histones were separated with SDS-PAGE (15\%) and transferred to nitrocellulose membranes by Western blotting. All membranes were incubated with antibodies raised against the respective histone modifications. (1) Anti-H3-dimethyl K4. (2) Anti-H3-dimethyl K9. (3) Anti-H3-dimethyl K36. (4) Anti-H3trimethyl K4. (5) Anti-H3-trimethyl K9. (6) Anti-H3-acetyl K9. (7) Anti-H3 acetyl K18. (8) Anti-H3-acetyl K23. A sample treated with the HDAC inhibitor trichostatin $A(400 \mathrm{ng} / \mathrm{ml})$ for $16 \mathrm{~h}$ was used as a positive control to check for positive H3 acetylation. (9) Anti-H2AX-phosphate S139. (10) Anti-H2Aubiquitylation. The signal intensity for $\mathrm{H} 2 \mathrm{AX}$ phosphorylation at serine 139 strongly increased from 30 min onwards until $12 \mathrm{~h}$ after induction, whereas histone H2A showed to be heavily de-ubiquitylated $6 \mathrm{~h}$ after induction of apoptosis. After $24 \mathrm{~h}$ no more ubiquitylated histone H2A was detected. 
1

cleavage of

nucleosomal DNA
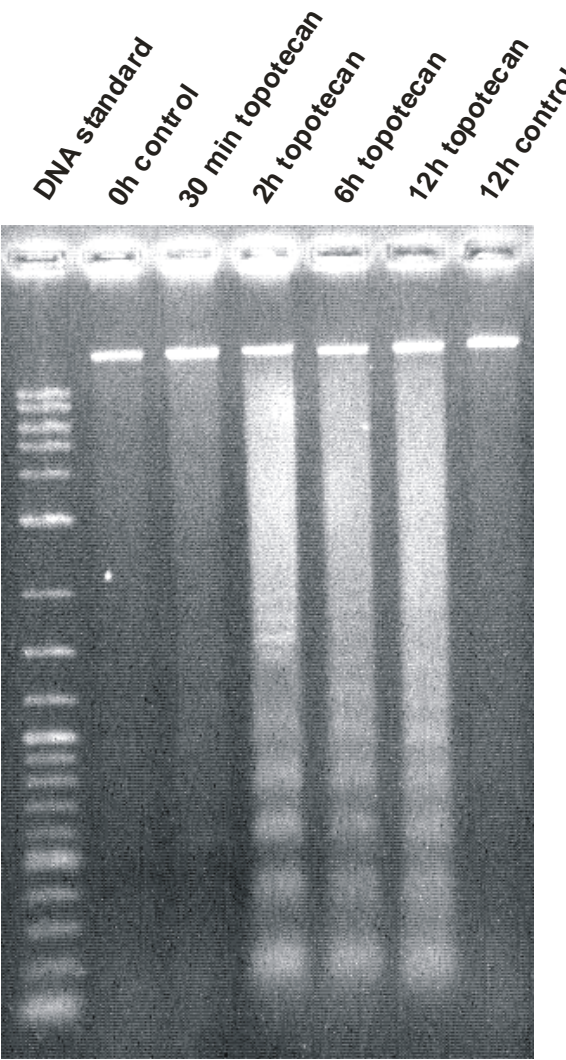

2

PARP cleavage

Ponceau

stain

alkaline phosphatase immuno-detection

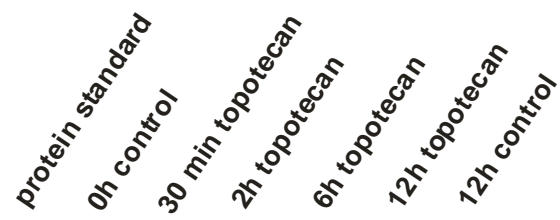$$
\text { stain }
$$

3

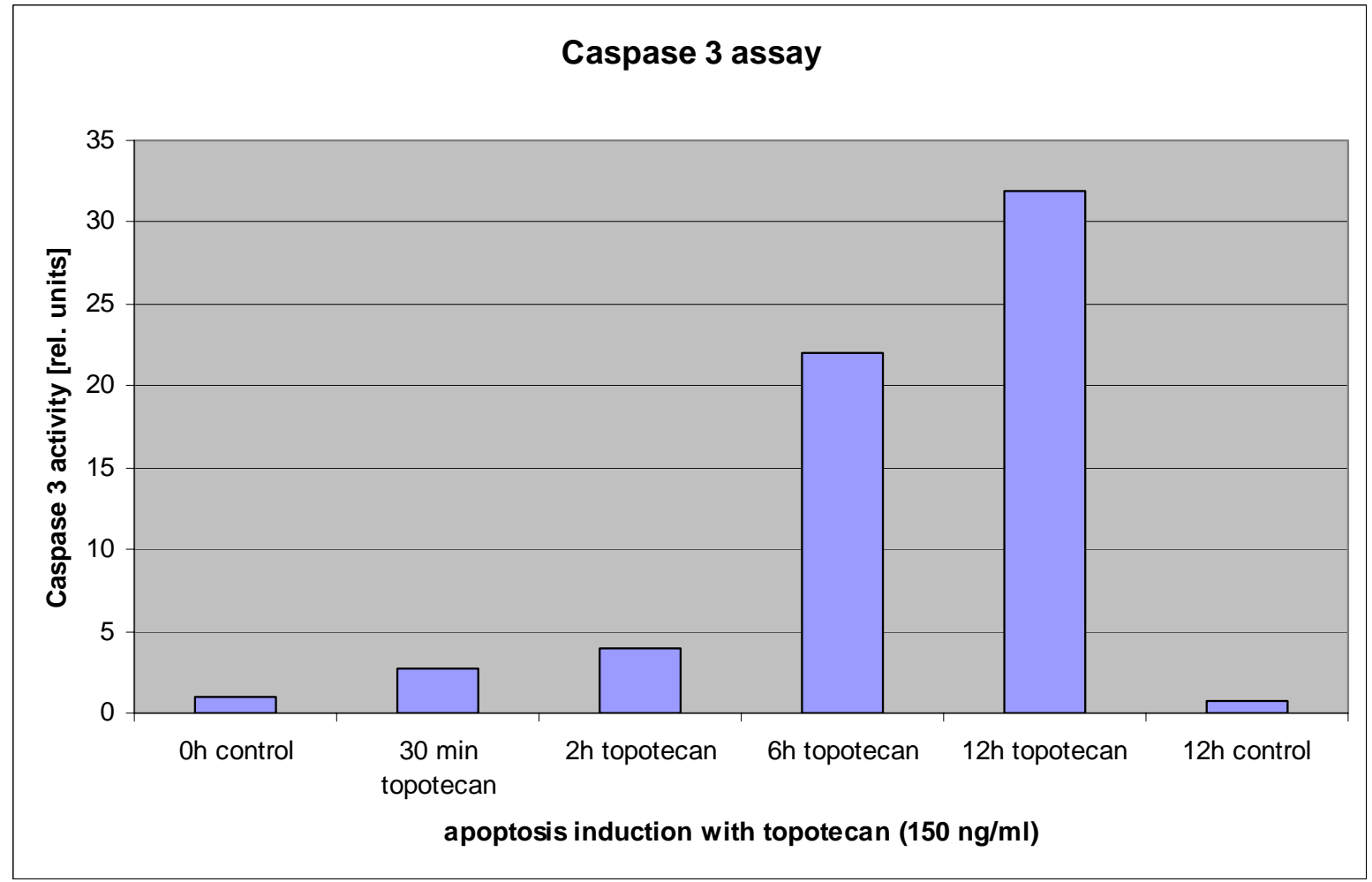




\subsection{Purification and separation of core histones from HL-60 control and apoptotic cells}

In the folowing part of this project our work mainly focussed on the purification and separation of core histones from HL-60 control and apoptotic cells, with subsequent and more specified analyses of putative changes in histone modifications connected with apoptosis. For a general overview, histones were further separated with AUT-2D gel electrophoresis. For a more detailed analysis, core histones were loaded onto the capillary zone electrophoresis system.

\subsubsection{P60 Bio-gel ${ }^{\circledR}$ size exclusion chromatography (P60 column)}

For the purification and a first crude separation of histones, these were extracted from HL-60 nuclei as described (chapter 2.2.7.1) and loaded onto a P60 Bio-gel ${ }^{\circledR}$ column. Core histones were fractionated with a column flow of $0.2-0.3 \mathrm{ml} / \mathrm{min}$. Sixty fractions were collected altogether and $20 \mu \mathrm{l}$ aliquots from each fraction were analysed with SDS-PAGE. All fractions collected were subsequently pooled into three major fractions, containing mainly histones $\mathrm{H} 1$ and H3 (Fig. 3.5.1 1; arrows), histones H2B and H2A (3.5.1 2; black arrow) and histone H4 (Fig. 3.5.1 3; arrow). As preliminary HPLC runs with crude core histone fractions either caused a total block up of the HPLC column or resulted in poor separations of single fractions, a different approach had to be taken. Size-fractionation of core histone extracts proved to be a pre-requisite for further separation by high performance liquid chromatography. The idea was to obtain four pure fractions, each containing only one single histone type.

Fig. 3.4.2 Monitoring the ongoing process of apoptosis during long-term kinetics: cleavage of nucleosomal DNA and PARP and caspase 3 assay. HL-60 cells were induced with topotecan ${ }^{\circledR}$ and harvested after $30 \mathrm{~min}, 2 \mathrm{~h}, 6 \mathrm{~h}$ and $12 \mathrm{~h}$. Cells which were harvested shortly after seeding and after $12 \mathrm{~h}$ incubation time served as control cells. Apoptotic nucleosomal DNA was prepared from all samples and separated on 1.5\% agarose gels. Proteins for PARP cleavage analyses were isolated and separated by SDS-PAGE (15\%). Subsequently, Western blot analysis of PARP was carried out. Proteins for the caspase 3 assay were harvested at the same times and protein lysates were used for fluorometric measurement of caspase 3 activity. (1) Separation of control cell DNA and apoptotic nucleosomal DNA on a 1.5\% agarose gel. Cleavage of nucleosomal DNA started as early as $2 \mathrm{~h}$ after induction of apoptosis. Control cell DNA did not show any cleavage of DNA. (2) The cleavage of PARP proteins started between $30 \mathrm{~min}$ and $2 \mathrm{~h}$ after induction of apoptosis. After $6 \mathrm{~h}$ full length PARP was not detectable any longer. Only little PARP cleavage was observed in control samples. (3) Measurement of caspase 3 activity in HL-60 lysates. From 2 h onward to $12 \mathrm{~h}$ the caspase 3 activity showed a gradual remarkable increase. 
P60 Biogel column

no. of fraction

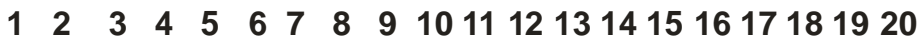

1

H3/H1

fractions: $13-25$

$\mathrm{H1} \rightarrow$

$\mathrm{H3} \longrightarrow$

2

H2B/H2A

fractions: $26-42$

2122232425262728293031323334353637383940

$\mathrm{H} 2 \mathrm{~B} / \mathrm{H} 2 \mathrm{~A} \rightarrow$

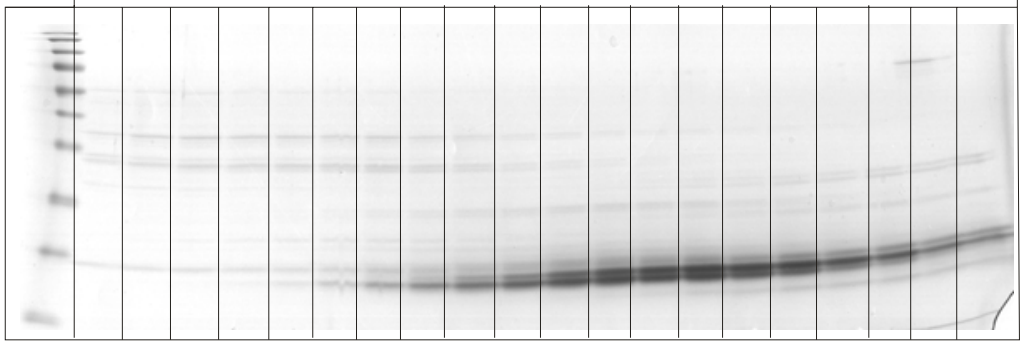

3

H4

fractions: $43-60$

H4

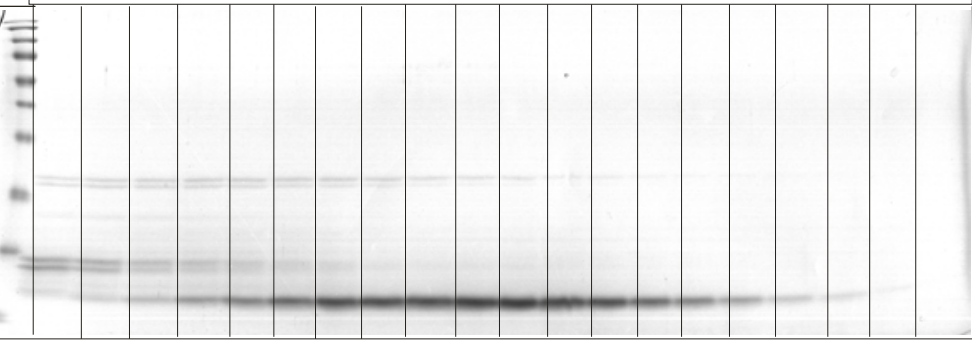

Fig. 3.5.1 Purification and separation of core histones from HL-60 control and apoptotic cells via P60 Biogel® size exclusion chromatography. Nuclei and core histones from control cells and topotecan treated cells were prepared. The histone protein extract was loaded onto a P60 Biogel ${ }^{\circledR}$ column and fractionated with a column flow of 0.2-0.3 $\mu \mathrm{l} / \mathrm{min}$. Size-fractionation of core histones (black arrows) resulted in three different crude fractions containing mainly (1) H1/H3 histones, (2) H2A/H2B histones and (3) $\mathrm{H} 4$ histones. There were no differences in separation and purification of control core histones compared to apoptotic core histones. 


\subsubsection{High performance liquid chromatography (HPLC)}

We used HPLC to further purify and separate all three core histone fractions, which were size-fractionated by P60 Biogel $^{\circledR}$ size exclusion chromatography and which were to be analysed via capillary zone electrophoresis. HPLC runs were carried out to single out and collect each histone type separately, which later on served as basis for identification and assignment of the different core histone types to the peaks received from CZE. This would not have been possible if just crude protein fractions had been used.

All three core histone fractions from HL-60 control cells, which were obtained from P60 size exclusion chromatography, were injected into the HPLC system and run for $2 \mathrm{~h}$ on a Jupiter C4 column with an inner diameter of $150 \times 4.6 \mathrm{~mm}$ and with a matrix of $5 \mu \mathrm{m}$ particle size and $300 \AA$ pore size. To get an overview of the specific separation pattern, as well as a time frame, in which the different histone species were eluted, most peak fractions were collected during the first few HPLC runs (Figs. 3.5.2 1 and 3.5.2 2) and analysed by SDS-PAGE and Western blotting (Fig. 3.5.2 3) for further specification. Histones $\mathrm{H} 1$ and $\mathrm{H} 3$ taken from the first fraction of the P60 column were eluted from the Jupiter column after 60 min (Fig. 3.5.2 1). Among the core histones and with reference to time, $\mathrm{H} 2 \mathrm{~B}$ and $\mathrm{H} 2 \mathrm{~A}$ were the first ones eluted from the column. Histone H2B was already collected after $32 \mathrm{~min}$, shortly followed by two histone $\mathrm{H} 2 \mathrm{~A}$ fractions after $36 \mathrm{~min}$ and $39 \mathrm{~min}$ (Fig. 3.5.2 2). As the P60 fractions with $\mathrm{H} 2 \mathrm{~B}$ and $\mathrm{H} 2 \mathrm{~A}$ histones still contained very low concentrations of $\mathrm{H} 3$, too, this histone type was additionally separated from this fraction. The retention times were the same already mentioned. The elution of histone $\mathrm{H} 4$ shortly followed the first $\mathrm{H} 2 \mathrm{~A}$ fraction, which was after 36.2 min. To further elucidate why histone $\mathrm{H} 2 \mathrm{~A}$ was eluted in two separate fractions, we ran Western blots and incubated the membrane with anti-H2AX-phosphate S139 antibody, as this was one of two histone modifications that changed remarkably during apoptosis (chap. 3.3.1 and 3.4.1). One suggestion for the different $\mathrm{H} 2 \mathrm{~A}$ elution profiles was a possible difference in their histone modifications, especially with a change in phosphorylation. For analytical purposes, samples which were isolated from cells treated with topotecan, were used as controls (Fig. 3.5.2.3 lanes 10/11 show control cells and lanes T10**/T11** show topotecan $^{\circledR}$ treated cells). Incubation of the membrane with anti-H2A antibody revealed specific signals for all four protein fractions, according to their protein contents: 10/11 and $\mathrm{T} 10^{* \star} / \mathrm{T} 11^{\star *}$ (Fig. 3.5.2.3 2). In contrast, incubation of the same membrane with anti-H2AXphosphate S139 antibody resulted in only one strong signal in one of the two H2A fractions, namely $\mathrm{H} 2 \mathrm{~A}(2)$ although both were treated with topotecan ${ }^{\circledR}$ and should otherwise have shown positive antibody staining (Fig. 3.5.2.3 2 lower panel). In other words, with the column used, it was possible to separate the specifically modified H2A subtype H2AX-phosphate S139 via HPLC. 


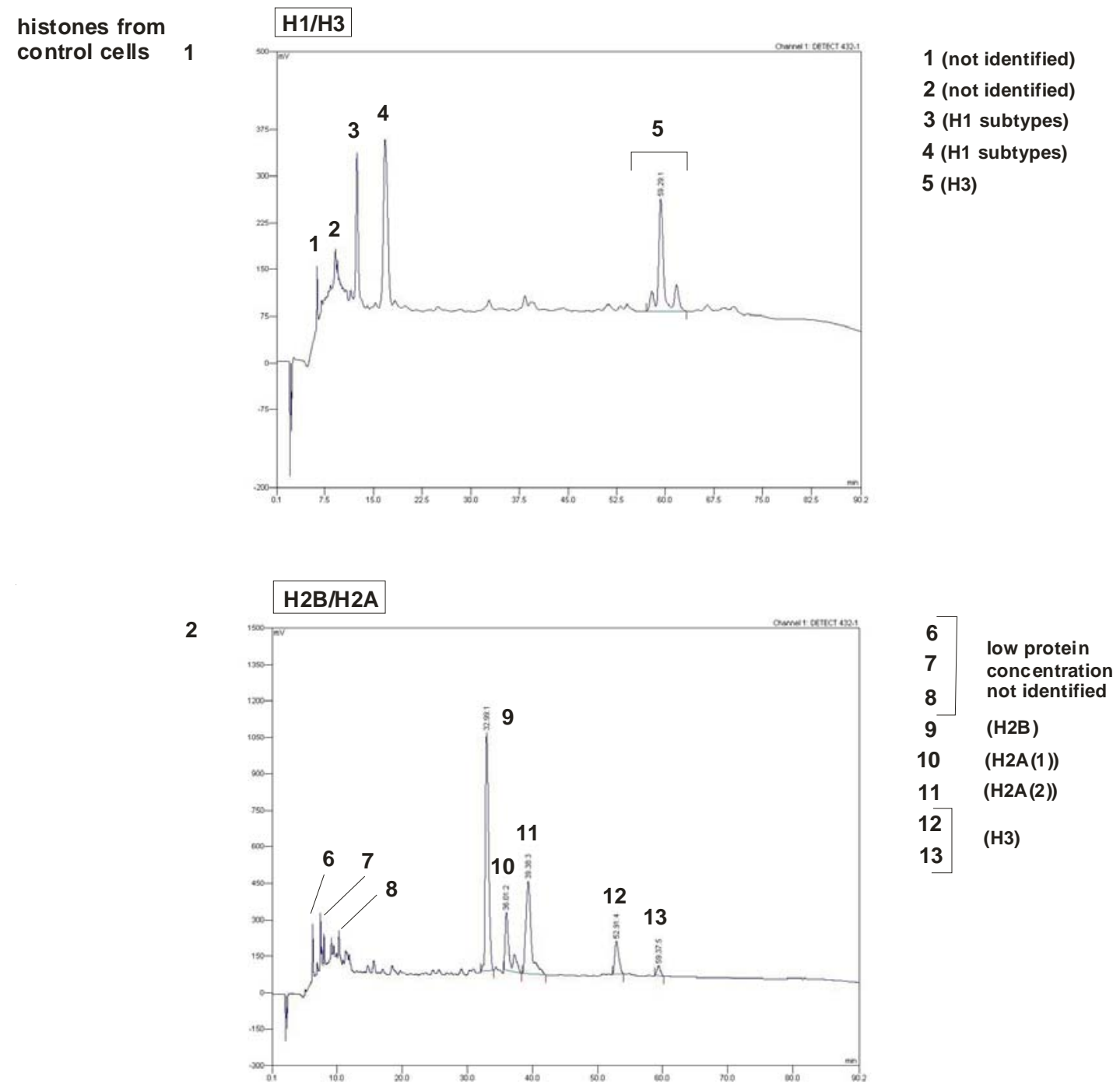

H4

3

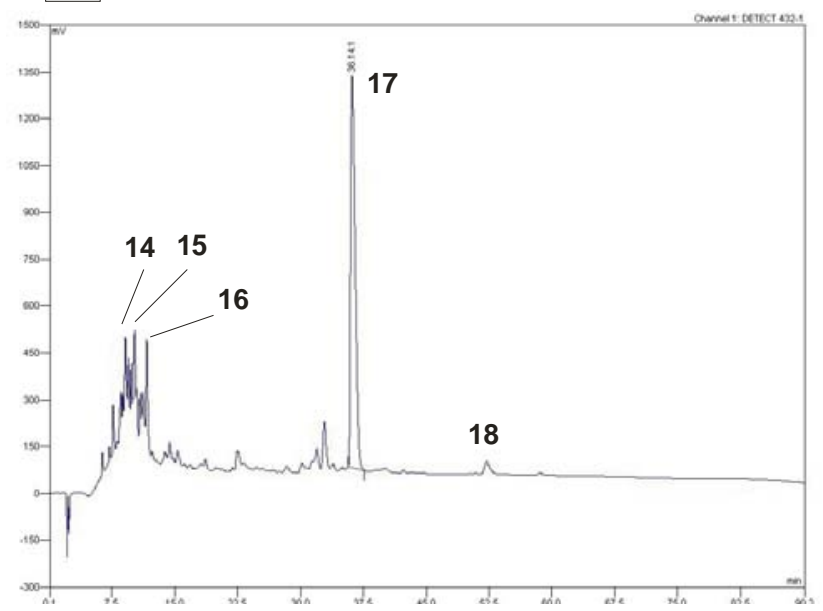

14 low protein

concentration

not identified

17 (H4)

18 low protein

concentration

not identified

Fig. 3.5.2.1 HPLC retention times of all four core histones from HL-60 control cells. Histones which were pre-purified by P60 Bio-gel ${ }^{\circledR}$ size exclusion chromatography were subsequently further separated and purified via HPLC. Elution profiles of the histones $\mathrm{H} 1 / \mathrm{H} 3$ fraction (1), the histones $\mathrm{H} 2 \mathrm{~B} / \mathrm{H} 2 \mathrm{~A}$ fraction (2) and of the histone $\mathrm{H} 4$ fraction (3). 

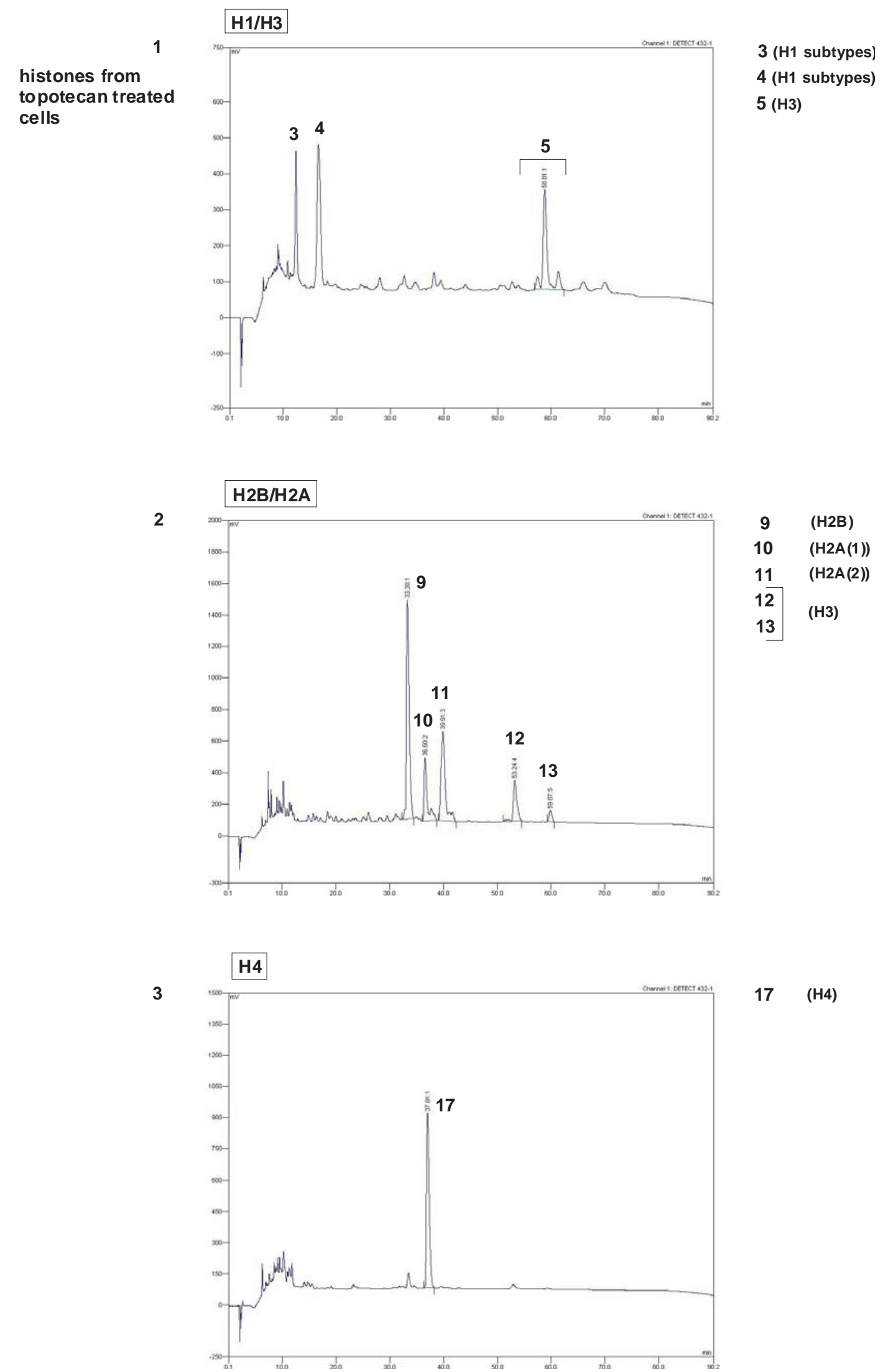

$17 \quad(\mathrm{H} 4)$

Fig. 3.5.2.2 HPLC retention times of all four core histones from topotecan ${ }^{\circledR}$ treated HL-60 cells. Histones which were pre-purified by P60 Bio-gel ${ }^{\circledR}$ size exclusion chromatography were subsequently further separated and purified via HPLC. Elution profiles of the histones H1/H3 fraction (1), the histones $\mathrm{H} 2 \mathrm{~B} / \mathrm{H} 2 \mathrm{~A}$ fraction (2) and of the histone $\mathrm{H} 4$ fraction (3). 
1

SDS-gel

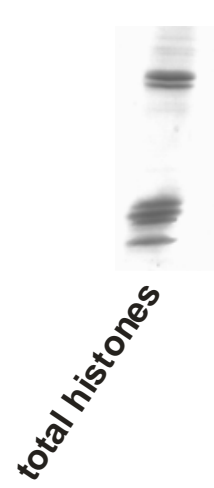

$12345667891011121314151617188^{5}$

no. of HPLC fraction

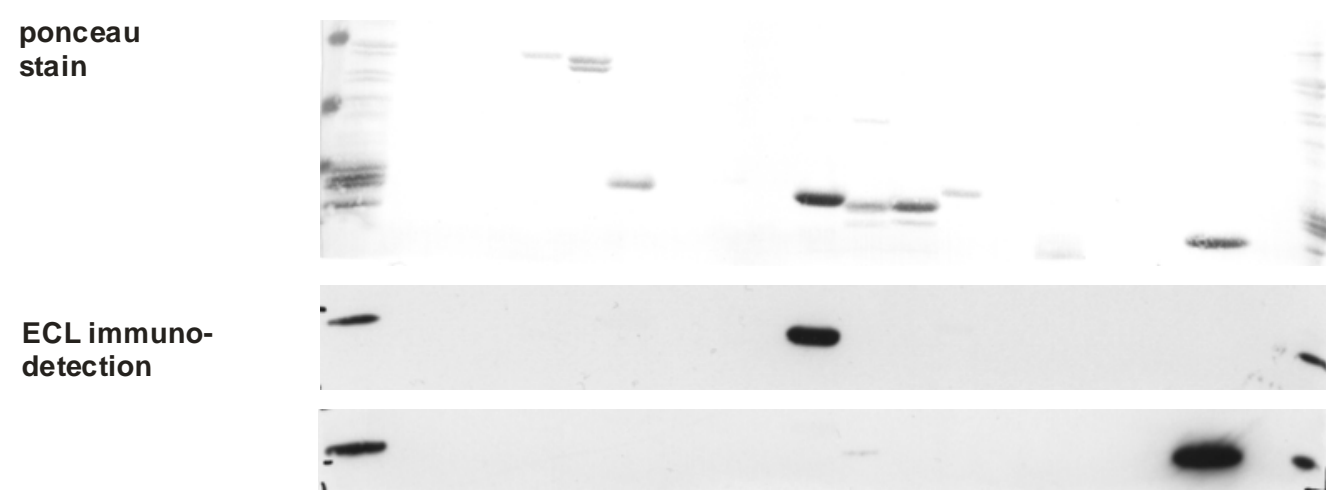

2

ponceau

stain

ECL immunodetection

$\sqrt{2+2}+x^{2}$

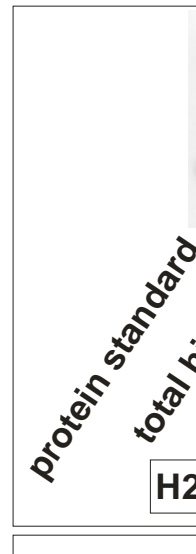

ECL immunodetection

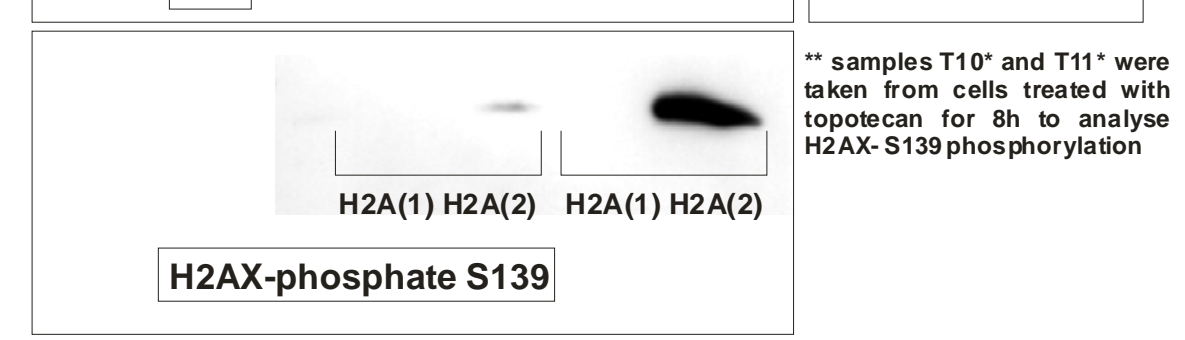

Fig. 3.5.2.3 Separation of core histones via HPLC and assignment of peaks to specific histone types. Histone fractions separated via HPLC were separated by SDS-PAGE (15\%) and subsequently incubated with primary antibodies raised against unmodified core histones or against $\mathrm{H} 2 \mathrm{AX}$-phosphate S139. $\mathrm{H}_{2} \mathrm{SO}_{4}$ extracted core histones from HL-60 cells served as overall controls. (1) SDS-gel showing all single HPLC fractions and Western blots incubated with anti-H2B and anti-H4 antibodies. (2) Western blots incubated with $\mathrm{H} 2 \mathrm{~A}, \mathrm{H} 3$ and $\mathrm{H} 2 \mathrm{AX}$-phosphate S139 antibodies. Bulk H2A was separated into two fractions, with fraction $\mathrm{H} 2 \mathrm{~A}(2)$ mostly containing the modified $\mathrm{H} 2 \mathrm{~A}$ subtype $\mathrm{H} 2 \mathrm{AX}$ phosphate S139. 
Because of the general heterogeneity of cell suspensions $\mathrm{H} 2 \mathrm{~A}(2)$ control cell fractions stained slightly positive for H2AX-phosphate S139.

All HPLC data presented in the above section refer to HL-60 control and topotecan treated cells. For further comparative analyses of apoptosis-related histone modifications via 2Delectrophoresis and CZE, we also used histones prepared from cells which were treated with butyrate for $24 \mathrm{~h}$ to block off histone deacetylation. These histones were also purified and separated via HPLC, however, the peak pattern turned out to be the same in each case compared with those histones of control cells and with topotecan ${ }^{\circledR}$ treated cells.

\subsection{Apoptosis-related changes of histone modifications in HL-60}

Core histones separated, purified and identified by HPLC, were subsequently analysed by AUT-2D gel electrophoresis and capillary zone electrophoresis for possible changes in histone modifications which might be caused by the onset of apoptosis in HL-60 cells. Investigations with antibodies raised against specific histone modifications, which were first carried out on Western blot level, were afterwards analysed on a more general basis, also including core histone subtypes.

\subsubsection{AUT-2D gel electrophoresis: $1^{\text {st }}$ dimension}

Core histones from the HPLC were at first analysed on AUT/AUC $1^{\text {st }}$ and $2^{\text {nd }}$ dimension gels. This was done to get an overview of putative changes of histone modifications in single core histone types. Moreover, it is a fine working method to separate core histones $(\mathrm{H} 2 \mathrm{~A} ; \mathrm{H} 2 \mathrm{~B} ; \mathrm{H} 3$ and $\mathrm{H} 4$ ) with reference to subtypes in some of them, especially with $\mathrm{H} 2 \mathrm{~B} / \mathrm{H} 2 \mathrm{~A}$ histones. In addition, according to the protocol used (Pilch et al., 2004), specific modifications can be identified such as acetylation and phosphorylation. The following results were compared to the published data of Bonner et al. (Bonner et al., 1980) and Boulikas (Boulikas, 1985), as these groups used similar AUT separating conditions which were used here, namely AUT separating gels with $8 \mathrm{M}$ urea and $2 \%$ Triton X-100. Still, all assumptions of an assignment of $1^{\text {st }}$ dimension histone bands to specific modified forms or subtypes can only be preliminary.

HL-60 cells were induced with topotecan ${ }^{\circledR}$ and incubated for $8 \mathrm{~h}$. In parallel HL-60 cells were incubated with the HDAC inhibitor butyrate, which served as a control for comparative analysis of the acetylation state of histones after induction of apoptosis. Along with this, cells harvested shortly after seeding served as untreated control cells. Each single core histone type was subsequently run on a $1^{\text {st }}$ dimension AUT gel to receive a separation of histone subtypes as well as separation of differently acetylated histones. In contrast to this, the $2^{\text {nd }}$ 
dimension (AUC gel) which is said to produce higher resolutions of $\mathrm{H} 2$ histones, was used to separate H2A and H2B subtypes and differently phosphorylated histones.

All single core histone types were run on the $1^{\text {st }}$ dimension gel for $18 \mathrm{~h}$ at a current of $5 \mathrm{~mA}$. The first dimension already separated most histones into their variants, or in case of $\mathrm{H} 4$ their differently acetylated forms (Fig. 3.6.1 1). The most obvious changes were observed with $\mathrm{H} 3$ and $\mathrm{H} 4$ histones. The histone $\mathrm{H} 3$ separation pattern of histones from topotecan ${ }^{\circledR}$ treated cells presented one additional band compared to the histone H3 band pattern from control histones (Fig. 3.6.1 2 lane 1 and lane 3). As the band pattern of the topotecan ${ }^{\circledR}$ treated sample was more comparable to the butyrate treated sample, it might be assumed that this can be referred to a possible change in the state of $\mathrm{H} 3$ acetylation. Although, as according to recent published data, butyrate treatment causes a $\mathrm{G}_{1}$-block, which is connected with a strong dephosphorylation of histones, the second H3 band might also be a dephosphorylated form of H3.3. To elucidate this matter further, it would be necessary to excise these bands from the gel and analyse them via mass spectrometry.

With reference to $\mathrm{H} 4$ histones, a slight deacetylation in the topotecan ${ }^{\circledR}$ treated sample was observed (Fig. 3.6.1 5 lane 3). Hyperacetylation of histone $\mathrm{H} 4$ after butyrate treatment of cells was described earlier by Riggs et al. (Riggs et al., 1977).

Taking a look at histone $\mathrm{H} 2 \mathrm{~B}$, only minor changes were revealed. The triple-band pattern was seemingly diminished in the topotecan ${ }^{\circledR}$ treated sample (Fig. 3.6.1 4 lane 3), however, according to some publications on separation techniques of modified core histones and their subtypes, it cannot be guaranteed that these bands represent protein derivatives of the actual H2B. It might still be the case that the H2B sample does also contain HMG proteins, which might have been co-eluted from the HPLC. According to Bonner et al. (1980), H2B is only resolved in one single band within the $1^{\text {st }}$ dimension AUT gel.

The separating pattern of histone $\mathrm{H}_{2} \mathrm{~A}^{7}$ did not provide any changes at all concerning a decrease or increase in bands or their signal intensities (Fig. 3.6.1 3). However, according to the $1^{\text {st }}$ dimension separation pattern by Bonner et al. (1980), three out of five differentiated bands from bulk H2A might be assigned as follows: uH2A for ubiquitylated H2A, H2A.1 and H2A.2. As for the remaining two bands marked with an $X$, an assignment is not possible at this point.

\footnotetext{
${ }^{7}$ For reasons of very low protein concentrations, the two H2A fractions from the HPLC were pooled for the analysis on AUC/AUT gels.
} 
1
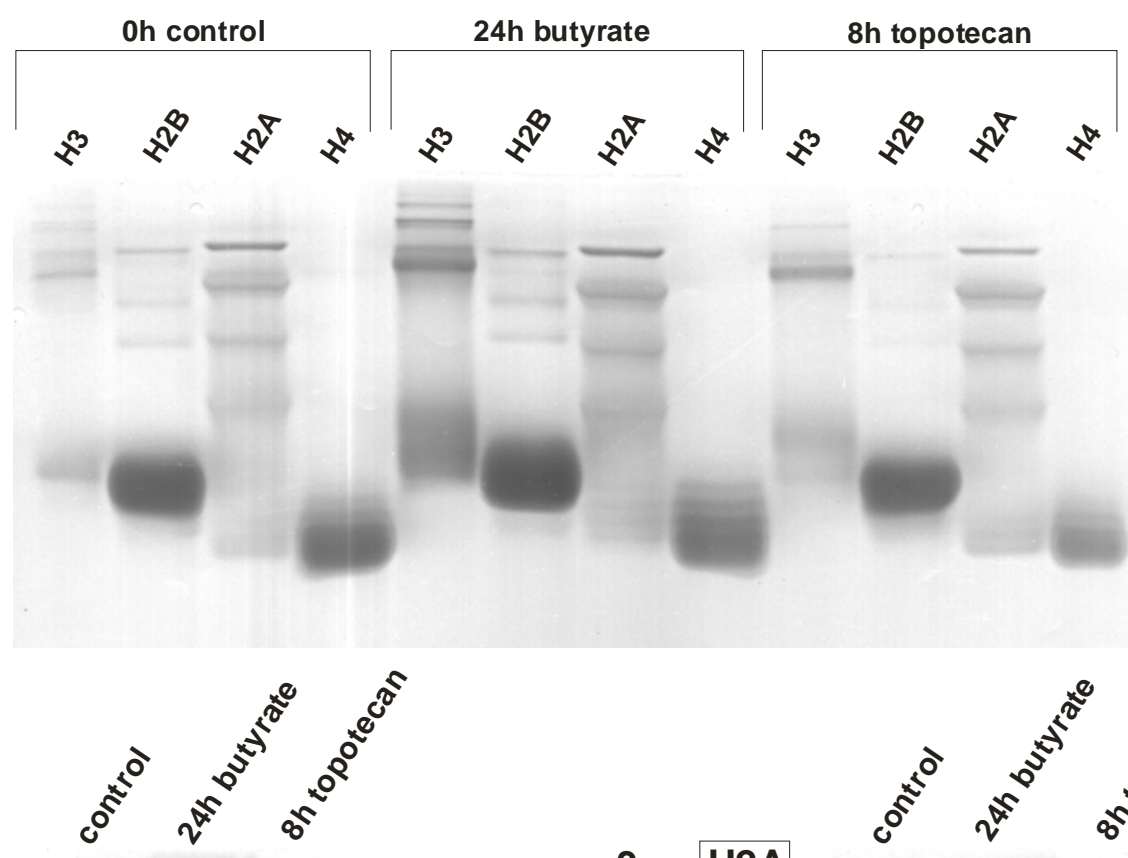

2

H3

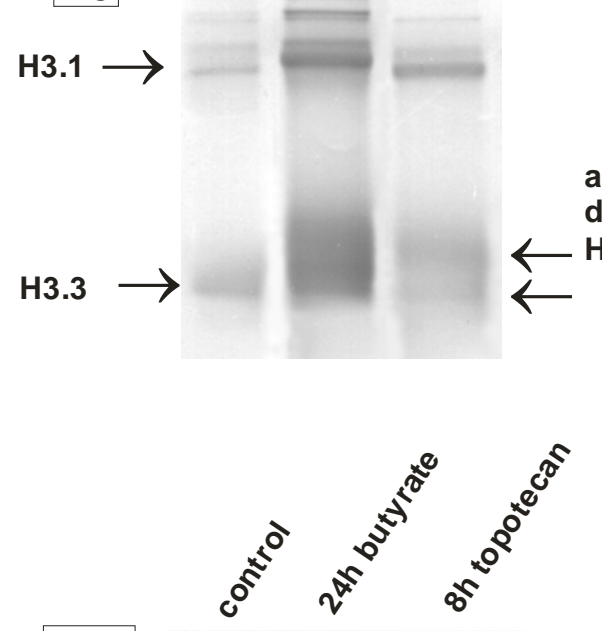

4 H2B

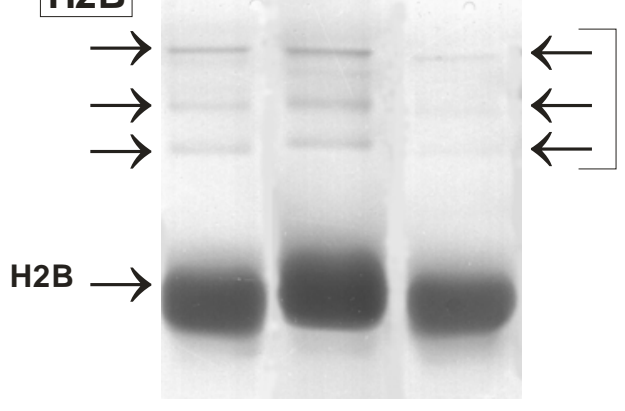

$3 \mathrm{H} 2 \mathrm{~A}$
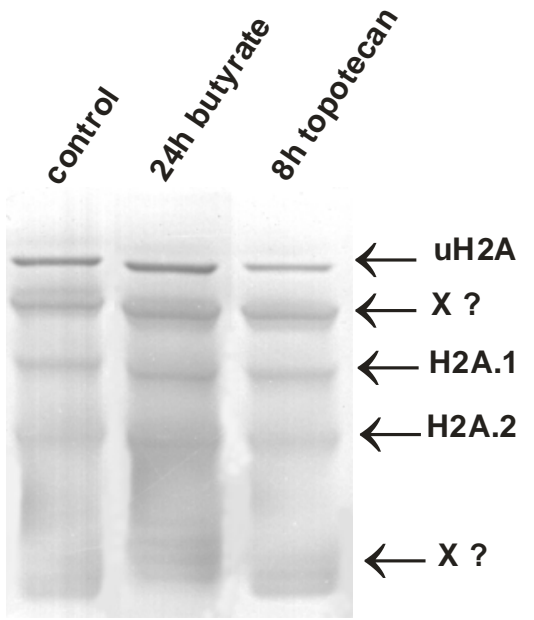

5

H4

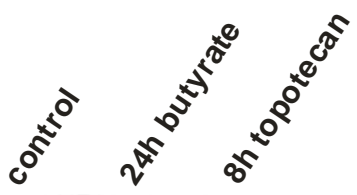

HMG

proteins ?

hyperacetylated histone $\mathrm{H} 4$

de-

acetylated histone $\mathrm{H} 4$

Fig. 3.6.1 AUT-1st dimension gel electrophoresis of single histone types. HL-60 cells were either treated with topotecan ${ }^{\circledR}$ to induce apoptosis or treated with the HDAC inhibitor butyrate to achieve a hyperacetylation of histones. This was done for comparative analysis. After separation via HPLC histones were run overnight for $18 \mathrm{~h}$ on an AUT-1 ${ }^{\text {st }}$ dimension gel. The gel was stained with Coomassie. (1) Overview of all core histones separated. (2) Histone H3 separation produced a higher resolution of $\mathrm{H} 3$ subtypes $\mathrm{H} 3.3 / \mathrm{H} 3.1$ and remarkable change of histone subtype modification (black arrows). (3) AUT-1 ${ }^{\text {st }}$ dimension separation of H2A histones. No changes were observed for $\mathrm{H} 2 \mathrm{~A}$ in the $1^{\text {st }}$ dimension. (4) AUT-1 $1^{\text {st }}$ dimension separation of H2B histones. Three distinctly separated proteins (arrows) were obviously diminished in the topotecan ${ }^{\circledR}$ treated sample. (5) AUT-1 ${ }^{\text {st }}$ dimension 
separation of $\mathrm{H} 4$ histones. A slight decrease in acetylation of histones from topotecan ${ }^{\circledR}$ treated cells was observed (arrows).

\subsubsection{AUT-2D gel electrophoresis: $2^{\text {nd }}$ dimension}

For further analysis of specifically modified core histones and their subtypes, all bands from the $1^{\text {st }}$ dimension gel were excised and loaded onto an AUC- $2^{\text {nd }}$ dimension gel. The gel was run overnight at a current of $5 \mathrm{~mA}$. Here our attention was mainly focussed on a further separation of histones $\mathrm{H} 2 \mathrm{~A}$ and $\mathrm{H} 2 \mathrm{~B}$, their subtypes and their specific modifications.

Unfortunately, against all expectations no remarkable apoptosis-related changes could be observed with reference to $\mathrm{H} 2 \mathrm{~A}$ and $\mathrm{H} 2 \mathrm{~B}$ histones, apart from a more detailed resolution of their subtypes or specific modifications.

$2^{\text {nd }}$ dimension separation patterns of histone $\mathrm{H} 3$ resulted in two more bands of the assigned H3.1 subtype. As this band was detected in all three samples, an apoptosis-related change of pattern could be excluded (Fig. 3.6.2 1). The red circles indicate the change of histone band pattern in the topotecan ${ }^{\circledR}$ treated sample compared to the control sample. The second band assigned with an $X$ ? cannot be clearly assigned. However, it might be assumed that due to its similarity to the band pattern of the butyrate treated sample, this band might either be an acetylated or a dephosphorylated form of H3.3. The 2D-separation of H2B resulted in five more bands, in which according to Bonner et al. (Bonner et al., 1980) only two bands could be assigned as H2B.2 and H2B.1 (Fig. 3.6.2 2). With reference to the work of Pilch et al. (Pilch et al., 2004) this group achieved at least a resolution of 5-6 bands from histone $\mathrm{H} 2 \mathrm{~B}$, although they did not define them in more detail. Apart from the decreased and not further defined additional triple-band pattern (Fig. 3.6.1 4), no apoptosis-related changes were observed (Fig. 3.6.2 2; red circle). The 2D-separation pattern of histone H2A unfortunately did not give us further information about any possible apoptosis-related modification or subtype changes, either. However, the method separated the assigned $\mathrm{uH} 2 \mathrm{~A}$ band in two, which according to Bonner et al. (Bonner et al., 1980) were defined as UH2A.1 and $\mathrm{uH} 2 \mathrm{~A}$.2. Still, the bands marked with an $\mathrm{X}$ ? could not be defined (Fig. 3.6.2 3; red circles).

As expected, the separation of $\mathrm{H} 4$ histones on the AUC- $2^{\text {nd }}$ dimension gel did not result in a further resolution of the bands, as $\mathrm{H} 4$ is the only histone without any subtypes. Those bands which represented the different states of acetylation of histone $\mathrm{H} 4$ are marked with numbers (Fig. 3.6.2 4; 1-4). Otherwise we did not observe any further apoptosis-related changes. These findings just gave us an overview over possible apoptosis-related changes of histone subtypes and their modifications. In a following step histones and their subtypes would have been analysed with mass spectrometry to gain more explicit results. 


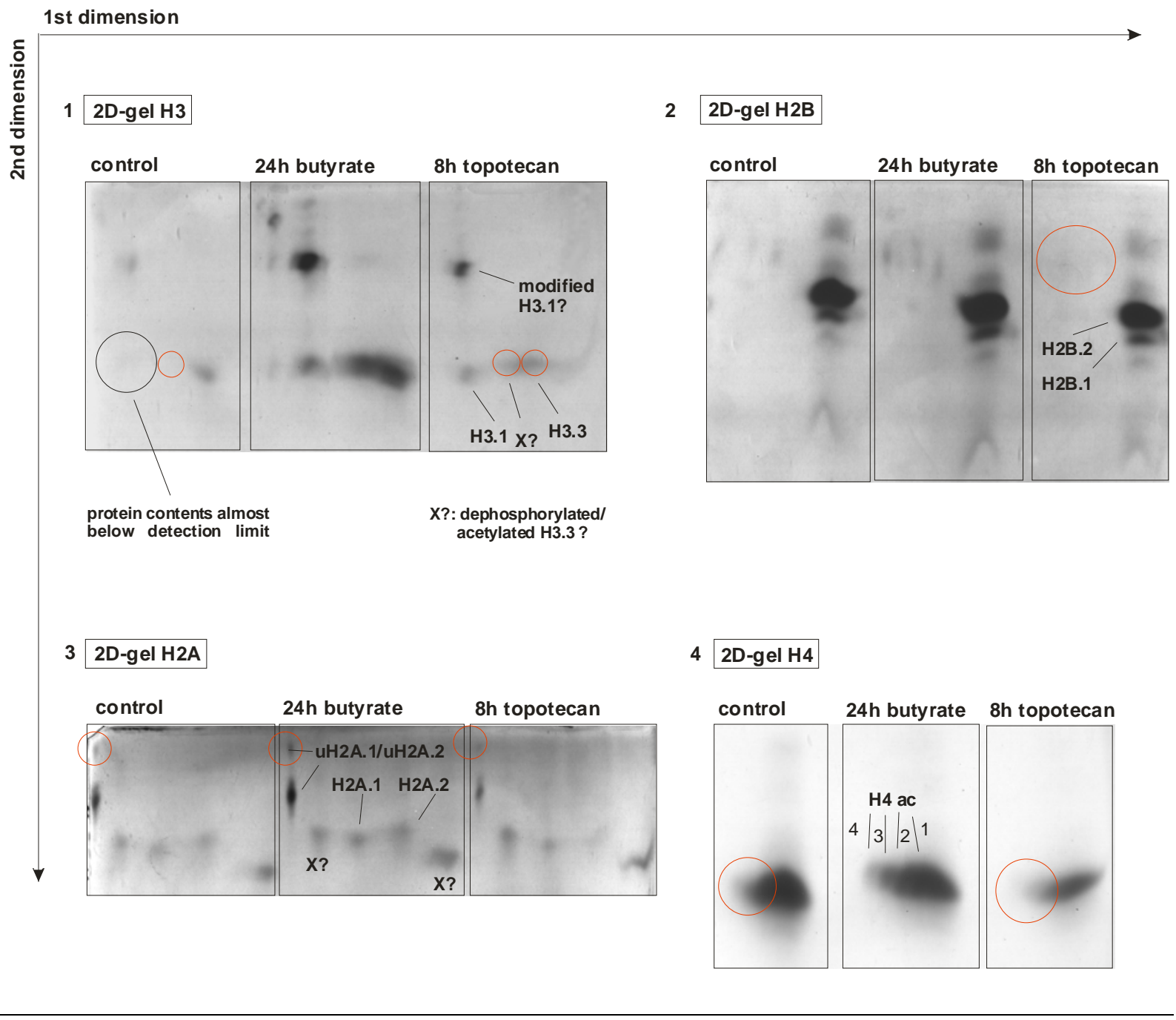

Fig. 3.6.2 AUT-2nd dimension gel electrophoresis of single histone subtypes. HL-60 cells were either treated with topotecan or with the HDAC inhibitor butyrate to achieve a hyperacetylation of histones. After separation on an AUT-1 $1^{\text {st }}$ dimension gel, histones were run on an AUT-2 ${ }^{\text {nd }}$ dimension gel. The gel was stained with Coomassie dye. (1) $\mathrm{H} 3$ histones separated on a $2^{\text {nd }}$ dimension gel. A further separation of possible modified forms was observed. The grey circle indicates very low concentrations of $\mathrm{H} 3$ protein but which were still detectable. (2) $\mathrm{H} 2 \mathrm{~B}$ histones separated on a $2^{\text {nd }}$ dimension gel. A further separation into H2B.1 and H2B.2 was achieved. The triple-band pattern from the $1^{\text {st }}$ dimension was not resolved any further (red circle). (3) H2A histones separated on a $2^{\text {nd }}$ dimension gel. Apart from a further separation of the first band, assigned with $\mathrm{UH} 2 \mathrm{~A}$ in the $1^{\text {st }}$ dimension (red circle), no changes were spotted. (4) $\mathrm{H} 4$ histones separated on a $2^{\text {nd }}$ dimension gel. The gel shows the differently acetylated forms of $\mathrm{H} 4$, which were decreasing in the topotecan ${ }^{\circledR}$ treated sample (red circles in control and topotecan ${ }^{\circledR}$ panel). 


\subsubsection{Capillary zone electrophoresis}

Supplementary to our HPLC analyses we approached the topic of apoptosis-related histone modifications by histone separation via capillary zone electrophoresis (CZE). This is a highly sensitive alternative method, which reaches by far better resolutions, when it comes down to histone modification analysis. Moreover, this method offers a time saving alternative to the time consuming 2D-gel electrophoresis.

$\mathrm{HL}-60$ cells were treated the same way as described and histones were isolated, purified and also separated via HPLC.

Compared to just slight changes in histone modifications and subtype pattern that were observed after 2D-gel electrophoresis, changes observed by CZE were more significant than expected. For comparative analysis, core histones from butyrate treated cells were analysed in parallel, which gave us the chance to investigate a possible connection of apoptosisrelated changes in the histone acetylation pattern. Although this is an often given statement in publications, it has to be qualified, as butyrate treatment of cells does not only cause hyperacetylation of some histone types but also leads to a $G_{1}$-arrest in cells, which is subsequently connected with large scale dephosphorylation. So, as histones were analysed mainly on the basis of an apoptosis-related change in their state of acetylation, a possible connection to a change in their phosphorylation pattern was still kept in mind.

Analysis of the histone $\mathrm{H} 3$ peak separation pattern revealed a reduction from four distinct peaks in the control sample to two large peaks and a smaller one in the topotecan ${ }^{\circledR}$ treated sample. Compared to that, the peak pattern in the butyrate treated sample appeared to be

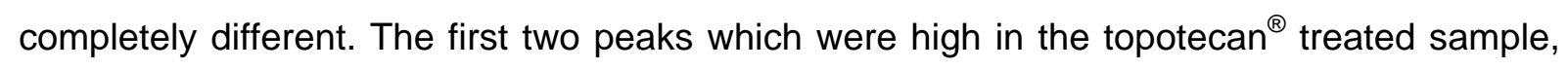
turned out to be low in the sample treated with butyrate and vice versa (Fig. 3.6.3 1; red arrows). So it might be assumed, that after induction of apoptosis, H3 histones are not subject to an increase in acetylation. However, those changes observed might readily be referred to a strong tendency of dephosphorylation, an observation that has already be described for both $\mathrm{H} 3$ at serine 10 and 28 and histone $\mathrm{H} 1$ (Happel et al., 2005). As this is still an assumption, it remains to be elucidated which other modifications might be responsible for the changes in peak patterns.

In the first of altogether two histone H2A HPLC fractions, the shape of the peak pattern did not show any remarkable changes, except for a slight peak shoulder in the control sample, which obviously almost disappeared from the peak pattern of topotecan ${ }^{\circledR}$ treated samples (Fig. 3.6.3; red and black arrows). A possible apoptosis-related change in the acetylation pattern of this histone type does not seem to be the case, as its peak shape compared with that of the butyrate treated sample was completely different. As it seems, the first peak in the

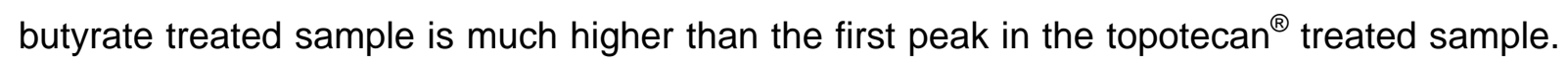
Peak shapes of histones from butyrate treated cells obviously undergo a shift to the left (Fig. 
3.6.3 3; black arrow in lower panel), a fact that was not observed with peaks from topotecan ${ }^{\circledR}$ treated cells. However, a possible dephosphorylation of histone H2A(1) might be assumed, all sorts of different modifications will most probably be involved in changes of these peak patterns.

Analysis of the second $\mathrm{H} 2 \mathrm{~A}(\mathrm{H} 2 \mathrm{~A}(2) \mathrm{HPLC}$ fraction revealed no changes at all, concerning the peak pattern. Peak shapes of all three samples, control, topotecan ${ }^{\circledR}$ and butyrate, were congruent (Fig. 3.6.3 5).

More severe changes in histone modifications could be evidenced in histones $\mathrm{H} 2 \mathrm{~B}$. The peak pattern of the control sample turned out to be a mirror image of the pattern in topotecan ${ }^{\circledR}$ treated samples. Peak shapes and heights almost remained unchanged but appeared in reverse order (Fig. 3.6.3 2). Apoptosis-related changes of peak patterns in histone H2B were the most severe observed. The first peak of the control sample seems to resemble the last peak in the topotecan ${ }^{\circledR}$ treated sample, with an additional small peak shoulder towards the end (Fig. 3.6.3 2; bend red and black arrows). Whereas control and butyrate samples both showed certain similarities in their peak pattern and peak shape, the topotecan ${ }^{\circledR}$ sample shows remarkable deviations, a fact which supports the assumption that here, too, treatment with topotecan ${ }^{\circledR}$ does not seem to be connected with an increase in acetylation of histone H2B.

Fig. 3.6.3 Capillary zone electrophoresis analyses of core histones. HL-60 cells were either treated with topotecan or with the HDAC inhibitor butyrate to achieve a hyperacetylation of histones. After purification and separation via HPLC single histone extracts were loaded onto the capillary zone electrophoresis unit and run for 2 h. (1) Separation of histone H3 control samples and with topotecan $^{\circledR}$ or butyrate treated samples. A strong shift of $\mathrm{H} 3$ histones was observed which were pre-treated with butyrate for $24 \mathrm{~h}$. Apoptosis-related changes in the peak pattern were also monitored. Peaks marked with *Ac0-Ac3 are putative acetylated forms of H3 following published data by (Lindner et al., 2003; Lindner et al., 1996). (2) Separation of the first H2A(1) of altogether two HPLC histone H2A fractions. The peak pattern of control histones and apoptosis induced $\mathrm{H} 2 \mathrm{~A}(1)$ histones was almost identical, except for a very small peak shoulder in control cells (black arrow compared to red arrow). (3) The peak pattern of $\mathrm{H} 2 \mathrm{~B}$ histones of control cells turned out to be a mirror image of topotecan ${ }^{\circledR}$ treated sample (black and red arrow). All peak heights were identical but appeared in a reverse order. All peaks of the butyrate treated sample bear quite a few similarities in shape and pattern compared to histone H2B from control cells. (4) Separation of the second H2A(2) HPLC fractions. No changes in the peak pattern was observed 


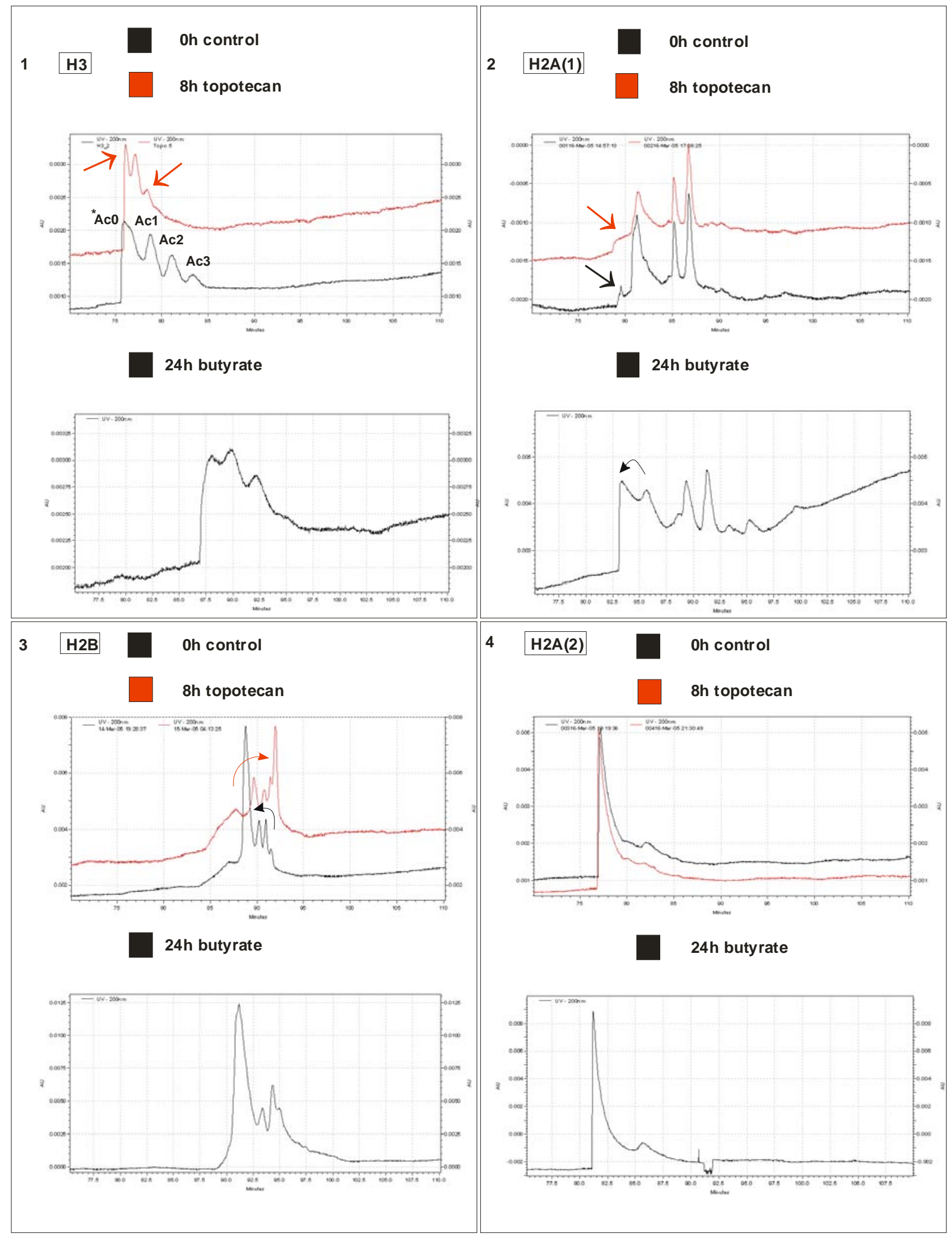




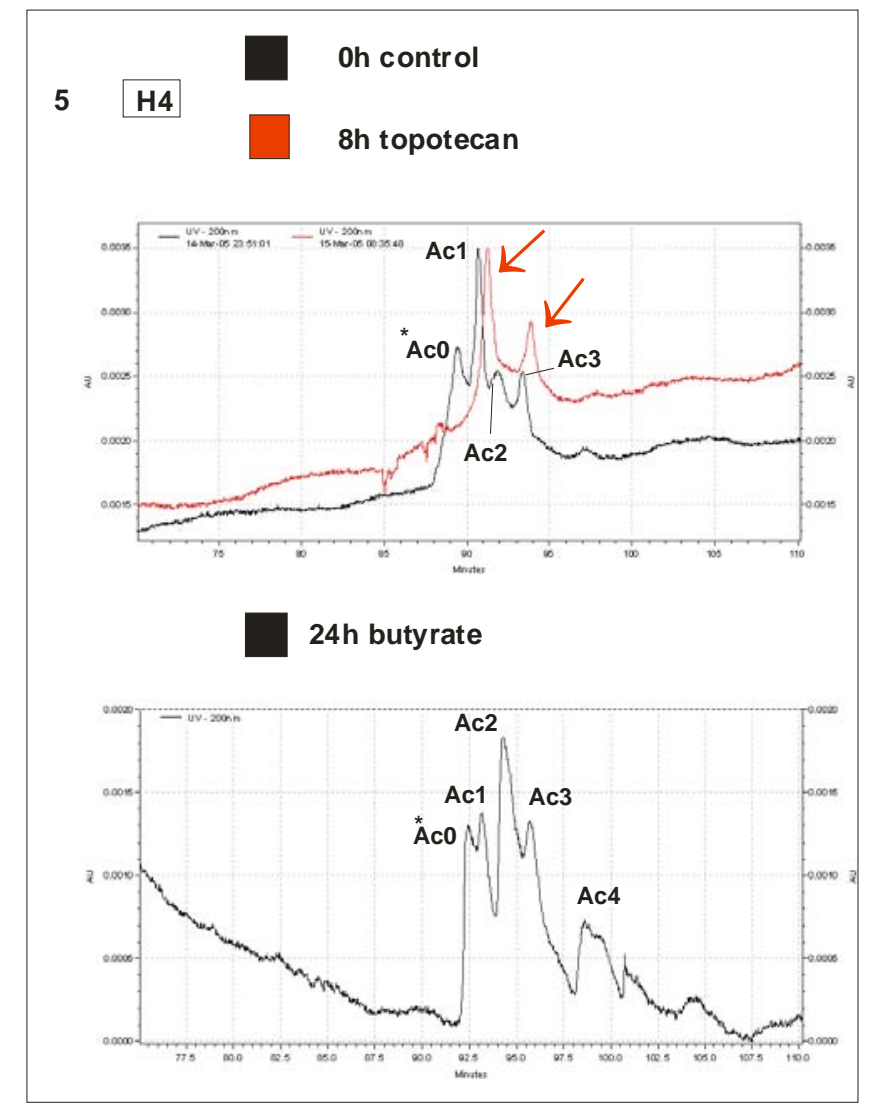

Fig. 3.6.3 (cont. 1) Capillary zone electrophoresis analyses of core histones. HL-60 cells were either treated with topotecan or with the HDAC inhibitor butyrate to achieve a hyperacetylation of histones. After purification and separation via HPLC single histone extracts were loaded onto the capillary zone electrophoresis unit and run for $2 \mathrm{~h}$. (5) Separation pattern of $\mathrm{H} 4$ histones. Two out of altogether four $\mathrm{H} 4$ control histone peaks vanished completely after topotecan ${ }^{\circledR}$ treatment (red arrows). Peaks marked with *ACO-Ac3 are putative acetylated forms of $\mathrm{H} 4$ following published data by Lindner et al. (Lindner et al., 2003; Lindner et al., 1996).

In analyses of histone $\mathrm{H} 4$ via CZE we evidenced that two out of altogether four $\mathrm{H} 4$ control histone peaks seemingly vanished completely after topotecan ${ }^{\circledR}$ treatment, which went ahead with a slight shift of the two remaining $\mathrm{H} 4$ peaks to the right (Fig. 3.6.3 5, red arrows). The peak pattern of $\mathrm{H} 4$ from the topotecan ${ }^{\circledR}$ treated sample showed great differences compared with those patterns of control cells and butyrate treated cells. The very first and last peak in the butyrate sample disappeared completely from the $\mathrm{H} 4$ peak separation pattern in the topotecan ${ }^{\circledR}$ sample. As a result and on the basis of the great differences between control and butyrate samples on the one hand and the topotecan ${ }^{\circledR}$ sample on the other hand, a tendency towards hyperacetylation of $\mathrm{H} 4$ during apoptosis can almost be excluded.

These studies made it quite clear that during the ongoing process of apoptosis there are apparently some major changes in histone modifications of the histones $\mathrm{H} 2 \mathrm{~B}, \mathrm{H} 3$ and $\mathrm{H} 4$, which can be well described by means of CZE analysis. However, it remains to be elucidated, which types of modification we are dealing with in particular, as in terms of 
analysis, these results reflect the changes of all different histone modifications, as there are acetylation, methylation, phosphorylation and ubiquitylation. In a following step it would be necessary to consider one single type of modification, e.g. histone acetylation or methylation, and to analyse it by means of mass spectrometry.

\subsection{Nucleus-cytosol preparations - a question of techniques}

The following test series of different nucleus-cytosol preparations served as a basis for all analyses of any kind of chromatin modifications. In this respect it was absolutely necessary to optimise nucleus-cytosol preparations for the specific cell types used here, with reference to nuclei showing intact morphology and biochemical features, as well as maximum yield. For this particular purpose four different protocols were chosen and tested.

\subsubsection{Microscopic analyses of nuclei}

Nuclei from all four preparations were analysed by means of fluorescence analyses, so that the nucleus preparations could be evaluated with reference to yields and quality of the nuclei.

Although the first protocol that was originally developed by Antalis and Godbolt (Antalis and Godbolt, 1991) to isolate nuclei from hematopoietic cell lines, brought forth maximum yields and nuclei were easy to prepare, it was not the preparation of choice, as finally quite a large number of nuclei turned out to be not fully separated from their cytosols (Fig. 3.7.1 1; black arrows).

The second protocol tested, which was originally used by Chen et al. (Chen et al., 2000) to prepare nuclei from human T-lymphocytes, did not produce satisfying results either. Apart from the fact that large amounts of cell debris still remained within the nuclei suspension, many nuclei were damaged during the preparation (Fig. 3.7.1 2; black arrows).

The third protocol tested, which was developed by Bunce et al. (Bunce et al., 1988) as a rapid method to isolate nuclei from hematopoietic cell lines, produced by far the best results concerning HL-60 cells. This preparation produced a maximum yield (about $70 \%$ ) of morphologically intact nuclei (Fig. 3.7.1 3; black arrows).

The fourth and last protocol, which was actually developed by Meergans (personal communications) for analyses of nuclear transport mechanisms, turned out to be the most unsuitable method for nuclei preparation. Although yields were acceptable, the preparation as such produced large amounts of debris (fig. 3.7.1 4; white arrows), which remained within the nuclei suspension, all along with severely damaged nuclei and still fully intact cells (Fig. 3.7.1 4; black arrows). 
1

protocoll

Antalis and Godbolt (1991)

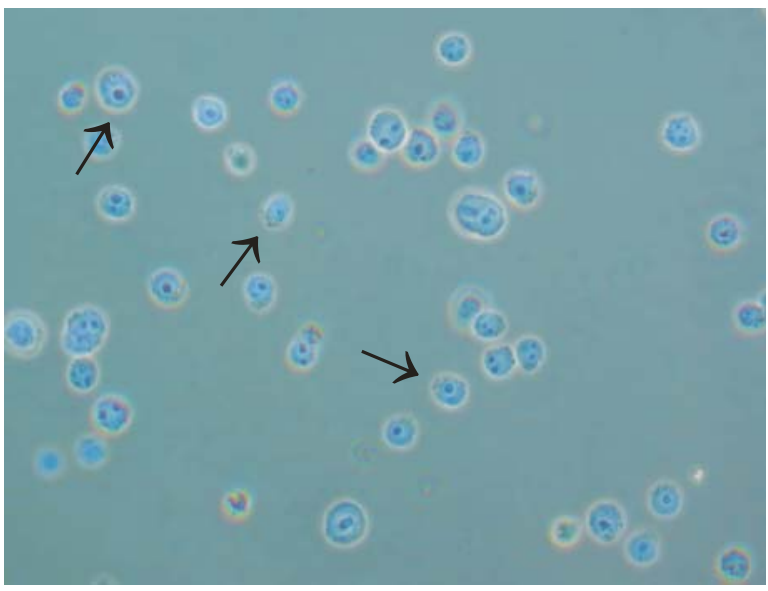

3

protocol III

Bunce et al. (1988)

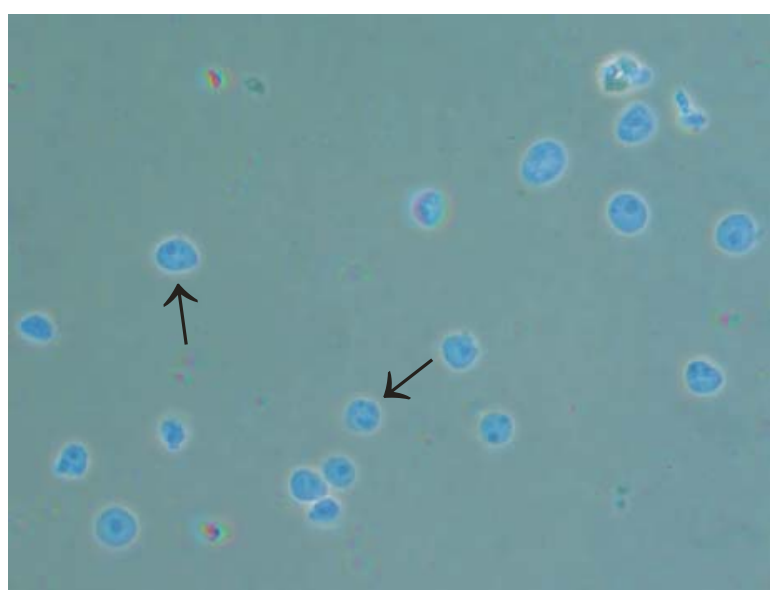

\section{2}

protocol II

Chen et al. (2000)

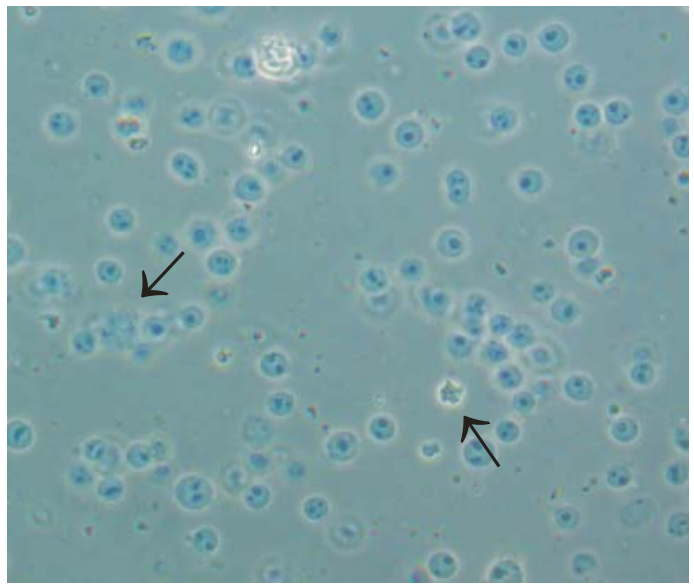

4

protocol IV

Meergans (personal communications)

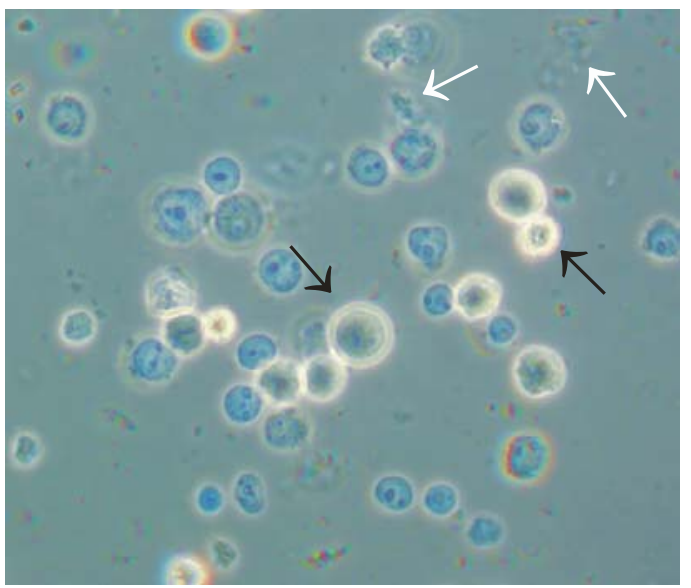

Fig. 3.7.1 Fluorescence microscopy of DAPI stained from HL-60 nuclei from four different nucleus-cytosol preparations. Nuclei from HL-60 cells were prepared according to four different protocols (chapter 2.2.5.1). Nuclei were stained with DAPI and analysed under the microscope. (1) Black arrows show nuclei from cells which were not properly separated from their cytosols. Membrane structures and fully intact cytosols could still be detected after preparation I. (2) Nuclei from preparation II appeared to be almost morphologically intact but revealed large amounts of debris in the nuclei suspension (black arrows). (3) Nuclei from preparation III seemed to be morphologically intact (black arrows). Isolated nuclei were obviously free from debris. (4) Preparation IV delivered the crudest nuclei suspension. Most nuclei were either severely damaged or were not properly separated. Black arrows point to large, still intact cells, whereas white arrows indicate large scale debris. 


\subsubsection{Biochemical analyses of nuclei}

In addition to microscopic analyses, nuclei from all preparations were tested for possible damage and leakage of the nuclear membrane. For this purpose, three molecular markers were chosen to test both cytosolic and nuclear fractions. We used PARP and the soluble protein RNA polymerase II as nuclear markers and lactate dehydrogenase as a cytosolic marker. Nuclei and cytosolic fractions from all preparations were separated by SDS-PAGE and transferred to nitrocellulose membranes via Western blotting. Membranes were incubated with antibodies raised against the specific marker proteins.

For preparation I, Western blots showed that the cytosolic marker protein lactate dehydrogenase was only found in the cytosolic fraction (Fig. 3.7.2 1; lanes 2/3) and the nuclear marker protein PARP could only be detected in the nuclear fraction (Fig. 3.7.2 2; lanes $2 / 3$ ) as expected. In contrast to that, the second nuclear marker RNA polymerase II was detected in the cytosolic as well as in the nuclear fraction (Fig.3.7.2 3; lanes 2/3), which showed that the nuclei were leaky to a certain degree.

Microscopic analyses of this preparation already revealed an accumulation of large amount of debris and damaged nuclei altogether. These results were further supported by the outcome of the biochemical analyses. Whereas lactate dehydrogenase could only be detected in the cytosolic fractions (Fig. 3.7.2 1; lanes 4/5), the nuclear marker proteins PARP (Fig. 3.7.2 2; lanes 4/5) and RNA polymerase II (Fig. 3.7.2 3; lanes 4/5) were detected in both the cytosolic and the nuclear fraction, a fact that proved this protocol to be useless for further analytic purposes.

For preparation III, the biochemical analyses produced by far the best results with reference to the cytosolic and nuclear marker proteins used. Lactate dehydrogenase was only traced in the cytosolic fraction (Fig. 3.7.2 1; lanes 6/7), whereas the nuclear marker proteins PARP and RNA polymerase II were exclusively detected in the nuclear fraction (Figs. 3.7.2 2 and 3; lanes 6/7). The protocol by Bunce and co-workers turned out to be the method of choice for all following analyses, as all parameters, morphological and biochemical, produced positive results throughout.

For preparation IV not only PARP (Fig. 3.7.2 2; lanes 8/9) but also RNA polymerase II (Fig. 3.7.2 3; lanes 8/9) were detected in both nuclear and cytosolic fractions. In addition, the cytosolic marker protein lactate dehydrogenase could even be traced in the nuclear fraction (Fig. 3.7.2 1; lanes 8/9), a fact that points out the crudeness of the resulting nuclei suspension. 
1

Ponceau

stain

lac tate

dehydrogenase

DAB immuno-

detection

2

Ponceau

stain

PARP

NBT/B CIP

immuno-detection

3

\section{Ponceau \\ stain}

cytosolic fraction marker

protocol:

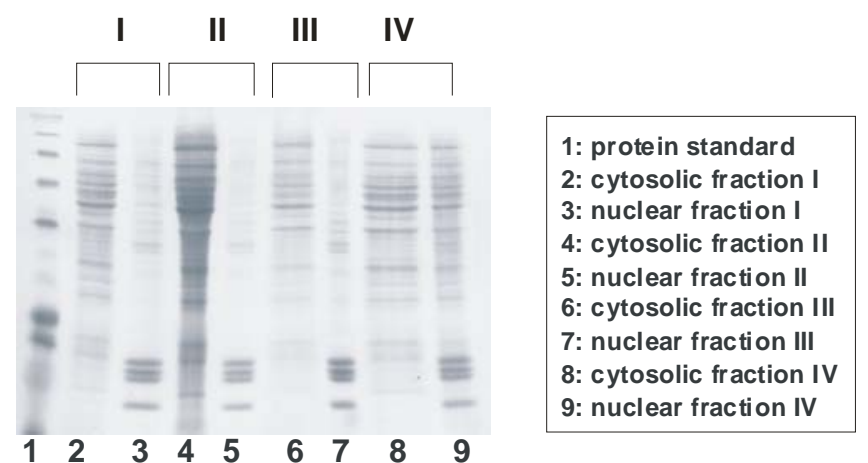

nuclear fraction marker

protocol:

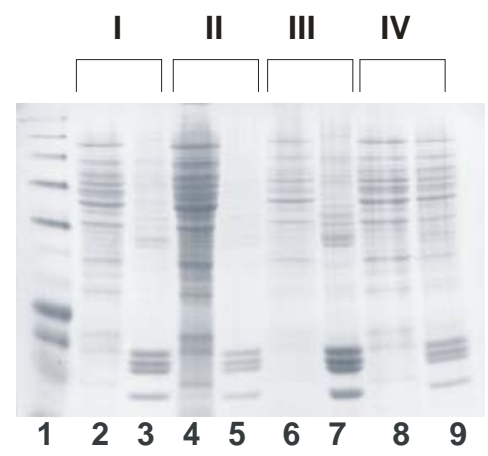

1: protein standard

2: cytosolic fraction I

3: nuclear fraction I

4: cytosolic fraction II

5: nuclear fraction II

6: cytosolic fraction III

7: nuclear fraction III

8: cytosolic fraction IV

9: nuclear fraction IV

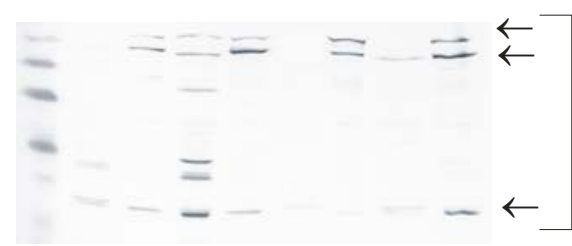

nuclear fraction marker

protocol:

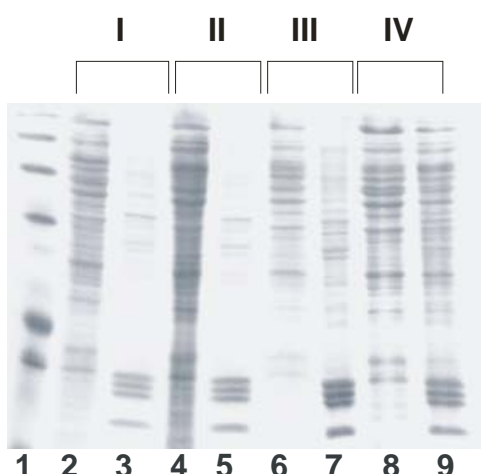

1: protein standard

2: cytosolic fraction I

3: nuclear fraction I

4: cytosolic fraction II

5: nuclear fraction II

6: cytosolic fraction III

7: nuclear fraction III

8: cytosolic fraction IV

9: nuclear fraction IV

RNA polymerase II

DAB immuno-

detection

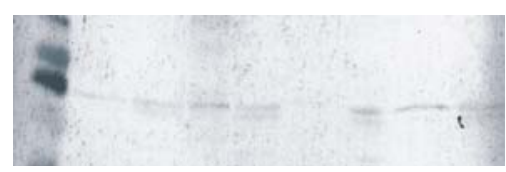


Fig. 3.7.2 Analysis of cytosolic fractions and nuclear fractions for the cytosolic marker protein lactate dehydrogenase and the nuclear marker proteins PARP and RNA polymerase II. Nuclear and cytosolic fractions were prepared according to the four protocols (chapter 2.2.5.1). Aliquots of all fractions were separated on SDS-PAGE (15\%) and subject to Western blotting. Cytosols and nuclear fractions from all four protocols were incubated with antibodies raised against lactate dehydrogenase, PARP and RNA polymerase II. (1) Membrane incubated with anti-lactate dehydrogenase antibody. Except for preparation IV no lactate dehydrogenase protein could be detected in any nuclear fraction. (2) Membrane incubated with anti-PARP antibody. The nuclear marker protein PARP was detected in the cytosols of preparation II and IV but remained undetected in cytosols of preparation I and III. (3) Membrane incubated with anti-RNA polymerase II antibody. The nuclear marker protein RNApolymerase II was detected in both nuclear and cytosolic fractions of all preparations except for preparation III.

\subsection{Apoptosis-related nucleosomal cleavage and nuclear release of specifically modified core histones from HL-60 cells}

Chromatin condensation and cleavage of the linker DNA between nucleosome core particles are biochemical hallmarks of apoptosis. In the following section we investigated the topic of nucleosomal cleavage and subsequent nuclear release of specifically modified core histones into the cytosol by means of Western blotting.

\subsubsection{Histone release in HL-60 cells}

To further investigate the topic of a putative histone release from nuclear bulk chromatin into the nucleus and later into the cytosol, two different nuclear fractions and one cytosolic fraction from HL-60 were prepared and analysed for their histone contents and their possibly changing histone modifications. We differentiated between two nuclear fractions, one containing the insoluble bulk chromatin fraction, the other containing the cleaved and subsequently released soluble nucleosomal material.

HL-60 cells were induced with topotecan ${ }^{\circledR}$ and harvested after $2 \mathrm{~h}, 8 \mathrm{~h}, 12 \mathrm{~h}$ and $24 \mathrm{~h}$ incubation time. Cells harvested shortly after the seeding and after $24 \mathrm{~h}$ of incubation served as control cells. In the following, nuclei were prepared according to the protocol by Bunce et al. (1988). Both cytosolic and nuclear fractions of each sample were kept. After that nuclei were lysed using hypotonic phosphate-EDTA buffer, which opened up the nuclei to release the cleaved, soluble nucleosomal material from the bulk chromatin region. In the following description, these are referred to as supernatants and pellets of the nuclear fraction, the first containing the soluble nucleosomal material, the latter containing the remaining insoluble bulk chromatin fraction. All three fractions from all samples were separated via SDS-PAGE and transferred to nitrocellulose membranes by Western blotting. After that all membranes were incubated with antibodies raised against the respective single, unmodified core histone or against any specific histone modification site. 


\begin{tabular}{|l|l|}
\hline \multicolumn{2}{|c|}{ cytosolic } \\
fractions
\end{tabular}$\quad$\begin{tabular}{|c|c} 
nuclear fractions \\
supernatants & pellets \\
\hline
\end{tabular}

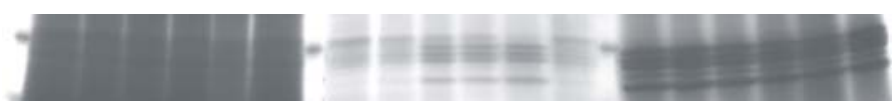

2

3

4

5

\section{Ponceau stain}

ECL-

Immuno-detection
Ponceau

stain

ECL-

immuno-detection
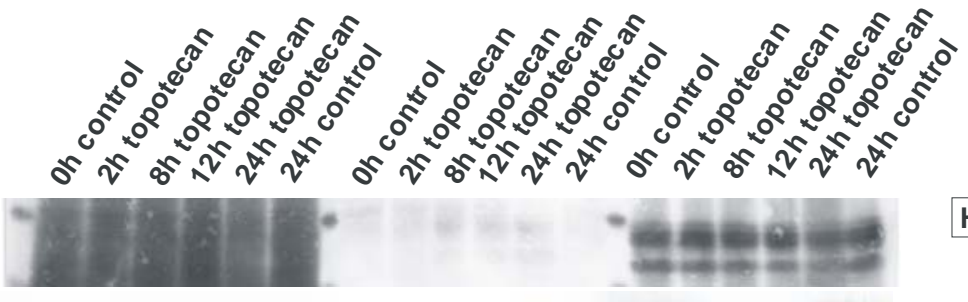

H3

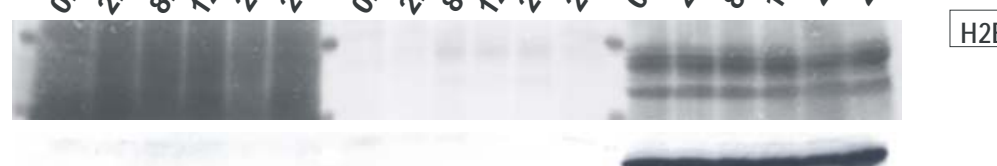

stain

ECL-

immuno-detection
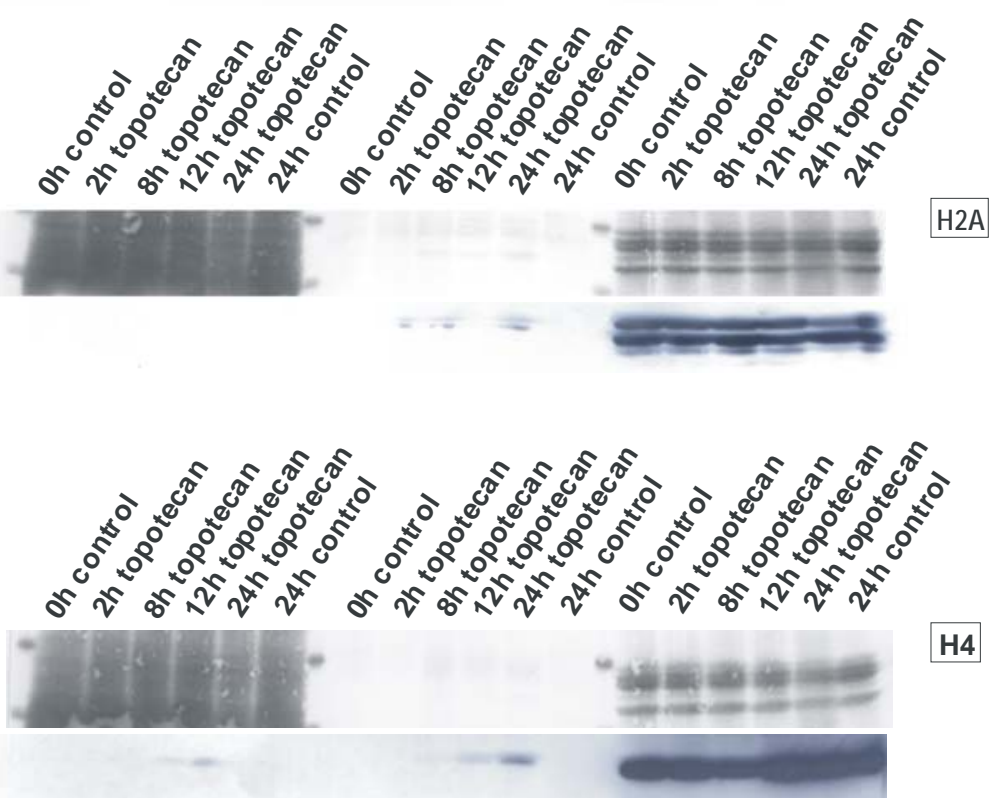

Fig. 3.8.1 Western blot analyses of apoptosis-related nucleosomal cleavage and release of unmodified core histones from bulk chromatin into the nucleus and cytosol. HL-60 cells were induced with topotecan $^{\circledR}$ and harvested after $2 \mathrm{~h}, 8 \mathrm{~h}, 12 \mathrm{~h}$ and $24 \mathrm{~h}$. Cells harvested shortly after seeding and after $24 \mathrm{~h}$ of incubation served as control cells. Nuclei were prepared according to the protocol by Bunce et al. (Bunce et al., 1988). (1) SDS-gel showing all fractions, cytosolic, soluble nucleosomal material containing fractions and nuclear pellet fractions. Nucleosomal material was cleaved to a certain extent and released from bulk chromatin regions into the nucleus and cytosol. The amount of released histones increased with time. (2) Western blot incubated with anti-H3 antibody. H3 was detected in increasing amounts in the supernatant and after $24 \mathrm{~h}$ in the cytosol. (3) Western blot incubated with anti-H2B antibody. Here the antibody failed to detect released H2B. (4) Western blot incubated with anti-H2A antibody. H2A was detected in the supernatants. This antibody did not detect any histone $\mathrm{H} 2 \mathrm{~A}$ in the cytosol. (5) Western blot incubated with anti-H4 antibody. $\mathrm{H} 4$ was released into the nucleus in increasing concentrations and could also be detected in the cytosol after $12 \mathrm{~h}$. 
With reference to detecting unmodified core histones in the different fractions, the cleavage and release pattern turned out to be quite heterogenic, although the SDS-gel plainly presented equal amounts of each histone type in nuclear supernatant fractions. Release of cleaved nucleosomal material was observed to accumulate gradually from around $8 \mathrm{~h}$ until $24 \mathrm{~h}$ (Fig. 3.8.1 1). For the histones $\mathrm{H} 3$ and $\mathrm{H} 4$, we could both observe a subsequent release first from bulk chromatin regions into the nucleus and $12 \mathrm{~h}$ to $24 \mathrm{~h}$ after induction of apoptosis they were even detected in the cytosolic fractions (Figs. 3.8.2 2 and 5). In contrast to this finding and apart from all nuclear pellet fractions, it was not possible to detect any histone $\mathrm{H} 2 \mathrm{~B}$, neither in nuclear supernatants nor in the cytosolic fractions (Fig. 3.8.1 3), whereas histone $\mathrm{H} 2 \mathrm{~A}$ was at least found to be accumulating gradually in nuclear supernatants. But the antibody failed to detect histone H2A within the cytosolic fractions (Fig. 3.8.1 4). These results are unfortunately incompatible with the fact that the SDS-gel shows increasing band signals for all four core histones types (Fig. 3.8 .11 ; supernatants from nuclear fractions). These findings might be explained with the fact, that at least some of the antibodies purchased did not possess high binding qualities. A similar heterogenic release pattern of unmodified core histones was later observed in the stable transfectants HeLa H2BYFP. Besides the analyses of putative releases of unmodified core histones, we further investigated this matter on the basis of specifically modified core histones. Western blots incubated with anti-H3-dimethyl K9 and H2AX-phosphate S139 produced signals showing large scale release for both histone types from bulk chromatin regions into the nucleus. Both specifically modified histone types were detected as early as $2 \mathrm{~h}$ after induction of apoptosis. Referring to H2AX-phosphate S139, such modified histone was even released into the cytosol and was found to be accumulating $8 \mathrm{~h}$ post-induction (Figs. 3.8 .11 and 10). In contrast to these findings only traces of trimethylated histone 3 at lysine 9 and acetylated histone $\mathrm{H} 3$ at lysine 9 were spotted in nuclear supernatants. None of these specifically modified core histones was found in any of the cytosolic fractions (Figs. 3.8.12 and 3).

Analyses of di- and trimethylated histone $\mathrm{H} 3$ at lysine 4 provided quite similar results compared to the specifically modified histone H2AX-phosphate S139. Both di- and trimethylated histone $\mathrm{H} 3$ at lysine 4 were found to be gradually accumulating in nuclear supernatants about $2 \mathrm{~h}$ after induction of apoptosis. Increasing concentrations of these histones were also detected in almost all cytosolic fractions (Fig. 3.8.1 12 and 13).

To shortly summarize our findings: it seems that $\mathrm{H} 3$ histones, trimethylated or acetylated at lysine 9 appear to be withheld in bulk chromatin regions after induction of apoptosis, whereas the following specifically modified histones H2AX-phosphate S139, H3-dimethyl K9, H3dimethyl $\mathrm{K} 4$ and $\mathrm{H} 3$-trimethyl $\mathrm{K} 4$ are readily released into the nucleus and all of them, except for H3-dimethyl $\mathrm{K} 9$, even accumulate in the cytosol after some time. 

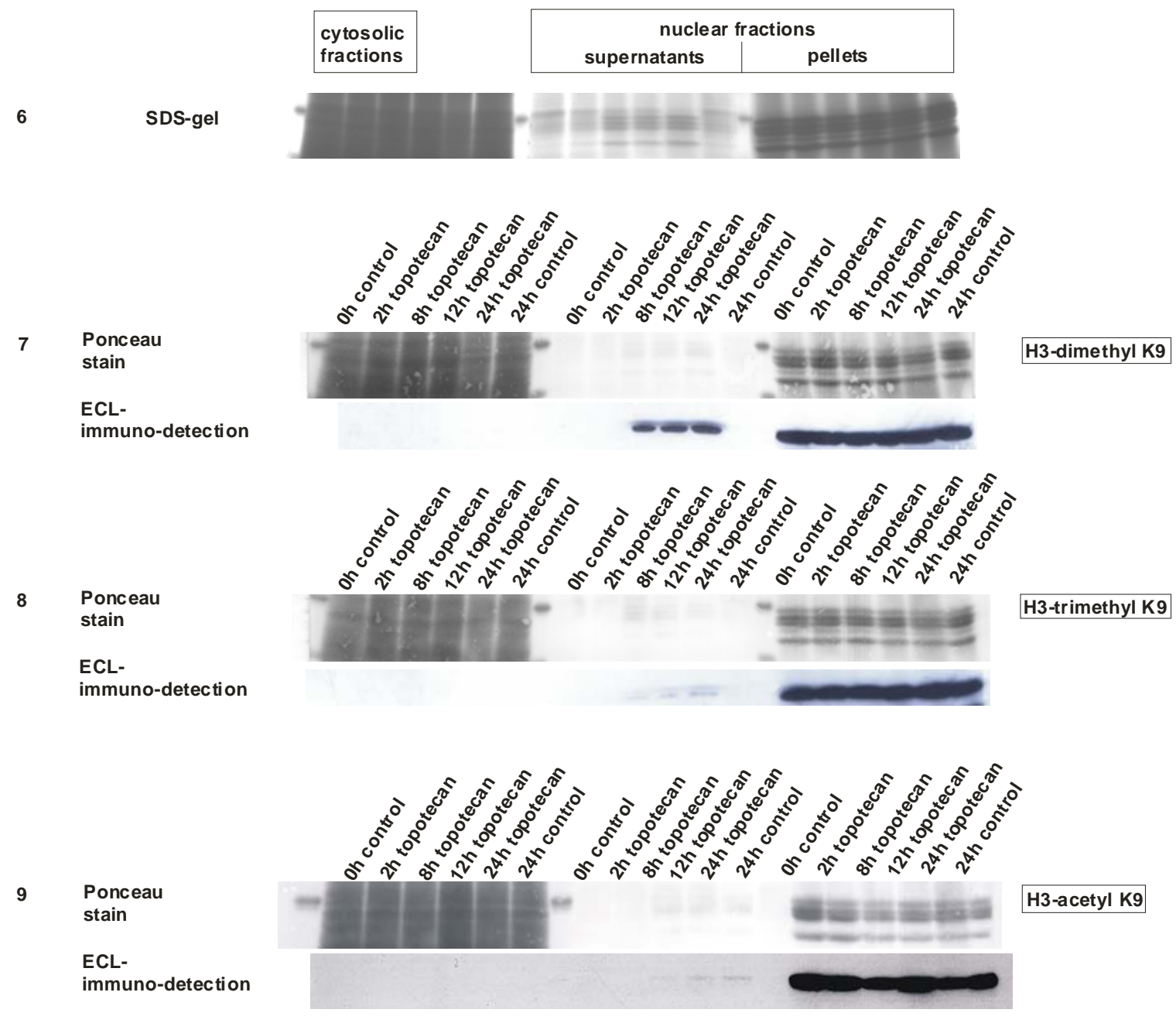

10 Ponceau

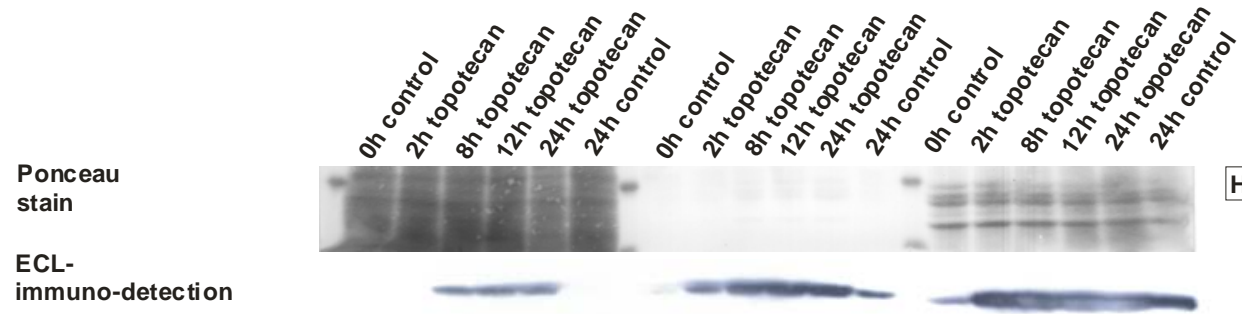

H2AX-phosphate S139

Fig. 3.8.1 (cont. 1) Western blot analyses of apoptosis-related nucleosomal cleavage and release of specifically modified core histones from bulk chromatin into the nucleus and cytosol. HL-60 cells were induced with topotecan ${ }^{\circledR}$ and harvested after $2 \mathrm{~h}, 8 \mathrm{~h}, 12 \mathrm{~h}$ and $24 \mathrm{~h}$. Cells harvested shortly after seeding and after $24 \mathrm{~h}$ of incubation served as control cells. Nuclei were prepared according to the protocol by Bunce et al. (Bunce et al., 1988). (6) SDS-gel presenting all cytosolic fractions, soluble nucleosomal material containing fractions and nuclear pellet fractions. Nucleosomal material was cleaved to a certain extent and histones were released from bulk chromatin regions into the nucleus and cytosol. (7) Western blot incubated with anti-H3-dimethyl K9 antibody. A gradual accumulation of dimethylated histone $\mathrm{H3}$ at lysine 9 was observed in nuclear supernatants. The concentration of $\mathrm{H3}-$ dimethyl K9 increased with time. No protein was detected in cytosolic fractions. (8) Western blot incubated with anti-H3-trimethyl K9 antibody. Only traces of trimethylated H3 were found in nuclear supernatants. No protein was detected in cytosolic fractions. (9) Western blot incubated with anti-H3acetyl K9 antibody. Only small traces of acetylated H3 on lysine 9 were detected within the nuclear supernatant. No H3 lysine 9 acetylation could be detected in the cytosolic fractions. (10) Western blot incubated with anti-H2AX-phosphate S139 antibody. This modification was massively released into the 


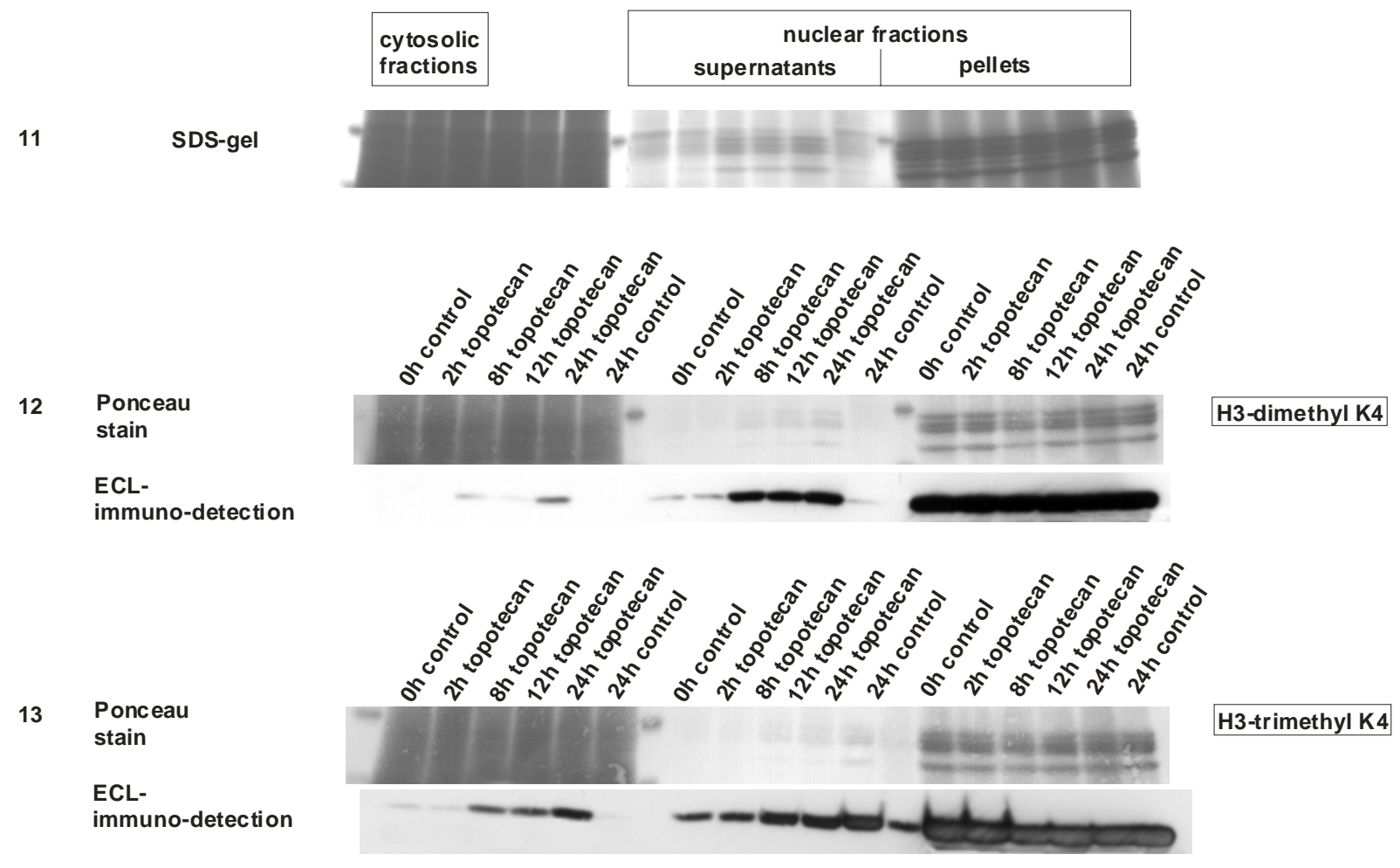

Fig. 3.8.1 (cont. 2) Western blot analyses of apoptosis-related nucleosomal cleavage and release of specifically modified core histones from bulk chromatin into the nucleus and cytosol. HL-60 cells were induced with topotecan ${ }^{\circledR}$ and harvested after 2 h, 8 h, 12 h and 24 h. Cells harvested shortly after seeding and after $24 \mathrm{~h}$ of incubation served as control cells. Nuclei were prepared according to the protocol by Bunce et al. (Bunce et al., 1988). (11) SDS-gel presenting all cytosolic fractions, soluble nucleosomal material containing fractions and nuclear pellet fractions. Nucleosomal material was cleaved to a certain extent and released from bulk chromatin regions into the nucleus. (12) Western blot incubated with anti-H3-dimethyl K4 and (13) anti-H3-trimethyl K4 antibody. H3-dimethyl K4 and H3-trimethyl K4 accumulated in large quantities in nuclear supernatants and were found in increasing concentrations in all cytosolic fractions.

\subsubsection{Histone release in HeLa H2B-YFP cells}

The histone release from nuclear bulk chromatin into the nucleoplasm and putatively into the cytosol was also investigated in the adherently growing cell line HeLa H2B-YFP.

For this purpose stably transfected HeLa H2B-YFP cells were induced with etoposide and harvested after 24 h, 36 h and 48 h incubation time. Additionally, cells which had not been induced were harvested after $24 \mathrm{~h}$ and $36 \mathrm{~h}$ and served as controls. Nuclei and cytosols were prepared from these cells according to the protocol by Bunce et al. (1988). Nuclei were subsequently lysed with hypotonic phosphate-EDTA buffer to open up the nuclear membrane and to release the soluble nucleosomal material. The nuclear pellet fraction and the supernatant were separated by centrifugation.

nucleus after induction of apoptosis. $8 \mathrm{~h}$ after induction of apoptosis, H2AX-phosphate S139 concentrations strongly increased in cytosolic fractions. 
All three fractions from all samples were separated by SDS-PAGE and transferred to nitrocellulose membranes by Western blotting. After that all membranes were incubated with antibodies raised against the respective single, unmodified core histone or against any specific histone modification.

Although slight signal intensities in the SDS-gel show a clear accumulation of low concentrations of all four core histones in nuclear supernatants from $24 \mathrm{~h}$ onwards after treatment with etoposide (Fig. 3.8.2 1), these results could only partially be confirmed by Western blots for reasons already mentioned. Results obtained from Western blots turned out to be quite heterogenic. For histones $\mathrm{H} 2 \mathrm{~A}$ and $\mathrm{H} 4$ we could neither detect any protein in nuclear supernatants nor in cytosolic fractions (Figs. 3.8.2 4 and 5). In contrast after induction of apoptosis, histone $\mathrm{H} 3$ was massively released from the chromatin and accumulated in the nuclear supernatants after $24 \mathrm{~h}$. After $36 \mathrm{~h}$ traces of $\mathrm{H} 3$ were also detected within the cytosolic fractions (Fig. 3.8.2 2). Comparatively low concentrations of histone $\mathrm{H} 2 \mathrm{~B}$ accumulated in nuclear supernatants $24 \mathrm{~h}$ after treatment with etoposide, but no $\mathrm{H} 2 \mathrm{~B}$ protein was found in any of the cytosolic fractions (Fig. 3.8.2 3). 


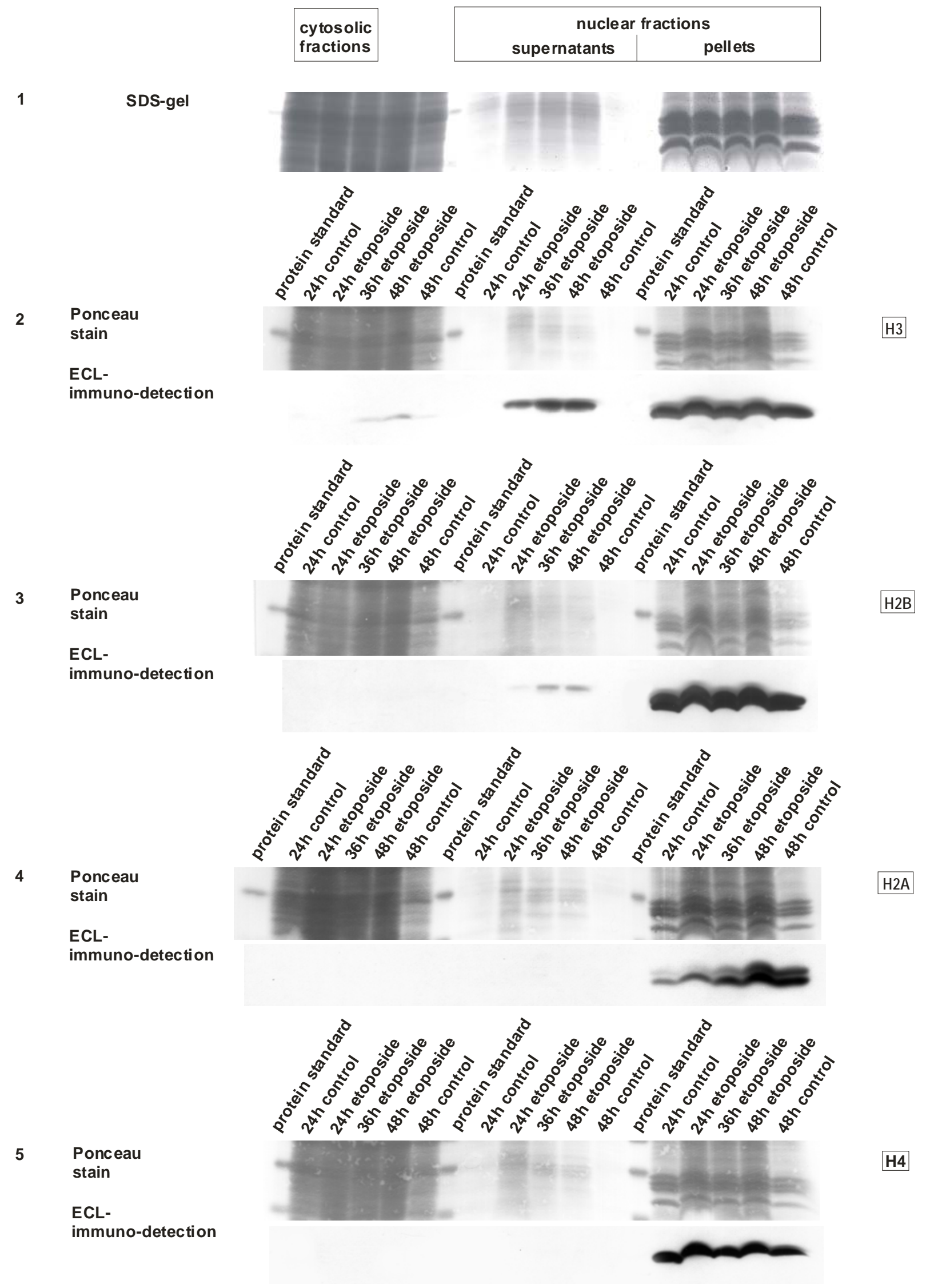


These variations within the series appeared to be less severe with reference to the analyses of specifically modified histones and their release into the cytosol. The same types of modification tested in HL-60 cells were also tested in HeLa-H2B-YFP cells.

Di- and trimethylated histone $\mathrm{H} 3$ at lysine 9 (Figs. 3.8.1 7 and 8) as well as phosphorylated histone subtype $\mathrm{H} 2 \mathrm{AX}$ (Fig. 3.8.2 10) were found to be accumulating in high concentrations in nuclear fractions $24 \mathrm{~h}$ post-induction. After $36 \mathrm{~h}-48 \mathrm{~h}$, traces of these modifications were even found in the cytosolic fractions. In contrast to that, acetylated histone $\mathrm{H} 3$ at lysine 9 was found in almost undetectable traces in nuclear supernatants. No H3-acetyl K9 protein was spotted in any of the cytosolic fractions (Fig. 3.8.2 9).

Analyses of di- and trimethylated histone $\mathrm{H} 3$ at lysine 4 showed almost identical results compared to di- and trimethylated histone $\mathrm{H} 3$ at lysine 9 . $\mathrm{H} 3$ histones methylated at lysine 4 also accumulated in large quantities in nuclear supernatants as early as $24 \mathrm{~h}$ post-induction. Small amounts of these histones were also found in the cytosolic fractions. H3-dimethyl K4 could only be detected after $48 \mathrm{~h}$, whereas H3-trimethyl $\mathrm{K} 4$ was even traced in cytosolic fractions of control cells and was found to be increasing with time (Figs. 3.8.2 12 and 13). Taking together all results from HeLa H2B-YFP cells, these differed in only one point from those, which were obtained from experiments with HL-60 with reference to trimethylated histone H3 at lysine 9. Whereas in HL-60 cells trimethylated histone H3 was found to be depleted in nuclear supernatants and cytosolic fractions, quite the opposite was observed in HeLa H2B-YFP cells. Here, trimethylated histone H3 accumulated in nuclear supernatants in large quantities $24 \mathrm{~h}$ after induction of apoptosis. So, it seems that cleavage of nucleosomal material from bulk chromatin regions together with the nuclear release of histones, is in some points dependent on multiple factors, such as cell type, concentration and type of inducer and incubation times.

Fig. 3.8.2 Western blot analyses of apoptosis-related nucleosomal cleavage and release of unmodified core histones from bulk chromatin into the nucleus and cytosol. HeLa H2B-YFP cells were induced with etoposide and harvested after $24 \mathrm{~h}, 36 \mathrm{~h}$ and $48 \mathrm{~h}$. Cells harvested after $24 \mathrm{~h}$ and $48 \mathrm{~h}$ without induction of apoptosis served as control cells. Nuclei were prepared according to the protocol by Bunce et al. (Bunce et al., 1988). The nuclei containing fractions were lysed subsequently using hypotonic phosphate-EDTA buffer. One of the resulting fractions contained soluble nucleosomal material, the other the remaining insoluble bulk chromatin. (1) SDS-gel showing all cytosolic fractions, soluble nucleosomal material containing fractions and nuclear pellet fractions. Very low concentrations of all types of core histones released from bulk chromatin regions into the nucleus. The amount of released histones increased with time. (2) Western blot incubated with anti-H3 antibody. Increasing amounts of histone $\mathrm{H} 3$ accumulated in the nucleus and low concentrations of $\mathrm{H} 3$ were also detected in the cytosol $36 \mathrm{~h}$ after incubation. (3) Western blot incubated with anti-H2B antibody. Small traces of histone $\mathrm{H} 2 \mathrm{~B}$ were detected in nuclear supernatants but not in any of the cytosolic fractions. (4) Western blot incubated with anti-H2A antibody. H2A was neither found in nuclear supernatants nor within cytosolic fractions. (5) Western blot incubated with anti-H4 antibody. No accumulation of $\mathrm{H} 4$ histones in nuclear supernatants or in cytosolic fractions could be observed. 


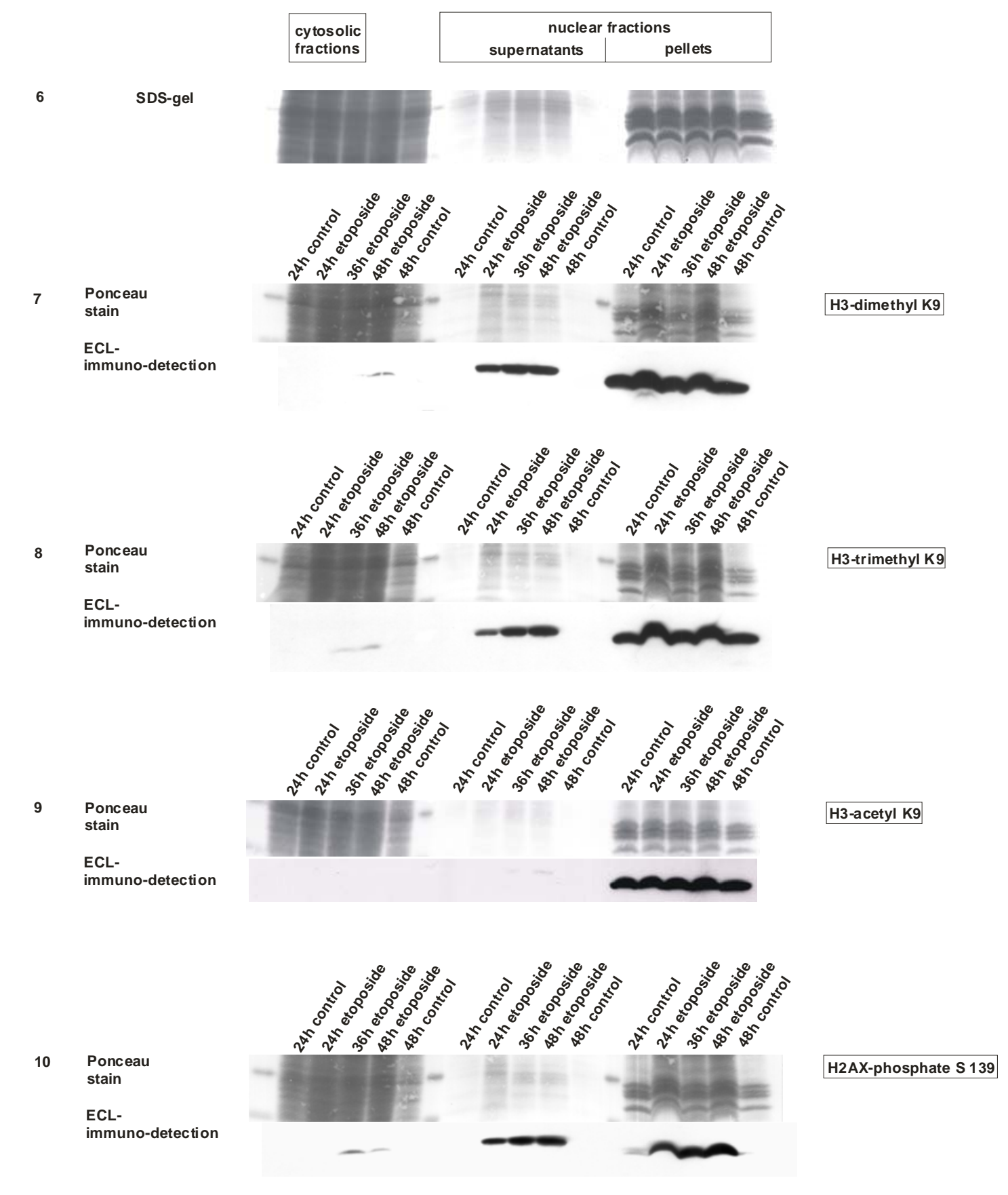

Fig. 3.8.2 (cont. 1) Western blot analyses of apoptosis-related nucleosomal cleavage and release of specifically modified core histones from bulk chromatin into the nucleus and cytosol. HeLa H2B-YFP cells were induced with etoposide and harvested after 24 h, 36 h and 48 h. Cells harvested after $24 \mathrm{~h}$ and $48 \mathrm{~h}$ without induction of apoptosis served as control cells. Nuclei were prepared according to the protocol by Bunce et al. (Bunce et al., 1988). The nuclei containing fractions were lysed subsequently using hypotonic phosphate-EDTA buffer. One of the resulting fractions contained soluble nucleosomal material, the other the remaining insoluble bulk chromatin. (6) SDS-gel with all cytosolic fractions, soluble nucleosomal material containing fractions and nuclear pellet fractions. All types of core histones were found to be accumulating in nuclear supernatants. The concentration of released histones increased with time from $24 \mathrm{~h}$ after induction onwards until $48 \mathrm{~h}$. (7) Western blot incubated with anti-H3-dimethyl K9 antibody, (8) anti-H3-trimethyl K9 (9) anti-H3-acetyl K9 antibody and (10) anti-H2AX-phosphate S139. H3-dimethyl K9, H3-trimethyl K9 and H2AX-phosphate S139 accumulated in large quantities in nuclear supernatants as early as $24 \mathrm{~h}$ and up to $48 \mathrm{~h}$ after etoposide treatment. Low concentrations were found in the cytosolic fractions $36 \mathrm{~h}$ post-induction. H3acetyl K9 was spotted in almost undetectable traces in nuclear supernatants after $24 \mathrm{~h}$, but there was no release of this modification observed in any of the cytosolic fractions. 


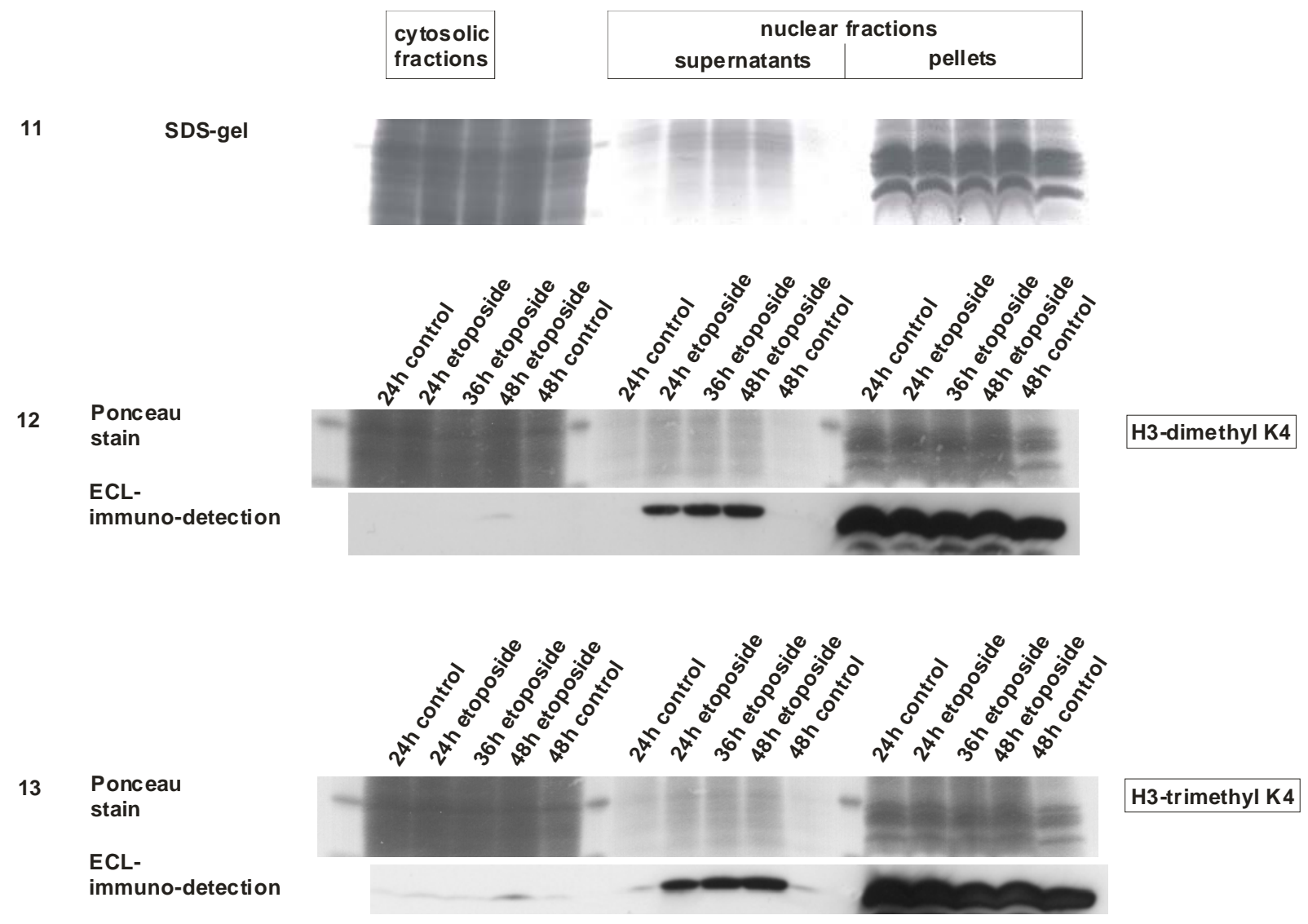

Fig. 3.8.2 (cont. 2) Western blot analyses of apoptosis-related nucleosomal cleavage and release of specifically modified core histones from bulk chromatin into the nucleus and cytosol. HeLa H2B-YFP cells were induced with etoposide and harvested after $24 \mathrm{~h}, 36 \mathrm{~h}$ and $48 \mathrm{~h}$. Cells harvested after $24 \mathrm{~h}$ and $48 \mathrm{~h}$ without induction of apoptosis served as control cells. Nuclei were prepared according to the protocol by Bunce et al. (Bunce et al., 1988). The nuclei containing fractions were lysed subsequently using hypotonic phosphate-EDTA buffer. One of the resulting fractions contained soluble nucleosomal material, the other the remaining insoluble bulk chromatin. (11) SDS-gel with all cytosolic fractions, soluble nucleosomal material containing fractions and nuclear pellet fractions. All types of core histones were released from bulk chromatin regions into the nucleus. The quantities of released histones increased with time from $24 \mathrm{~h}$ after induction onwards until $48 \mathrm{~h}$. (12) Western blot incubated with anti-H3-dimethyl K4 antibody and (13) anti-H3-trimethyl K4 antibody. High concentrations of both types of modification accumulated in nuclear supernatants as early as $24 \mathrm{~h}$ and up to $48 \mathrm{~h}$ after etoposide treatment. Low concentrations of them were traced in the cytosolic fractions. H3-dimethyl K4 could only be detected after $48 \mathrm{~h}$, whereas H3-trimethyl K4 was even traced in cytosolic fractions of control cells and was found to be increasing with time.

\subsubsection{Comparative analysis of nuclear histone release}

To compare and evaluate our results in connection with one of the main present date publications by Radic et al. (Radic et al., 2004), we used the nucleus-cytosol preparation protocol of this group and tested it with our cell line HL-60. This group analysed the apoptosis-related release of core histones and nucleosomes into the cytosol in Jurkat cells. As a result Radic et al. (Radic et al., 2004) stated that nucleosomes were exposed at the cell surface after the onset of apoptosis and this would indicate a key role for nucleosomes in the execution of apoptosis as well as a clearance of apoptotic cells. 
In our own experiments we observed a time-dependent release of specifically modified core histones into the nucleoplasm of both HeLa and HL-60 cells. However, a further massive release of these nuclear components could not be confirmed. Therefore we compared our own results and the nucleus-cytosol preparation that was used, with the protocol by Radic et al. (Radic et al., 2004). We tested the HL-60 cells using the same nucleus-cytosol preparation that Radic and co-workers used. The quality of the preparation was surveyed using markers of apoptosis, such as cleavage of nucleosomal DNA and PARP. About $2 \mathrm{~h}$ after induction of apoptosis, cleavage of nucleosomal DNA was monitored (Fig. 3.8.3 1; lane 3). PARP cleavage was observed $4 \mathrm{~h}$ after treatment with topotecan ${ }^{\circledR}$ with a slight delay in time (Fig. 3.8.3 2; lane 4). To check if the nuclei prepared were intact before the actual analysis was carried out, protein lysates from nuclear and cytosolic fractions were incubated with anti-lactate dehydrogenase as a cytosolic marker and anti-PARP antibody as a nuclear marker. No cytosolic protein was found in any of the nuclear fractions (Fig. 3.8.3 3), however, various small and full length fragments of PARP were traced in different concentrations in all cytosolic fractions (Fig. 3.8.3 4; lanes 2-6). Due to this fact it cannot be denied that nuclei from this preparation seemed to have suffered some greater leaks resulting from preparation procedures. In this study this particular problem was avoided in a way that several protocols had been tested in advance for their yield of morphologically and biochemically intact nuclei. 


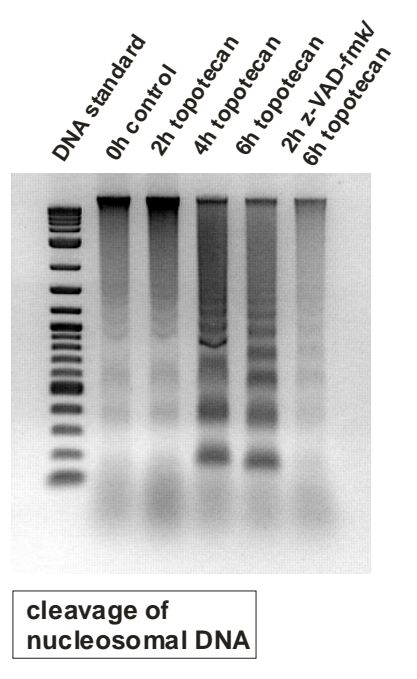

3

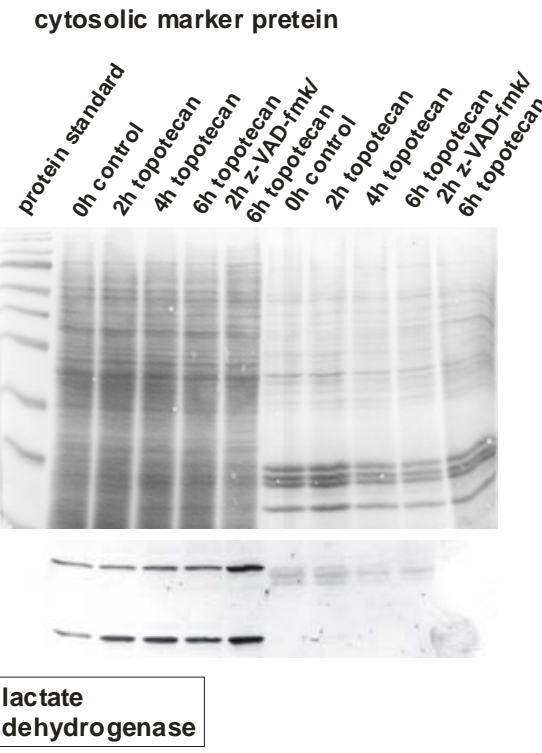

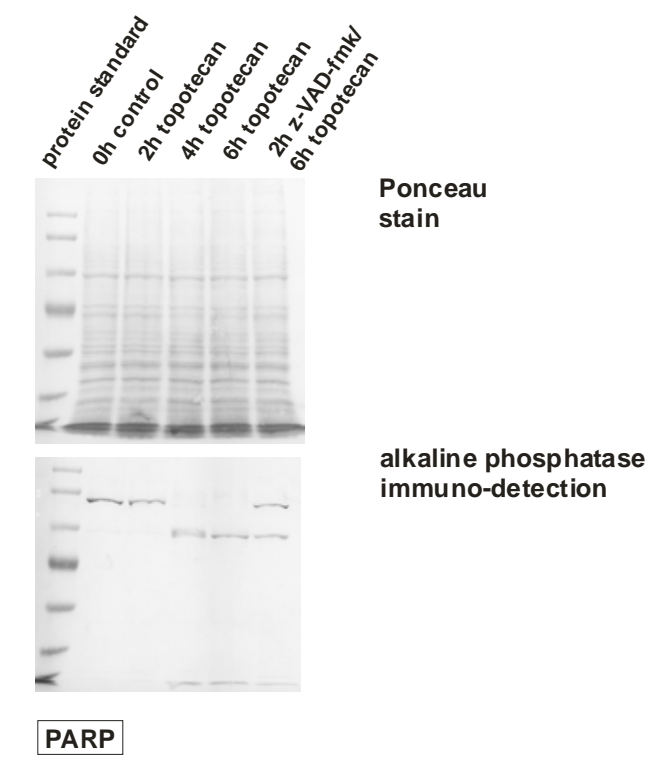

4

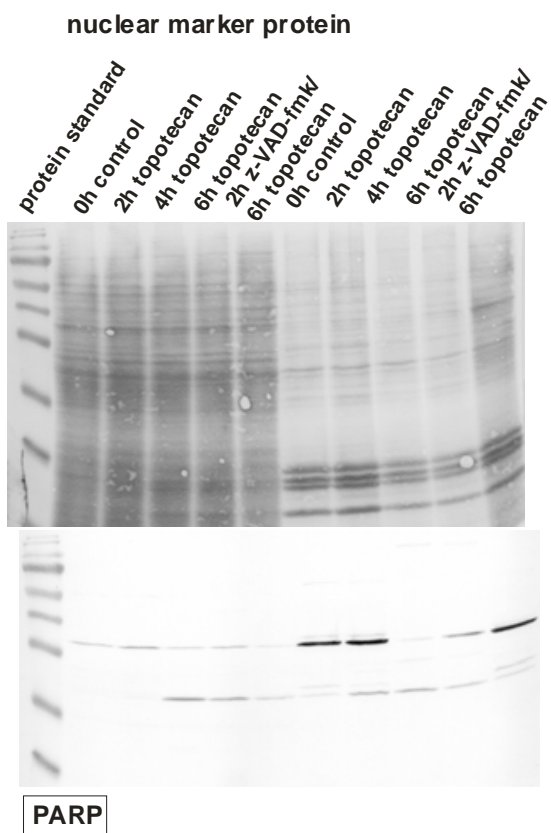

Fig. 3.8.3 Monitoring the ongoing process of apoptosis with reference to the nucleus-cytosol preparation protocol according to Radic et al. (2004). HL-60 cells were induced with topotecan ${ }^{\circledR}$ and harvested according to the protocol by Radic et al. (Radic et al., 2004). Cells harvested shortly after seeding served as negative controls, whereas cells pre-treated with the caspase 3 inhibitor z-VAD-fmk before induction, were used as positive control, to monitor the induction efficiency. Nucleosomal DNA and cell lysates for PARP cleavage were prepared. (1) Nucleosomal DNA after induction of apoptosis. Nucleosomes were detected as early as $2 \mathrm{~h}$ after drug treatment and their concentration increased during apoptosis. (2) Western blot incubated with anti-PARP antibody. PARP cleavage was first monitored $4 \mathrm{~h}$ after induction of apoptosis. (3) Western blot incubated with anti-lactate dehydrogenase antibody. With reference to the nucleus-cytosol preparation protocol by Radic et al. (2004) the cytosolic marker lactate dehydrogenase was not detected in any of the nuclear fractions prepared. (4) Western blot incubated with anti-PARP antibody. PARP was used as a nuclear marker. Various small and full length fragments of PARP were traced in all cytosolic fractions. 


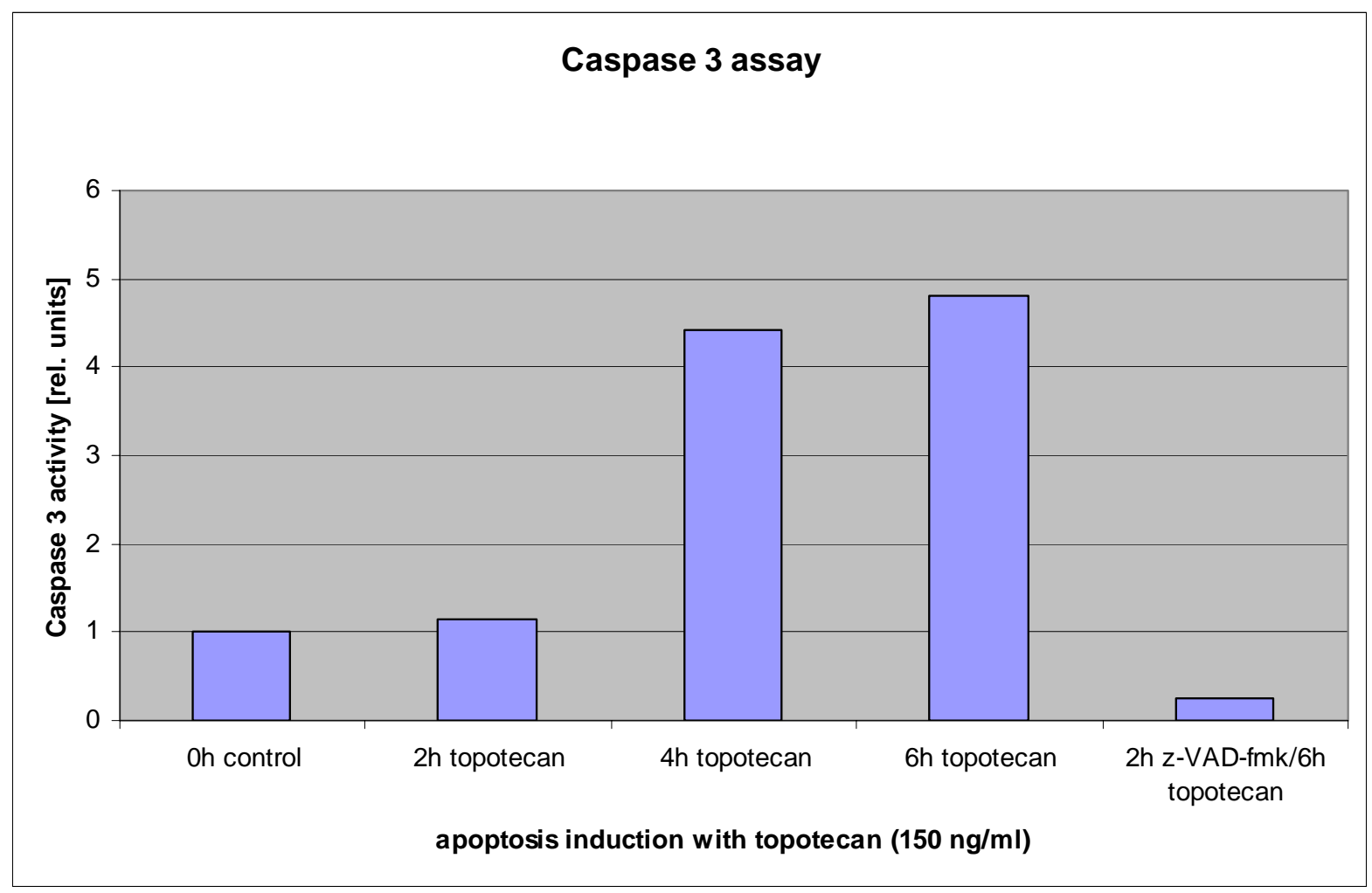

Fig. 3.8.3 (cont. 1) Monitoring the ongoing process of apoptosis with reference to the nucleus-cytosol preparation protocol according to Radic et al. (2004). HL-60 cells were induced with topotecan ${ }^{\circledR}$ and harvested according to the protocol by Radic et al. (Radic et al., 2004). Cells harvested shortly after seeding served as negative controls, whereas cells pre-treated with the caspase 3 inhibitor z-VAD-fmk before induction, were used as positive control, to monitor the induction efficiency. (5) Caspase 3 assay. A strong increase in caspase 3 activity was observed $4 \mathrm{~h}$ after induction of apoptosis.

To investigate a putative apoptosis-related nuclear histone release on the basis of the preparation by Radic et al. (Radic et al., 2004) compared to our own experiments reported earlier (chap. 3.8.1), protein lysates from nuclear and cytosolic fractions were separated via SDS-PAGE. As a result, gradually increasing concentrations of all four histone types were detected to a certain extent in all cytosolic fractions, including the cytosolic control fraction (Fig. 3.8.3 6; lanes 2-5). Western blot analyses just confirmed these findings. Blots incubated with anti-H3, anti-H2B, anti-H2A and anti-H4 antibodies showed a gradual accumulation of all four core histones into the cytosol (Fig. 3.8.3 7-10). Depending on the quality of the antibody's binding specificity, signal intensities varied quite a bit, however, the overall result was not influenced by it.

As a general rule, it can be assumed that the outcome of most experiments in the area of apoptosis-related nucleosomal cleavage and subsequent release of core histones from bulk chromatin into the nucleus and later on into the cytosol, always remains a question of methodical approach. Only if these differences are taken into account, it will be possible to pronounce general statements that can be properly evaluated. 
6

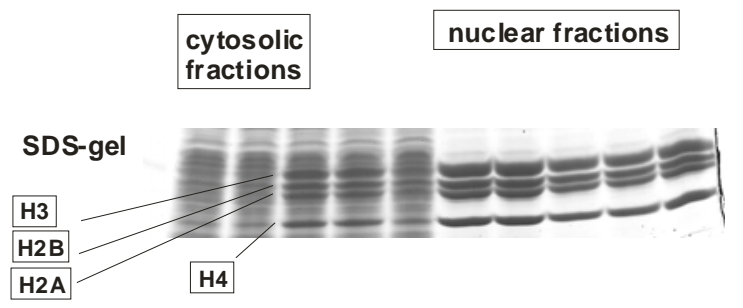

8
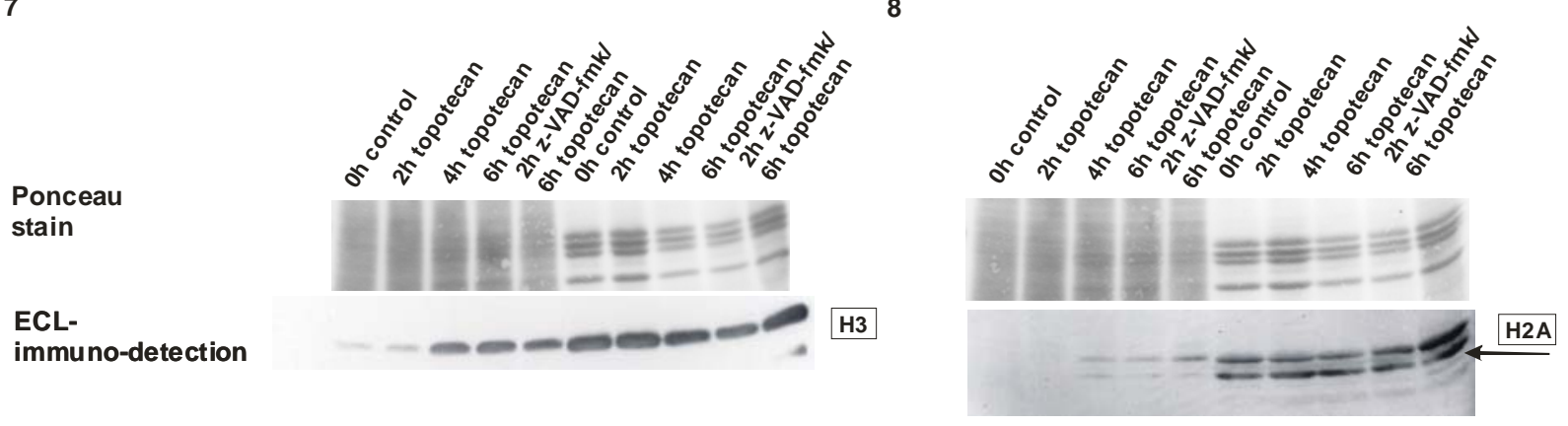

9

Ponceau

stain

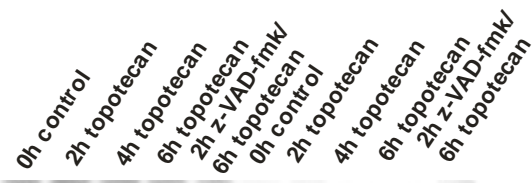

10
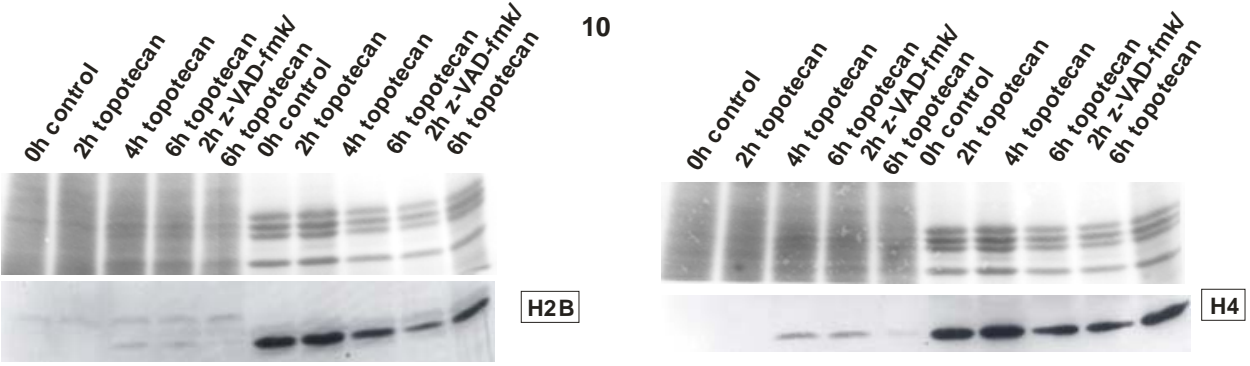

ECL-

immuno-detection

H2B

Fig. 3.8.3 (cont. 2) Western blot analyses of apoptosis-related nucleosomal cleavage and release of core histones from bulk chromatin into the nucleus and cytosol with reference to a nucleus-cytosol preparation protocol by Radic et al. (2004). HL-60 cells were induced and harvested as described by Radic et al. (Radic et al., 2004). (6) Coomassie stained SDS-gel showing cytosolic fractions (left) and nuclear fractions (right) after nucleus-cytosol preparation. With the onset of apoptosis increasing concentrations of all four core histone types were visible in all cytosolic fractions. These could even be traced in control samples. (7, 8 and 10) Western blots incubated with anti- $\mathrm{H} 3$, anti- $\mathrm{H} 2 \mathrm{~A}$ and anti- $\mathrm{H} 4$ antibodies. The signal intensities in all three blots more or less increased gradually after induction of apoptosis, however, traces of $\mathrm{H} 3$ were already found in the cytosolic fraction of the control sample. (9) Western blot incubated with anti-H2B antibody. Although the antibody almost failed to detect $\mathrm{H} 2 \mathrm{~B}$ protein in the cytosolic fractions, traces could still be found.

With relation to the protocol by Radic et al. (Radic et al., 2004), all Western blot analyses of apoptosis-related nucleosomal cleavage and release of core histones from bulk chromatin into the nucleus and cytosol, of course could not have produced any different results, as the ones presented here. The fact that Radic and co-workers used cytosolic and nuclear lysates rather than cautiously prepared morphological as well as biochemically intact nuclei, could only result in a gradual increase in released histone types from the nucleus into the cytosol. 


\subsection{Microscopic analyses of an apoptosis-related nuclear release of core histones in stably transfected HeLa H2B-YFP cells}

To further investigate a possible release of core histones first into the nucleoplasm and finally into the cytosol, a different methodical approach on the basis of fluorescence microscopy with stably transfected HeLa YFP-H2B cells was taken, to verify or confirm the results from the Western blot analyses (chapter 3.8).

\subsubsection{Microscopic analysis of the nuclear lamina (lamin A/C) in HeLa H2B-YFP cells after induction of apoptosis.}

For the analysis of a putative histone $\mathrm{H} 2 \mathrm{~B}$ release into the cytosol after induction of apoptosis, we chose two proteins, lamin $\mathrm{A} / \mathrm{C}$ and $\mathrm{N}$-acetylglucosamine to check if either the nuclear envelope or the lamina might show a leakage, which finally might lead to a histone release in the course of these events. Moreover, a protein of the cytoskeleton, tubulin- $\alpha$, was chosen, which gave us the opportunity to trace any possibly released $\mathrm{H} 2 \mathrm{~B}$ histones into the cytosol.

HeLa H2B-YFP cells were cultivated on cover slips and treated with etoposide to induce apoptosis. The cells were harvested after $36 \mathrm{~h}$. Untreated cells harvested in parallel after 24 $\mathrm{h}$ and $48 \mathrm{~h}$ served as controls (data not shown). Cells were incubated with anti-lamin A/C primary antibody and AlexaFluor488-labelled goat anti-rabbit antibody as secondary antibody. All cells were subsequently embedded in mounting medium with DAPI.

After $36 \mathrm{~h}$ of incubation the majority of cells showed signs of chromatin condensation, forming up regions of tightly packaged chromatin (Fig. 3.9.1 DAPI; top). At this point the YFP-tagged histone $\mathrm{H} 2 \mathrm{~B}$ was co-located with the DAPI stained chromatin. All condensed chromatin regions were congruent with the regions marked with YFP-tagged $\mathrm{H} 2 \mathrm{~B}$. Histone $\mathrm{H} 2 \mathrm{~B}$ was not spotted outside the nuclear area (Fig. 3.9.1 H2B-YFP; centre). To support these findings, a closer look was taken at the structure of the nuclear lamina. In physiological and morphological intact cells the nuclear lamina usually forms a kind of smooth, close-fit meshwork at the inner surface of the nuclear membrane, which keeps the chromatin within its boundaries. Once the cells underwent apoptosis between $24 \mathrm{~h}$ to $36 \mathrm{~h}$, while the chromatin reached a certain state of compaction, the lamina in HeLa H2B-YFP cells started to disintegrate (Fig. 3.9.1; bottom). Even though the internal nuclear structure was degraded, histone $\mathrm{H} 2 \mathrm{~B}$ remained tightly packaged within the centre of the nucleus, where it was colocated in the same places as was the chromatin (DAPI stain). No H2B histones were found outside the condensed chromatin region. 

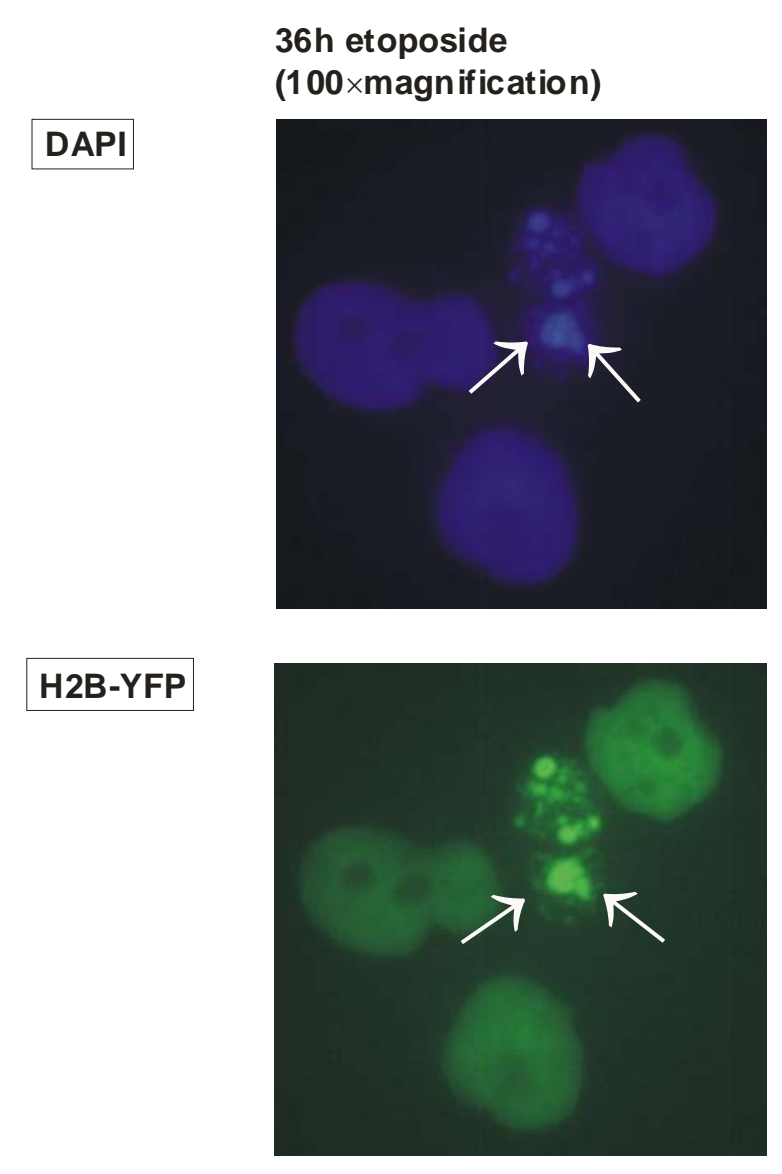

$\operatorname{lamin} A / C$

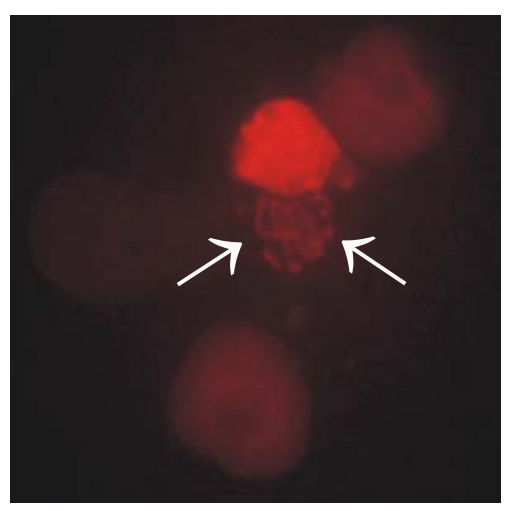

Fig. 3.9.1 Immuno-fluorescence microscopic analysis of histone H2B release in comparison with lamin A/C $36 \mathrm{~h}$ after induction of apoptosis (100xmagnification). Stably transfected HeLa H2B-YFP cells were treated with etoposide to induce apoptosis. The cells were harvested after $36 \mathrm{~h}$. Untreated cells were harvested after $24 \mathrm{~h}$ and $48 \mathrm{~h}$ and served as controls (data not shown). Cells were incubated with antilamin A/C primary antibody and were embedded in mounting medium containing the DNA dye DAPI. The cells were analysed via fluorescence microscopy. Besides three unaffected cells the panels show two single apoptotic cells with regions of highly condensed chromatin within the nuclear area, which is still surrounded by the slowly disintegrating nuclear lamina (100×magnification). DNA stained with DAPI (top); YFP tagged H2B (centre); immuno-staining with anti-lamin A/C antibody (bottom). No leakage of histone H2B was observed. 


\subsubsection{Analysis of the nuclear lamina in HeLa H2B-YFP cells after induction of apoptosis via laser-scan microscopy}

In addition to analyses with a conventional microscope, we also approached the question of a putative histone $\mathrm{H} 2 \mathrm{~B}$ release into the cytosol after induction of apoptosis, in more detail via laser-scan microscopy. This gave us the chance of a higher resolution as well as a direct localisation of $\mathrm{H} 2 \mathrm{~B}$ histones with relation to the lamin meshwork. A co-localisation was achieved with the help of merging figures.

HeLa H2B-YFP cells were treated as described. To ensure that the cells were morphologically intact at the time of induction of apoptosis and even after $48 \mathrm{~h}$ of further cultivation, $24 \mathrm{~h}$ and $48 \mathrm{~h}$ controls were harvested in parallel. All control cells showed a smooth, fully intact nuclear lamina, which holds histones H2B (i.e. the chromatin) within the centre of the nucleus (Figs. 3.9.2 1 and 5).

A comparison of lamin A/C with YFP-tagged H2B clearly showed that from $24 \mathrm{~h}$ postinduction onwards, chromatin condensation and $\mathrm{H} 2 \mathrm{~B}$ histones respectively were constantly increasing, until almost all chromatin was tightly packaged into small, vesicle-like structures (Figs. 3.9.2 2-4). Despite the slowly disintegrating lamin meshwork, regions of tightly packaged YFP-tagged histones H2B clearly remained fixed within the nuclear area (Fig. 3.9.2 3; white arrows). We did not observe any histone $\mathrm{H} 2 \mathrm{~B}$ release from the nucleus into the cytosol at any time during the chosen incubation times.

With the help of Western blot analyses, apoptosis-related cleavage of lamin A was observed in HeLa H2B-YFP (Fig. 3.9.2 6), a finding that additionally supports the results already gained from microscopy and the LSM data. The smaller fragments of lamin A (23 kDa) were released into the cytosol $24 \mathrm{~h}$ post-induction. Low concentrations of lamin A were also traced within nuclear supernatant fractions (Fig. 3.9.2 5). Concentrations of cleaved lamin $A$ increased with time in both nuclear supernatants and cytosolic fractions.

All in all it can be recorded that even $48 \mathrm{~h}$ after induction of apoptosis, while the nuclear lamina was slowly breaking up, no histones H2B were detected outside the nuclear boundaries. Still it remains to be elucidated, why histones and chromatin are kept tightly packaged within the nucleus despite its slowly collapsing structures.

medium containing the DNA dye DAPI. The cells were analysed via laser-scan microscopy. (1) $24 \mathrm{~h}$ controls and (5) $48 \mathrm{~h}$ controls confirmed that the cells were morphologically intact at the time of induction of apoptosis and even after $48 \mathrm{~h}$ of further cultivation. (2 merge) $24 \mathrm{~h}$ after induction of apoptosis some cells showed signs of chromatin condensation. Regions of tightly packaged YFPtagged histones $\mathrm{H} 2 \mathrm{~B}$ clearly remained within the nuclear area, surrounded by the nuclear lamin meshwork. (3 merge) After $36 \mathrm{~h}$ and with the progressing state of apoptosis, compaction of $\mathrm{H} 2 \mathrm{~B}$ histones went on but despite the disintegrating lamin meshwork (white arrows), H2B histones were still kept in the centre of the nucleus. (4 merge) $48 \mathrm{~h}$ post-induction $\mathrm{H} 2 \mathrm{~B}$ histones were only detected within the boundaries of the nucleus. 


\section{H2B-YFP}

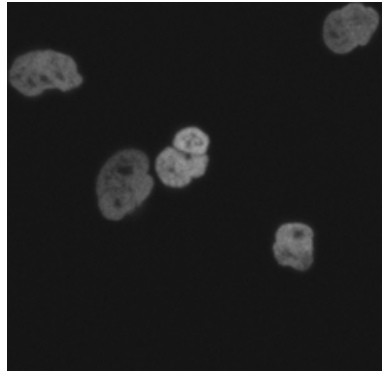

2

$24 \mathrm{~h}$ etoposide

$36 \mathrm{~h}$ etoposide

48h etoposide

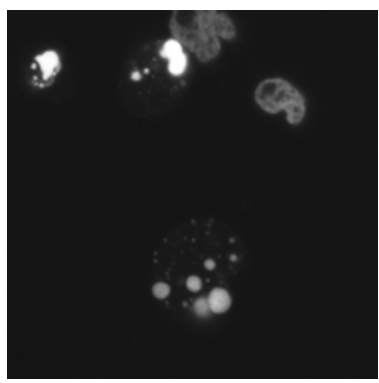

48h control
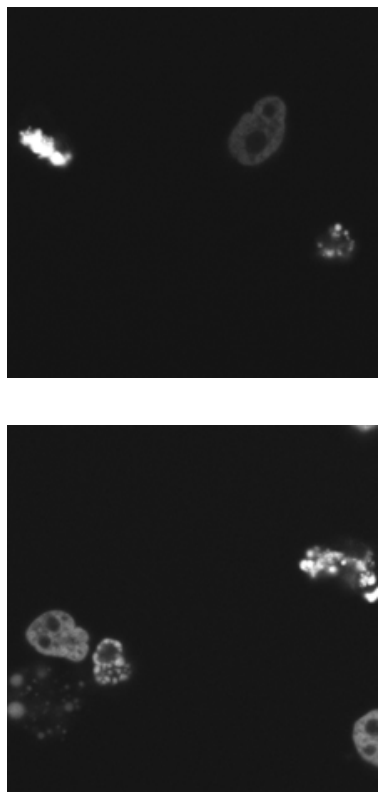

$\operatorname{lamin} A / C$

merge
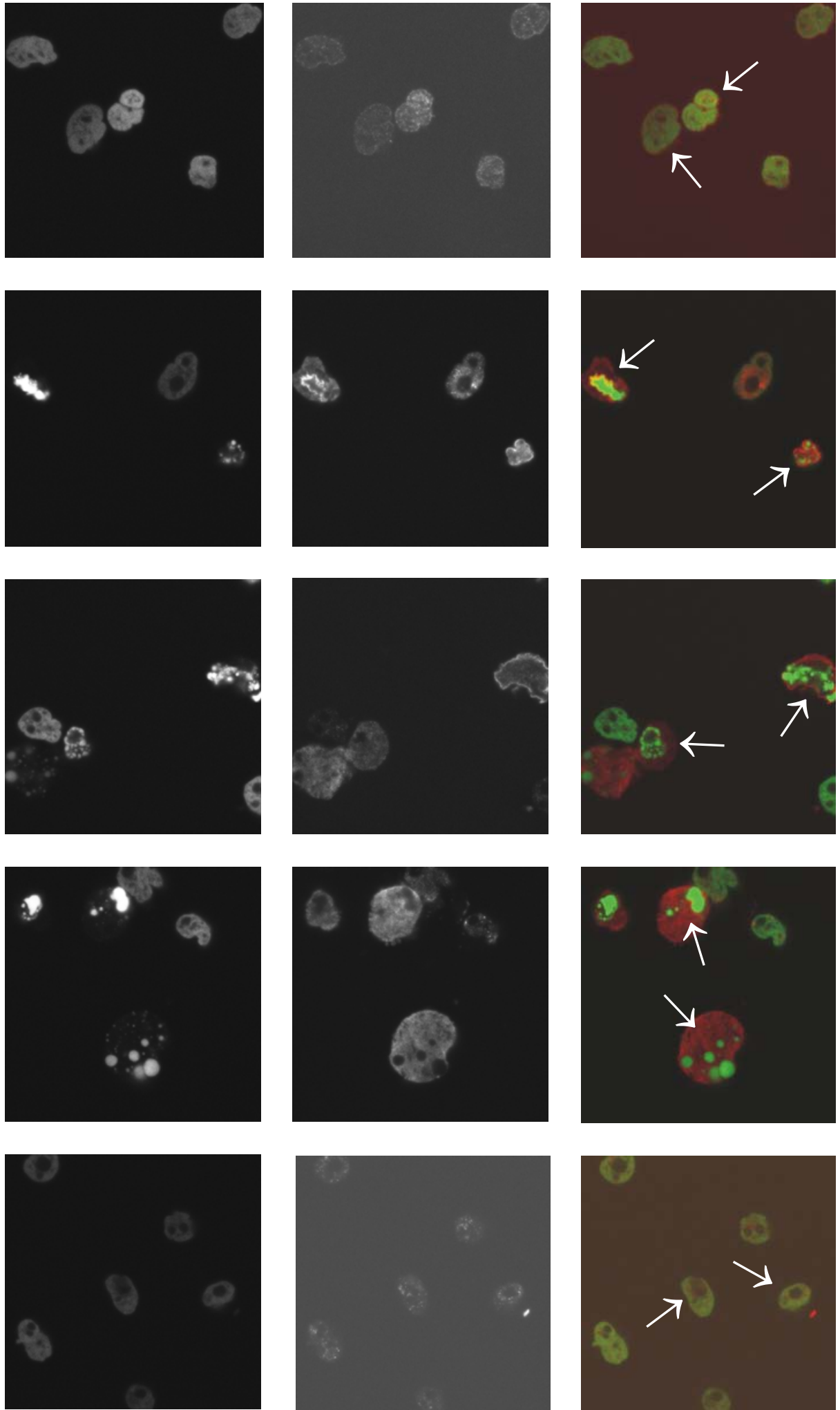

Fig. 3.9.2 Laser-scan microscopic analysis of histone H2B release in comparison with the nuclear marker protein lamin A after treatment with etoposide (100xmagnification). Stably transfected HeLa H2B-YFP cells were treated with etoposide to induce apoptosis and harvested after $24 \mathrm{~h}, 36 \mathrm{~h}$ and $48 \mathrm{~h}$. Untreated cells were harvested after $24 \mathrm{~h}$ and $48 \mathrm{~h}$ and served as controls. All cells were incubated with anti-lamin A/C primary antibody and were subsequently embedded in mounting 


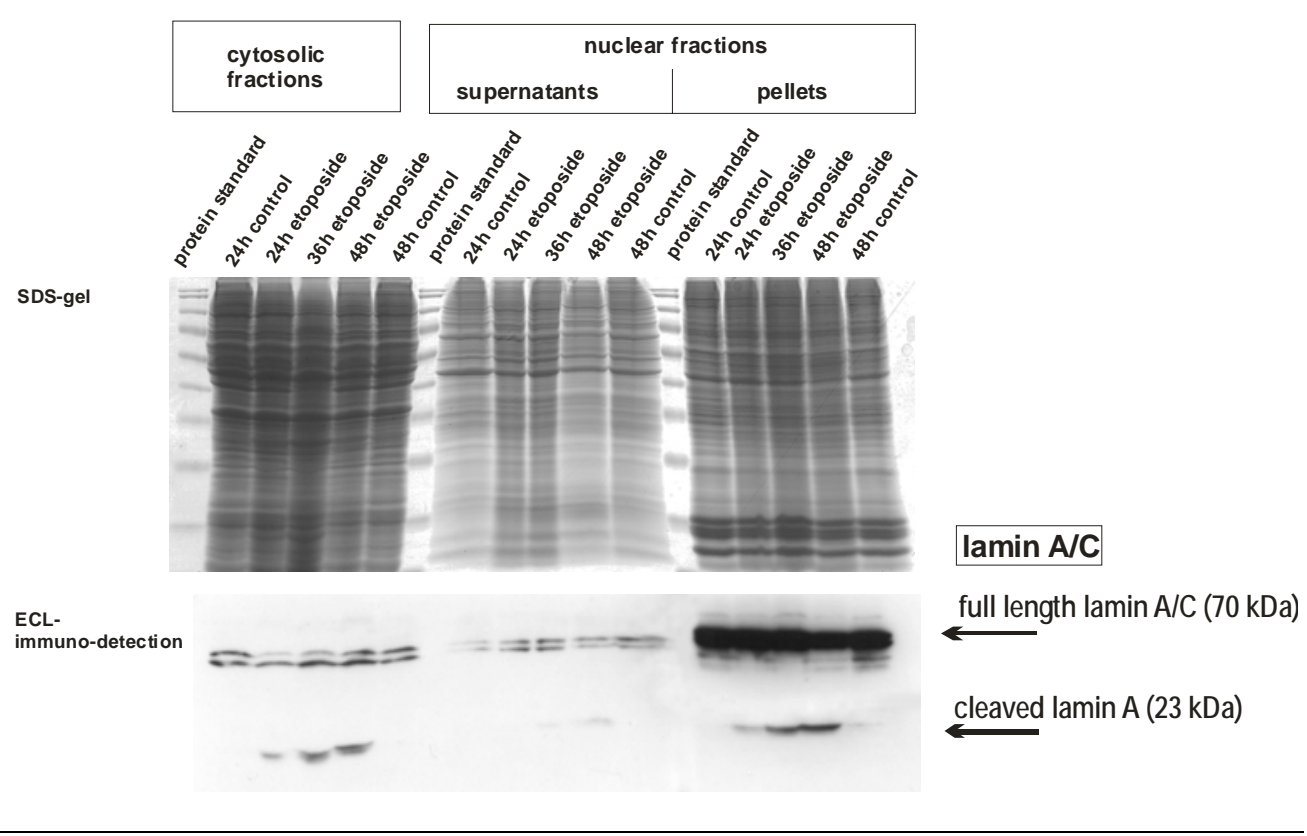

Fig. 3.9.2 (cont. 1) Western blots of apoptosis-related lamin A cleavage and release into the cytosol. HeLa H2B-YFP cells were induced with etoposide and harvested after $24 \mathrm{~h}, 36 \mathrm{~h}$ and $48 \mathrm{~h}$. Cells harvested after $24 \mathrm{~h}$ and $48 \mathrm{~h}$ without induction of apoptosis served as control cells. Nuclei were prepared according to the protocol by Bunce et al. (Bunce et al., 1988). The nuclei containing fractions were lysed subsequently using hypotonic phosphate-EDTA buffer. One of the resulting fractions contained soluble nucleosomal material, the other the remaining insoluble bulk chromatin. (6) Cleavage of nuclear lamin A in HeLa H2B-YFP cells after induction of apoptosis. Small fragments of cleaved lamin A $(23 \mathrm{kDa})$ were detected in all fractions after $24 \mathrm{~h}$ (nuclear pellet, nuclear supernatant and cytosolic fractions) in different concentrations. Concentrations of cleaved lamin A increased with time.

\subsubsection{Microscopic analysis of the nuclear membrane via $\mathrm{N}$-gycosylated nuclear pore complex proteins (anti-N-acetylglucosamine) in HeLa H2B-YFP cells after induction of apoptosis.}

Although we could show the apoptosis-related release of cleaved lamin A into the cytosol using conventional and laser-scan microscopy, we could not observe any leakage of $\mathrm{H} 2 \mathrm{~B}$ histones from the nucleus into the cytosol. To further verify this data, additional analyses were carried out, using an anti-N-acetylglucosamine primary antibody, which detects eight different glycosylated proteins from the nuclear pore complex. With the help of this antibody we could monitor the possible interaction of nuclear structures together with a putative release of $\mathrm{H} 2 \mathrm{~B}$ histones. 
For the following series of microscopic analyses HeLa H2B-YFP cells were treated in the same way as described above. To ascertain that all cells were morphologically intact at the time of induction of apoptosis and even after $48 \mathrm{~h}$ of further cultivation, $24 \mathrm{~h}$ and $48 \mathrm{~h}$ controls were harvested in parallel (data not shown). A comparison of our nuclear membrane structure marker $\mathrm{N}$-acetylglucosamine with YFP-tagged H2B clearly showed, that $36 \mathrm{~h}$ after induction of apoptosis, with the increasing state of chromatin condensation and H2B histone packaging respectively, no release of chromatin or histone $\mathrm{H} 2 \mathrm{~B}$ was observed, despite the disintegration of nuclear membrane structures (Fig. 3.9.3). The chromatin (i.e. H2B histones) remained fixed in its place inside the 'nucleus' until all cellular material was packaged into apoptotic bodies. The phase contrast and H2B-YFP photos show the tightly enclosed chromatin particles within the remaining part of the nucleus, which in itself showed to be slowly degraded (Fig. 3.9.3; N-acetylglucosamine).

36h etoposide

(40× magnification)

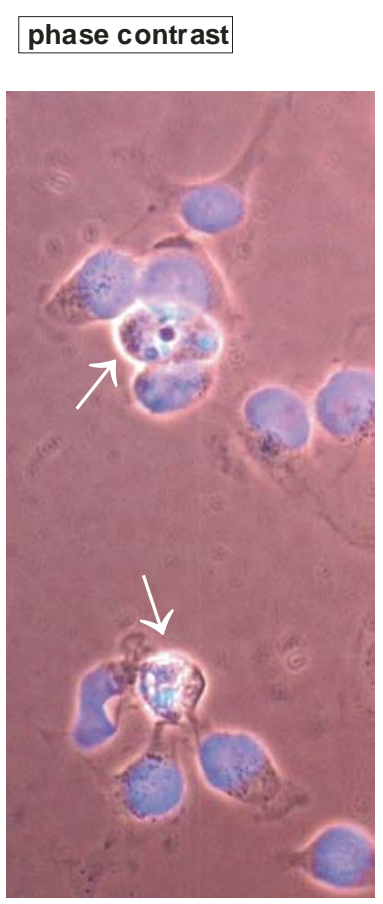

DAPI

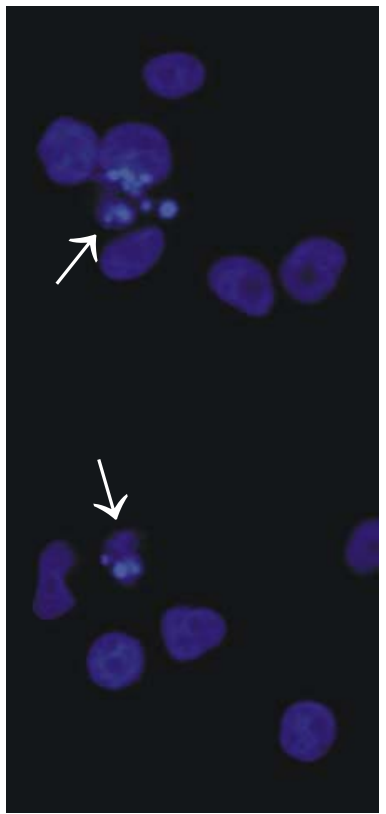

H2B-YFP

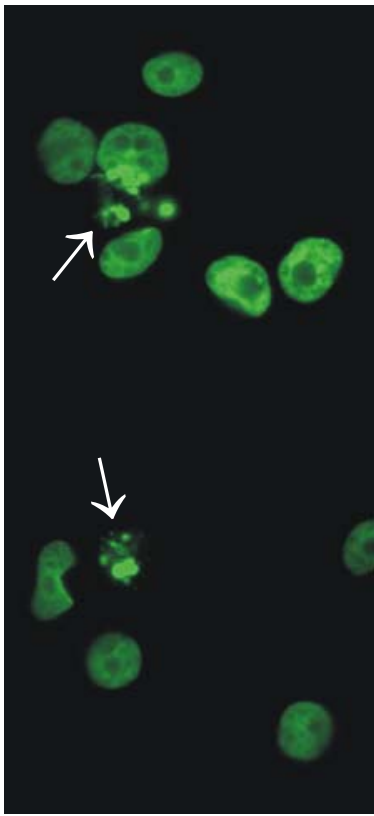

N-acetylglucosamine

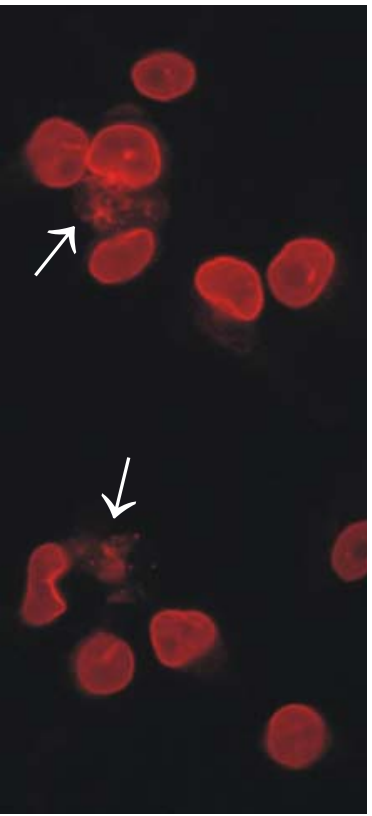

Fig. 3.9.3 Immuno-fluorescence microscopic analysis of histone $\mathrm{H} 2 \mathrm{~B}$ release in comparison with $\mathrm{N}$ acetylglucosamine after treatment with etoposide (40xmagnification). Stably transfected HeLa H2B-YFP cells were treated with etoposide to induce apoptosis. The cells were harvested after $24 \mathrm{~h}, 36 \mathrm{~h}$ and $48 \mathrm{~h}$ (data for $24 \mathrm{~h}$ and $48 \mathrm{~h}$ not shown). Untreated cells were harvested after $24 \mathrm{~h}$ and $48 \mathrm{~h}$ and served as controls. All cells were incubated with anti-N-acetylglucosamine primary antibody and were embedded in mounting medium containing DAPI. The cells were analysed via fluorescence microscopy. $36 \mathrm{~h}$ post-induction the packaging of chromatin and H2B histones was clearly visible. Regions of chromatin condensation were surrounded by the nuclear envelope, which in itself was slowly breaking up. Chromatin and histones remained fixed within the centre of the nucleus. No chromatin or histone $\mathrm{H} 2 \mathrm{~B}$ was observed to leak from the nuclear centre. 


\subsubsection{Analysis of the nuclear envelope in HeLa H2B-YFP cells via laser-scan microscopy after induction of apoptosis}

Further analyses of this matter via laser-scan microscopy basically support these facts. HeLa H2B-YFP cells were treated as before. Untreated cells that were harvested after $24 \mathrm{~h}$ and 48 $\mathrm{h}$ served as control cells. The smooth appearance of the nuclear membrane indicates that all cells were morphologically intact at the time of induction of apoptosis and for further cultivation over $48 \mathrm{~h}$ (Figs. 3.9.4 1 and 5).

$24 \mathrm{~h}$ after treatment with etoposide the nuclear membrane was found to neatly enclose the already condensing chromatin particles and tightly packaged H2B histones (Fig. 3.9.4 2; white arrows). No histones or DNA were detected outside the nuclear membrane, which seemed to function as a kind of barrier. During the ongoing process of apoptosis, the nuclear membrane somehow collapsed (Figs. 3.9.4 3 and 4; white arrows), however, condensed chromatin particles and $\mathrm{H} 2 \mathrm{~B}$ histones respectively were still held back in their position within the nucleus. Even with reference to the outer part of the nuclear membrane, no signs of a release and subsequent accumulation of $\mathrm{H} 2 \mathrm{~B}$ histones were visible.

As a result, these laser-scan analyses confirmed the findings already obtained by conventional microscopy. It was still surprising that obviously with the loss of integrity of the nuclear membrane and lamina during the process of apoptosis, chromatin and histones (i.e. H2B) still remained in their places. This result put up the following question: how and by which molecular structures is the chromatin still held in its place? To approach this question we finally chose an antibody directed against the cytosolic structure component tubulin- $\alpha$.

(1) $24 \mathrm{~h}$ controls and (5) $48 \mathrm{~h}$ controls confirmed that the cells were morphologically intact at the time of induction of apoptosis and even after $48 \mathrm{~h}$ of further cultivation. (2 merge) The nuclear membrane was wrapped around the condensed chromatin particles and tightly packaged H2B histones. No histones or DNA were detected outside the nuclear membrane. (3) $36 \mathrm{~h}$ and (4) $48 \mathrm{~h}$ after etoposide treatment, although the nuclear membrane slowly collapsed, condensed chromatin particles and $\mathrm{H} 2 \mathrm{~B}$ histones respectively were held in their position within the nucleus (white arrows). 
$24 \mathrm{~h}$ etoposide

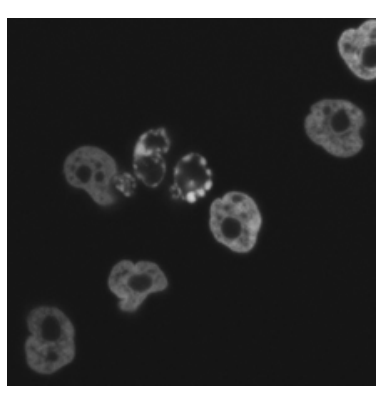

$36 \mathrm{~h}$ etoposide

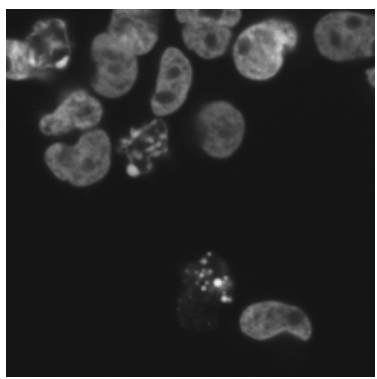

4

48h etoposide

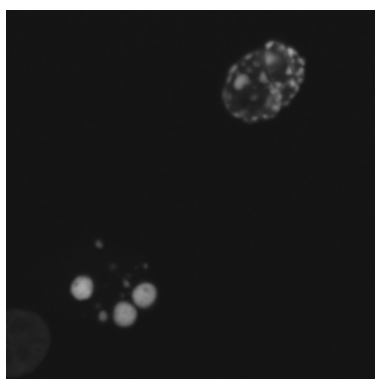

$48 \mathrm{~h}$ control

\section{H2B-YFP}
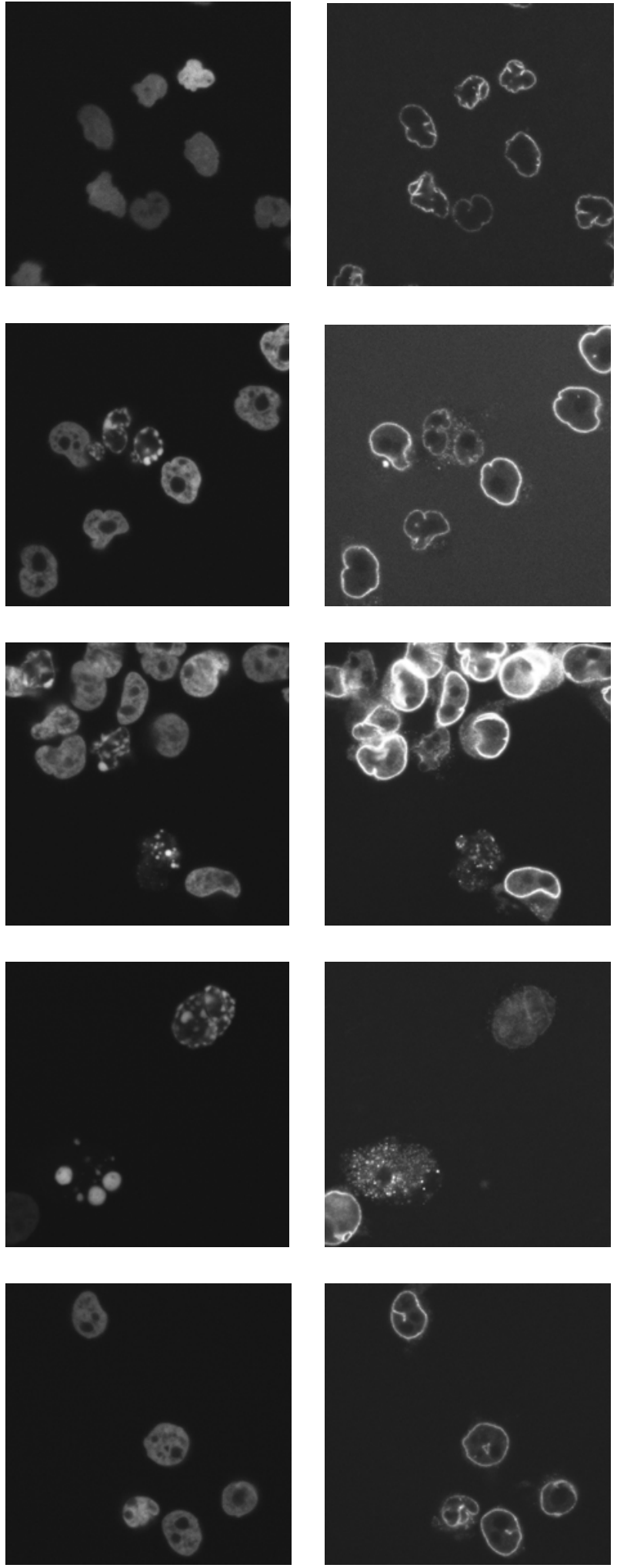

\section{N-acetylglucosamine}
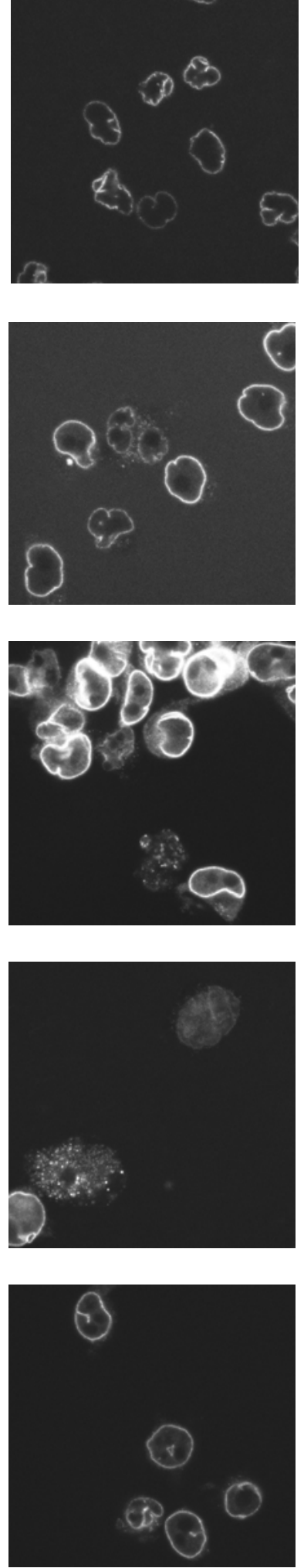

merge
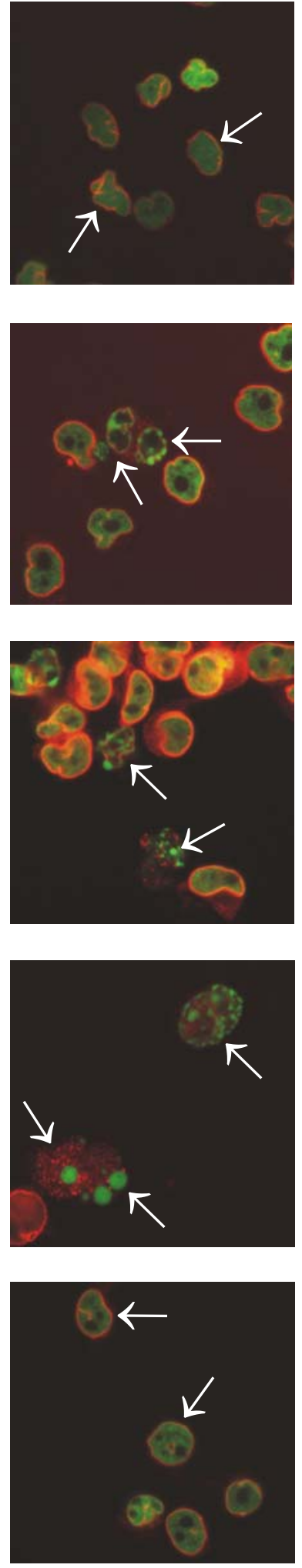

Fig. 3.9.4 Laser-scan microscopic analysis of histone H2B release in comparison with the nuclear marker protein $\mathrm{N}$-acetylglucosamine after treatment with etoposide (100xmagnification). Stably transfected HeLa H2B-YFP cells were treated with etoposide to induce apoptosis. The cells were harvested after $24 \mathrm{~h}$, $36 \mathrm{~h}$ and $48 \mathrm{~h}$. Untreated cells were harvested after $24 \mathrm{~h}$ and $48 \mathrm{~h}$ and served as controls. All cells were incubated with anti-N-acetylglucosamine primary antibody and were embedded in mounting medium containing DAPI. All cells were analysed via laser-scan microscopy. 


\subsubsection{Microscopic analysis of cytosolic structures (tubulin- $\alpha$ ) in HeLa H2B-YFP cells after induction of apoptosis.}

To complete our studies, we chose tubulin- $\alpha$, a structural protein of the cytoskeleton, to follow up the putative apoptosis-related release of histones (i.e. H2B). This structural element was used for putative co-localisation with H2B. Moreover, we still tried to find a structural component which holds the tightly packaged chromatin in place before finally everything is shut down within the cell during the process of apoptosis.

HeLa H2B-YFP cells were treated as described. To confirm that the cells were morphologically intact at the time of induction of apoptosis and even after $48 \mathrm{~h}$ of cultivation, $24 \mathrm{~h}$ and $48 \mathrm{~h}$ controls were harvested in parallel (data not shown). After $48 \mathrm{~h}$, once the chromatin had reached an advanced state of compaction, the tubulin fibres started to shrink and somehow collapsed onto the nucleus. This process was usually followed by the detaching of cells from their surface. Despite the shrinking and collapsing of tubulin fibres, these still seemed to form an outer ring around the condensed chromatin particles with the tightly packaged histones. The process of shrinking and collapsing was observed to go on, until the whole cell seemed to have reached the size of the nucleus (Fig. 3.9.5). Quite similar observations have recently been reported by Grzanka et al. (Grzanka et al., 2005), which correspond to our findings. This group analysed the influence of taxol on tubulin and vimentin in HL-60 cells. Like tubulin fibres, vimentin was reported to collapse on the nucleus and at sites of apoptotic body formation.

Although, having even analysed the apoptosis-related histone release on the basis of cytosolic structure changes, we could not find any supporting evidence that histones, though tightly packaged, were really released into the cytosol. Nevertheless, to round it up we pursued additional laser-san microscopic analyses for co-localisation of histone H2B with tubulin structures. 
48h etoposide

(40× magnification)

phase contrast

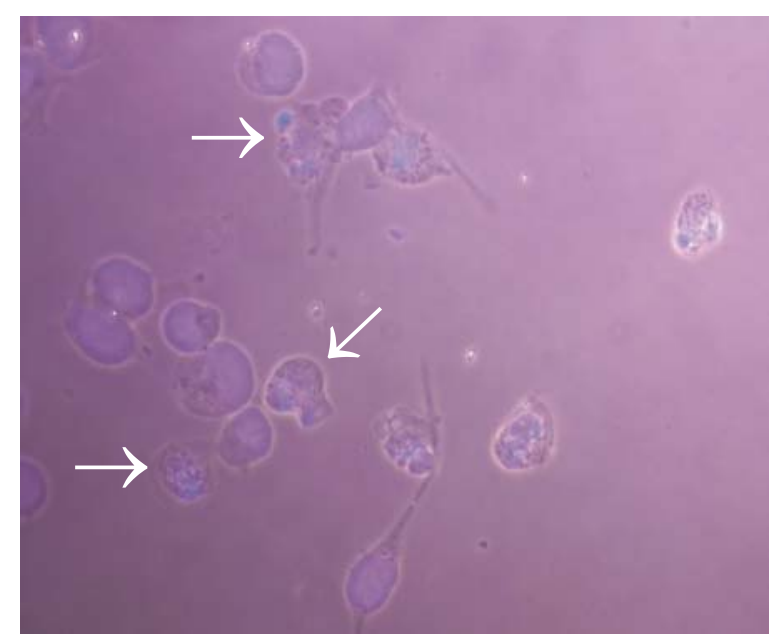

H2B-YFP

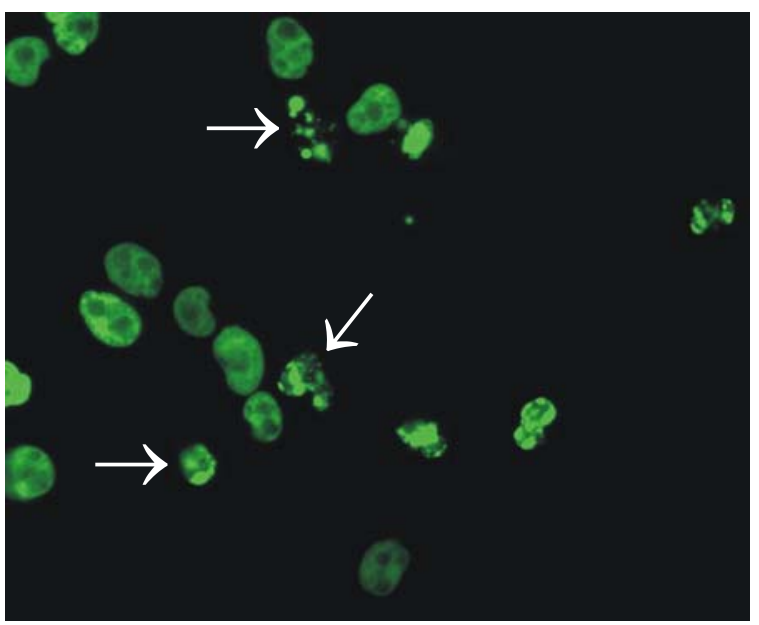

DAPI

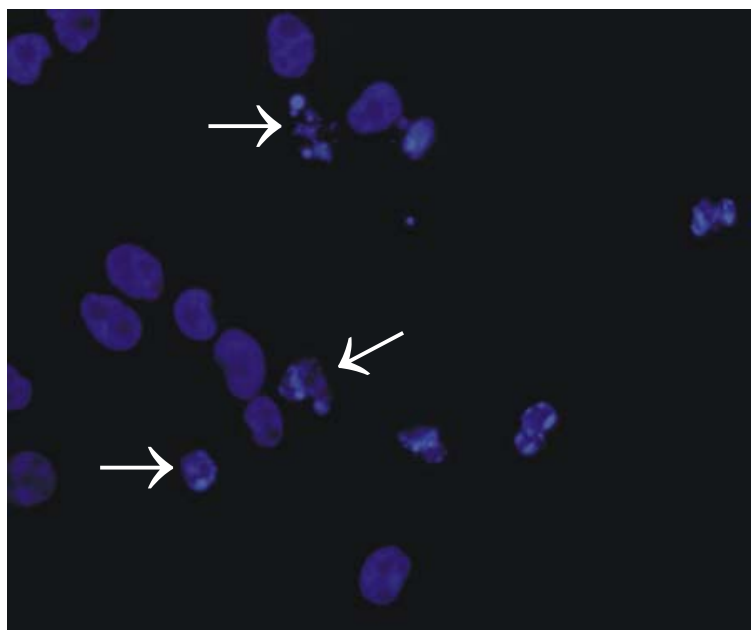

tubulin- $\alpha$

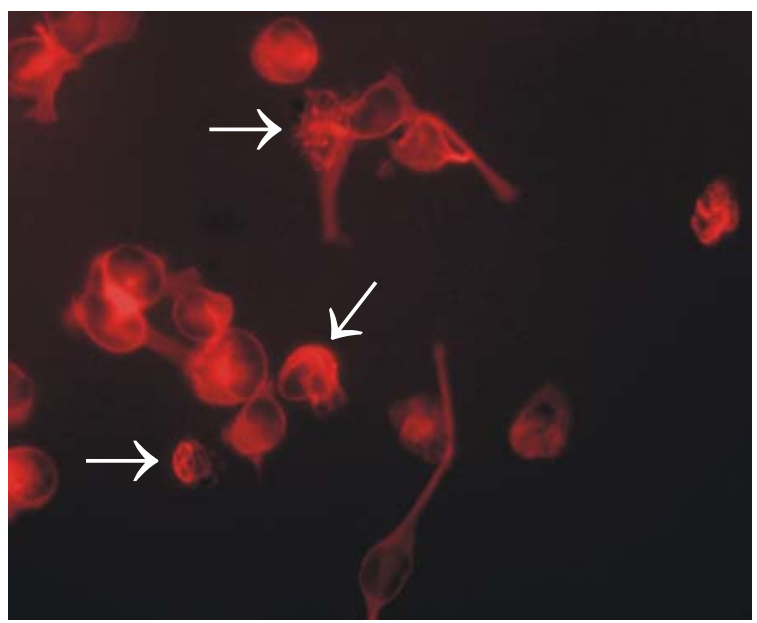

Fig. 3.9.5 Immuno-fluorescence microscopic analysis of histone H2B release in comparison with tubulin- $\alpha$ after treatment with etoposide (40xmagnification). Stably transfected HeLa H2B-YFP cells were treated with etoposide to induce apoptosis and harvested $48 \mathrm{~h}$. Untreated cells were harvested after $24 \mathrm{~h}$ and $48 \mathrm{~h}$ and served as controls (data not shown). All cells were incubated with anti-tubulin- $\alpha$ primary antibody and were embedded in mounting medium containing DAPI. All cells were analysed via fluorescence microscopy. After $48 \mathrm{~h}$ with the progressing state of apoptosis, most cells were found in an advanced stage of chromatin condensation and histone $\mathrm{H} 2 \mathrm{~B}$ compaction respectively. The tubulin meshwork was observed to shrink and collapse onto the remaining nuclear structure at sites of apoptotic body formation. 


\subsubsection{Analysis of cytosolic structures (tubulin- $\alpha$ ) in HeLa H2B-YFP cells after induction of apoptosis via laser-scan microscopy}

To get a more detailed view of the results obtained by conventional microscopy, the same cells were also analysed with a laser-scan microscope with higher resolution. Moreover, it gave us the chance of co-localisation experiments.

Cells were treated as described. Control cells were harvested after $24 \mathrm{~h}$ and $48 \mathrm{~h}$. The weblike tubulin structure equally surrounds the nucleus and additionally gives the cytosol its clear-cut shape, indicating that all cells were morphologically intact at the time of induction of apoptosis and after further cultivation over 48h (Fig. 3.9.6 1 and 5; white arrows).

From $24 \mathrm{~h}$ onwards after induction of apoptosis, this web-like structure started to shrink gradually until it finally collapsed onto the remaining 'nuclear scaffold'. Without exceptions these processes where observed to take place around apoptotic nuclei and especially at sites with highly condensed chromatin and packaged histone H2B (Figs. 3.9.6 2-4; white arrows). Although evidence was found that tubulin structures seem to vanish at some point during apoptosis (Fig. 3.9.6 2 and 3; white arrows), neither did we perceive a break up of the tightly packaged, condensed chromatin, nor any release of histones from this bulk chromatin structure into the cytosol.

Fig. 3.9.6 Laser-scan microscopic analysis of histone H2B release in comparison with tubulin- $\alpha$ after treatment with etoposide (100xmagnification). Stably transfected HeLa H2B-YFP cells were treated with etoposide to induce apoptosis. The cells were harvested after $24 \mathrm{~h}, 36 \mathrm{~h}$ and $48 \mathrm{~h}$. Control cells were harvested after $24 \mathrm{~h}$ and $48 \mathrm{~h}$. All cells were incubated with anti-tubulin- $\alpha$ primary antibody and were embedded in mounting medium with DAPI. The cells were analysed via laser-scan microscopy. (1) 24 $\mathrm{h}$ control and (5) $48 \mathrm{~h}$ control confirmed that the cells were morphologically intact at the time of induction of apoptosis and after $48 \mathrm{~h}$ cultivation. Tubulin fibres formed up a smooth web-like structure around the nucleus. (2) After $24 \mathrm{~h}$ with the onset of chromatin condensation and tight packaging of histones, tubulin fibres started to shrink and started to collapse onto the nucleus, which kept chromatin and histones fixed in their centre. (3) After $36 \mathrm{~h}$ and (4) $48 \mathrm{~h}$ with the progressing state of apoptosis, the tubulin web-like structure was observed to shrink even further and finally collapsed completely on the remaining nuclear structure. 
$24 h$ control

H2B-YFP

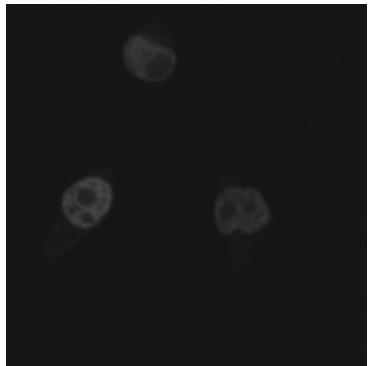

24h etoposide

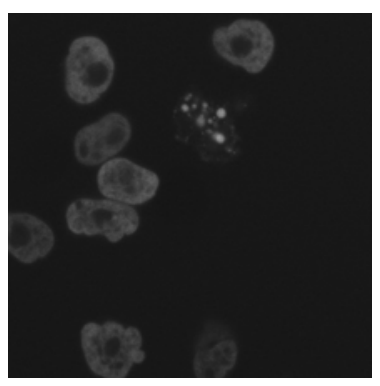

$36 \mathrm{~h}$ etoposide

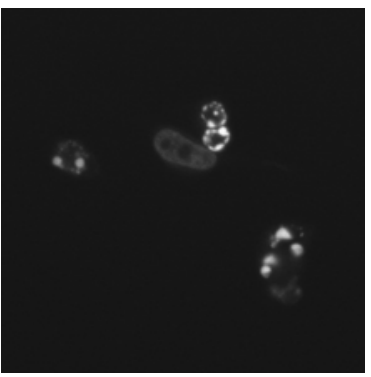

48h etoposide

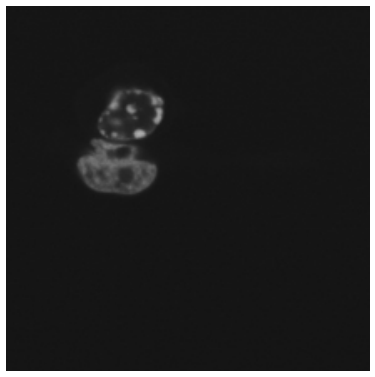

48h control

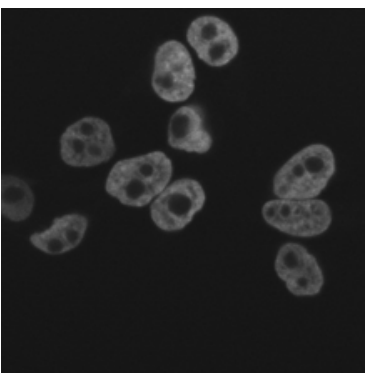

tubulin- $\alpha$
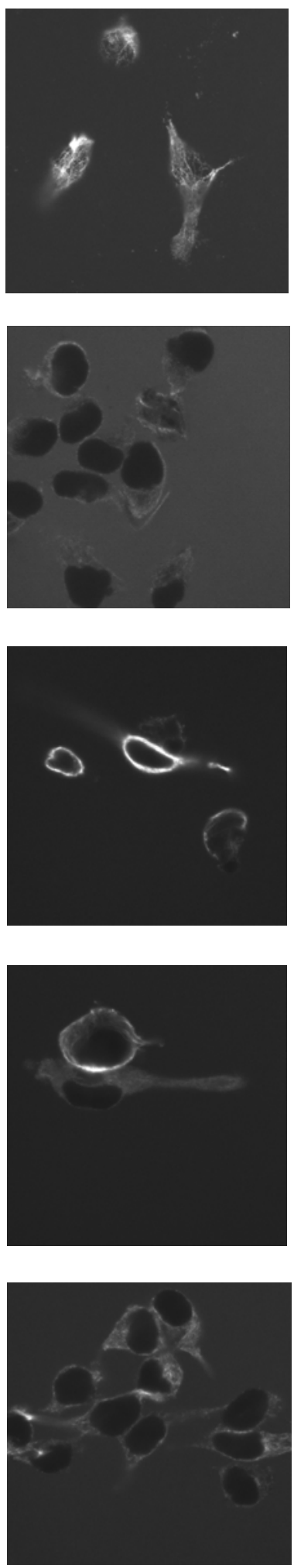
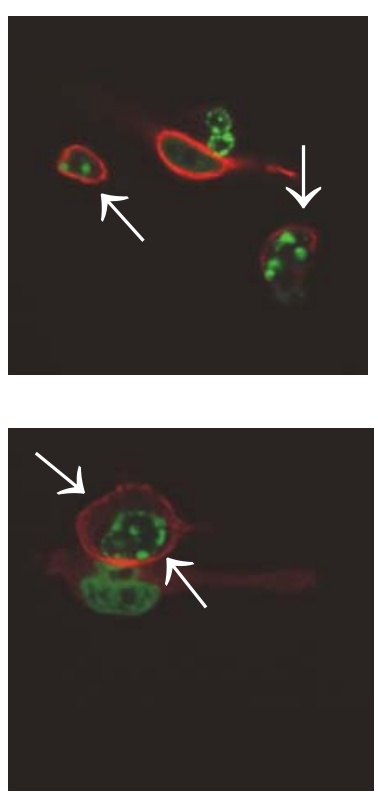

merge
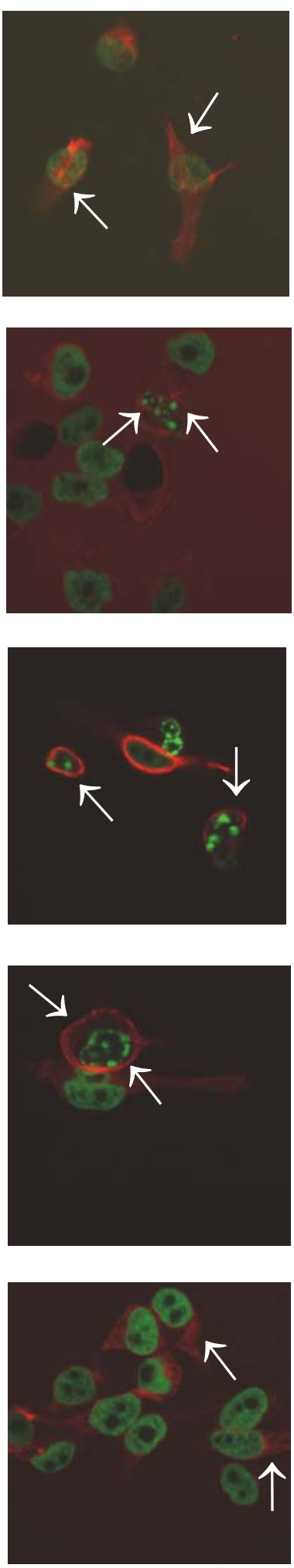


\subsection{Analysis of different histone modifications in nucleosomes of fragmented chromatin after induction of apoptosis compared to modifications in unfragmented chromatin}

It is supposed that particular histone modifications might function as specific signals, when released from bulk chromatin during the ongoing process of apoptosis, to initiate processes of transcriptional repression and gene silencing, as well as chromatin compaction that often goes with it. Previous experiments showed that histone modifications e.g. H2AX-phosphate S139 and ubiquitylated $\mathrm{H} 2 \mathrm{~A}$ change in a time-dependent manner during apoptosis. Moreover it was demonstrated that HL-60 and HeLa cells show an apoptosis-related release of specifically modified core histones into the nucleoplasm and partially into the cytoplasm. In a following step we therefore analysed released nucleosomes of apoptotic fragmented and non-fragmented chromatin for their contents of specifically modified core histones, which might function as marks for chromatin regions where preferential cleavage takes place.

\subsubsection{Accumulation of specific modifications in fragmented chromatin}

HL-60 cells were treated with the apoptosis inducer topotecan ${ }^{\circledR}$ and were incubated for $8 \mathrm{~h}$. After this time cells were harvested and nuclei were prepared from cell pellets according to protocol III (chap. 3.7.1 and 3.7.2) After hypotonic lysis of nuclei, the lysates were subject to isopycnic centrifugation (sucrose gradient with 4\%-25\% sucrose concentration), to separate apoptotic nucleosomal fragments of different sizes for further analysis. One half of each collected sucrose gradient fraction was analysed on an agarose gel to check the nucleosomal fragment sizes. Moreover, histones from these nucleosomes were separated with SDS-PAGE (15\%) and transferred to nitrocellulose membranes by Western blotting. Modifications of histones from all sucrose gradient fractions were analysed by incubating the membranes with antibodies raised against the respective modification to be analysed. Figure 3.10.1 1 gives an overall view on the linear distribution of nucleosomes of different sizes within the sucrose gradient.

Densitometric analyses of the two histone modifications H3-dimethylation at lysine 9 and $\mathrm{H} 2 \mathrm{AX}$-phosphorylation at serine 139 with relation to total protein contents in each gradient fraction disclosed that both these modifications accumulate in higher quantities in fragmented chromatin, compared to histones in nucleosomes from bulk chromatin regions (Fig. 3.10.1 $2 / 4$ and $3 / 5$ ). The tables present the distribution of each specific histone modification. It must be noted though, the last pair of columns in each table represents the pellet fraction. As the distribution of histones varied slightly from one gradient to the next, it was not possible to always analyse the equal number of fractions in each gradient. It must also be noted that the tables only present general correlations of total protein contents compared to the extent of the specific histone modification. Absolute protein concentrations cannot be taken into 
account here. The results just give a first estimation. The method used in this case is not purely quantitative. For comparative analysis usually the second last fraction of the gradient was set to $100 \%$ and from this fraction the others were calculated. In some cases the second gradient fraction was used as a standard, depending on the overall signal intensity. In this case only those bands were chosen, where signal intensities were not overdosed.

Whereas the H2AX-phosphate S139 concentration appeared to be quite low in the nuclear pellet (Fig. 3.10.1 4; columns 11) compared to total protein contents, its concentration was largely increased in fractions containing fragmented chromatin (Fig. 3.10 .14 ; columns 1-9). For H3-dimethyl K9 although obvious, the changes were not that severe. We already found high concentrations of this modification in the nuclear pellet fraction (column 13). However, with relation to protein concentrations in fragmented chromatin, concentrations of $\mathrm{H} 3-$ dimethyl K9 were still increased in most fractions (Fig. 3.10.1 5; columns 1-12). 


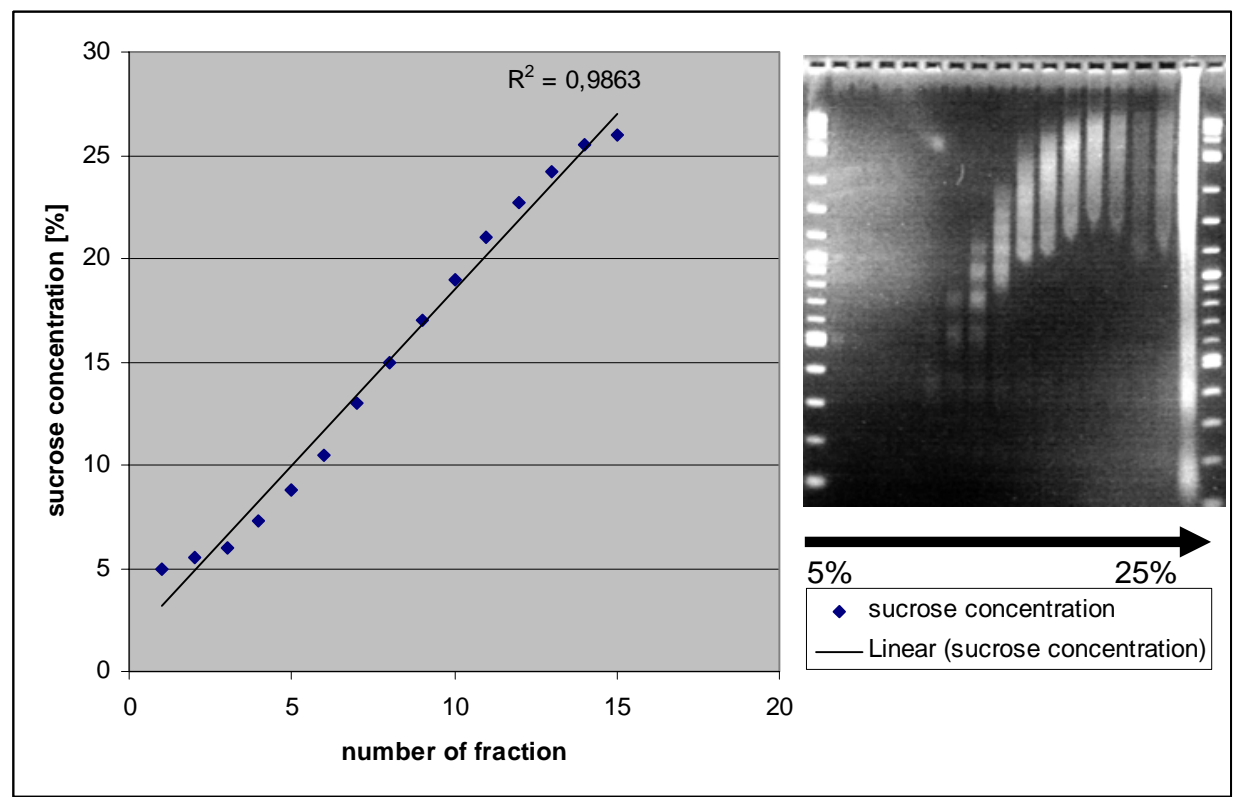

2

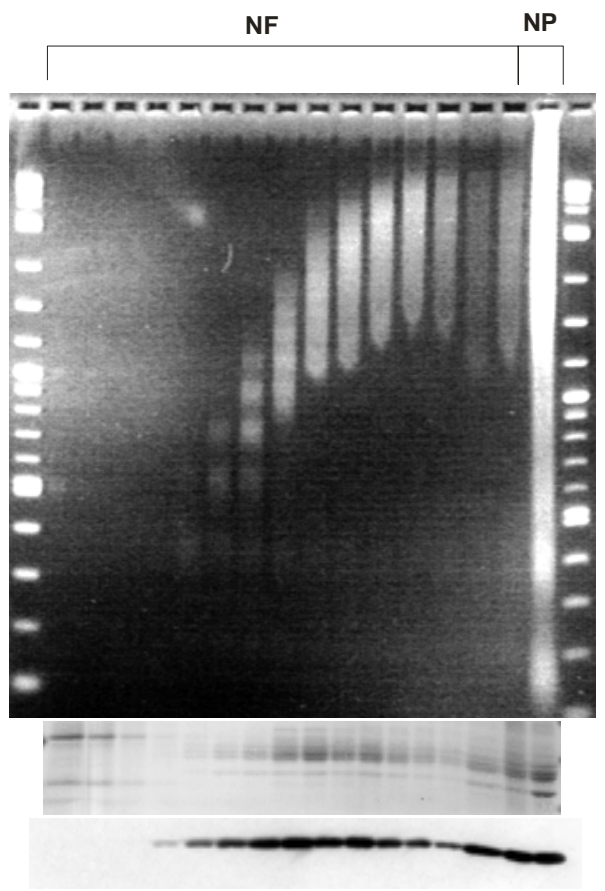

H3-dimethyl K9
NF: nucleosomal fractions

NP: nuclear pellet

3

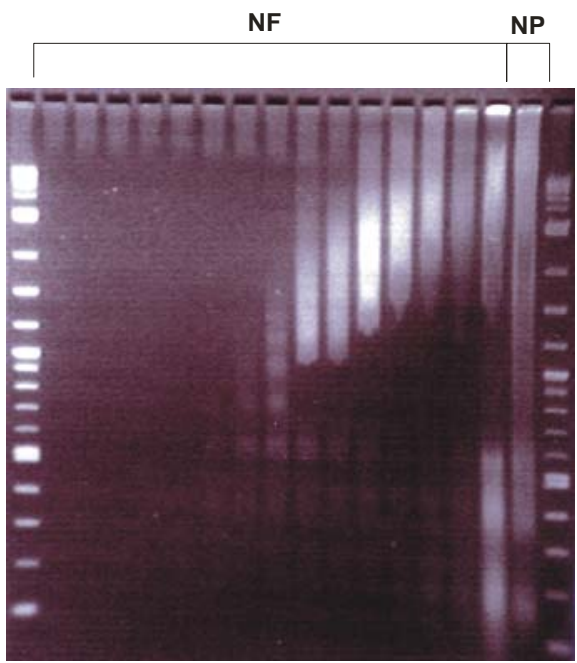

Ponceau
stain
ECL-
immuno-detection

sucrose gradient fractions containing nucleosomes

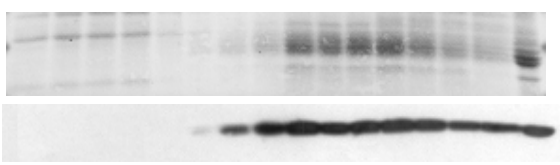

H2AX-phosphate S139

Fig. 3.10.1 Accumulation of specific histone modifications in apoptotic nucleosomes of fragmented chromatin. HL-60 cells were treated with topotecan ${ }^{\circledR}$ and incubated for $8 \mathrm{~h}$. Nuclei were isolated according to protocol III by Bunce et al. (Bunce et al., 1988), lysed and were subject to isopycnic centrifugation. Nucleosomes were analysed on agarose gels for their sizes. Histones were separated by SDS-PAGE (15\%) and transferred to nitrocellulose membranes by Western blotting for further antibody treatment with antibodies raised against H3-dimethyl K9 and H2AX-phosphate S139. (1) Distribution of apoptotic nucleosomes in a linear sucrose gradient. (2) Agarose gel and Western blot membrane incubated with anti-H3-dimethyl K9 antibody. (3) Agarose gel and Western blot incubated with anti-H2AX-phosphate S139 antibody. 
4

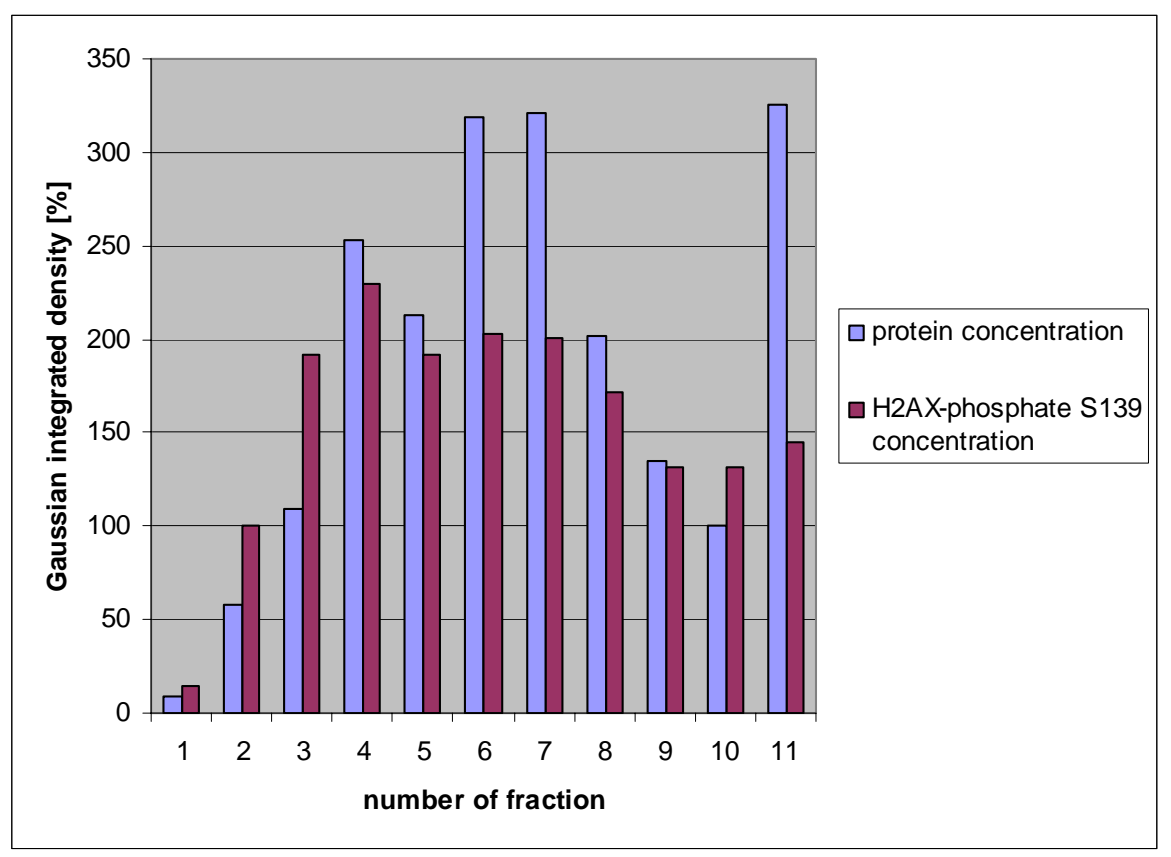

5

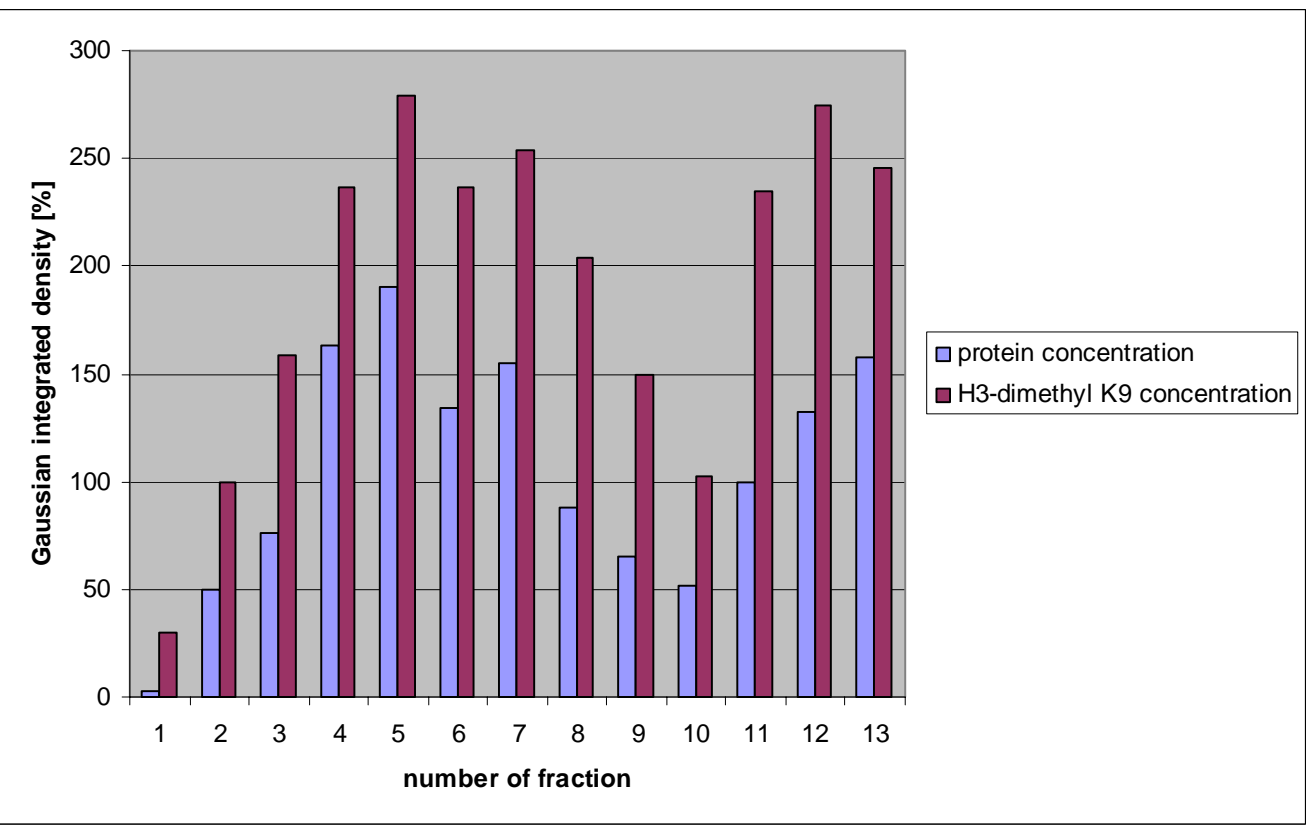

Fig. 3.10.1 (cont. 1) Accumulation of specific histone modifications in apoptotic nucleosomes of fragmented chromatin. HL-60 cells were treated with topotecan ${ }^{\circledR}$ and incubated for $8 \mathrm{~h}$. Nuclei were isolated according to protocol III by Bunce et al. (Bunce et al., 1988), lysed and were subject to isopycnic centrifugation. Nucleosomes were analysed on agarose gels for their sizes. Histones were separated by SDS-PAGE (15\%) and transferred to nitrocellulose membranes by Western blotting for further antibody treatment with antibodies raised against H3-dimethyl K9 and H2AX-phosphate S139. (4) Densitometric analysis of the Western blot membrane with relation to specific distribution of H2AXphosphate S139. (5) Densitometric analysis of the Western blot membrane with relation to specific distribution of $\mathrm{H3}$-dimethyl $\mathrm{K} 9$. Both histone modifications were found to be accumulating in fragmented chromatin. 


\subsubsection{Depletion of specific modifications in fragmented chromatin}

Furthermore, apoptotic nucleosomes from fragmented chromatin were also analysed for H3acetylation at lysine 9 and H3-trimethylation at lysine 9 . These specific histone modifications appeared to be depleted in fragmented chromatin (columns 1-9) compared to their concentrations in the chromatin of the nuclear pellet (Figs. 3.10.2 1-4). Here the results for acetylated $\mathrm{H} 3$ at lysine 9 appeared to be more obvious compared to those for trimethylated $\mathrm{H} 3$ at lysine 9. Whereas in relation to the total protein contents more H3-acetyl K9 was found in the nuclear pellet (Fig. 3.10.2 3; column 11) fraction, its concentration was greatly reduced in fractions containing fragmented chromatin. The same was observed with the modification H3-trimethyl K9. Its concentration within the nuclear pellet fraction was found to be much higher (Fig. 3.10.2 4; column 11), compared to the concentration in fractions with fragmented chromatin.

1

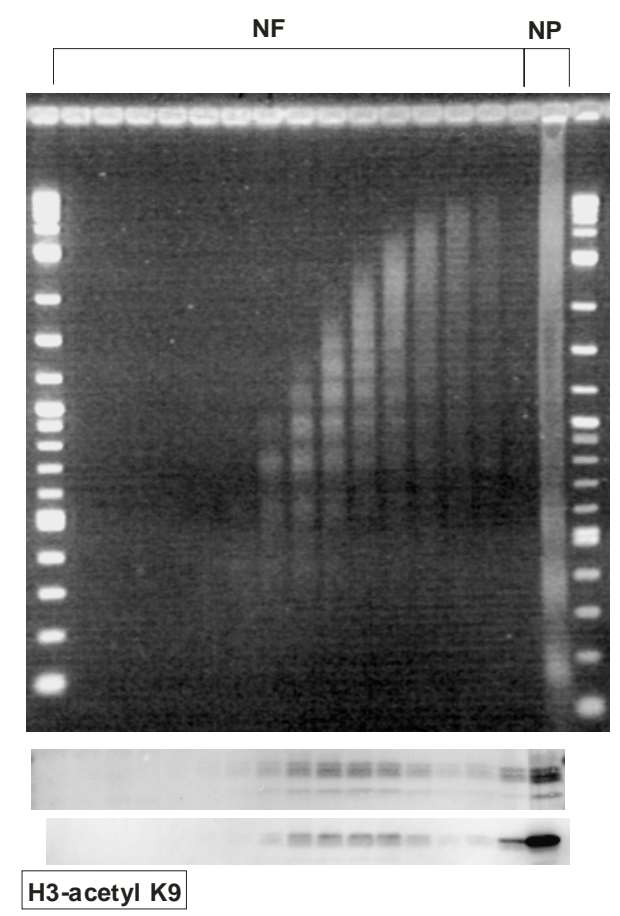

NF: nucleosomal fractions NP: nuclear pellet

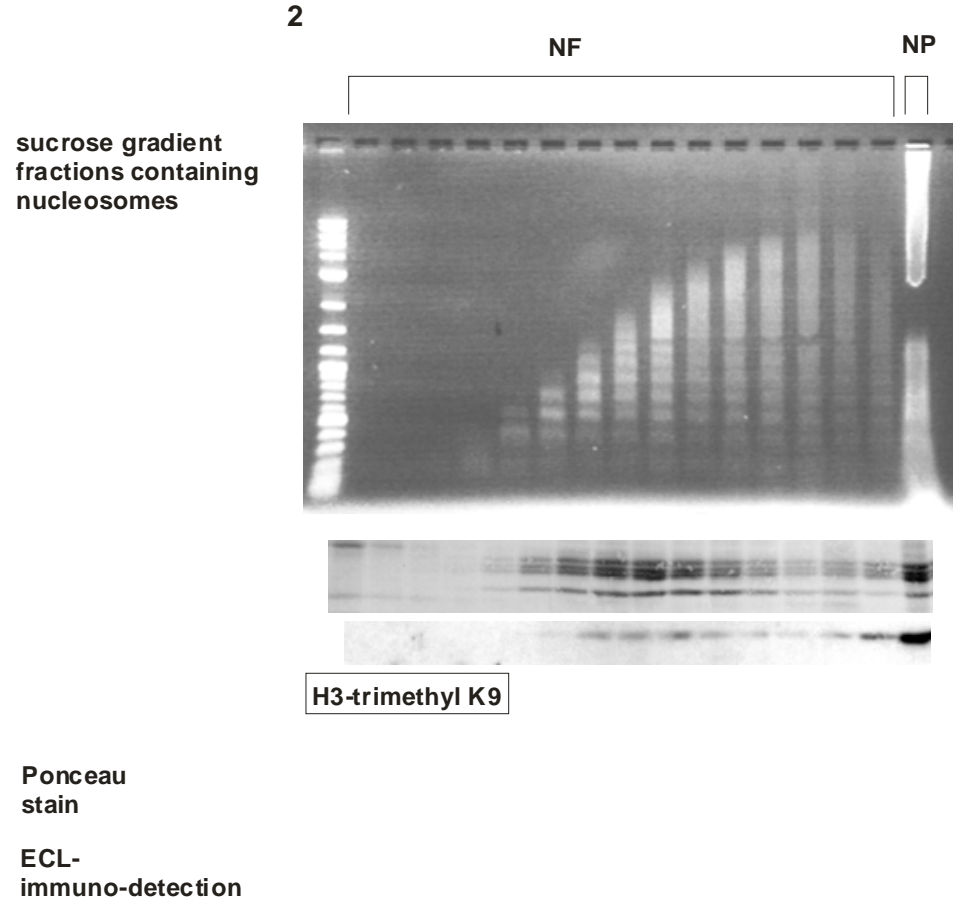

Fig. 3.10.2 Depletion of specific histone modifications in apoptotic nucleosomes of fragmented chromatin. HL-60 cells were treated with topotecan ${ }^{\circledR}$ and incubated for $8 \mathrm{~h}$. Nuclei were isolated according to protocol III by Bunce et al. (Bunce et al., 1988), lysed and were subject to isopycnic centrifugation. Nucleosomes were analysed on agarose gels for their sizes. Histones were separated with SDS-PAGE (15\%) and transferred to nitrocellulose membranes by Western blotting for further antibody treatment with antibodies raised against H3-acetyl K9 and H3-trimethyl K9. (1) Agarose gel and Western blot membrane incubated with anti-H3-acetyl K9 antibody. (2) Agarose gel and Western blot incubated with anti-H3-trimethyl K9 antibody. 
3

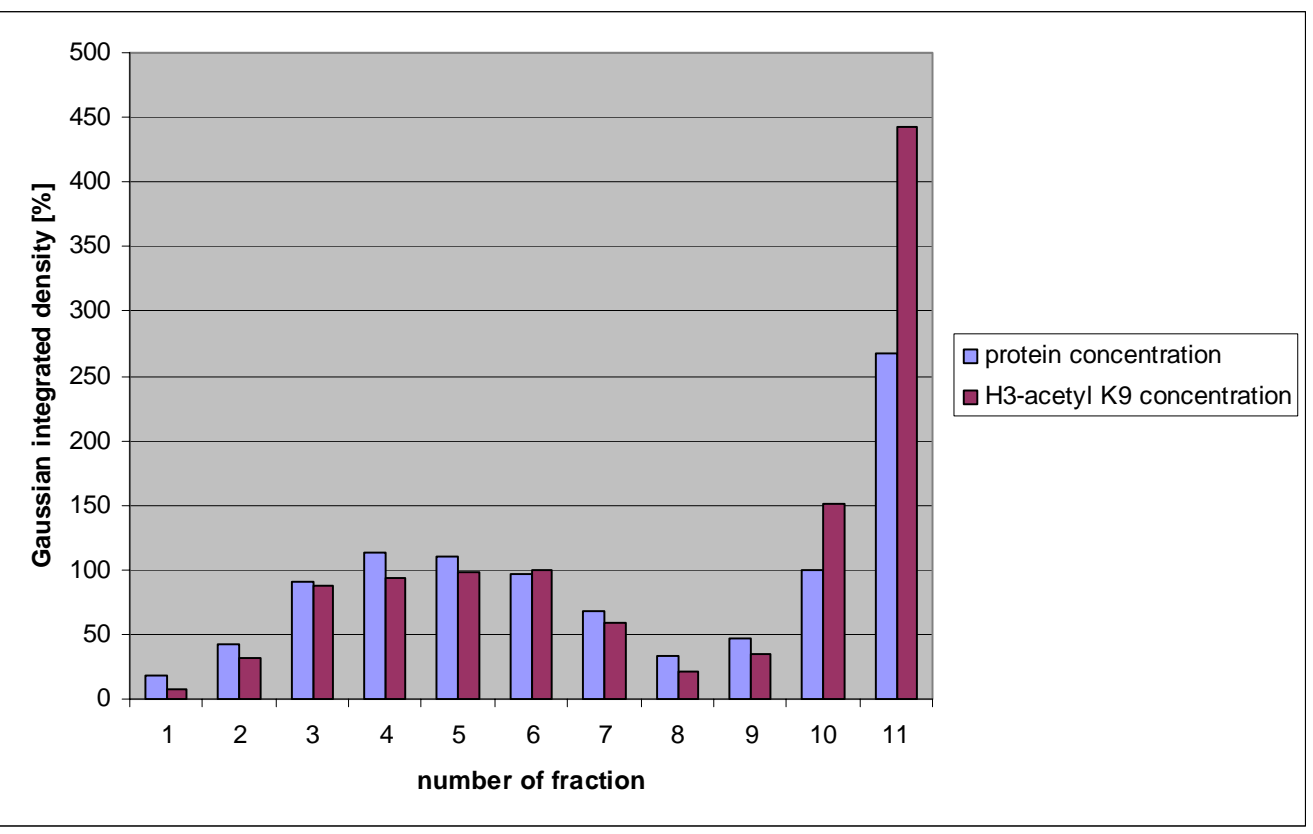

4

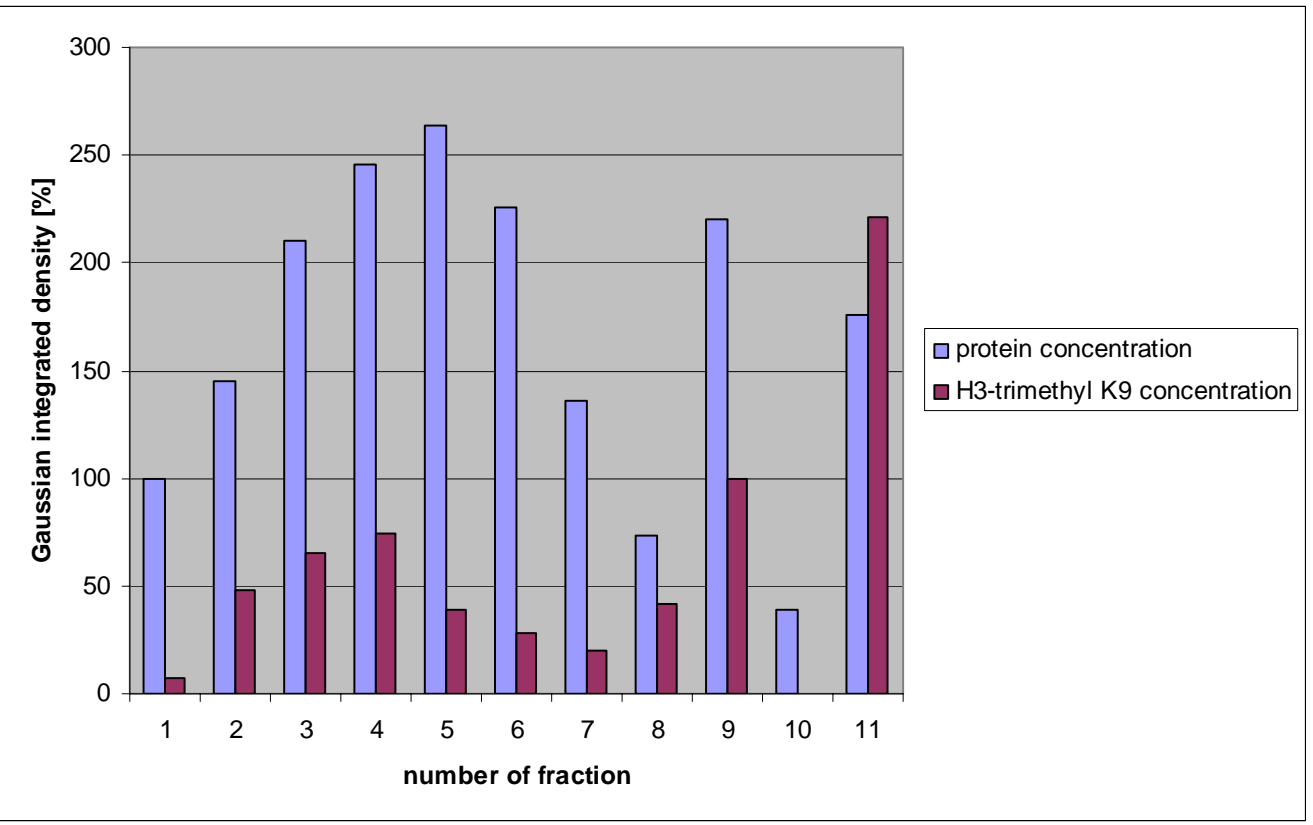

Fig. 3.10.2 (cont. 1) Depletion of specific histone modifications in apoptotic nucleosomes of fragmented chromatin. HL-60 cells were treated with topotecan ${ }^{\circledR}$ and incubated for $8 \mathrm{~h}$. Nuclei were isolated according to protocol III by Bunce et al. (Bunce et al., 1988), lysed and were subject to isopycnic centrifugation. Nucleosomes were analysed on agarose gels for their sizes. Histones were separated with SDS-PAGE (15\%) and transferred to nitrocellulose membranes by Western blotting for further antibody treatment with antibodies raised against H3-acetyl K9 and H3-trimethyl K9. (3) Densitometric analysis of the Western blot membrane with relation to specific distribution of H3-acetyl K9. (4) Densitometric analysis of the Western blot membrane with relation to a specific distribution of $\mathrm{H} 3-$ trimethyl K9. Both histone modifications were found to be depleted in fragmented chromatin. 


\subsubsection{Histone modifications showing no specific distribution in fragmented or bulk chromatin regions}

For all other modifications that were analysed, such as H3-dimethyl K4, H3-dimethyl K36, H3-trimethyl K4, H3-acetyl K18 and H3-acetyl K23, no such changes as were described above were observed. We could not observe any specific distribution pattern for any of the above mentioned histone modifications with reference to either nuclear pellet fraction or fractions containing fragmented chromatin. The signal intensity for each type of specific modification was presented according to the amount of total protein, determined by Ponceau staining of the membrane (Figs. 3.10.3 1-5).

1
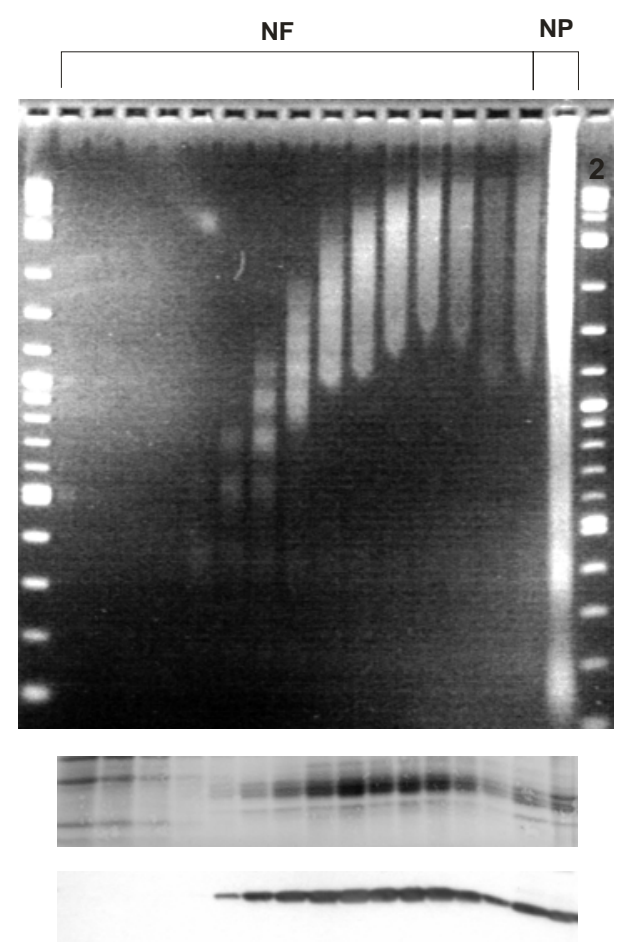

H3-dimethyl K4
NF: nucleosomal fractions

NP: nuclear pellet

2

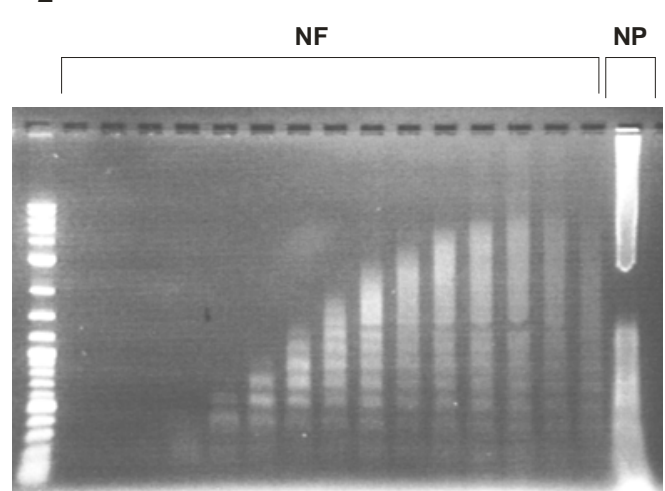

sucrose gradient fractions containing nucleosomes

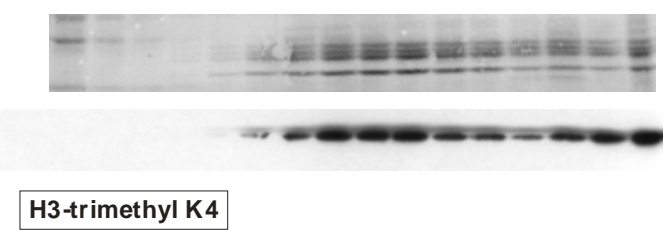

Ponceau

stain

ECL-

immuno-detection

Fig. 3.10.3 No changes of specific histone modifications in apoptotic nucleosomes of fragmented chromatin. HL-60 cells were treated with topotecan ${ }^{\circledR}$ and incubated for $8 \mathrm{~h}$. Nuclei were isolated according to protocol III by Bunce et al. (Bunce et al., 1988), lysed and were subject to isopycnic centrifugation. Nucleosomes were analysed on agarose gels for their sizes. Histones were separated with SDS-PAGE (15\%) and transferred to nitrocellulose membranes by Western blotting for further antibody treatment with antibodies raised against the respective histone modification. Agarose gel and Western blot membranes incubated with (1) anti-H3-dimethyl K4, (2) anti-H3-dimethyl K36. 
NF: nucleosomal fractions

NP: nuclear pellet

3
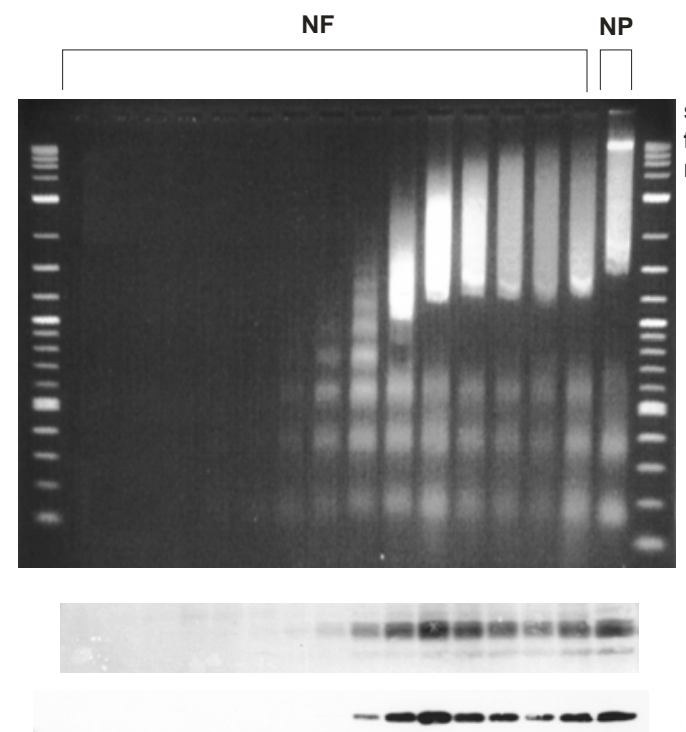

H3-dimethyl K36

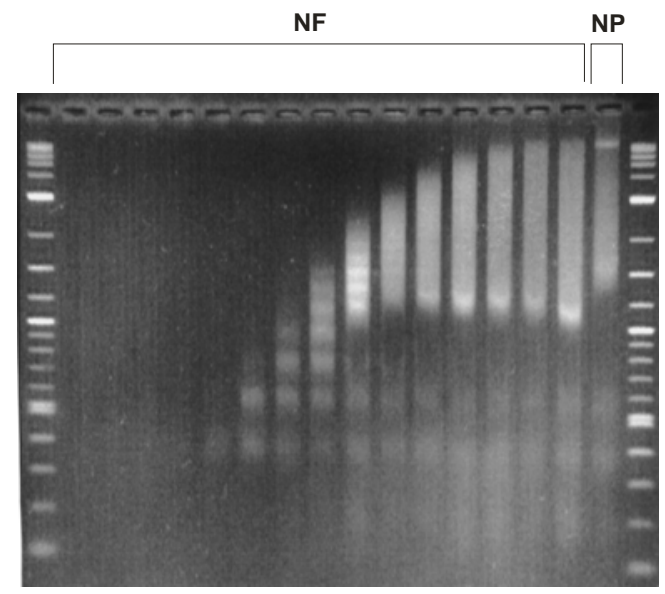

\section{Ponceau}

stain

ECL-

immuno-detection

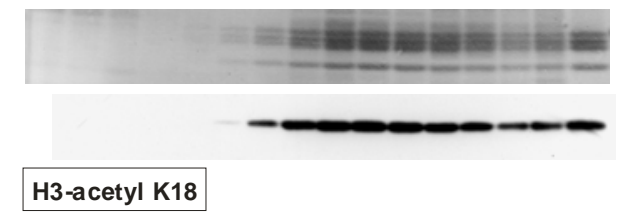

5

NF: nucleosomal fractions

NP: nuclear pellet

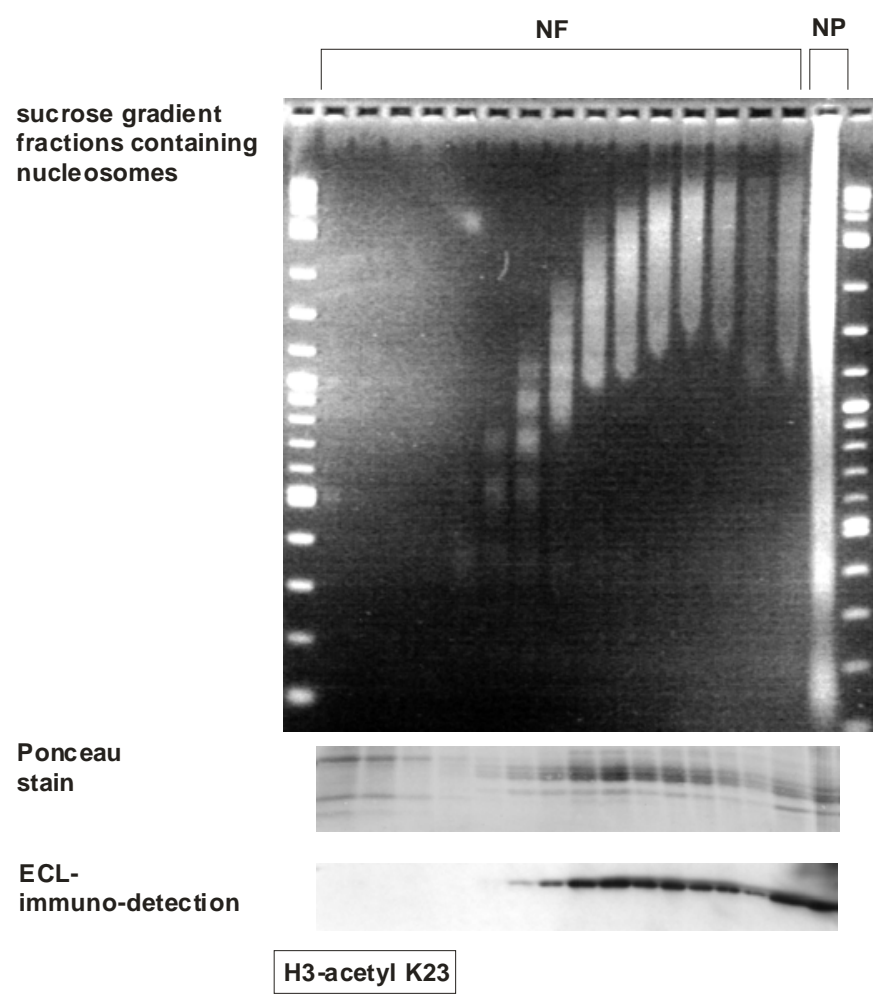

Fig. 3.10.3 (cont. 1) No changes of specific histone modifications in apoptotic nucleosomes of fragmented chromatin. HL-60 cells were treated with topotecan ${ }^{\circledR}$ and incubated for $8 \mathrm{~h}$. Nuclei were isolated according to protocol III by Bunce et al. (Bunce et al., 1988), lysed and were subject to isopycnic centrifugation. Nucleosomes were analysed on agarose gels for their sizes. Histones were separated with SDS-PAGE (15\%) and transferred to nitrocellulose membranes by Western blotting for further 
antibody treatment with antibodies raised against the respective histone modification. Agarose gel and Western blot membranes incubated with (3) anti-H3-trimethyl K4, (4) anti-H3-acetyl K18 and (5) antiH3-acetyl K23 antibodies. No specific distributions of these histone modifications in fragmented/nonfragmented chromatin were observed.

\subsubsection{Specific techniques for the extraction of histone proteins from nuclear pellets}

With reference to isolation procedures of total histones from the insoluble bulk chromatin pellet (sucrose gradient fraction), four different approaches were taken to extract all types of histones. This step was necessary to avoid selective analysis of only partially soluble material, which might have resulted from less efficient extraction methods. All bulk chromatin pellets were prepared according to the four different extraction protocols described in chapter 2.2.6.2.

Taking together all results from the four different extraction protocols, it turned out that neither way of core histone preparation did make any difference compared to the outcome of signal intensity of the respective histone modification. Without any exceptions, protein contents basically match the signal intensity of single histone modifications tested: H3dimethyl K4 (Fig.3.10.4 1), H3-dimethyl K9 (Fig. 3.10.4 2), H3-dimethyl K36 (Fig. 3.10.4 3), H3-trimethyl K4 (Fig. 3.10.4 4), H3-acetyl K9 (Fig. 3.10.4 5), H3-acetyl K18 (Fig. 3.10.4 6), H3-acetyl K23 (Fig. 3.10.4 7), H3-trimethyl K9 (Fig. 3.10.4 8) and H2AX-phosphate S139 (Fig. 3.10.4 9). All in all, a putative selectivity caused by insufficient histone extraction methods was definitely excluded.

Fig. 3.10.4 Extraction of core histones from insoluble nuclear bulk chromatin pellets taken from sucrose gradient fractions. HL-60 cells were treated with topotecan ${ }^{\circledR}$ and incubated for $8 \mathrm{~h}$. Nuclei were isolated according to protocol III by Bunce et al. (Bunce et al., 1988), lysed and were subject to isopycnic centrifugation. Histones from chromatin pellet fractions were isolated as described in chapter 2.2.6.2. Histones were separated with SDS-PAGE (15\%) and transferred to nitrocellulose membranes by Western blotting for further antibody treatment. A possible selectivity on the basis of extraction protocols used was analysed, using antibodies raised against the following histone modifications: (1) anti-H3-dimethyl K4; (2) anti-H3-dimethyl K9; (3) anti-H3-dimethyl K36; (4) anti-H3-trimethyl K4; (5) anti-H3-acetyl K9; (6) anti-H3-acetyl K18; (7) anti-H3-acetyl K23; (8) anti-H3-trimethyl K9 and (9) antiH2AX-phosphate S139. 
1

Ponceau

stain

alkaline

phosphatase

immuno-detection

2

Ponceau

stain

alkaline

phosphatase

immuno-detection

3

Ponceau

stain

alkaline

phosphatase

immuno-detection

4

Ponceau

stain

alkaline

phosphatase

immuno-detection
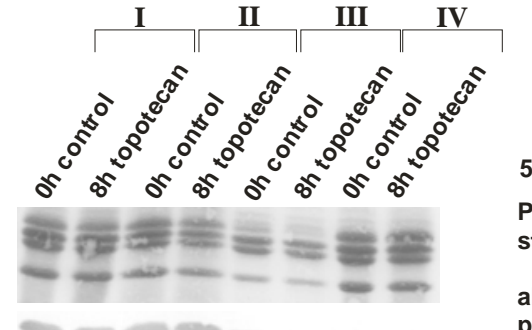

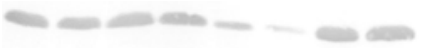

H3-dimethyl K4
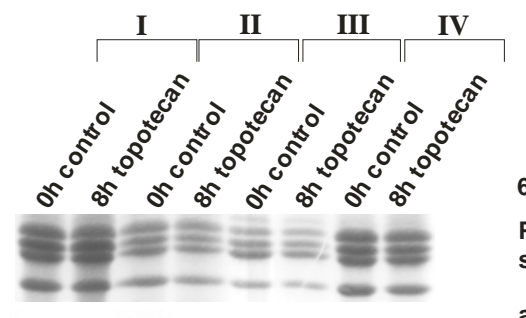

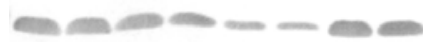

H3-dimethyl K9
Ponceau

stain

alkaline

phosphatase

immuno-detection

Ponceau

stain

alkaline

phosphatase

immuno-detection

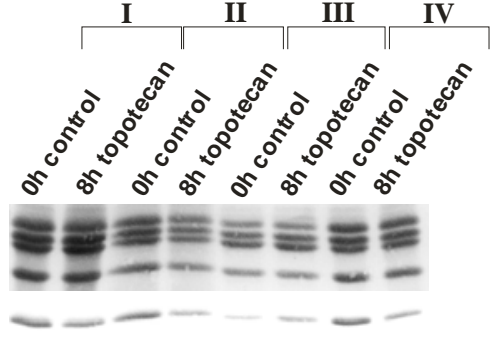

H3-acetyl K9
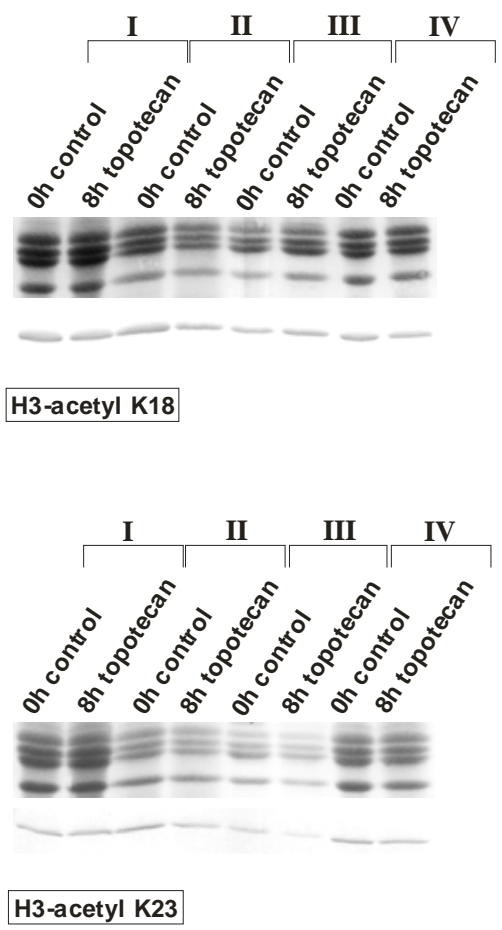

9

Ponceau
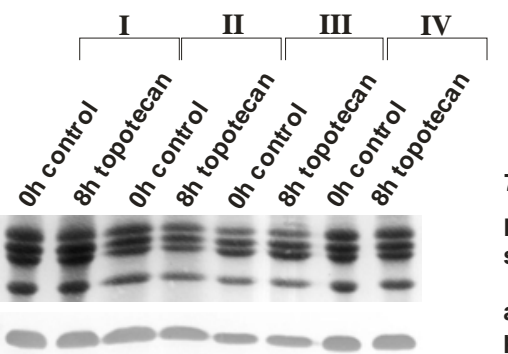

Ponceau

stain

alkaline

phosphatase

Immuno-detection

H3-dimethyl K36
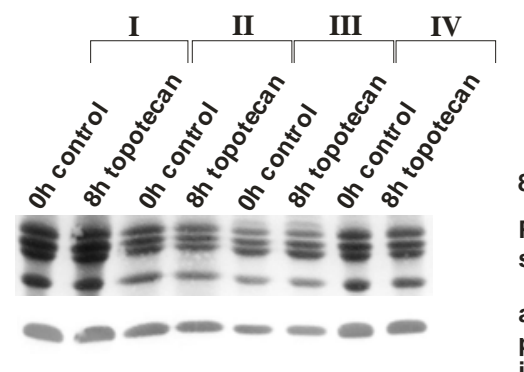

Ponceau

stain

alkaline

phosphatase

immuno-detection

H3-trimethyl K4
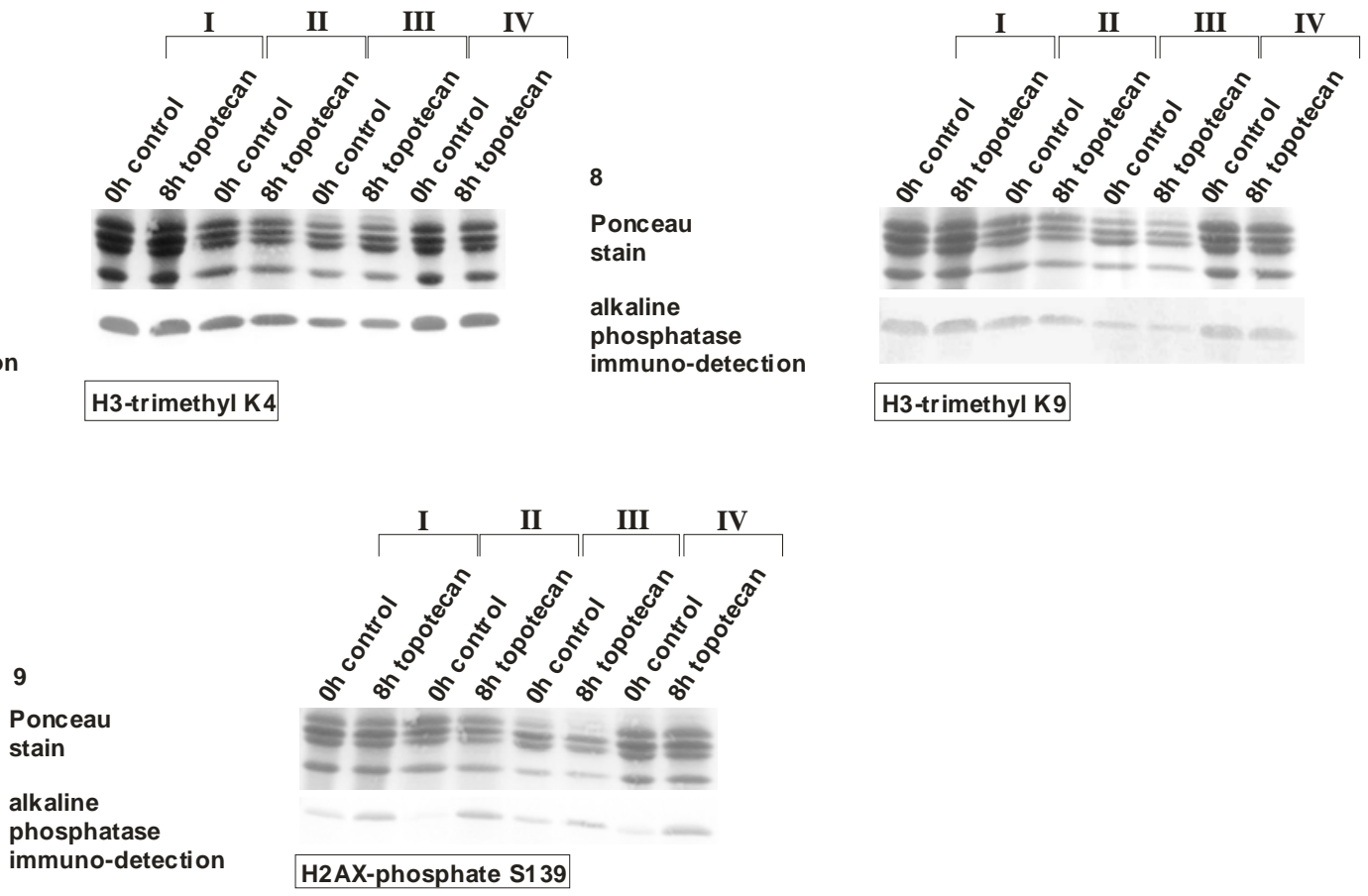


\subsubsection{Analysis of a putative accumulation of heterochromatin protein HP1- $\alpha$ in regions of fragmented chromatin}

More and more evidence stresses the importance of the histone modification H3-dimethyl K9 in epigenetics and its putative function in transcriptional repression and gene silencing. During the ongoing process of apoptosis, the cell is supposed to suppress and shut down several regions within the bulk chromatin, still showing transcriptional activity and gene expression. Nakayama and co-workers (Nakayama et al., 2001) particularly analysed the role of histone $\mathrm{H} 3$ lysine 9 methylation with reference to epigenetic control of heterochromatin assembly. They found out that H3 lysine 9 together with heterochromatin protein HP1- $\alpha$ in fission yeast mediate the formation of heterochromatin regions.

Due to these facts, we tried to find out, if there is a possible correlation of accumulation of heterochromatin protein HP1- $\alpha$ together with the investigated accumulation of histone H3dimethyl $\mathrm{K} 9$ in fragmented chromatin. Such an accumulation could not be observed. As figure 3.10.5 shows, higher concentrations of HP1- $\alpha$ were found in sucrose gradient fractions, which did not contain nucleosomes from fragmented chromatin. These concentrations can be referred to the pool of unbound protein, which is found inside the nucleus. Equal concentrations of HP1- $\alpha$ were co-located with H3-dimethyl K9 in all other fractions. We could not detect an additional accumulation of this protein in these sucrose gradient fractions.

As an overall result of all sucrose gradient analyses, the dissimilar distribution pattern of differently modified histones in fragmented compared to non-fragmented chromatin, can be filed into three different categories: firstly, an accumulation of histones with specific modifications in fragmented chromatin, such as H3-dimethyl K9 and H2AX-phosphate S139, secondly, a depletion of histones with specific modifications in fragmented chromatin, such as H3-acetyl $\mathrm{K} 9$ and $\mathrm{H} 3$-trimethyl $\mathrm{K} 9$ and finally specifically modified histones showing no specific distribution pattern at all in this respect. Moreover, a putative accumulation of the heterochromatin protein HP1- $\alpha$ in regions of fragmented or non-fragmented chromatin was not perceived. To define the accumulation pattern of H3-dimethyl $\mathrm{K} 9$ and H2AX-phosphate S139 as well as the depletion of H3-acetyl K9, we finally analysed HL60-cells after induction of apoptosis via FACS. 


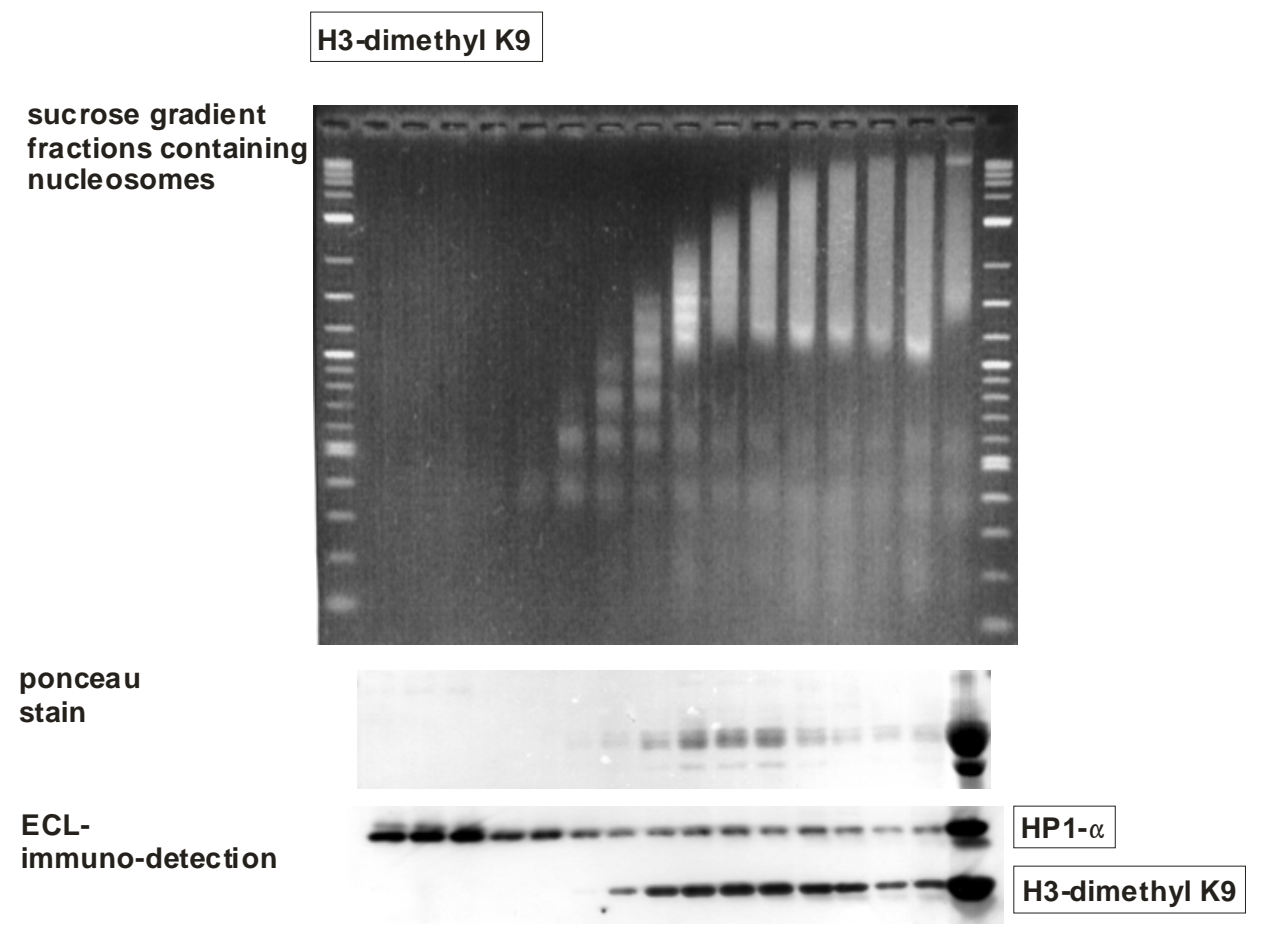

Fig. 3.10.5 Analysis of a putative accumulation of heterochromatin protein HP1- $\alpha$ in regions of fragmented chromatin. HL-60 cells were treated with topotecan ${ }^{\circledR}$ and incubated for $8 \mathrm{~h}$. Nuclei were isolated according to protocol III by Bunce et al. (Bunce et al., 1988), lysed and were subjected to isopycnic centrifugation. Nucleosomes were analysed on an agarose gel for their sizes. Histones were separated with SDS-PAGE (15\%) and transferred to nitrocellulose membranes by Western blotting for further antibody treatment with anti-H3-dimethyl K9 and anti-HP-1 $\alpha$.

\subsection{Quantitative analysis of apoptosis-related DNA fragmentation via FACS (fluorescence activated cell sorting)}

To quantitatively analyse the process of DNA fragmentation in connection with an accumulation of $\mathrm{H} 2 \mathrm{AX}$-phosphorylation at serine 139 and a general depletion of acetylated histone $\mathrm{H} 3$ at lysine 9 as well as a depletion of trimethylated histone $\mathrm{H} 3$ at lysine 9 , we used a flow cytometer. With the help of the TUNEL-assay, a method that is often used to detect DNA fragmentation (Darzynkiewicz et al., 1997), and in conjunction with specific antibody binding we were able to relate at least one part of these two processes to each other. HL-60 cell were treated with topotecan ${ }^{\circledR}$ and harvested after $8 \mathrm{~h}$. Cells shortly harvested after seeding served as control cells. All cells were incubated with primary antibodies raised against one of the following modifications: H2AX-phosphate S139, H3-trimethyl K9 and H3acetyl K9. Although all antibodies were tested in single experiments, it turned out that neither of the two anti-H3-trimethyl K9 antibody and anti-H3-acetyl K9 antibody showed any specific binding (although both were recommended for immuno-fluorescence and FACS analyses). Therefore, we had to restrict our experiments to the analyses of H2AX-phosphate S139. Analysis of control cell samples showed that only a small number of cells stained H2AXphosphate S139 positive (Fig. 3.11 1; red histogram). 
As these experiments were carried out with non-synchronised cells, it is not surprising that one will always find a minor fraction of cells showing DNA-double strand breaks, for which H2AX-phosphate S139 is a general marker. After induction of apoptosis, the majority of the cell population proved to be $\mathrm{H} 2 \mathrm{AX}$-phosphate S139 positive (Fig. 3.11 2; red histogram). This indirectly shows the strong effect the apoptosis inducer topotecan ${ }^{\circledR}$ has on DNA replication, namely by inhibiting the enzyme topoisomerase I, this compound causes massive DNA double strand breaks, which is subsequently indicated by rapid phosphorylation of the histone subtype $\mathrm{H} 2 \mathrm{AX}$ at serine 139. In parallel to $\mathrm{H} 2 \mathrm{AX}$ phosphorylation, we also pursued TUNEL-assays to correlate the state of DNA fragmentation to an accumulation of H2AXphosphate S139 on quantitative terms. Similar to the results obtained from the H2AXphosphate S139 analysis, the control cell fraction also contained a small number of cells which stained TUNEL positive, indicated by the red histogram (Fig. 3.113 ). Once the cells were treated with topotecan ${ }^{\circledR}$, we observed a large scale increase in TUNEL positive cells (Fig. 3.114 ; red histogram). In a tandem dot plot which correlates results of the TUNELassay with those of H2AX-phosphate S139 antibody binding, it can be summed up that all cells which turned out to be H2AX-phosphate S139 positive, were also stained TUNEL positive (Fig. 3.116 ). With these findings we could confirm the earlier results obtained from the sucrose gradients, namely that phosphorylated H2AX histones at serine 139 chiefly accumulate in regions of fragmented chromatin.

\footnotetext{
Fig. 3.11 Quantitative analysis of apoptosis-related DNA fragmentation in connection with accumulation of histone H2AX-phosphate S139 via FACS. HL-60 cells were treated with topotecan and harvested after $8 \mathrm{~h}$. Cells without treatment were harvested in parallel and served as controls. For FACS analyses the cells were marked with anti-H2AX-phosphate S139 antibody and AlexaFluor 555-labelled anti-mouse antibody as secondary antibody. (1) Control cells only contained a small number of H2AX-phosphate S139 positive cells (red histogram). This was defined as the usual background in a cell suspension. (2) After induction of apoptosis the number of cells which were stained H2AX-phosphate S139 positive (red histogram) strongly increased. (3) Only a very small number in the control cell fraction turned out to be TUNEL positive (red histogram). This was also defined as the usual background. (4) $8 \mathrm{~h}$ after induction of apoptosis, the number of cells staining TUNEL positive strongly increased (red histogram). (5) Merge of H2AX-phosphate S139 results and TUNEL-assay results. The red dots indicate the H2AX-phosphate S139/TUNEL positive cells, whereas the control cells are represented by grey dots. H2AX-phosphate S139/TUNEL negative cells were predominant in control samples. Topotecan ${ }^{\circledR}$ treated samples mainly contained H2AX-phosphate S139/TUNEL positive cells (red dots).
} 

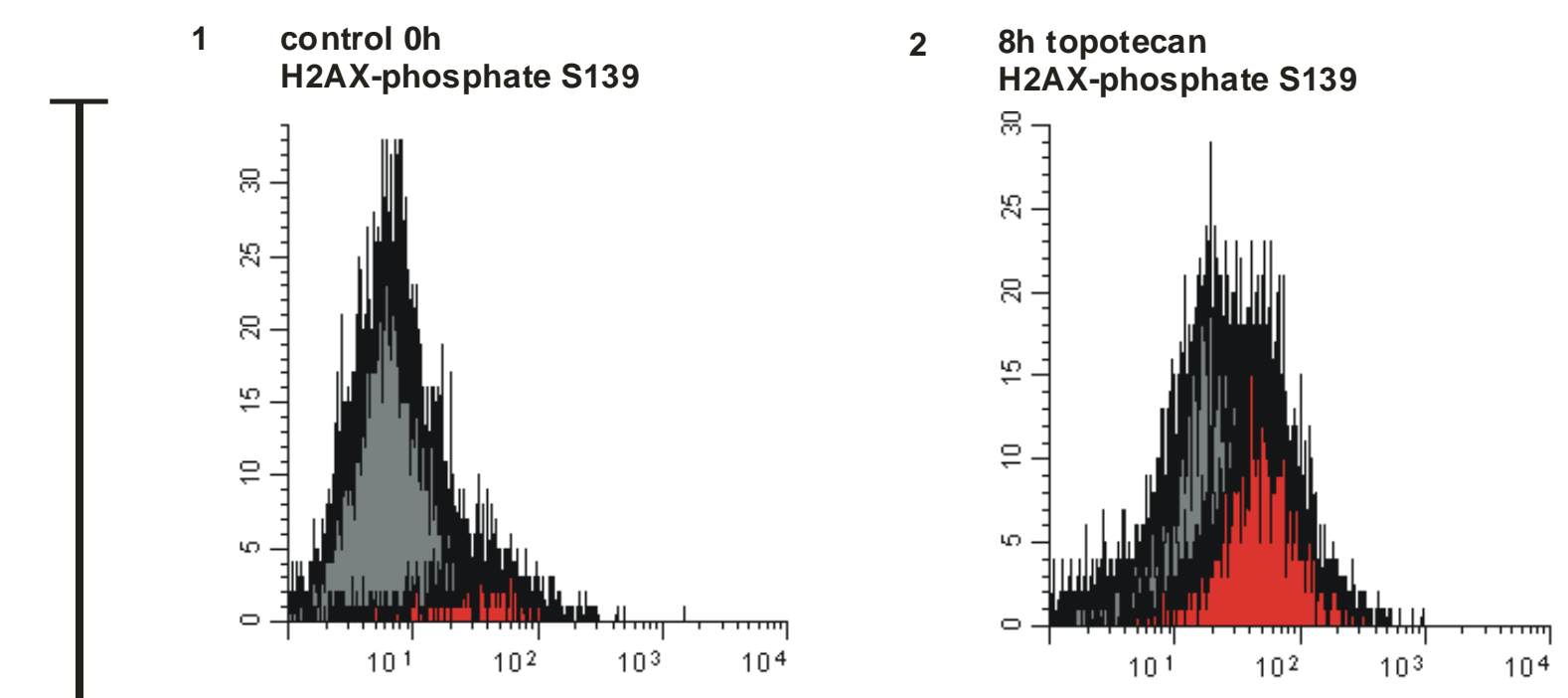

3

control oh

TUNEL-assay

4 8h topotecan

TUNEL-assay
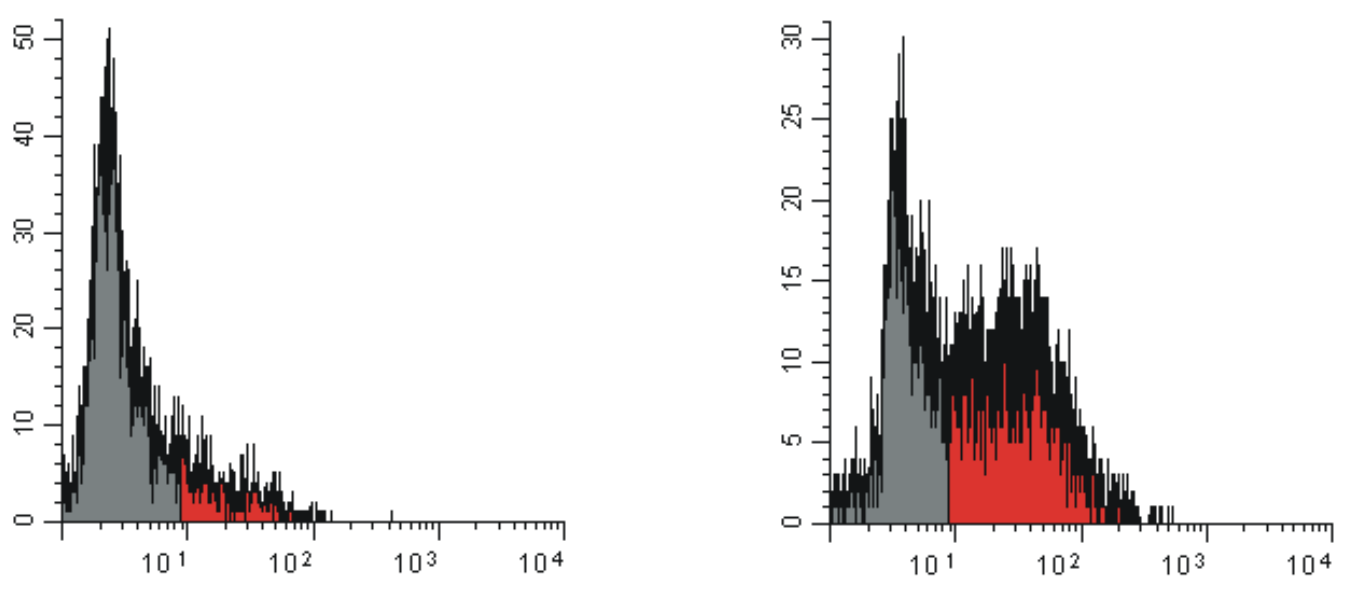

5 control Oh

H2AX-phophate S139/

Tunel-assay

6 8h topotecan

H2AX-phosphate S139/

TUNEL-assay
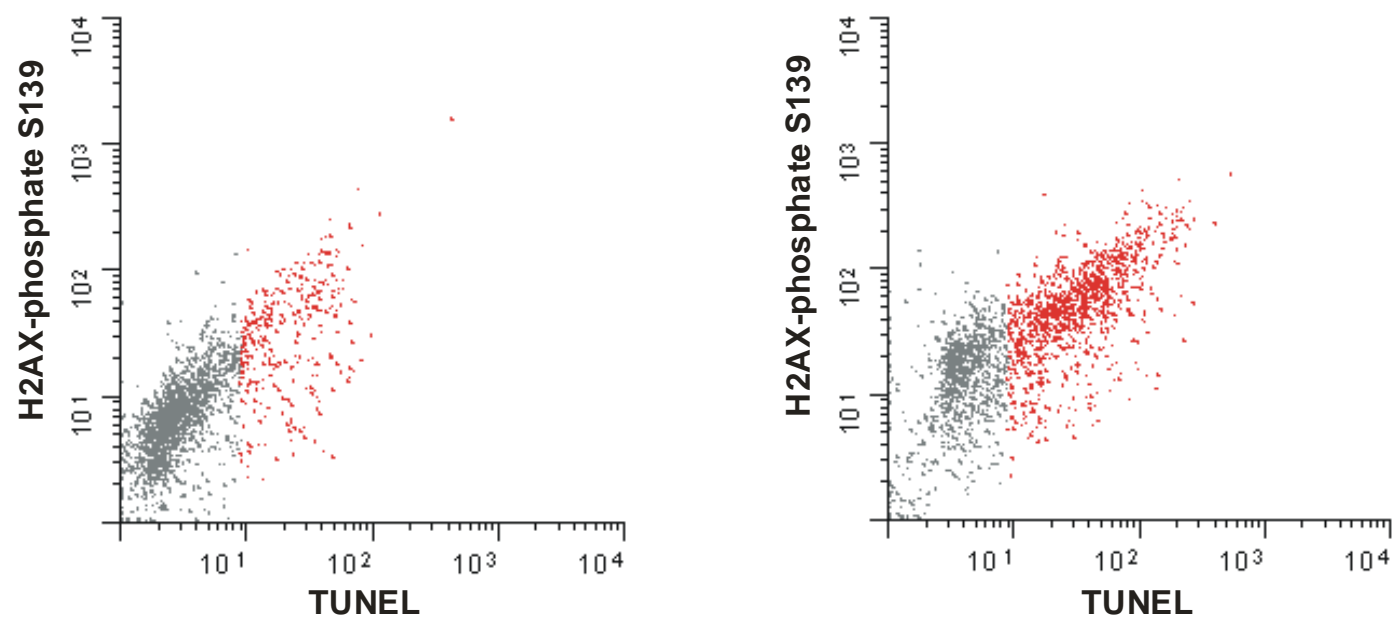

channels 


\section{Discussion}

\subsection{The role of post translational histone modifications for chromatin structure during apotosis}

Chromatin is the overall physiological template of all eukaryotic genetic information, which is tightly packaged into the nucleus which measures $10 \mu \mathrm{m}$ in diameter. Higher order chromatin structures play an important role with respect to biological functions such as DNA replication and recombination, gene regulation and DNA repair. Only a small percentage of the chromatin is actually made available to both transcription factors and transcription machinery, while the lion's share of the genome remains essentially inaccessible to enzymes like RNA polymerases. In eukaryotes, DNA and histone proteins together form the smallest, basic repeating unit of chromatin, the nucleosome. Histones are subject to various posttranslational modifications such as methylation, acetylation, phosphorylation, ubiquitinylation, sumoylation and ADP-ribosylation. The majority of them were detected at the N-terminal tail of the core histones, although more and more evidence is coming up for modifications along the globular domain (Cosgrove et al., 2004) and the C-terminal tails (Felsenfeld and Groudine, 2003) as well. Post-translational modifications on histones have been found to play a key role in altering higher order chromatin structure and function. With reference to different types of modification, histone acetylation is usually correlated with transcriptionally active chromatin (euchromatin) (Felsenfeld and Groudine, 2003; Grunstein, 1997; Hendzel et al., 1998a; Sarg et al., 2004; Struhl, 1998; Thorne et al., 1990; Walia et al., 1998), whereas histone methylation is a more heterogenic field, being linked with both transcriptionally active genes as well as gene silencing (heterochromatin), depending on the site of modification (Bannister et al., 2005; Lachner and Jenuwein, 2002; Santos-Rosa et al., 2002). This is why Allis and Strahl (Strahl and Allis, 2000) proposed that distinct modifications singularly or in combination form the so-called 'histone code', meaning a certain pattern of histone marks, which can be read by other proteins or protein complexes to initiate defined downstream events. Different levels of cross-talk between several components of this gene regulation machinery have just come up and these epigenetic circuits have been the main focus in recent histone studies (Briggs et al., 2002; Fischle et al., 2003).

During the last years of intensive research in the field of histone modifications and epigenetics, clear evidence of alterations in chromatin structure could be directly linked with cell cycle progression, DNA replication, DNA damage and repair, genetic recombination and overall chromosome stability (Wolffe et al., 2000). Moreover, it was suggested that the regulatory impact of post-translational histone modifications on X-chromosome inactivation, genetic imprinting, developmental reprogramming of cell lineages and plasticity of stem cells might in the end have far reaching consequences for human biology and disease. These of 
course include processes like cancer, aging and apoptosis (Strahl and Allis, 2000). The latter is an active process, by means of which the cell initiates its own death. This is most important for normal development and for keeping up the homeostasis in multi-cellular organisms. Biochemical and morphological features like fragmentation of nucleosomal DNA, as well as the formation of apoptotic condensed chromatin bodies are hallmarks of apoptosis (Wyllie et al., 1981; Wyllie et al., 1980; Wyllie et al., 1984). Dramatic changes in the integrity of the DNA and the tight, very compact packaging of chromatin during apoptosis suggest that post-translational histone modifications play a key role in propelling these changes (Cheung et al., 2003). On the basis of these correlations, one of the main aims of this work was to analyse cause and effects of changes in histone modifications on chromatin condensation and fragmentation during apoptosis. To settle this question, possible overall changes in histone modification patterns after induction of apoptosis were examined, together with the specific modification pattern in fragmented and non-fragmented chromatin. As the cleavage of nucleosomal DNA is a pivotal point in later stages of apoptosis, a second aim of this project was the analysis of a putative nuclear histone release into the cytosol, which may occur as a consequence of chromatin fragmentation.

\subsection{Topotecan $^{\circledR}$ and etoposide induce apoptosis in human cell lines HL-60 and HeLa}

For the induction of apoptosis, two chemical compounds were used, depending on the cell type. The human leukaemia cell line HL-60 was induced with the topoisomerase I inhibitor topotecan ${ }^{\circledR}$ (chap. 3.2). As the cervix carcinoma cell line HeLa failed to respond to topotecan ${ }^{\circledR}$ (data not shown), the topoisomerase II inhibitor etoposide was used instead (chap. 3.2). The following section gives a short survey of some characteristic chemical features, the mechanisms of action and biological effects for both inhibitors.

In terms of anti-cancer drug therapy, two physiologically relevant topoisomerases, namely I and II, have been identified in humans. Topoisomerases relieve the torsional strain in the DNA double helix by reversibly complexing it. Furthermore, they introduce transient enzymebridged single (topoisomerase I) or double (topoisomerase II) strand breaks, through which the intact strand can pass (Creemers et al., 1994). With the help of these enzymes, a continuing DNA replication process is guaranteed. In case of a malfunction of topoisomerases, this would lead to a rapid unwinding of the DNA double helix during replication, which subsequently would cause an increased coiling of the helix ahead of the replication fork. The increased torsional strain would put an end to transcription and replication (Kollmannsberger et al., 1999).

Topotecan $^{\circledR}$ is a semi-synthetic, water soluble analogue of the alkaloid plant compound camptothecin (extracted from Camptotheca accuminata). The chemical structure of topotecan ${ }^{\circledR}$ is, like camptothecin, based on a saturated lactone ring. 


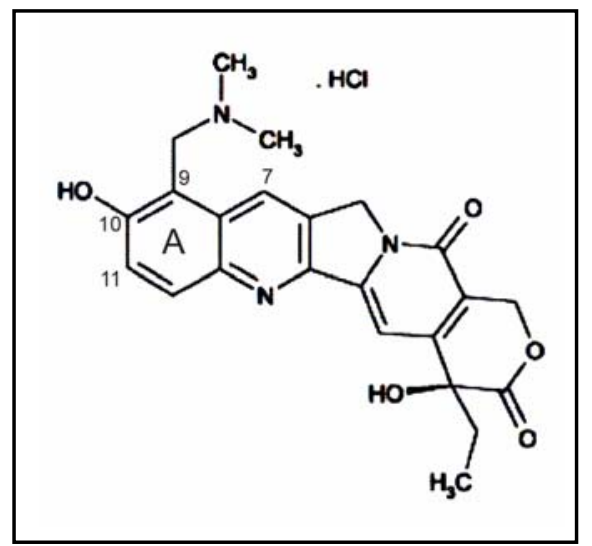

Fig. 4.2.1 Chemical structure of the camptothecin derivative topotecan ${ }^{\circledR}$ (manual ALEXIS Biochemicals).

Its water solubility is based on a basic side chain at position 9 of the A ring. Depending on the $\mathrm{pH}$, topotecan ${ }^{\circledR}$ undergoes reversible hydrolysis from lactone to carboxylate form, whereby only the lactone form is the biologically active. Whereas the former predominates at basic $\mathrm{pH}$, the latter is found at acidic $\mathrm{pH}$ (Herben et al., 1996). The cytotoxic activity of this drug is determined by the concentration of the non-hydrolysed form of topotecan ${ }^{\circledR}$, as the closed lactone ring is the crucial feature for the interaction between topotecan ${ }^{\circledR}$ with the topoisomerase I/DNA complex.

Topotecan $^{\circledR}$ is a specific potent inhibitor of topoisomerase I (Hsiang et al., 1985; Hsiang et al., 1989a; Hsiang et al., 1989b; Hsiang et al., 1989c; Jaxel et al., 1989). Its specific mechanism of action is to form a stable covalent complex with the DNA/topoisomerase I aggregate. The resulting 'cleavable complex' is responsible for the cytotoxic properties of topotecan ${ }^{\circledR}$ (Hsiang and Liu, 1988). Although the expression of topoisomerase is cell cycle independent, the inhibition of this enzyme by topotecan ${ }^{\circledR}$ showed to be most effective during S-phase (Del Bino et al., 1991). Formation of the meta-stable 'cleavable complex' leads to a complete block-up of DNA relaxation and subsequent replication. In the following S-phase cells are irreversibly damaged by DNA strand breaks and a block of DNA synthesis. In addition, replication forks are destroyed and DNA transcription is made impossible. All these processes will inevitably lead to apoptosis (Caserini et al., 1997). These results were most recently supplemented by Happel et al. (Happel et al., 2005), who observed a strong dephosphorylation of histones $\mathrm{H} 3$ serine 10 and 28 and histone $\mathrm{H} 1$ due to the treatment of different cell types with topotecan ${ }^{\circledR}$, which led to a cell cycle arrest.

The clinical relevance of topotecan ${ }^{\circledR}$ lies in its anti-tumor activity. It has been demonstrated that its activity is among others directed against lung, colon, renal, breast and ovary tumorderived cell lines (Burris et al., 1992; Holm et al., 1989; Johnson et al., 1997a; Johnson et al., 1997b; Li et al., 1972; Perez-Soler et al., 1996). A few years ago topotecan ${ }^{\circledR}$ was licensed for clinical use in platinum-refractory ovarian cancer and small-cell lung cancer (Creemers et al., 
1996). However, its application has been restricted to patients who failed to respond to prior chemotherapy with platinum compounds and paclitaxel.

The anti-tumor agent and topoisomerase II inhibitor etoposide acts in a similar way as topotecan ${ }^{\circledR}$. It binds to the complex DNA/topoisomerase II to enhance double strand and single strand cleavage of DNA (Burden et al., 1996; Hande, 1996). It reversibly inhibits relegation (Osheroff, 1989; Osheroff et al., 1991) and subsequently blocks the cell cycle in Sphase and $\mathrm{G}_{2}$-phase (Chow and Ross, 1987). As a consequence, normal and tumor cell lines undergo apoptosis (Droin et al., 1998).

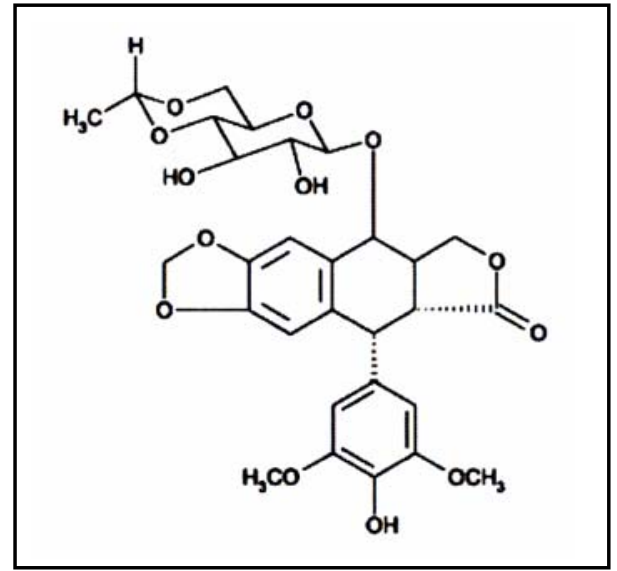

Fig. 4.2.2 Chemical structure of etoposide (manual ALEXIS Biochemicals).

Since both apoptosis inducers are topoisomerase inhibitors, they both interfere severely with the process of DNA replication and transcription, blocking both effectively. Subsequently, in both cases apoptosis is induced via DNA damage, involving the intrinsic apoptosis pathway. In the present study both topotecan ${ }^{\circledR}$ for the leukaemia cell line HL-60 (Kratzmeier et al., 2000; Kratzmeier et al., 1999) and etoposide (dose-response curve tested in own experiments) for the cervix carcinoma derived cell line HeLa were used to induce apoptosis. In both cases apoptotic markers such as PARP cleavage, fragmentation of nucleosomal DNA and caspase activity were gradually increased depending on the induction time and concentration of the inducer used (chap. 3.1 and 3.2). PARP cleavage and cleavage of nucleosomal DNA in HL-60 cells were observed from $2 \mathrm{~h}$ post-induction. After $24 \mathrm{~h}$ we detected a DNA smear in the agarose gel, which is an indication for the onset of secondary necrosis. Around this time DNA is completely degraded and only traces of oligonucleosomes were monitored. Caspase 3 activity was observed to increase strongly in HL-60 cells from $8 \mathrm{~h}$ up to $24 \mathrm{~h}$ after induction of apoptosis.

Similar results but with differences in the time span were obtained from dose-response curves in HeLa H2B-YFP cells. PARP cleavage and caspase 3 activity both were concomitantly increased $24 \mathrm{~h}$ after drug treatment. Moreover, a gradual degradation of DNA 
was detected after $36 \mathrm{~h}$ of apoptosis with $100 \mu \mathrm{M}$ etoposide and after $48 \mathrm{~h}$ incubation with any of the etoposide concentrations used $(25 \mu \mathrm{M}, 50 \mu \mathrm{M}$ and $100 \mu \mathrm{M})$. This slight 'overincubation' of both cell lines ensured that the whole spectrum of apoptotic processes was covered with reference to all subsequent experiments.

\subsection{Linking changes in histone modifications with apoptosis}

The interest in the influence of post-translational histone modifications on chromatin structure and DNA packaging, combined with those far-reaching implications for biology and disease, has grown dramatically over the last years. Many research groups focussed on histone modifications and their functional association with apoptosis. Several types of modifications that are especially induced during apoptosis have already been proposed. Interestingly, a majority of them were most often related to different phosphorylated or dephosphorylated sites of the histones $\mathrm{H} 2 \mathrm{~A}, \mathrm{H} 2 \mathrm{~B}$ and $\mathrm{H} 3$, including the histone variant $\mathrm{H} 2 \mathrm{AX}$ (Ajiro and Allis, 2002; Ajiro et al., 2004; Enomoto et al., 2001; Enomoto et al., 2003; Rogakou et al., 1999; Rogakou et al., 1998; Waring et al., 1997). However, phosphorylation of histones induced by the onset of apoptosis still remains a controversially discussed field. Waring et al. (Waring et al., 1997) investigated a possible link of chromatin condensation during apoptosis with histone H3 phosphorylation. This group induced apoptosis in thymocytes with gliotoxin, which resulted in increased levels of histone H3 serine 10 phosphorylation. Additional chemical agents like forskolin and cholera toxin were used to examine an apoptosis-related increase in $\mathrm{H} 3$ phosphorylation at this site. However, a rapid increase was only observed with gliotoxin (Waring et al., 1997). Enomoto, Lee and co-workers reported similar results (Enomoto et al., 2001; Enomoto et al., 2003; Lee et al., 1999). They induced apoptosis in thymocytes using the phosphatase inhibitors okadaic acid and calyculin A. Their induction experiments resulted in a concomitant increase in histones $\mathrm{H} 2 \mathrm{~A}, \mathrm{H} 3$ and $\mathrm{H} 1$ phosphorylation. Moreover, treatment of thymocytes with calyculin A increased the chromatin sensitivity towards endogenous DNase in nuclei. This group deducted from these results that the phosphorylation of histones $\mathrm{H} 1, \mathrm{H} 2 \mathrm{~A}$ and $\mathrm{H} 3$ is an early step to trigger DNA fragmentation during apoptosis in thymocytes. However, it remains questionable if these findings might really be put down to apoptosis-related effects, as it seems obvious that treatment of cells with the phosphatase inhibitors okadaic acid and calyculin A will inevitably lead to excessive increase in histone protein phosphorylation. So it can be assumed that hyperphosphorylation of histone $\mathrm{H} 3$ is rather a side effect and an artefact, than a specific apoptotic feature.

In contrast to these findings, earlier on Ajiro et al. (Ajiro et al., 1996), who also reported an increase in phosphorylation of histone $\mathrm{H} 3$ at serine 10 as well as an excessive phosphorylation of $\mathrm{H} 2 \mathrm{~A}$ after induction by okadaic acid, defined their results to be cell cycle dependent, rather than being connected with apoptosis. This group even declared the 
phosphorylation of $\mathrm{H} 3$ serine 10 to be mitosis specific. Hendzel et al. (Hendzel et al., 1998b) pursued similar experiments using different cell types and inducers. After induction Hendzel and co-workers could not detect any apoptosis-related increase in H3 phosphorylation, and unlike during mitosis, they could not bring forth any evidence for a requirement of phosphorylated histones $\mathrm{H} 1$ and $\mathrm{H} 3$ as a kind of mark, to maintain the chromatin in a condensed state. These results are in agreement with those of Marushige and Marushige (Marushige and Marushige, 1995), who had stated earlier that they could not confirm these phosphorylations in apoptotic glioma and neurinoma cells, either. In the majority of publications histone H3 phosphorylation is associated with mitosis, cell cycle events in general and chromosome condensation (Bradbury, 1992; Koshland and Strunnikov, 1996). However, some research groups linked H3 phosphorylation with apoptosis. Hendzel et al. (Hendzel et al., 1998b) earlier reported that phosphorylation at $H 3$ serine 10 started at $G_{2} / M$ transition of the cell cycle and was then initially located to pericentric heterochromatin of each chromosome. By means of flow cytometry and Western blotting, Happel et al. (Happel et al., 2005) most recently could provide fundamental evidence that histone $\mathrm{H} 3$ phosphorylation at serine 10 and 28 was strongly decreased $1 \mathrm{~h}$ after induction of apoptosis in HL-60 cells with either topotecan ${ }^{\circledR}$ or in HeLa cells with etoposide (both topoisomerase inhibitors). Dephosphorylation of both histone sites S10 and S28 did not correlate with the timing and intensity of the apoptotic parameters, which were measured in parallel. This phenomenon was confirmed not to be apoptosis-related but rather reflected the changes which refer to the cell cycle distribution of cells treated with these inducers. In a most recent study, Ahn and co-workers (Ahn et al., 2005a; Ahn et al., 2005b) investigated the phosphorylation pattern of $\mathrm{H} 2 \mathrm{~B}$ in the yeast strain $\mathrm{S}$. cerevisiae. This group found out that $\mathrm{H} 2 \mathrm{~B}$ serine 10 phosphorylation is absolutely necessary to induce cell death, which exhibits phenotypic hallmarks of apoptosis including chromatin condensation and DNA fragmentation. In addition, these findings were extended to the point that $\mathrm{H} 2 \mathrm{~B}$ serine 10 phosphorylation serves as a mark during the pachytene stage of yeast meiotic prophase. This function in chromatin remodelling closely correlates with chromatin compaction. How this mark can serve in processes so diverse as apoptosis and meiosis still remains elusive, though.

Besides the phosphorylation of specific histone $\mathrm{H} 3$ sites, Ajiro and co-workers (Ajiro et al., 2004) investigated an apoptosis-related histone phosphorylation in several mammalian tumor cell lines like HL-60 (induced with etoposide, cisplatin, ethanol, demecolcin, UV-radiation and anti-FAS antibody), HeLa (induced with okadaic acid), mouse FM3A (induced with etoposide), N18 cells (induced by mitogen starvation) and rat thymocytes (induced with corticosterone and dexamethasone). They found that phosphorylation of histone H2B, which is usually unphosphorylated in quiescent or growing cells, was temporally linked to initiation of nucleosomal DNA fragmentation. Both DNA fragmentation and H2B phosphorylation were 
blocked completely when the ICE or ICE-like caspase inhibitor Z-Asp-CH(2)-DCB was used. In vitro phosphorylation assays involving a protein kinase $\mathrm{C}$ showed specific single site phosphorylation of $\mathrm{H} 2 \mathrm{~B}$ at serine 32 (Ajiro, 2000). Additional experiments analysing a possible apoptosis-related histone $\mathrm{H} 3$ phosphorylation showed that $\mathrm{H} 3$ phosphorylation was at a very low level and the sites which were analysed in more detail did not include any mitosis-specific phosphopeptides. Apart from histones $\mathrm{H} 2 \mathrm{~B}$ and $\mathrm{H} 3$, phosphorylation of $\mathrm{H} 4$ was also found to be slightly increased, whereas histone $\mathrm{H} 2 \mathrm{~A}$ did not show any remarkable increases. Due to these results Ajiro concluded that firstly, H2B phosphorylation occurred exceptionally in apoptotic cells and was associated with apoptosis-specific nucleosomal DNA fragmentation. Secondly, chromatin condensation occurred by a different biochemical mechanism compared to those which were switched on during mitosis or premature chromosome condensation and finally this exceptional phosphorylation of histone $\mathrm{H} 2 \mathrm{~B}$ could be taken for a useful biochemical hallmark of apoptotic cells.

During following experiments with the help of size-fractionating apoptotic mammalian cells via a simple discontinuous BSA density gradient centrifugation, the same group investigated the possible relation of histone $\mathrm{H} 2 \mathrm{~B}$ phophorylation with apoptotic DNA fragmentation in more detail (Ajiro et al., 2004). They found apoptosis-specific H2B phosphorylation to be strongly increased together with DNA fragmentation activity. Both were exclusively observed in cells undergoing apoptosis. Non-apoptotic cells failed to show these effects. In cooperation with Ajiro, Cheung et al. (Cheung et al., 2003) extended the analyses of the apoptosis-related phosphorylation of $\mathrm{H} 2 \mathrm{~B}$ in a way that they were able to confirm serine 14 to be a second specific site which is phosphorylated once apoptosis is induced. Thereby, the responsible kinase Mst1 (mammalian sterile twenty $\mathbf{1}$ ), which is known to cause apoptosisrelated chromatin condensation in vitro (Graves et al., 2001; Ura et al., 2001a; Ura et al., 2001b), was cleaved into action by a caspase. Cheung and co-workers (Cheung et al., 2003) suggested that $\mathrm{H} 2 \mathrm{~B}$ serine 14 was the physiological target for Mst1 and that its phosphorylation might facilitate apoptotic chromatin condensation, DNA fragmentation and would finally lead to cell death. The summary of the data on apoptosis-related histone phosphorylation underlines the controversially discussed topic. In general the outcome of any experiment in this field is to a great extent dependent on the cell line, the inducer and inductions times.

\subsubsection{Overall time-dependent changes in histone modifications linked with apoptosis}

Apart from the fact that it has already been difficult for researchers to explicitly link particular histone modifications to apoptosis, the matter is getting even more complex, with reference to histone modification cross-talk. With relation to DNA damage repair, phosphorylation of histone H2B S 14 and its deposition at sites of double strand breaks (DSB) have been 
reported to be dependent on previous deposition of the phosphorylated histone $\mathrm{H} 2 \mathrm{~A}$ variant H2AX S 139 at the same site (Fernandez-Capetillo et al., 2004). However, this group claimed that accumulation of H2B phosphate S14 at DSB and formation of foci at late points of induced DNA damage by radiation was not connected with apoptosis, whereas the actual phosphorylation of $\mathrm{H} 2 \mathrm{~B}$ S14 was. Despite the fact that this still needs to be further elucidated, it has become quite clear how tightly biological processes like DNA damage repair and apoptosis are interwoven. As the phosphorylation of H2AX S139 was long supposed to be a marker for apoptosis by indicating DNA double strand breaks (Rogakou et al., 1999; Rogakou et al., 1998; Rogakou et al., 2000b), this modification was the first to be analysed in short-term and long-term kinetics in the present work. Along with H2AX phosphorylation, the main focus in the present work was laid on the analysis of apoptosisrelated changes in the methylation and acetylation patterns of core histones and histone $\mathrm{H} 3$ in particular, as this has remained a rather elusive area. Moreover, so far the amino terminal tail of histone $\mathrm{H} 3$ was shown to have the highest density of post-translational modifications mapped along all histones and on top of that a complex pattern of putative combinations of marks is now emerging (Fischle et al., 2003). Among the following modifications tested in Western blots, H2AX-phosphate S139, H3 dimethyl K4, K9, K36, H3 trimethyl K4 and K9, H3 acetyl K9, K18, K23 and H2A ubiquityl, only H2AX-phosphate S139 and H2A ubiquityl showed a time-dependent change in their modification pattern (chap. 3.3.1 and 3.4.1). Hyperphosphorylation of H2AX S139 was observed as early as 10 min after induction of apoptosis with the topoisomerase inhibitor I topotecan ${ }^{\circledR}$. These findings have previously been reported by Rogakou and others (Rogakou et al., 1998, 1999, 2000; Talasz et al., 2002; Huang et al., 2003), who used various chemical compounds or UV-radiation to induce apoptosis via DNA double strand breaks. The state of phosphorylation was in most cases either measured by Western blotting (Rogakou et al., 1999; Rogakou et al., 1998; Rogakou et al., 2000b) or flow cytometry (Huang et al., 2003). With relation to ubiquitylation of $\mathrm{H} 2 \mathrm{~A}$ ( $\mathrm{uH} 2 \mathrm{~A})$, we could show that this histone type was strongly deubiquitylated 2-6 $\mathrm{h}$ postinduction (chap. 3.4.1). This has also been reported by previous groups (Marushige and Marushige, 1995; Mimnaugh et al., 2001; Tanimoto et al., 1997). All these groups confirmed a deubiquitylation of mono-ubiquitylated $\mathrm{H} 2 \mathrm{~A}$ in response to induction of apoptosis by various differently acting inducers in various cell types. Like Mimnaugh and co-workers (Mimnaugh et al., 2001) we could provide evidence that apoptosis markers like caspase 3 activity, cleavage of nucleosomal DNA and PARP cleavage, with only a slight delay, almost coincided with the observed depletion of mono-uH2A (chap. 3.1 and 3.4.1). All four processes were observed within 2-8 $\mathrm{h}$ after apoptosis induction. It was therefore assumed that, rather than being a mark for the actual induction of apoptosis, deubiquitylated $\mathrm{H} 2 \mathrm{~A}$ must be seen as a downstream event during the execution of apoptosis, initiated by caspase cleavage. With 
relation to a specific function, Mimnaugh et al. (Mimnaugh et al., 2001) suggested a survival response mechanism to protect the genome from attack by hazardous chemical compounds. Deubiquitylated H2A might be a 'nuclear sensor to indicate cellular stress'.

The remaining histone modifications tested did not show any remarkable changes throughout the ongoing process of apoptosis, however, with relation to some of their already described functions, this was unexpected. One might have expected that modifications such as $\mathrm{H} 3 \mathrm{di}-$, and trimethyl K4, dimethyl K36 and $\mathrm{H} 3$ acetyl K9, 18 and 23, which all are assumed to form transcriptionally active chromatin by opening up its structure and making it more accessible, are removed during apoptosis to shut down transcriptional processes within the genome. In contrast to that, specific modifications which are generally associated with gene silencing like $\mathrm{H} 3$ di-, and trimethyl K9, were supposed to be increased within the chromatin. However, as histone tails in general are not only modified by one single type of modification and preparations of core histones always present a mixture of various types of modifications, which all change and interact in the way of a particular 'cross talk', it is probably difficult to monitor these on Western blot level only.

\subsubsection{Overall time-dependent changes in histone modifications and histone variants linked with apoptosis}

Apart from post-translational histone modifications, which have been assigned to different functions concerning chromatin structure and gene regulation, another factor that contributes to chromatin functional heterogeneity are the non allelic, replication independent histone variants or subtypes (Hayes, 2002; Hayes and Hansen, 2002). The works of Wolffe and Pruss (Wolffe and Pruss, 1996a; Wolffe and Pruss, 1996b) which demonstrated that some histone mutations have highly specific effects on transcription, in addition to the observation that the expression of some histone subtypes is temporally, developmentally and spatially regulated suggests that histone variants also fulfil different functions. For this purpose, we purified histones from control and apoptosis induced cells via HPLC and subsequently analysed them with AUT/AUC-2 ${ }^{\text {nd }}$ gel electrophoresis and capillary zone electrophoresis.

\subsubsection{Purification and separation of histones via HPLC}

In previous works HPLC was introduced as a highly efficient chromatographic technique to separate histones, their variants and post translationally modified histones (Helliger et al., 1992; Helliger et al., 1988; Lindner et al., 1992; Lindner et al., 1986; Lindner et al., 1988; Lindner et al., 1990). In this work, the separation of core histones was done by HPLC on a Jupiter C4 column with $150 \times 4.6 \mathrm{~mm}$ in diameter, a matrix of $5 \mu \mathrm{m}$ particle size and $300 \AA$ pore size. Lindner and co-workers usually first de-salted their core histone fractions by 
reversed-phase HPLC and then separated the histones and their variants via hydrophilic interaction liquid chromatography (HILIC), using a Nucleosil 300-5 $\mathrm{C}_{4}$ column, and a multistep water-acetonitrile gradient. This had turned out to be particularly useful with histone variants (Lindner et al., 1996). Subsequent to these procedures, post-translationally modified core histones were analysed by HPCE (high performance capillary electrophoresis). The purification and separation parameters for core histones and their variants were proceeded with in a similar way in this work, although with some variations concerning solvent concentration and gradient formation. Whereas Lindner et al. (Lindner et al., 1996) used higher acetonitrile stock concentrations of $70 \%$, together with $10 \%$ ethylene glycol monomethyl ether (EGME) and $0.1 \%$ TFA, only $59.5 \%$ acetonitrile with $0.1 \%$ TFA and no EGME were used in this work. It is of course quite difficult as well as critical to compare HPLC results which were received by different protocol parameters. Therefore in the following only preliminary assumptions are made to get an idea which HPLC fraction has to be analysed in more detail.

With the HPLC parameters used in this study, we observed a great shift in peak retention times compared to the results of Lindner et al. (Lindner et al., 1992; Lindner et al., 1996), which is most probably due to their different gradient and HILIC system conditions. Lindner and co-workers assigned their HPLC peaks with the additional help of AUT gel electrophoresis.

By means of HPLC we received a separation pattern of five major and two smaller peaks (chap. 3.5.2.1 and 3.5.2.2) for the core histones. Following the separation pattern of Lindner et al. (Lindner et al., 1996), it might be possible that the two H2A fractions we obtained after around 36-39 min represent two of the H2A subtypes, H2A.1 and H2A.2. However, this would still have to be determined by further analyses. This will also have to be the case for the fractions of $\mathrm{H} 3$. Three different peaks were obtained for $\mathrm{H} 3$, one major and two smaller peaks (chap. 3.5.2.2). Following Lindner's separation pattern, the major peak possibly contains H3.2 and H3.3, whereas the second smaller peak might be H3.1. However here, too, further analyses by mass spectrometry or Western blot analyses with subtype specific antibodies will be inevitable.

In subsequent analyses of the two $\mathrm{H} 2 \mathrm{~A}$ fractions, we found that our second $\mathrm{H} 2 \mathrm{~A}$ fraction also contained a third H2A subtype in its phosphorylated form, namely H2AX-phosphate S139, whereas the first $\mathrm{H} 2 \mathrm{~A}$ fraction did not. According to Lindner et al. (Lindner et al., 1996) it has always been quite difficult to precisely separate the subtype H2AX from subtype H2A.1. This might be the explanation why we detected the phosphorylated form of $\mathrm{H} 2 \mathrm{AX}$ within the second $\mathrm{H} 2 \mathrm{~A}$ fraction. To receive higher resolutions and precise separation of $\mathrm{H} 3$ and $\mathrm{H} 2 \mathrm{~A}$ in particular, different system parameters will still have to be tested. 
The pre-purification of core histones via HPLC made it possible to analyse separate histone fractions for a possible change in their specific modification pattern during apoptosis. As an additional result it is quite interesting that we did not observe a change in the HPLC resolution pattern of core histones from control cells compared to histones isolated from apoptotic cells. So, it might be assumed that apoptosis as such does not seem to cause a change of concentration with relation to specific histone types within the cell. For further analysis of subtype specific histone modifications core histones were separated on AUT/AUC $2^{\text {nd }}$ dimension gels.

\subsubsection{Separation of histones via AUTIAUC-2 ${ }^{\text {nd }}$ dimension gel electrophoresis}

To get a first impression of putative overall changes in post translational modification patterns of core histones we ran the HPLC fractions on AUT/AUC- $2^{\text {nd }}$ dimension gels. As protein concentrations of each single $\mathrm{H} 3$ fraction as well as of the $\mathrm{H} 2 \mathrm{~A}(1)$ and $\mathrm{H} 2 \mathrm{~A}(2)$ fractions were often very poor, all $\mathrm{H} 2 \mathrm{~A}$ peaks and all $\mathrm{H} 3$ peaks had to be pooled again for this method.

Our results presented changes in the separation patterns of histone $\mathrm{H} 3$ and histone $\mathrm{H} 4$ but not in those of $\mathrm{H} 2 \mathrm{~A}$ and $\mathrm{H} 2 \mathrm{~B}$ in the first dimension. Moreover, no further apoptosis-related changes for any of these histones were observed in the second dimension.

For H4 we might assume a slight deacetylation in apoptosis induced core histones. The separation patterns of control $\mathrm{H} 4$ and butyrate treated $\mathrm{H} 4$ were compared to $\mathrm{H} 4$ pre-treated with topotecan ${ }^{\circledR}$. Several $\mathrm{H} 4$ bands in the butyrate sample were identified, whereas separated $\mathrm{H} 4$ from topotecan ${ }^{\circledR}$ treated cells failed to show this band pattern. So it might be concluded that induction of apoptosis seems to cause a certain degree of deacetylation in $\mathrm{H} 4$. The separation pattern of control $\mathrm{H} 4$ showed an intermediate acetylation state compared to butyrate treated $\mathrm{H} 4$ and topotecan ${ }^{\circledR}$ treated $\mathrm{H} 4$. Prior to our experiments this has also been stated by Lindner et al. (Lindner et al., 1996), who found mono-, di-, tri-, and tetraacetylated $\mathrm{H} 4$ beside non-acetylated $\mathrm{H} 4$ in butyrate treated cells. Hyperacetylation of histone $\mathrm{H} 4$ after induction with butyrate was also described by McBain et al. (McBain et al., 1997). This group used butyrate not only to hyperacetylate histone $\mathrm{H} 4$, which was subsequently analysed by AUT-gel electrophoresis but also to induce apoptosis in the two colon cancer cell lines HCT 116 and VACO 5. In this way, induction of apoptosis and histone $\mathrm{H} 4$ hyperacetylation were correlated. The fact that the latter underwent apoptosis $30 \mathrm{~min}$ post-induction, whereas the former only showed reversible growth inhibition demonstrated that a specific reaction of particular cell types is dependent on concentration of the inducer and the duration of incubation. In this study butyrate concentrations were used that did not induce apoptosis in HL-60 cells, which could be confirmed by apoptosis markers. We did not 
detect PARP cleavage or cleavage of nucleosomal DNA. Moreover, the caspase 3 activity was not increased after $8 \mathrm{~h}$ (own experiments, data not shown).

With reference to the observed change in the band pattern of separated histone $\mathrm{H} 3$ in the first dimension, we noted a further separation of the assumed histone H3.3 band into two distinct bands. Moreover, the signal intensity of the $\mathrm{H} 3.3$ band noted in control $\mathrm{H} 3$ decreased, whereas the signal intensity of the second band was noted to increase (chap. 3.6.1). Two explanations for the distinct changes in topotecan ${ }^{\circledR}$ treated $\mathrm{H} 3$ might be possible. As published in recent works, treatment of cells with cytotoxic agents like topotecan ${ }^{\circledR}$ causes DNA double-strand breaks and a dephosphorylation of histone H3 at serines 10 and 28 (Happel et al., 2005). Moreover, it is widely accepted that transcriptional inactivation and gene silencing correlates with a general histone hypoacetylation of histones $\mathrm{H} 3$ and $\mathrm{H} 4$ in particular (Grunstein, 1997; Tamburini et al., 2005; Turner, 2000). If we assume that induction of apoptosis occurs concomitantly with transcriptional silencing and formation of heterochromatin (Bannister et al., 2001; Nakayama et al., 2001), it might also be assumed that treatment of $\mathrm{H} 3$ with topotecan ${ }^{\circledR}$ will result in $\mathrm{H} 3$ hypoacetylation and dephosphorylation. Both changes might then be related to the observed band shift.

A second possible explanation might be a change in composition of histone $\mathrm{H} 3$ variants and a difference in their post-translational modifications. We did not perceive any changes in the HPLC separation pattern of histone $\mathrm{H} 3$ fractions from cells treated with topotecan ${ }^{\circledR}$ compared to control H3. However, it cannot be ruled out that with different system settings changes might have turned up, as differences in apoptotic $\mathrm{H} 3$ versus control $\mathrm{H} 3$ were quite obvious after their separation by AUT/AUC- ${ }^{\text {nd }}$ dimension gel electrophoresis.

In their study on histone $\mathrm{H} 3$ variants and their possible functions, Ahmad and Henikoff (Ahmad and Henikoff, 2002a; Ahmad and Henikoff, 2002b) suggest that during gene transcription the histone variant $\mathrm{H} 3.3$ is introduced at replication sites, replacing bulk $\mathrm{H} 3$ and concomitantly attracting activating histone modifications. Through this H3.3 actively participates in the assembly of chromatin configurations that propel the process of transcription. Due to these findings the view was taken up that $\mathrm{H} 3$ replacement with $\mathrm{H} 3.3$ is informational and serves as a catalyst for covalent modifications connected with transcriptionally active chromatin (Goll and Bestor, 2002). As was also found out by Ahmad and co-workers that pre-existing histone modifications were also eliminated by the exchange of histones, this type of replacement model offers an additional mechanism by which particular inhibitory post translational modifications can be removed. Furthermore, McKittrick et al. (McKittrick et al., 2004) supplemented the work of Ahmad and Henikoff. They found out that modifications specifically assigned for regions of actively transcribed chromatin such as $\mathrm{H} 3$ methylated at $\mathrm{K} 4$ and $\mathrm{K} 79$ and acetylated at $\mathrm{K} 9, \mathrm{~K} 14, \mathrm{~K} 18$ and $\mathrm{K} 23$ are enriched on $\mathrm{H} 3.3$, whereas dimethylated $\mathrm{K} 9$, which is said to be specific for chromatin silencing, was only found 
in traces on H3.3 (Workman and Abmayr, 2004). Another possible explanation for the observed change in the separation pattern of apoptotic $\mathrm{H} 3$ might be the most recent works by Hake et al. (Hake et al., 2005). This group found a unique, subtype H3.3 specific phosphorylation site at serine 32. This modification is missing in H3.1 and H3.2 as these subtypes carry an alanine instead of a serine at this position. Hake and co-workers reported this modification to be mitosis specific, which differs from other mitotic marks such as phosphorylated $\mathrm{H} 3$ at serine 10 and 28 in both timing and localisation. H3.3 S31 was only observed during late prometaphase and metaphase, where it forms a discrete speckled band over the dense region of the metaphase plate. As this modification is obviously mitosis specific and as this process is blocked effectively in cells with topotecan ${ }^{\circledR}$, which causes a $\mathrm{G}_{1}-\mathrm{M}$ arrest (c.f. chap. 4.2 for effects of $\operatorname{topotecan}^{\circledR}$ ), our observed apoptosis-related $\mathrm{H} 3$ band shift might as well be associated with a strong dephosphorylation of the subtype specific serine 31 .

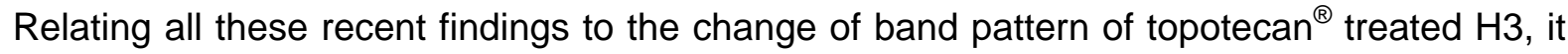
might be assumed that H3.3, carrying post-translational modifications which are specific for transcriptional activity is deposited and accumulated in intact cells. Once apoptosis is induced in the cell, H3.3 itself or its site specific phosphorylation at S31 might be quickly removed to ensure that all transcription processes are down-regulated and chromatin structures are tightly packaged for subsequent chromatin condensation, which is thought to be one hallmark of apoptosis. But to clearly identify the change in H3.3 band pattern, further analysis with mass spectrometry will be inevitable.

\subsubsection{Separation of core histones via capillary zone electrophoresis}

To analyse apoptosis-related changes in the histone modification pattern and changes in histone variants which were obtained from AUT/AUC-gel electrophoresis in more detail, HPLC purified core histones were also run on a CZE system. CZE analytics made it possible to analyse the $\mathrm{H} 2 \mathrm{~A}$ subtype fractions $\mathrm{H} 2 \mathrm{~A}(1)$ and $\mathrm{H} 2 \mathrm{~A}(2)$ separately, as this technique requires only very small amounts of protein. The evaluation of most results turned out to be a real challenge, as the great majority of publications in this section focussed on separation techniques of $\mathrm{H} 1$ linker histones, their modified forms and their variants (Lindner et al., 1992; Lindner et al., 1999; Lindner et al., 1993).

All results obtained from the CZE were compared to results from HPCE core histone analytics pursued by Lindner et al. (Lindner et al., 1992; Lindner et al., 2003; Lindner et al., 1996). System parameter requirements and experimental conditions applied in the present study were mostly different compared to the settings used by Lindner and co-workers. Differences were found in the voltage applied, cartridge temperature and buffer composition. Lindner and co-workers separated histone $\mathrm{H} 2 \mathrm{~A}$ and $\mathrm{H} 4$ at $12 \mathrm{kV}$ with a cartridge temperature 
of $25^{\circ} \mathrm{C}$, whereas in this work a voltage of $10 \mathrm{kV}$ was applied. The cartridge temperature in our system was $30^{\circ} \mathrm{C}$. Whereas we used a separation buffer with the following composition: $30 \mathrm{mM} \mathrm{H}_{3} \mathrm{PO}_{4}, 60 \mathrm{mM} \mathrm{HClO}{ }_{4}, 0.02 \%$ (w/v) hydroxypropylmethylcellulose (HPMC), pH 2.0, adjusted with triethylamine, Lindner and co-workers used the following buffer system: 110 mM-phosphate buffer, pH 2.0, with 0.03\% HPMC.

Out of five different core histone fractions $\mathrm{H} 2 \mathrm{~A}(1), \mathrm{H} 2 \mathrm{~A}(2), \mathrm{H} 2 \mathrm{~B}, \mathrm{H} 3$ and $\mathrm{H} 4$, which were previously purified via HPLC, three showed a change in their peak pattern after treatment with topotecan ${ }^{\circledR}$. Until now, Gurley et al. (Gurley et al., 1991) and Lindner et al. (Lindner et al., 2003; Lindner et al., 1996) were the only groups to have separated differently modified butyrate treated histone $\mathrm{H} 4$ and untreated histone $\mathrm{H} 2 \mathrm{~A}$ by HPCE. With relation to their peak pattern received for hyperacetylated $\mathrm{H} 4$, we might cautiously draw the conclusion for the observed change in acetylation pattern after induction of apoptosis that monoacetylated and triacetylated forms of apoptotic $\mathrm{H} 4$ remain stable, whereas apoptotic $\mathrm{H} 4$ seems to be depleted of unacetylated and diacetylated forms (for comparison see chap. 3.6.3). These findings would slightly contradict the results obtained from the AUC-2 ${ }^{\text {nd }}$ dimension gel electrophoresis, where changes in the band pattern of histone $\mathrm{H} 4$ were assigned to its complete hypoacetylation after induction of apoptosis. However, with relation to multiple functions of the chemical compound butyrate, these results are only preliminary, as CZE derived peaks not only incorporate the change of one single type of modification but reflect the sum of changes caused by interaction of all sorts of different modifications, as there are methylation, acetylation, phosphorylation ubiquitylation and ADP-ribosylation. So the observed change in peak formation of $\mathrm{H} 4$ after topotecan ${ }^{\circledR}$ treatment, a change in its acetylation pattern might not be the only explanation. In experiments where butyrate was used to analyse cell cycle events, Milsted et al. (Milsted et al., 1987) reported that this compound induced a cell cycle block in $G_{1}$ phase (D'Anna et al., 1980). Moreover butyrate interfered in cell cycle progression by altering its rate through $\mathrm{G}_{2} \mathrm{M}$ and $\mathrm{S}$ phase. Although this group reported that in butyrate treated cells histone $\mathrm{H} 2 \mathrm{~A}$ presented one, $\mathrm{H} 2 \mathrm{~B}$ four, $\mathrm{H} 3$ five and $\mathrm{H} 4$ four sites of acetylation, histone $\mathrm{H} 2 \mathrm{~A}$ turned out to be appreciably phosphorylated. In contrast to that the $\mathrm{H} 1$ linker histone was completely dephosphorylated, which was correlated with gradually increasing proportions of cells accumulating in $G_{1}$ phase. So the observed change in the $\mathrm{H} 4$ topotecan ${ }^{\circledR}$ peak pattern might also have been caused by phosphorylation or dephosphorylation. This assumption is based on recent works by Barber et al. (Barber et al., 2004), who observed a particular enhancement of histone $\mathrm{H} 4$ and $\mathrm{H} 2 \mathrm{~A}$ phosphorylation at serine 1 during cell cycle mitosis and S-phase. As already described both processes are blocked by topotecan ${ }^{\circledR}$ treatment, which would automatically lead to dephosphorylation of these histones. Supplementary data by Utley et al. (Utley et al., 2005) additionally supports the assumption of $\mathrm{H} 4$ dephosphorylation after induction with 
topotecan $^{\circledR}$. This group analysed the regulatory effect of the histone $H 4 / H 2 A$ acetyltransferase NuA4 during transcription and DNA repair via phosphorylation of histone $\mathrm{H} 4$ at serine 1 . Their experiments showed that chromatin from cells induced with DNA damage-inducing agents displayed a strong increase of $\mathrm{H} 4$ serine 1 phosphorylation with a concomitant decrease in $\mathrm{H} 4$ acetylation. It was observed that histone $\mathrm{H} 4$ phosphorylation occurs during double-strand DNA repair at the step of chromatin restoration and deacetylation. According to this recent data more and more evidence is accumulating which seems to fully exclude certain $\mathrm{H} 4$ acetylation patterns after treatment of cells with cytotoxic drugs like topotecan ${ }^{\circledR}$. This would again be in agreement with our results of a $\mathrm{H} 4$ deacetylation after topotecan ${ }^{\circledR}$ treatment, which were obtained from AUC-2 $2^{\text {nd }}$ dimension gel electrophoresis experiments.

The CZE peak pattern of $\mathrm{H} 2 \mathrm{~B}$ after treatment with topotecan ${ }^{\circledR}$ changed remarkably in comparison to control and butyrate treated H2B histones. The CZE separation pattern of control H2B histones from CHO cells (Chinese hamster ovary) in the works of Gurley and coworkers (Gurley et al., 1991) were very similar to the patterns seen in this present work. Unfortunately, neither group (Lindner nor Gurley) analysed core histones after treatment with cytotoxic drugs to compare possible peak shifts. Publications dealing with analyses of changes in post-translational histone modifications on the basis of CZE are rare. The only two exceptions to this rule were the two groups mentioned, who analysed butyrate treated $\mathrm{H} 4$ histones. Therefore, it is not possible at this point to evaluate our results with reference to $\mathrm{H} 2 \mathrm{~B}$ in more detail. The observed peak shift might either be linked with de-/acetylation or de/phosphorylation.

The third histone type which was observed to show remarkable changes in its peak pattern after treatment with topotecan ${ }^{\circledR}$ was histone $\mathrm{H} 3$. The quadruple peak pattern observed in our own results in control $\mathrm{H} 3$ was reduced to just two major peaks and a small peak in topotecan $^{\circledR}$ treated H3 (chap. 3.6.3 5). In comparison to that butyrate treated H3 peaks showed a third variation of a change in peak pattern. Comparing the peaks of control $\mathrm{H} 3$ and butyrate $\mathrm{H} 3$ with topotecan ${ }^{\circledR}$ treated histone $\mathrm{H} 3$ two possible explanations turn up. Despite overall changes of modification on multiple levels, shifts of single peaks might either be related to changes in $\mathrm{H} 3$ subtype compositions, as has already been suggested according to the results obtained by AUT/AUC- $2^{\text {nd }}$ gel electrophoresis. Another option would be, similar to the changes observed in $\mathrm{H} 4$, that each single peak in the quadruple peak pattern of control $\mathrm{H} 3$ resembles a differently acetylated form of $\mathrm{H} 3$, some of which might be lost after treatment with topotecan ${ }^{\circledR}$. For example, assuming that from left to right in electropherogram for control $\mathrm{H} 3$ the first peak stands for unacetylated $\mathrm{H} 4$, the second for monoacetylated, the third for diacetylated and the fourth for triacetylated $\mathrm{H} 3$, it might be deducted that topotecan ${ }^{\circledR}$ treated 
H3 unacetylated and monoacetylated forms predominate over a very small fraction of diacetylated $\mathrm{H} 3$ forms. However, at this point all further attempts to look for possible explanations still have to remain theoretical until further data by mass spectrometry, production of unmodified recombinant core histones and subsequent chemical modification of them, as well as gradual mixing experiments with defined shares of single core histone types further elucidate this matter.

\subsection{Linking apoptosis-related cleavage and release of nucleosomal DNA with specifically modified core histones: cell signalling mechanism or pathological condition?}

Chromatin condensation and cleavage of nucleosomal DNA are both seen as hallmarks of apoptosis. After having analysed overall changes of histone modifications after induction of apoptosis, we subsequently investigated the cleavage of nucleosomal DNA with relation to specific post-translationally modified core histones and their release into the cytosol. Quite a few groups have repeatedly reported a massive release of histones and nucleosomes from the nucleus into the cytosol. However, most of these publications had restricted and tightly linked their results with the autoimmune disease systemic lupus erythematosus (SLE) (Cabrespines et al., 1998; Gabler et al., 2003b; van Nieuwenhuijze et al., 2003). This disease is characterised by the body generating an array of auto-antibodies which are directed against the native nucleosome, its DNA or its set of histones (Gabler et al., 2003a). Gabler and co-workers hypothesised that under defined circumstances circulating lymphocytes of SLE patients would undergo accelerated apoptosis. As a consequence an increased rate of apoptosis would mean overloading the phagocytic system with apoptotic bodies, which would finally result in increased concentrations of nuclear material such as dsDNA or histones in the serum of these patients (Gabler et al., 2003b). In this present work the putative release of nucleosomes / histones was analysed in the suspension cell line HL-60 and in adherent HeLa cells. Besides a general investigation of a release of unmodified core histones, specifically modified histones were analysed, too.

\subsubsection{Analysing the release of unmodified and post-translationally modified core histones into the nucleoplams / cytoplasm after induction of apoptosis}

Before the actual experiment was set about, several nucleus-cytosol preparations were tested to ensure that later results would be based on morphologically and biochemically intact nuclei. Great differences were observed with reference to yield and quality of the obtained nuclei (compare chap. 3.7.1 and 3.7.2). The majority of nucleus-cytosol preparations tested, ((Antalis and Godbolt, 1991; Chen et al., 2000); protocol according to 
Thomas Meergans after personal communications) revealed a certain leakage of the nuclei in addition to the already observed morphological damages. In cases where nuclei seemed to be morphologically intact, biochemical analyses using nuclear and cytosolic markers such as PARP, lactate dehydrogenase and RNA polymerase I, finally detected the leakage. Only one out of four preparations produced acceptable results. This protocol was originally developed by Bunce and co-workers (Bunce et al., 1988) to isolate hemopoietic cell nuclei from several cell lines, among them HL-60 cells. All of the following experiments were pursued with nuclei prepared according to their protocol, as our nuclei proved to be morphologically intact. Moreover, neither cytosolic markers were found in any of the nuclear fractions nor did we find any nuclear markers in any of the cytosolic fractions.

To analyse the cleavage of nucleosomes and the release of histones into the cytosol after induction of apoptosis in HeLa and HL-60 cells, we ran Western blots using three different fractions, namely cytosolic fractions, the supernatant of the nuclear fractions and the nuclear pellet fractions (chap. 3.8.1). All of them were incubated with antibodies raised against unmodified and specifically modified core histones. Our results obtained by SDS-PAGE showed a gradual increase of released core histones $\mathrm{H} 2 \mathrm{~A}, \mathrm{H} 2 \mathrm{~B}, \mathrm{H} 3$ and $\mathrm{H} 4$ into the nucleoplasm (nuclear supernatants) but not into the cytosol for both cell lines. Due to a lack of high binding quality of some histone specific antibodies used (anti-H2A and anti-H2B in particular), it cannot be ruled out that traces of core histones might also be detected in cytosolic fractions. However, it can definitely be ruled out that this would be the majority of histones, as a massive release would have been detected by simple SDS-PAGE. A release into the nucleoplasm was only observed for some specifically modified core histones. The gradual increase was noted in HL-60 cells for H3-dimethyl $\mathrm{K} 9$ and the histone $\mathrm{H} 2 \mathrm{~A}$ variant $\mathrm{H} 2 \mathrm{AX}$-phosphate serine 139, but we could not detect a release of H3-trimethyl $\mathrm{K} 9$ and H3acetyl K9. On the other hand we found that H3-dimethyl K4 and H3-trimethyl K4 were detected in increasing amounts in both the nuclear supernatant and in the cytosolic fractions of HL-60 cells. These findings were almost identical with those in HeLa cells, with only one exception. H3-trimethyl K9 was found in gradually increasing amounts in the nucleoplasm and at a later time in the cytosol. With reference to the release of nuclear material into the cytosol during apoptosis, this has already been reported by different groups. Radic and coworkers analysed the exposal of nucleosomes at the cell surface during apoptosis (Radic et al., 2004). This group reported that within 2-6 h after induction of apoptosis with camptothecin all four core histones were released in gradually increasing amounts into the cytosol. However, these results have to be cautiously evaluated. For comparative analysis with our own results, we tested the protocol of this group with our own cell line and our inducer. As Radic et al. (Radic et al., 2004) used the hemopoietic B-cell line Jurkat and camptothecin as inducing agent, of which topotecan ${ }^{\circledR}$ is a derivative, both of our experimental 
parameters were comparable. Our tests showed that Radic's protocol did not produce biochemically intact nuclei. Having checked their cytosolic and nuclear fractions for nuclear marker proteins like PARP and cytosolic marker proteins like lactate dehydrogenase and RNA polymerase I, it turned out that rather than using intact nuclei, Radic and co-workers based their results on the works with cell lysates. Their cells were lysed using a hypotonic buffer together with $0.5 \%$ IGEPAL. On top of that the cells were vigorously vortexed, which definitely must have disrupted all remaining membrane structures. Therefore, it is not surprising that increasing amounts of nucleosomes and core histones were found in the cytosolic fractions after induction of apoptosis. Of course, results might vary with this kind of experiment, as they are always dependent on the cell type, the inducer and the duration of incubation times. However, a cautious separation of all different cell fractions has always to be given utmost priority. In this respect, results from other groups like Wu et al. (Wu et al., 2002), Konishi et al. (Konishi et al., 2003) and Salgame et al. (Salgame et al., 1997), who all worked on the nuclear release of nucleosomes and histones into the cytosol after induction of apoptosis have to be viewed critically. Wu et al. (Wu et al., 2002) provided evidence for a release of apoptotic nucleosomes into the cytosol in Jurkat cells but not in the fibroblast cell line NIH3T3. Konishi and co-workers (Konishi et al., 2003) reported that the $\mathrm{H} 1$ linker histone variant $\mathrm{H} 1.2$ was found to be released from the nucleus into the cytosol after induction of apoptosis via DNA double strand breaks. According to this data, $\mathrm{H} 1.2$ was thought to trigger permeabilisation of the outer mitochondrial membrane. It was further proposed that this histone subtype co-operated with various proapoptotic proteins, including physiological targets of $p 53$. With relation to their separation techniques of cytosols and nuclei both Konishi and Wu worked with cell lysates, not with physiologically intact nuclei. Wu et al. Iysed their cells in a hypotonic buffer containing 1\% Triton X-100. They kept the lysates on ice for 20 min. Konishi et al. prepared their cells in a similar way compared to the protocol of Radic. Their cells were suspended in hypotonic buffer, kept on ice for 10 min and lysed with $0.2 \%$ IGEPAL. Here, too, the cell pellet was vigorously vortexed. In preliminary experiments we experienced that a combination of hypotonic buffers together with the use of strong detergents, almost always resulted in a disruption of nuclei, which automatically led to a fatal leakage.

Generally speaking, we found profound evidence for an apoptosis-related release of core histones from bulk chromatin into the nucleoplasm. However, a further general release of histones into the cytosol could not be confirmed. This data was supplemented and confirmed by laser-scan fluorescence microscopy analyses of an apoptosis-related H2B release from bulk chromatin into the nucleoplasm and later into the cytosol. For this purpose stably transfected HeLa H2B-YFP cells were used. To test whether apoptosis-related changes in the structures of the nuclear envelope or cytoskeleton structures might facilitate or propagate 
a release of these histones, we also examined proteins like lamin $A / C, N$-glycosylated nuclear pore complex proteins and tubulin- $\alpha$ in parallel. All cells were analysed by fluorescence microscopy. In the cases of lamin A/C and N-glycosylated nuclear pore complex (NPC) proteins we observed a stepwise degradation of these protein structures, whereas the tubulin- $\alpha$ fibres started to 'collapse' onto the remaining nuclear structures after the onset of apoptosis (chap. 3.9.2; 3.9.4 and 3.9.6). With reference to lamin $A / C$ and $N$ glycosylated NPC proteins, these were found to vanish completely after some time. Our results are well supported by the earlier studies of Snow et al. (Snow et al., 1987) and Holdt et al. (Holt et al., 1987), who localised N-glycosylated NPC proteins during mitosis-related disintegration of nuclear membrane structures via immunogold staining and electron microscopy. These two groups generated the antibody raised against eight $\mathrm{N}$-glycosylated NPC proteins, which was used in the present work. Moreover, Snow, Holdt and co-workers described that during the disassembly of the nuclear envelope and its subsequent reforming during mitosis, these eight glycosylated proteins were reversibly dispersed throughout the cytoplasm in form of minute foci. Our results presented a similar, however irreversible, phenomenon for the processes at the nuclear membrane during apoptosis. Concomitantly with the vanishing nuclear envelope and lamina structures, we observed that the chromatin and with it $\mathrm{H} 2 \mathrm{~B}$ started to condense gradually after $24 \mathrm{~h}$ of incubation, which was temporally correlated with the degradation and disintegration of the lamins (also confirmed by (Oberhammer et al., 1994)), NPC proteins and the collapse of tubulin- $\alpha$. However, we could neither perceive any leakage of H2B nor detect any DNA fragments (compare DAPI figures in chap. 3.9.1; 3.9.3 and 3.9.5) outside the nuclear boundaries. These findings are in agreement with data published on the apoptosis-related degradation of the nuclear lamina, NPC proteins and the collapse of the tubulin- $\alpha$ fibres onto the nucleus. Grzanka et al. (Grzanka and Grzanka, 2003; Grzanka et al., 2003; Grzanka et al., 2005) studied the reorganisation of cytoskeleton structures like F-actin, vimentin and tubulin in K-562 and HL60 cell lines during apoptosis. This group confirmed that the reorganisation of these cell structure proteins were consistent with features of apoptosis. A strong increase in the brightness of the antibody signal from tubulin was noted, a fact that was also noticed in the present study. The concentration of tubulin- $\alpha$ was particularly high at sites with intensive chromatin condensation and apoptosis-related 'blebbing'. As tubulin structures do not seem to be degraded in the first place, this fact might suggest that they have a particular function in chromatin compaction during apoptosis.

A stepwise degradation of the nuclear lamin meshwork and the nuclear envelope was reported by several groups. Here, too, despite the fact that lamins are completely degraded during apoptosis, no leakage of $\mathrm{H} 2 \mathrm{~B}$ or chromatin material was noticed. In more detailed laser-scan microscopy analyses, no DNA fragments or H2B could be detected outside the 
remaining nuclear structures. It seemed as if the tightly condensed chromatin particles and $\mathrm{H} 2 \mathrm{~B}$ respectively, were held together tightly by some invisible nuclear structural components. Taimen and Kallajoki (Taimen and Kallajoki, 2003) analysed the degradation of NuMa and nuclear lamins after Fas-mediated apoptosis. NuMa is a nuclear matrix protein, which is assumed to have a crucial function during mitosis as an organising element of the mitotic spindle (Kallajoki et al., 1991; Merdes et al., 1996; Yang et al., 1992). Along with others, this group found out that NuMa is specifically degraded in early apoptosis by several caspases 3 , 4, 6 and 7 (Casiano and Tan, 1996; Greidinger et al., 1996; Hirata et al., 1998; Weaver et al., 1996). These findings further support our results. With the help of an antibody raised against eight N-acetylglycosylated different NPC proteins, we also could provide evidence that the nuclear envelope is subject to a stepwise degradation. Within the first $24 \mathrm{~h}$ the nuclear envelope still remained intact, while chromatin condensation already progressed. After $36 \mathrm{~h}$ with some temporal delay, the nuclear envelope started to disintegrate in parallel with the still progressing chromatin condensation, until all envelope structures finally vanished completely (3.9.4). Kihlmark et al. (Kihlmark et al., 2001) and Buendia et al. (Buendia et al., 1999) worked on the caspase dependent proteolysis of integral and peripheral proteins of the nuclear envelope and the NPC. They found out that the degradation of proteins from different layers of the nuclear envelope took place in a specific order. Proteins from the integral pore membrane like POM121 were among the first to be degraded. Nup 153, a protein from the nucleoplasmic basket and lamin B, shortly followed. Their cleavage was found to coincide with the onset of DNA fragmentation. Nucleoporin p62 and glycoprotein gp210 were found to be degraded much later in apoptosis. As they are exposed at the inner face of the nuclear envelope, where they interact with chromatin structures, it might be assumed that their cleavage finally allows the detachment of the nuclear envelope from the chromatin, which then reaches its final compaction.

A similar phenomenon was reported for the nuclear lamins $A, B$ and $C$, which were stated to be the first apoptotic target proteins identified. Whereas lamins $A$ and $C$ are exclusive cleavage substrates for caspase 6 (Orth et al., 1996; Takahashi et al., 1996a; Takahashi et al., 1996b), lamin B is cleaved by caspase 3 (Slee et al., 2001). The cleavage of lamins is assumed to play a key role in the complete breakdown of the nuclear structure (Lazebnik et al., 1995). These findings agree with our results. After the stepwise disassembly of the nuclear lamina, this structure was found to vanish completely. Moreover, a steady release of lamin A/C fragments into the cytosol was detected $24 \mathrm{~h}$ after induction of apoptosis in HeLa cells (3.9.2).

All these findings can be summed up in a final conclusion. Although all nuclear membrane structures are sequentially degraded, before, concomitantly with or even after apoptosisrelated chromatin condensation and DNA cleavage were initiated, condensed DNA and $\mathrm{H} 2 \mathrm{~B}$ 
respectively stayed fixed in the place, where these used to be surrounded by nuclear structures. Independent of the time after induction of apoptosis, neither histone H2B nor DNA or nucleosomes were found outside nuclear structures.

\subsection{Differences in histone modification composition of histones from fragmented chromatin compared to histones from non-fragmented chromatin after induction of apoptosis}

Nucleosomal DNA fragmentation in association with chromatin condensation is one of the most important nuclear events occurring during apoptosis (Ajiro, 2000; Ajiro et al., 2004; Lee et al., 1999; Waring et al., 1997). Specific histone modifications have been proposed to affect chromatin structure and functions during both cell cycle events and apoptosis (Kratzmeier et al., 2000; Kratzmeier et al., 1999; Talasz et al., 2002; Widlak et al., 2005). Therefore we have investigated histone modifications which are connected with transcriptional activation like $\mathrm{H} 3-$ dimethyl K4, K36, H3-trimethyl K4, H3-acetyl K9, K18, K23, those connected with gene silencing like $\mathrm{H3}$-di- and trimethyl $\mathrm{K} 9$ and one which is connected with DNA fragmentation and DNA repair, H2AX-phosphate S139. Apoptosis derived nucleosomal fragments of different sizes were analysed for their contents of these histones, to investigate a functional correlation between their modification and DNA fragmentation. Our results demonstrated that dimethylated histone $\mathrm{H} 3$ at lysine 9 and phosphorylated histone $\mathrm{H} 2 \mathrm{AX}$ at serine 139 were accumulated in fragmented chromatin (chapt. 3.10.1), whereas H3-trimethyl K9 and H3acetyl K9 were depleted in fragmented chromatin fractions (chap. 3.10.2). All other histone modifications, H3-dimethyl K4, K36, H3-trimethyl K4, H3-acetyl K18 and H3-acetyl K23 appeared to be almost equally distributed in fragmented and non-fragmented chromatin (3.10.3). This agrees with the data already described in chapter 4.5.2.

Most publications dealing with apoptosis-related chromatin condensation, nucleosomal DNA fragmentation and its functional correlation with histone modifications, have up to now only reported about phosphorylation or dephosphorylation, including the particular function of linker histone H1 (Ajiro and Allis, 2002; Enomoto et al., 2003; Waring et al., 1997). Enomoto et al. (Enomoto et al., 2003; Waring et al., 1997) even postulated that phosphorylation of H1, $\mathrm{H} 2 \mathrm{~A}$ and $\mathrm{H} 3$ in particular is supposed to be an early event to trigger DNA fragmentation in thymocytes during apoptosis

The phosphorylation or dephosphorylation of histones $\mathrm{H} 1, \mathrm{H} 2 \mathrm{~A}$ and their respective variants have up to now been the most controversially discussed candidates, responsible for triggering apoptosis-related chromatin condensation and DNA fragmentation. Most recent works of Talasz et al. (Talasz et al., 2002) and Widlak et al. (Widlak et al., 2005) assign this crucial role to $\mathrm{H} 1$ and its subtypes. Widlak and co-workers analysed histone $\mathrm{H} 1$ and subtype interaction with the apoptotic nuclease DNA fragmentation factor (DFF40/CAD). This group 
provided strong evidence that the histone H1.2 subtype preferentially initiates and enhances the DFF40 mediated cleavage of apoptotic nucleosomal DNA by binding to this nuclease. However, all other somatic subtypes of $\mathrm{H} 1$ were equally able to stimulate the nuclease activity in vitro. Moreover it could be shown that the $\mathrm{H} 1 \mathrm{C}$-terminal tail is responsible for the activation of DFF40. As a conclusion, this group suggested that on the basis of the described strong interactions between the C-terminal domain of $\mathrm{H} 1$ histones and DFF40, linker DNA cleavage during the final stages of apoptosis was triggered.

With relation to specific histone modifications Kratzmeiser and co-workers (Kratzmeier et al., 2000; Kratzmeier et al., 1999) reported a rapid dephosphorylation of $\mathrm{H} 1$ and its subtypes after treatment of HL-60 cells with the topoisomerase I inhibitor topotecan ${ }^{\circledR}$. Later Talasz et al. (Talasz et al., 2002) stated the same phenomenon for murine cell line NIH3T3, which were treated with various inducers such as TNF- $\alpha, \mathrm{CD} 95$ and cycloheximide. H1 dephosphorylation was accompanied by chromatin condensation and preceding the onset of chromatin oligonucleosomal DNA fragmentation. In contrast hyperphosphorylation of the histone H2A subtype H2AX but not H2A.1 or H2A.2 was found to be strongly correlated with DNA fragmentation. The latter findings are in agreement with our own results. Investigations of topotecan ${ }^{\circledR}$ induced histone H2AX-phosphorylation of serine 139 in association with apoptosis-related DNA fragmentation, which was analysed via sucrose gradients and quantitative FACS measurements, showed that H2AX-phosphate S139 predominantly accumulated in regions of fragmented chromatin, presenting the highest degree of DNA double strand breaks. These findings were supplemented by TUNEL-assay measurements (chap. 3.11). All data obtained strongly supports the general idea of H2AX-phosphate S139 as an early marker for DNA double strand breaks and an indicator for sites of DNA repair (our results and (Fernandez-Capetillo et al., 2004; Halicka et al., 2005; Huang et al., 2003; Rogakou et al., 2000b).

Up to now no studies have been published with reference to a correlation of methylated and acetylated histones and their putative function on DNA fragmentation. As already mentioned, in parallel with $\mathrm{H} 2 \mathrm{AX}$ phosphorylation, we observed a strong accumulation of H3-dimethyl $\mathrm{K} 9$ in the fragmented chromatin. Dimethylated and trimethylated histone H3 at lysine 9 have been generally stated to function in transcription repression and gene silencing (Bryk et al., 2002; Jiang et al., 2004; Rogakou et al., 2000b; Schotta et al., 2004a; Wang et al., 2001a). An explanation for the possible function of this accumulation might lie in its already assigned role of gene silencing. A silencing pathway, in which H3-dimethyl $\mathrm{K} 9$ in co-operation with the heterochromatin protein HP1 form heterochromatin regions, has already been described for yeast and mammalian cells (Bannister et al., 2001; Nakayama et al., 2001). This might well support the assumption that after induction of apoptosis certain chromatin areas are to be marked for preferential cleavage by histone modifications functioning in gene repression. 
This might be important to ensure that during the following disintegration of the cell, no uncontrolled gene expression takes place which then might lead to cancer. Therefore, we additionally analysed a possible concomitant accumulation of HP1- $\alpha$ in fragmented chromatin regions. However, such a correlation could not be confirmed (chap. 3.10.5).

Our observations of the accumulation of H3-trimethyl K9 in non-fragmented chromatin regions (depletion in fragmented chromatin) appears to be compatible with the idea that this particular modification has also been described as a mark and enhancer for heterochromatin formation. Wang et al. (Wang et al., 2001a) reported that trimethylated histone H3 at K9 inhibits the acetylation of $\mathrm{H} 3$ at $\mathrm{K} 14, \mathrm{~K} 18$ and $\mathrm{K} 23$ by interfering with acetyltransferases. Schotta et al. (Schotta et al., 2004a; Schotta et al., 2004b) and Jiang et al. (Jiang et al., 2004) even observed a kind of synergism with two histone modifications functioning together in the formation of constitutive heterochromatin. Both $\mathrm{H} 3$-trimethyl $\mathrm{K} 9$ and $\mathrm{H} 4$-trimethyl $\mathrm{K} 20$ emerged as hallmarks of pericentric heterochromatin in mammals. In this respect H3trimethyl $\mathrm{K} 9$ is required to induce H4-trimethyl K20. In association with all these findings and our own results, H3-trimethyl $\mathrm{K} 9$ might function almost the same way as H3-dimethyl $\mathrm{K} 9$, as a marker for preferential chromatin cleavage sites during apoptotic DNA fragmentation. In addition, besides marking particular chromatin regions for DNA cleavage H3-trimethyl K9 promotes gene silencing by recruiting other modifications to the site of action (e.g. H4trimethyl K20).

Together with $\mathrm{H} 3$-trimethyl $\mathrm{K} 9, \mathrm{H} 3$-acetyl $\mathrm{K} 9$ was also found to be accumulating in nonfragmented chromatin (chap. 3.10.2). Generally published data proposes histone acetylation, and thereby acetylation of histones $\mathrm{H} 3$ and $\mathrm{H} 4$ in particular, to have an overall function in transcription activation and enhancing gene expression (Grunstein, 1997; Turner, 2000). The most well established acetylation sites on the $\mathrm{N}$-terminal tail of histone $\mathrm{H} 3$ are $\mathrm{K} 9, \mathrm{~K} 14, \mathrm{~K} 18$ and K23 (Roth et al., 2001). Acetylation of histone N-terminal tails can weaken DNA-histone contacts (Allfrey, 1966), they might alter histone-histone interactions between neighbouring nucleosomes (Luger et al., 1997; Richmond et al., 1993; Tse et al., 1998a; Tse et al., 1998b; Wolffe and Hayes, 1999), as well as interactions between histones and regulatory proteins (Edmondson and Roth, 1996; Hecht et al., 1995). Any or all of these impacts on chromatin higher-order folding will finally lead to a more open and permissive chromatin structure which is accessible for the transcription machinery (Roth et al., 2001). Taking this background information into account including our results, it might be possible that H3-acetyl K9 usually plays a special role in transcription activation but might via histone 'cross talk' be marked for transcription repression by modifications like H3-trimethyl K9. We might even suggest a kind of antagonistic effect between those two modifications. This would possibly explain why these two were both found to be accumulating in non-fragmented chromatin during apoptosis. Trimethylated H3 K9 might be induced during apoptosis to indicate or even 
replace previously acetylated $\mathrm{H} 3$ at $\mathrm{K} 9$, finally setting a mark for preferential cleavage of those chromatin regions which used to be active.

Besides the just mentioned histone modifications, we observed a kind of 'random distribution' for H3-di- and trimethyl K4, H3-dimethyl K36 and H3-acetyl K18 and K23. As di- and trimethylated $\mathrm{H} 3$ at lysine 4 and 36 has been announced to function as useful markers of active genes (Bannister et al., 2005; Santos-Rosa et al., 2004; Santos-Rosa et al., 2002), one might assume that these modifications would also be depleted in fragmented chromatin. This would also be assumed to be the case with acetylated histone $\mathrm{H} 3$ at lysines $\mathrm{K} 18$ and K23. These modifications, too, are generally correlated with active chromatin (Richards and Elgin, 2002; Turner, 2002) and were even reported by McKittrick and co-workers (McKittrick et al., 2004) to be enriched on the replication independent histone variant H3.3. This does even more support the idea of a transcription activating function of H3-acetyl K18 and K23, which might have to be removed during apoptosis to reach a final state of heterochromatin formation.

All in all histone modifications in association with apoptosis-related DNA fragmentation on the one hand seem to be markers for hetero- or euchromatin formation; on the other hand some of them apparently function as markers to indicate preferential cleavage sites for subsequent enzymatic activity by endonucleases. Examples for both would be the synergistic effect of H3-trimethyl $\mathrm{K} 9$ and $\mathrm{H} 4$-trimethyl $\mathrm{K} 20$ in forming pericentric heterochromatin regions and the suggested antagonism of H3-trimethyl K9 versus H3-acetyl K9.

\subsection{Future prospects}

Although we have extensively worked on apoptosis-related changes in post-translational histone modifications in general, in connection with DNA fragmentation and with reference to histone release into the nucleoplasm and cytoplasm, some questions have still remained unanswered.

Especially in the field of apoptosis-related changes in post-translational histone modifications and histone variants, further analyses will be inevitable a) to define the respective modifications and b) for the association of modifications/variants with specific functions during apoptosis. For that particular purpose it will be necessary to purify eukaryotic core histones and analyse them via mass spectrometry. Furthermore, it might be helpful to express recombinant core histone proteins $\mathrm{H} 3, \mathrm{H} 2 \mathrm{~B}, \mathrm{H} 2 \mathrm{~A}$ and $\mathrm{H} 4$, including the histone variant $\mathrm{H} 3.3$ either in $E$. coli or in yeast. In a second step these would have to be chemically modified so that they could serve as reference proteins for the analysis of mammalian core histones via capillary electrophoresis. However, this will not be an easy task to manage, as the in vivo histone modification pattern is very complex, drawing in all types of modifications at numerous sites. A very first approach would be combinatorial mixing experiments in which 
different, well defined core histone fractions before and after treatment with apoptosis inducers, will be pooled in a defined ratio. The changing peak patterns obtained by CZE will then give additional information, with the help of which it might be possible to reduce the options of relevant histone modifications to just one or two.

Another point, where research can be led further, would be an advanced analysis of those apoptosis induced histones, which were found to be accumulating in fragmented chromatin. Although we could put down their accumulation and depletion to at least one or two important histone modifications, it might be possible that other histone modifications might synergistically or antagonistically act with those found. Subsequent investigations should more focus on the other, not yet analysed core histones $\mathrm{H} 2 \mathrm{~A}, \mathrm{H} 2 \mathrm{~B}$ and H4. This would supplement the works of Ajiro (Ajiro, 2000), who related H2B serine 32 phosphorylation to apoptosis-related DNA fragmentation. In addition to that, it would be most interesting to know, given the role of histone deposition and transcriptional activation, whether the histone subtype H3.3 plays a crucial role in formation of chromatin structure in apoptosis induced cells. In this respect it might be assumed that a depletion of histone H3.3 in apoptotic chromatin could be an indication for transcriptionally silenced heterochromatin regions. For the analysis of that phenomenon it would be most helpful, to generate a high affinity histone H3.3 specific antibody.

With relation to the analyses of cytoplasmic release of core histones, additional constructions of stably transfected mammalian cells expressing the core histone types $\mathrm{H} 3, \mathrm{H} 3.3, \mathrm{H} 2 \mathrm{~A}$ and H4. These experiments would well complete our studies in the field of cytoplasmic histone release. Moreover, there might be a chance to find molecules, which might interfere in the apoptosis signalling cascade as was suggested for the histone subtype $\mathrm{H} 1.2$ (Konishi et al., 2003). 


\section{Summary}

The first aim of this present study was the analysis of time-dependent changes in histone modifications in the human leukaemia cell line HL-60 after induction of apoptosis with the topoisomerase I inhibitor topotecan ${ }^{\circledR}$. For this purpose we ran short-term ( 0 h-2 h) and longterm kinetics ( 0 h-12 h/24 h). Core histones were incubated with specific antibodies raised against different core histone modifications. The only changes observed were the hyperphosphorylation of $\mathrm{H} 2 \mathrm{AX}$ at serine 139 as early as 10 min post-induction and a strong deubiquitylation of histone $\mathrm{H} 2 \mathrm{~A} 6 \mathrm{~h}$ after induction of apoptosis. No changes in the methylation or acetylation pattern at the remaining modification sites were observed. By means of apoptosis markers, the induction efficiency was monitored. In the following, putative apoptosis-related changes of specific histone modifications were examined on single histone type level, including histone subtypes. Histones from HL-60 nuclei were extracted, purified and separated by size exclusion chromatography and HPLC. Each single histone type fraction was subsequently analysed by acid-urea-triton/acid-urea-CTAB (AUT/AUC-2 ${ }^{\text {nd }}$ dimension) second dimension electrophoresis and capillary zone electrophoresis (CZE). With the help of HPLC and AUT/AUC-2 ${ }^{\text {nd }}$ dimension electrophoresis we were able to separate different $\mathrm{H} 2 \mathrm{~A}$ fractions which might be subtypes of $\mathrm{H} 2 \mathrm{~A}$ and two different $\mathrm{H} 3$ fractions which might possibly contain the subtypes H3.1 and H3.3. We could not detect any remarkable changes in the $\mathrm{H} 2 \mathrm{~A}$ histone patterns. In contrast to that we were able to detect a change of band pattern for H3/H3.3 in the AUT/AUC gel. However, it remains to be elucidated, if this difference is based on a change in the overall concentration of $\mathrm{H} 3 / \mathrm{H} 3.3$ within the cell after induction of apoptosis or if it can be put down to a change in modification marks on H3/H3.3. Single histone type analyses via CZE brought forth significant changes in the peak cluster of histones $\mathrm{H} 2 \mathrm{~B}, \mathrm{H} 3$ and $\mathrm{H} 4$ but not for the two $\mathrm{H} 2 \mathrm{~A}$ fractions. After comparison with the peak pattern from hyperacetylated histones, which were isolated from cells pre-treated with butyrate, we suggest for histones $\mathrm{H} 2 \mathrm{~B}, \mathrm{H} 3$ and $\mathrm{H} 4$ that the difference in the peak pattern might be based on a loss of specific acetylated isoforms of these histones. However, these findings will have to be further analysed by mass spectrometry, to specify the responsible histone modification sites.

The second aim of this study focussed on the analysis of changes in histone modifications during chromatin condensation and nucleosomal DNA fragmentation in the process of apoptosis. Therefore, a possible apoptosis-related release of fragmented nucleosomes into the nucleoplasm and later on into the cytoplasm was analysed. The work was mostly focussed on a putative release of specifically modified core histones. In preliminary experiments, four different nucleus-cytosol preparations were tested for their yield of high quality nuclei, to exclude an unspecific leakage of nuclear material. Both fractions obtained 
were analysed using the cytosolic marker lactate dehydrogenase and the two nuclear markers PARP and RNA polymerase I. Each of these three markers was only found in its respective fraction.

Apoptosis was induced in HL-60 cells with topotecan ${ }^{\circledR}$ and HeLa cells, which were stably transfected with YFP-tagged histone $\mathrm{H} 2 \mathrm{~B}$, were treated with etoposide. Cytosolic fractions, nuclear supernatants and nuclear pellets were prepared from these cells. Subsequently all fractions were analysed for their contents of specifically modified core histones. Nuclear supernatant fractions from HL-60 cells showed a gradual increase in concentration of all four core histones $2 \mathrm{~h}$ after induction of apoptosis. We found cytosolic di- and trimethylated $\mathrm{H} 3$ at serine 4 in increasing amounts $2 \mathrm{~h}$ post-induction. Modified core histones like H3-dimethyl K9 and H2AX-phosphate S139 were accumulated in nuclear supernatants $2 \mathrm{~h}$ after topotecan ${ }^{\circledR}$ treatment. In contrast, H3-acetyl $\mathrm{K} 9$ and $\mathrm{H} 3$-trimethyl $\mathrm{K} 9$ failed to be detected in these fractions. All these findings were almost equal in HeLa H2B-YFP cells, with only one exception. Trimethylated $\mathrm{H} 3$ at lysine 9 was found to accumulate in the nuclear supernatant fractions shortly after induction of apoptosis. However, due to problems with antibody binding specificity a final statement on cytosolic histone release cannot be made.

Our Western blot data on apoptosis-related histone release into the cytosol was supplemented with laser-scan microscopy of stably transfected HeLa H2B-YFP cells in association with the nuclear lamina protein lamin A/C, N-acetylglucosamine linked NPC proteins and tubulin- $\alpha$. Our analyses showed that tubulin- $\alpha$ started to collapse 'onto the nucleus' after induction of apoptosis, lamin A/C and N-acetylglucosamine linked NPC proteins first shrank 'onto the condensed chromatin' and were finally degraded. However, neither histone H2B nor DNA was found outside the remaining nuclear structures.

A third aim of this project was the analysis of a specific modification pattern in fragmented and non-fragmented chromatin. Methods applied to investigate this matter included sucrose gradients, isopycnic ultracentrifugation and Western blotting. We observed an accumulation of histone H3-dimethyl $\mathrm{K} 9$ and histone H2AX-phosphate S139 in fragmented chromatin, whereas the fragmented chromatin was depleted of histone H3-trimethyl $\mathrm{K} 9$ and histone H3acetyl K9. In parallel experiments, concentrations of the heterochromatin protein HP1- $\alpha$ were measured in fragmented chromatin together with concentrations of H3-dimethyl K9 to find a possible correlation between these two. However, no such correlation could be confirmed. In addition to the observed accumulation of H2AX-phosphate S139 in fragmented chromatin, this modification was analysed by flow cytometry in relation to induced DNA double strand breaks. As a result we could confirm that the accumulation of H2AX-phosphate S139 in fragmented chromatin regions is definitely correlated with apoptosis induced double strand breaks. These findings correlate well with the results obtained from the sucrose gradients 
and those observed with the release of specific histone modifications into the nuclear supernatants after induction of apoptosis. 


\section{References}

Acehan, D., Jiang, X., Morgan, D.G., Heuser, J.E., Wang, X. and Akey, C.W. (2002) Threedimensional structure of the apoptosome: implications for assembly, procaspase-9 binding, and activation. Mol Cell, 9, 423-432.

Achenbach, T.V., Slater, E.P., Brummerhop, H., Bach, T. and Muller, R. (2000) Inhibition of cyclindependent kinase activity and induction of apoptosis by preussin in human tumor cells. Antimicrob Agents Chemother, 44, 2794-2801.

Adams, C.R. and Kamakaka, R.T. (1999) Chromatin assembly: biochemical identities and genetic redundancy. Curr Opin Genet Dev, 9, 185-190.

Ahmad, K. and Henikoff, S. (2002a) Histone H3 variants specify modes of chromatin assembly. Proc Natl Acad Sci U S A, 99 Suppl 4, 16477-16484.

Ahmad, K. and Henikoff, S. (2002b) The histone variant H3.3 marks active chromatin by replicationindependent nucleosome assembly. Mol Cell, 9, 1191-1200.

Ahn, S.H., Cheung, W.L., Hsu, J.Y., Diaz, R.L., Smith, M.M. and Allis, C.D. (2005a) Sterile 20 kinase phosphorylates histone $\mathrm{H} 2 \mathrm{~B}$ at serine 10 during hydrogen peroxide-induced apoptosis in $\mathrm{S}$. cerevisiae. Cell, 120, 25-36.

Ahn, S.H., Henderson, K.A., Keeney, S. and Allis, C.D. (2005b) H2B (Ser10) phosphorylation is induced during apoptosis and meiosis in S. cerevisiae. Cell Cycle, 4, 780-783.

Aihara, H., Nakagawa, T., Yasui, K., Ohta, T., Hirose, S., Dhomae, N., Takio, K., Kaneko, M., Takeshima, Y., Muramatsu, M. and Ito, T. (2004) Nucleosomal histone kinase-1 phosphorylates H2A Thr 119 during mitosis in the early Drosophila embryo. Genes Dev, 18, 877-888.

Ajiro, K. (2000) Histone H2B phosphorylation in mammalian apoptotic cells. An association with DNA fragmentation. J Biol Chem, 275, 439-443.

Ajiro, K. and Allis, C.D. (2002) [Histone code hypothesis]. Tanpakushitsu Kakusan Koso, 47, 753-760.

Ajiro, K., Th'ng, J., Yau, J. and Nishi, Y. (2004) Isolation and characterization of mammalian cells that are undergoing apoptosis by a bovine serum albumin density gradient. Anal Biochem, 332, 226-233.

Ajiro, K., Yoda, K., Utsumi, K. and Nishikawa, Y. (1996) Alteration of cell cycle-dependent histone phosphorylations by okadaic acid. Induction of mitosis-specific H3 phosphorylation and chromatin condensation in mammalian interphase cells. J Biol Chem, 271, 13197-13201.

Albig, W., Drabent, B., Kunz, J., Kalff-Suske, M., Grzeschik, K.H. and Doenecke, D. (1993) All known human $\mathrm{H} 1$ histone genes except the $\mathrm{H} 1(0)$ gene are clustered on chromosome 6. Genomics, 16, 649-654.

Albig, W., Kardalinou, E., Drabent, B., Zimmer, A. and Doenecke, D. (1991) Isolation and characterization of two human $\mathrm{H} 1$ histone genes within clusters of core histone genes. Genomics, 10, 940-948.

Allfrey, V.G. (1966) Structural modifications of histones and their possible role in the regulation of ribonucleic acid synthesis. Proc Can Cancer Conf, 6, 313-335. 
Antalis, T.M. and Godbolt, D. (1991) Isolation of intact nuclei from hematopoietic cell types. Nucleic Acids Res, 19, 4301.

Arends, M.J., Morris, R.G. and Wyllie, A.H. (1990) Apoptosis. The role of the endonuclease. Am J Pathol, 136, 593-608.

Arents, G., Burlingame, R.W., Wang, B.C., Love, W.E. and Moudrianakis, E.N. (1991) The nucleosomal core histone octamer at $3.1 \mathrm{~A}$ resolution: a tripartite protein assembly and a lefthanded superhelix. Proc Natl Acad Sci U S A, 88, 10148-10152.

Ashkenazi, A. (2002) Targeting death and decoy receptors of the tumour-necrosis factor superfamily. Nat Rev Cancer, 2, 420-430.

Ashkenazi, A. and Dixit, V.M. (1998) Death receptors: signaling and modulation. Science, 281, 13051308.

Athey, B.D., Smith, M.F., Rankert, D.A., Williams, S.P. and Langmore, J.P. (1990) The diameters of frozen-hydrated chromatin fibers increase with DNA linker length: evidence in support of variable diameter models for chromatin. J Cell Biol, 111, 795-806.

Baarends, W.M., Hoogerbrugge, J.W., Roest, H.P., Ooms, M., Vreeburg, J., Hoeijmakers, J.H. and Grootegoed, J.A. (1999a) Histone ubiquitination and chromatin remodeling in mouse spermatogenesis. Dev Biol, 207, 322-333.

Baarends, W.M., Roest, H.P. and Grootegoed, J.A. (1999b) The ubiquitin system in gametogenesis. Mol Cell Endocrinol, 151, 5-16.

Bannister, A.J., Schneider, R., Myers, F.A., Thorne, A.W., Crane-Robinson, C. and Kouzarides, T. (2005) Spatial distribution of di- and tri-methyl lysine 36 of histone $\mathrm{H} 3$ at active genes. J Biol Chem, 280, 17732-17736.

Bannister, A.J., Zegerman, P., Partridge, J.F., Miska, E.A., Thomas, J.O., Allshire, R.C. and Kouzarides, T. (2001) Selective recognition of methylated lysine 9 on histone H3 by the HP1 chromo domain. Nature, 410, 120-124.

Barber, C.M., Turner, F.B., Wang, Y., Hagstrom, K., Taverna, S.D., Mollah, S., Ueberheide, B., Meyer, B.J., Hunt, D.F., Cheung, P. and Allis, C.D. (2004) The enhancement of histone H4 and H2A serine 1 phosphorylation during mitosis and S-phase is evolutionarily conserved. Chromosoma, 112, 360-371.

Bauer, U.M., Daujat, S., Nielsen, S.J., Nightingale, K. and Kouzarides, T. (2002) Methylation at arginine 17 of histone $\mathrm{H} 3$ is linked to gene activation. EMBO Rep, 3, 39-44.

Bernardi, P., Scorrano, L., Colonna, R., Petronilli, V. and Di Lisa, F. (1999) Mitochondria and cell death. Mechanistic aspects and methodological issues. Eur J Biochem, 264, 687-701.

Bonner, W.M., West, M.H. and Stedman, J.D. (1980) Two-dimensional gel analysis of histones in acid extracts of nuclei, cells, and tissues. Eur J Biochem, 109, 17-23.

Borner, C. (2003) The Bcl-2 protein family: sensors and checkpoints for life-or-death decisions. Mol Immunol, 39, 615-647.

Boulikas, T. (1985) Electrophoretic separation of histones and high-mobility-group proteins on acidurea-Triton gels. Anal Biochem, 149, 379-386.

Bradbury, E.M. (1992) Reversible histone modifications and the chromosome cell cycle. Bioessays, 14, 9-16. 
Bradbury, E.M., Chapman, G.E., Danby, S.E., Hartman, P.G. and Riches, P.L. (1975) Studies on the role and mode of operation of the very-lysine-rich histone H1 (F1) in eukaryote chromatin. The properties of the N-terminal and C-terminal halves of histone H1. Eur J Biochem, 57, 521-528.

Bradford, M.M. (1976) A rapid and sensitive method for the quantitation of microgram quantities of protein utilizing the principle of protein-dye binding. Anal Biochem, 72, 248-254.

Briggs, S.D., Xiao, T., Sun, Z.W., Caldwell, J.A., Shabanowitz, J., Hunt, D.F., Allis, C.D. and Strahl, B.D. (2002) Gene silencing: trans-histone regulatory pathway in chromatin. Nature, 418, 498.

Brown, D.G., Sun, X.M. and Cohen, G.M. (1993) Dexamethasone-induced apoptosis involves cleavage of DNA to large fragments prior to internucleosomal fragmentation. $\mathrm{J}$ Biol Chem, 268, 3037-3039.

Brown, G., Turner, B.M., Morris, C.J., Bahman, A.M., Fisher, A.G., Whitfield, W.G., Davies, S., Barthakur, R. and Johnson, G.D. (1985) A monoclonal antibody identifies a 215 000-dalton nuclear envelope protein restricted to certain cell types. Eur J Cell Biol, 39, 86-96.

Brown, M. and Wittwer, C. (2000) Flow cytometry: principles and clinical applications in hematology. Clin Chem, 46, 1221-1229.

Bryk, M., Briggs, S.D., Strahl, B.D., Curcio, M.J., Allis, C.D. and Winston, F. (2002) Evidence that Set1, a factor required for methylation of histone $\mathrm{H} 3$, regulates rDNA silencing in $\mathrm{S}$. cerevisiae by a Sir2-independent mechanism. Curr Biol, 12, 165-170.

Buendia, B., Santa-Maria, A. and Courvalin, J.C. (1999) Caspase-dependent proteolysis of integral and peripheral proteins of nuclear membranes and nuclear pore complex proteins during apoptosis. J Cell Sci, 112 ( Pt 11), 1743-1753.

Bunce, C.M., Thick, J.A., Lord, J.M., Mills, D. and Brown, G. (1988) A rapid procedure for isolating hemopoietic cell nuclei. Anal Biochem, 175, 67-73.

Burden, D.A., Kingma, P.S., Froelich-Ammon, S.J., Bjornsti, M.A., Patchan, M.W., Thompson, R.B. and Osheroff, N. (1996) Topoisomerase II.etoposide interactions direct the formation of druginduced enzyme-DNA cleavage complexes. J Biol Chem, 271, 29238-29244.

Burris, H.A., 3rd, Hanauske, A.R., Johnson, R.K., Marshall, M.H., Kuhn, J.G., Hilsenbeck, S.G. and Von Hoff, D.D. (1992) Activity of topotecan, a new topoisomerase I inhibitor, against human tumor colony-forming units in vitro. J Natl Cancer Inst, 84, 1816-1820.

Butler, P.J. and Thomas, J.O. (1980) Changes in chromatin folding in solution. J Mol Biol, 140, 505529.

Butler, P.J. and Thomas, J.O. (1998) Dinucleosomes show compaction by ionic strength, consistent with bending of linker DNA. J Mol Biol, 281, 401-407.

Cabrespines, A., Laderach, D., Lebosse, C., Bach, J.F. and Koutouzov, S. (1998) Isolation and characterization of apoptotic nucleosomes, free and complexed with lupus autoantibody generated during hybridoma B-cell apoptosis. J Autoimmun, 11, 19-27.

Callahan, M.K., Williamson, P. and Schlegel, R.A. (2000) Surface expression of phosphatidylserine on macrophages is required for phagocytosis of apoptotic thymocytes. Cell Death Differ, 7, 645653. 
Carruthers, L.M., Bednar, J., Woodcock, C.L. and Hansen, J.C. (1998) Linker histones stabilize the intrinsic salt-dependent folding of nucleosomal arrays: mechanistic ramifications for higherorder chromatin folding. Biochemistry, 37, 14776-14787.

Caserini, C., Pratesi, G., Tortoreto, M., Bedogne, B., Carenini, N., Supino, R., Perego, P., Righetti, S.C. and Zunino, F. (1997) Apoptosis as a determinant of tumor sensitivity to topotecan in human ovarian tumors: preclinical in vitro/in vivo studies. Clin Cancer Res, 3, 955-961.

Casiano, C.A. and Tan, E.M. (1996) Antinuclear autoantibodies: probes for defining proteolytic events associated with apoptosis. Mol Biol Rep, 23, 211-216.

Chen, G.L., Yang, L., Rowe, T.C., Halligan, B.D., Tewey, K.M. and Liu, L.F. (1984) Nonintercalative antitumor drugs interfere with the breakage-reunion reaction of mammalian DNA topoisomerase II. J Biol Chem, 259, 13560-13566.

Chen, H.J., Hwong, C.L., Wang, C.H. and Hwang, J. (2000) Degradation of DNA topoisomerase I by a novel trypsin-like serine protease in proliferating human T lymphocytes. J Biol Chem, 275, 13109-13117.

Cheung, P., Allis, C.D. and Sassone-Corsi, P. (2000) Signaling to chromatin through histone modifications. Cell, 103, 263-271.

Cheung, W.L., Ajiro, K., Samejima, K., Kloc, M., Cheung, P., Mizzen, C.A., Beeser, A., Etkin, L.D., Chernoff, J., Earnshaw, W.C. and Allis, C.D. (2003) Apoptotic phosphorylation of histone H2B is mediated by mammalian sterile twenty kinase. Cell, 113, 507-517.

Chow, K.C. and Ross, W.E. (1987) Topoisomerase-specific drug sensitivity in relation to cell cycle progression. Mol Cell Biol, 7, 3119-3123.

Clark, D.J. and Kimura, T. (1990) Electrostatic mechanism of chromatin folding. J Mol Biol, 211, 883896.

Cohen, J.J. (1993a) Apoptosis. Immunol Today, 14, 126-130.

Cohen, J.J. (1993b) Programmed cell death and apoptosis in lymphocyte development and function. Chest, 103, 99S-101S.

Collins, S.J., Gallo, R.C. and Gallagher, R.E. (1977) Continuous growth and differentiation of human myeloid leukaemic cells in suspension culture. Nature, 270, 347-349.

Cosgrove, M.S., Boeke, J.D. and Wolberger, C. (2004) Regulated nucleosome mobility and the histone code. Nat Struct Mol Biol, 11, 1037-1043.

Crane-Robinson, C. and Ptitsyn, O.B. (1989) Binding of the globular domain of linker histones H5/H1 to the nucleosome: a hypothesis. Protein Eng, 2, 577-582.

Creemers, G.J., Bolis, G., Gore, M., Scarfone, G., Lacave, A.J., Guastalla, J.P., Despax, R., Favalli, G., Kreinberg, R., Van Belle, S., Hudson, I., Verweij, J. and Ten Bokkel Huinink, W.W. (1996) Topotecan, an active drug in the second-line treatment of epithelial ovarian cancer: results of a large European phase II study. J Clin Oncol, 14, 3056-3061.

Creemers, G.J., Lund, B. and Verweij, J. (1994) Topoisomerase I inhibitors: topotecan and irenotecan. Cancer Treat Rev, 20, 73-96.

Cremisi, C., Chestier, A. and Yaniv, M. (1977) Preferential association of newly synthesized histones with replicating SV40 DNA. Cell, 12, 947-951. 
Cuthbert, G.L., Daujat, S., Snowden, A.W., Erdjument-Bromage, H., Hagiwara, T., Yamada, M., Schneider, R., Gregory, P.D., Tempst, P., Bannister, A.J. and Kouzarides, T. (2004) Histone deimination antagonizes arginine methylation. Cell, 118, 545-553.

D'Anna, J.A., Tobey, R.A. and Gurley, L.R. (1980) Concentration-dependent effects of sodium butyrate in Chinese hamster cells: cell-cycle progression, inner-histone acetylation, histone $\mathrm{H} 1$ dephosphorylation, and induction of an H1-like protein. Biochemistry, 19, 2656-2671.

Darzynkiewicz, Z., Juan, G., Li, X., Gorczyca, W., Murakami, T. and Traganos, F. (1997) Cytometry in cell necrobiology: analysis of apoptosis and accidental cell death (necrosis). Cytometry, 27, 120.

Dasso, M., Dimitrov, S. and Wolffe, A.P. (1994) Nuclear assembly is independent of linker histones. Proc Natl Acad Sci U S A, 91, 12477-12481.

Davey, C.A. and Richmond, T.J. (2002) DNA-dependent divalent cation binding in the nucleosome core particle. Proc Natl Acad Sci U S A, 99, 11169-11174.

Davey, C.A., Sargent, D.F., Luger, K., Maeder, A.W. and Richmond, T.J. (2002) Solvent mediated interactions in the structure of the nucleosome core particle at 1.9 a resolution. $\mathrm{J} \mathrm{Mol} \mathrm{Biol,}$ 319, 1097-1113.

Davis, B.J. (1964) Disc Electrophoresis. Ii. Method and Application to Human Serum Proteins. Ann N Y Acad Sci, 121, 404-427.

Del Bino, G., Skierski, J.S. and Darzynkiewicz, Z. (1991) The concentration-dependent diversity of effects of DNA topoisomerase I and II inhibitors on the cell cycle of HL-60 cells. Exp Cell Res, 195, 485-491.

Denault, J.B. and Salvesen, G.S. (2002) Caspases: keys in the ignition of cell death. Chem Rev, 102, 4489-4500.

Dion, M.F., Altschuler, S.J., Wu, L.F. and Rando, O.J. (2005) Genomic characterization reveals a simple histone H4 acetylation code. Proc Natl Acad Sci U S A, 102, 5501-5506.

Dive, C., Gregory, C.D., Phipps, D.J., Evans, D.L., Milner, A.E. and Wyllie, A.H. (1992) Analysis and discrimination of necrosis and apoptosis (programmed cell death) by multiparameter flow cytometry. Biochim Biophys Acta, 1133, 275-285.

Doenecke, D., Albig, W., Bouterfa, H. and Drabent, B. (1994) Organization and expression of H1 histone and H1 replacement histone genes. J Cell Biochem, 54, 423-431.

Doenecke, D. and Tonjes, R. (1986) Differential distribution of lysine and arginine residues in the closely related histones $\mathrm{H} 1$ and $\mathrm{H} 5$. Analysis of a human $\mathrm{H} 1$ gene. $\mathrm{J} \mathrm{Mol} \mathrm{Biol,} \mathrm{187,} \mathrm{461-464.}$

Drabent, B., Kardalinou, E. and Doenecke, D. (1991) Structure and expression of the human gene encoding testicular $\mathrm{H} 1$ histone (H1t). Gene, 103, 263-268.

Droin, N., Dubrez, L., Eymin, B., Renvoize, C., Breard, J., Dimanche-Boitrel, M.T. and Solary, E. (1998) Upregulation of CASP genes in human tumor cells undergoing etoposide-induced apoptosis. Oncogene, 16, 2885-2894.

Dyer, R.B. and Herzog, N.K. (1995) Isolation of intact nuclei for nuclear extract preparation from a fragile B-lymphocyte cell line. Biotechniques, 19, 192-195.

Earnshaw, W.C., Martins, L.M. and Kaufmann, S.H. (1999) Mammalian caspases: structure, activation, substrates, and functions during apoptosis. Annu Rev Biochem, 68, 383-424. 
Edmondson, D.G. and Roth, S.Y. (1996) Chromatin and transcription. Faseb J, 10, 1173-1182.

Eick, S., Nicolai, M., Mumberg, D. and Doenecke, D. (1989) Human H1 histones: conserved and varied sequence elements in two H1 subtype genes. Eur J Cell Biol, 49, 110-115.

Enomoto, R., Koyamazaki, R., Maruta, Y., Tanaka, M., Takuma, K., Mori, K. and Lee, E. (2001) Phosphorylation of histones triggers DNA fragmentation in thymocyte undergoing apoptosis induced by protein phosphatase inhibitors. Mol Cell Biol Res Commun, 4, 276-281.

Enomoto, R., Yoshida, Y., Komai, T., Sugahara, C., Yasuoka, Y. and Lee, E. (2003) Involvement of the change in chromatin structure in thymocyte apoptosis induced by phosphorylation of histones. Ann N Y Acad Sci, 1010, 218-220.

Fadeel, B., Gleiss, B., Hogstrand, K., Chandra, J., Wiedmer, T., Sims, P.J., Henter, J.I., Orrenius, S. and Samali, A. (1999a) Phosphatidylserine exposure during apoptosis is a cell-type-specific event and does not correlate with plasma membrane phospholipid scramblase expression. Biochem Biophys Res Commun, 266, 504-511.

Fadeel, B., Orrenius, S. and Zhivotovsky, B. (1999b) Apoptosis in human disease: a new skin for the old ceremony? Biochem Biophys Res Commun, 266, 699-717.

Felsenfeld, G. (1992) Chromatin as an essential part of the transcriptional mechanism. Nature, 355, 219-224.

Felsenfeld, G. and Groudine, M. (2003) Controlling the double helix. Nature, 421, 448-453.

Fernandez-Capetillo, O., Lee, A., Nussenzweig, M. and Nussenzweig, A. (2004) H2AX: the histone guardian of the genome. DNA Repair (Amst), 3, 959-967.

Finch, J.T. and Klug, A. (1976) Solenoidal model for superstructure in chromatin. Proc Natl Acad Sci U $S A, 73,1897-1901$.

Finch, J.T., Lutter, L.C., Rhodes, D., Brown, R.S., Rushton, B., Levitt, M. and Klug, A. (1977) Structure of nucleosome core particles of chromatin. Nature, 269, 29-36.

Fischle, W., Wang, Y. and Allis, C.D. (2003) Histone and chromatin cross-talk. Curr Opin Cell Biol, 15, 172-183.

Gabler, C., Blank, N., Winkler, S., Kalden, J.R. and Lorenz, H.M. (2003a) Accumulation of histones in cell lysates precedes expression of apoptosis-related phagocytosis signals in human lymphoblasts. Ann N Y Acad Sci, 1010, 221-224.

Gabler, C., Kalden, J.R. and Lorenz, H.M. (2003b) The putative role of apoptosis-modified histones for the induction of autoimmunity in Systemic Lupus Erythematosus. Biochem Pharmacol, 66, 1441-1446.

Gallagher, R., Collins, S., Trujillo, J., McCredie, K., Ahearn, M., Tsai, S., Metzgar, R., Aulakh, G., Ting, R., Ruscetti, F. and Gallo, R. (1979) Characterization of the continuous, differentiating myeloid cell line (HL-60) from a patient with acute promyelocytic leukemia. Blood, 54, 713-733.

Gernand, D., Demidov, D. and Houben, A. (2003) The temporal and spatial pattern of histone H3 phosphorylation at serine 28 and serine 10 is similar in plants but differs between mono- and polycentric chromosomes. Cytogenet Genome Res, 101, 172-176.

Gey, G.O., Coffman, W.D. and Kubicek, M.T. (1952) Tissue Culture Studies of the Proliferative Capacity of Cervical Carcinoma and Normal Epithelium. Cancer Research, 12, 264-265. 
Goldknopf, I.L., Wilson, G., Ballal, N.R. and Busch, H. (1980) Chromatin conjugate protein A24 is cleaved and ubiquitin is lost during chicken erythropoiesis. J Biol Chem, 255, 10555-10558.

Goll, M.G. and Bestor, T.H. (2002) Histone modification and replacement in chromatin activation. Genes Dev, 16, 1739-1742.

Graves, J.D., Draves, K.E., Gotoh, Y., Krebs, E.G. and Clark, E.A. (2001) Both phosphorylation and caspase-mediated cleavage contribute to regulation of the Ste20-like protein kinase Mst1 during CD95/Fas-induced apoptosis. J Biol Chem, 276, 14909-14915.

Greidinger, E.L., Miller, D.K., Yamin, T.T., Casciola-Rosen, L. and Rosen, A. (1996) Sequential activation of three distinct ICE-like activities in Fas-ligated Jurkat cells. FEBS Lett, 390, 299303.

Grunstein, M. (1997) Histone acetylation in chromatin structure and transcription. Nature, 389, 349352.

Grzanka, A. and Grzanka, D. (2003) The influence of etoposide on the distribution of tubulin in human leukemia cell line HL-60. Med Sci Monit, 9, BR66-69.

Grzanka, A., Grzanka, D. and Orlikowska, M. (2003) Cytoskeletal reorganization during process of apoptosis induced by cytostatic drugs in K-562 and HL-60 leukemia cell lines. Biochem Pharmacol, 66, 1611-1617.

Grzanka, A., Grzanka, D., Orlikowska, M. and Zuryn, A. (2005) Estimation of taxol influence on changes in tubulin and vimentin systems in K-562 and HL-60 cell lines by immunofluorescence microscopy. Neoplasma, 52, 193-198.

Gurley, L.R., London, J.E. and Valdez, J.G. (1991) High-performance capillary electrophoresis of histones. J Chromatogr, 559, 431-443.

Hake, S.B., Garcia, B.A., Kauer, M., Baker, S.P., Shabanowitz, J., Hunt, D.F. and Allis, C.D. (2005) Serine 31 phosphorylation of histone variant $\mathrm{H} 3.3$ is specific to regions bordering centromeres in metaphase chromosomes. Proc Natl Acad Sci U S A, 102, 6344-6349.

Hale, A.J., Smith, C.A., Sutherland, L.C., Stoneman, V.E., Longthorne, V., Culhane, A.C. and Williams, G.T. (1996) Apoptosis: molecular regulation of cell death. Eur J Biochem, 237, 884.

Halicka, H.D., Huang, X., Traganos, F., King, M.A., Dai, W. and Darzynkiewicz, Z. (2005) Histone H2AX phosphorylation after cell irradiation with UV-B: relationship to cell cycle phase and induction of apoptosis. Cell Cycle, 4, 339-345.

Hande, K.R. (1996) The importance of drug scheduling in cancer chemotherapy: etoposide as an example. Stem Cells, 14, 18-24.

Happel, N., Sommer, A., Hanecke, K., Albig, W. and Doenecke, D. (2005) Topoisomerase inhibitor induced dephosphorylation of $\mathrm{H} 1$ and $\mathrm{H} 3$ histones as a consequence of cell cycle arrest. $\mathrm{J}$ Cell Biochem, 95, 1235-1247.

Harmon, B.V. and Allan, D.J. (1997) Apoptosis. Adv Genet, 35, 35-56.

Hayes, J.J. (2002) Changing chromatin from the inside. Nat Struct Biol, 9, 161-163.

Hayes, J.J. and Hansen, J.C. (2002) New insights into unwrapping DNA from the nucleosome from a single-molecule optical tweezers method. Proc Natl Acad Sci U S A, 99, 1752-1754. 
Hecht, A., Laroche, T., Strahl-Bolsinger, S., Gasser, S.M. and Grunstein, M. (1995) Histone H3 and $\mathrm{H} 4 \mathrm{~N}$-termini interact with SIR3 and SIR4 proteins: a molecular model for the formation of heterochromatin in yeast. Cell, 80, 583-592.

Helliger, W., Lindner, H., Grubl-Knosp, O. and Puschendorf, B. (1992) Alteration in proportions of histone $\mathrm{H} 1$ variants during the differentiation of murine erythroleukaemic cells. Biochem $\mathrm{J}, \mathbf{2 8 8}$ ( Pt 3), 747-751.

Helliger, W., Lindner, H., Hauptlorenz, S. and Puschendorf, B. (1988) A new h.p.l.c. isolation procedure for chicken and goose erythrocyte histones. Biochem J, 255, 23-27.

Hendzel, M.J., Kruhlak, M.J. and Bazett-Jones, D.P. (1998a) Organization of highly acetylated chromatin around sites of heterogeneous nuclear RNA accumulation. Mol Biol Cell, 9, 24912507.

Hendzel, M.J., Nishioka, W.K., Raymond, Y., Allis, C.D., Bazett-Jones, D.P. and Th'ng, J.P. (1998b) Chromatin condensation is not associated with apoptosis. J Biol Chem, 273, 24470-24478.

Herben, V.M., ten Bokkel Huinink, W.W. and Beijnen, J.H. (1996) Clinical pharmacokinetics of topotecan. Clin Pharmacokinet, 31, 85-102.

Herrera, B., Fernandez, M., Alvarez, A.M., Roncero, C., Benito, M., Gil, J. and Fabregat, I. (2001) Activation of caspases occurs downstream from radical oxygen species production, Bcl-xL down-regulation, and early cytochrome $\mathrm{C}$ release in apoptosis induced by transforming growth factor beta in rat fetal hepatocytes. Hepatology, 34, 548-556.

Hirata, H., Takahashi, A., Kobayashi, S., Yonehara, S., Sawai, H., Okazaki, T., Yamamoto, K. and Sasada, M. (1998) Caspases are activated in a branched protease cascade and control distinct downstream processes in Fas-induced apoptosis. J Exp Med, 187, 587-600.

Holm, C., Covey, J.M., Kerrigan, D. and Pommier, Y. (1989) Differential requirement of DNA replication for the cytotoxicity of DNA topoisomerase I and II inhibitors in Chinese hamster DC3F cells. Cancer Res, 49, 6365-6368.

Holt, G.D., Snow, C.M., Senior, A., Haltiwanger, R.S., Gerace, L. and Hart, G.W. (1987) Nuclear pore complex glycoproteins contain cytoplasmically disposed O-linked $\mathrm{N}$-acetylglucosamine. J Cell Biol, 104, 1157-1164.

Horowitz, R.A., Agard, D.A., Sedat, J.W. and Woodcock, C.L. (1994) The three-dimensional architecture of chromatin in situ: electron tomography reveals fibers composed of a continuously variable zig-zag nucleosomal ribbon. J Cell Biol, 125, 1-10.

Houben, A., Demidov, D., Rutten, T. and Scheidtmann, K.H. (2005) Novel phosphorylation of histone $\mathrm{H} 3$ at threonine 11 that temporally correlates with condensation of mitotic and meiotic chromosomes in plant cells. Cytogenet Genome Res, 109, 148-155.

Hsiang, Y.H., Hertzberg, R., Hecht, S. and Liu, L.F. (1985) Camptothecin induces protein-linked DNA breaks via mammalian DNA topoisomerase I. J Biol Chem, 260, 14873-14878.

Hsiang, Y.H., Jiang, J.B. and Liu, L.F. (1989a) Topoisomerase II-mediated DNA cleavage by amonafide and its structural analogs. Mol Pharmacol, 36, 371-376.

Hsiang, Y.H., Lihou, M.G. and Liu, L.F. (1989b) Arrest of replication forks by drug-stabilized topoisomerase I-DNA cleavable complexes as a mechanism of cell killing by camptothecin. Cancer Res, 49, 5077-5082. 
Hsiang, Y.H. and Liu, L.F. (1988) Identification of mammalian DNA topoisomerase I as an intracellular target of the anticancer drug camptothecin. Cancer Res, 48, 1722-1726.

Hsiang, Y.H., Liu, L.F., Wall, M.E., Wani, M.C., Nicholas, A.W., Manikumar, G., Kirschenbaum, S., Silber, R. and Potmesil, M. (1989c) DNA topoisomerase I-mediated DNA cleavage and cytotoxicity of camptothecin analogues. Cancer Res, 49, 4385-4389.

Huang, X., Traganos, F. and Darzynkiewicz, Z. (2003) DNA damage induced by DNA topoisomerase $\mathrm{I}$ - and topoisomerase II-inhibitors detected by histone H2AX phosphorylation in relation to the cell cycle phase and apoptosis. Cell Cycle, 2, 614-619.

Hutchins, J.B. and Barger, S.W. (1998) Why neurons die: cell death in the nervous system. Anat Rec, 253, 79-90.

Ito, T., Tyler, J.K. and Kadonaga, J.T. (1997) Chromatin assembly factors: a dual function in nucleosome formation and mobilization? Genes Cells, 2, 593-600.

Jason, L.J., Moore, S.C., Ausio, J. and Lindsey, G. (2001) Magnesium-dependent association and folding of oligonucleosomes reconstituted with ubiquitinated H2A. J Biol Chem, 276, 1459714601.

Jaxel, C., Kohn, K.W., Wani, M.C., Wall, M.E. and Pommier, Y. (1989) Structure-activity study of the actions of camptothecin derivatives on mammalian topoisomerase I: evidence for a specific receptor site and a relation to antitumor activity. Cancer Res, 49, 1465-1469.

Jenuwein, T. and Allis, C.D. (2001) Translating the histone code. Science, 293, 1074-1080.

Jiang, G., Yang, F., Sanchez, C. and Ehrlich, M. (2004) Histone modification in constitutive heterochromatin versus unexpressed euchromatin in human cells. J Cell Biochem, 93, 286300.

Johnson, N., Ng, T.C. and Parkin, J.M. (1997a) Induction of apoptosis within T lymphoblastoid cells by a topoisomerase I inhibitor. Biochem Soc Trans, 25, 240 S.

Johnson, N., Ng, T.T. and Parkin, J.M. (1997b) Camptothecin causes cell cycle perturbations within Tlymphoblastoid cells followed by dose dependent induction of apoptosis. Leuk Res, 21, 961972.

Joss, U.R. and Towbin, H. (1994) Acridinium Ester Labeled Cytokines - Receptor-Binding Studies with Human Interleukin-1-Alpha, Interleukin-1-Beta and Interferon-Gamma. Journal of Bioluminescence and Chemiluminescence, 9, 21-28.

Kallajoki, M., Weber, K. and Osborn, M. (1991) A $210 \mathrm{kDa}$ nuclear matrix protein is a functional part of the mitotic spindle; a microinjection study using SPN monoclonal antibodies. Embo J, 10, 3351-3362.

Kao, C.F., Hillyer, C., Tsukuda, T., Henry, K., Berger, S. and Osley, M.A. (2004) Rad6 plays a role in transcriptional activation through ubiquitylation of histone H2B. Genes Dev, 18, 184-195.

Kaufman, P.D., Kobayashi, R., Kessler, N. and Stillman, B. (1995) The p150 and p60 subunits of chromatin assembly factor I: a molecular link between newly synthesized histones and DNA replication. Cell, 81, 1105-1114.

Kaufmann, S.H. and Earnshaw, W.C. (2000) Induction of apoptosis by cancer chemotherapy. Exp Cell Res, 256, 42-49. 
Kerr, J.F., Wyllie, A.H. and Currie, A.R. (1972) Apoptosis: a basic biological phenomenon with wideranging implications in tissue kinetics. Br J Cancer, 26, 239-257.

Khodarev, N.N., Sokolova, I.A. and Vaughan, A.T. (1998) Mechanisms of induction of apoptotic DNA fragmentation. Int J Radiat Biol, 73, 455-467.

Khorasanizadeh, S. (2004) The nucleosome: from genomic organization to genomic regulation. Cell, 116, 259-272.

Kihlmark, M., Imreh, G. and Hallberg, E. (2001) Sequential degradation of proteins from the nuclear envelope during apoptosis. J Cell Sci, 114, 3643-3653.

Kim, J., Jia, L., Tilley, W.D. and Coetzee, G.A. (2003) Dynamic methylation of histone H3 at lysine 4 in transcriptional regulation by the androgen receptor. Nucleic Acids Res, 31, 6741-6747.

Klug, A., Rhodes, D., Smith, J., Finch, J.T. and Thomas, J.O. (1980) A low resolution structure for the histone core of the nucleosome. Nature, 287, 509-516.

Kollmannsberger, C., Mross, K., Jakob, A., Kanz, L. and Bokemeyer, C. (1999) Topotecan - A novel topoisomerase I inhibitor: pharmacology and clinical experience. Oncology, 56, 1-12.

Konishi, A., Shimizu, S., Hirota, J., Takao, T., Fan, Y., Matsuoka, Y., Zhang, L., Yoneda, Y., Fujii, Y., Skoultchi, A.I. and Tsujimoto, Y. (2003) Involvement of histone H1.2 in apoptosis induced by DNA double-strand breaks. Cell, 114, 673-688.

Kornberg, R.D. (1977) Structure of chromatin. Annu Rev Biochem, 46, 931-954.

Kornberg, R.D. and Thomas, J.O. (1974) Chromatin structure; oligomers of the histones. Science, 184, 865-868.

Koshland, D. and Strunnikov, A. (1996) Mitotic chromosome condensation. Annu Rev Cell Dev Biol, 12, 305-333.

Kratzmeier, M., Albig, W., Hanecke, K. and Doenecke, D. (2000) Rapid dephosphorylation of H1 histones after apoptosis induction. J Biol Chem, 275, 30478-30486.

Kratzmeier, M., Albig, W., Meergans, T. and Doenecke, D. (1999) Changes in the protein pattern of H1 histones associated with apoptotic DNA fragmentation. Biochem J, 337 ( Pt 2), 319-327.

Lachner, M. and Jenuwein, T. (2002) The many faces of histone lysine methylation. Curr Opin Cell Biol, 14, 286-298.

Laemmli, U.K. (1978) Levels of organization of the DNA in eucaryotic chromosomes. Pharmacol Rev, 30, 469-476.

Laemmli, U.K., Amos, L.A. and Klug, A. (1976) Correlation between structural transformation and cleavage of the major head protein of T4 bacteriophage. Cell, 7, 191-203.

Laemmli, U.K., Beguin, F. and Gujer-Kellenberger, G. (1970a) A factor preventing the major head protein of bacteriophage T4 from random aggregation. J Mol Biol, 47, 69-85.

Laemmli, U.K., Molbert, E., Showe, M. and Kellenberger, E. (1970b) Form-determining function of the genes required for the assembly of the head of bacteriophage T4. J Mol Biol, 49, 99-113.

Lazebnik, Y.A., Takahashi, A., Moir, R.D., Goldman, R.D., Poirier, G.G., Kaufmann, S.H. and Earnshaw, W.C. (1995) Studies of the lamin proteinase reveal multiple parallel biochemical pathways during apoptotic execution. Proc Natl Acad Sci U S A, 92, 9042-9046. 
Lee, E., Nakatsuma, A., Hiraoka, R., Ishikawa, E., Enomoto, R. and Yamauchi, A. (1999) Involvement of histone phosphorylation in thymocyte apoptosis by protein phosphatase inhibitors. IUBMB Life, 48, 79-83.

Leist, M. and Jaattela, M. (2001a) Four deaths and a funeral: from caspases to alternative mechanisms. Nat Rev Mol Cell Biol, 2, 589-598.

Leist, M. and Jaattela, M. (2001b) Triggering of apoptosis by cathepsins. Cell Death Differ, 8, 324-326.

Li, L.H., Fraser, T.J., Olin, E.J. and Bhuyan, B.K. (1972) Action of camptothecin on mammalian cells in culture. Cancer Res, 32, 2643-2650.

Lim, J.H., West, K.L., Rubinstein, Y., Bergel, M., Postnikov, Y.V. and Bustin, M. (2005) Chromosomal protein HMGN1 enhances the acetylation of lysine 14 in histone H3. Embo J, 24, 3038-3048.

Lindner, H., Helliger, W., Dirschlmayer, A., Jaquemar, M. and Puschendorf, B. (1992) Highperformance capillary electrophoresis of core histones and their acetylated modified derivatives. Biochem J, 283 ( Pt 2), 467-471.

Lindner, H., Helliger, W. and Puschendorf, B. (1986) Histone separation by high-performance liquid chromatography on C4 reverse-phase columns. Anal Biochem, 158, 424-430.

Lindner, H., Helliger, W. and Puschendorf, B. (1988) Separation of Friend erythroleukaemic cell histones and high-mobility-group proteins by reversed-phase high-performance liquid chromatography. J Chromatogr, 450, 309-316.

Lindner, H., Helliger, W. and Puschendorf, B. (1990) Separation of rat tissue histone H1 subtypes by reverse-phase h.p.I.c. Identification and assignment to a standard $\mathrm{H} 1$ nomenclature. Biochem J, 269, 359-363.

Lindner, H., Helliger, W., Sarg, B. and Meraner, C. (1995) Effect of buffer composition on the migration order and separation of histone $\mathrm{H} 1$ subtypes. Electrophoresis, 16, 604-610.

Lindner, H., Sarg, B., Grunicke, H. and Helliger, W. (1999) Age-dependent deamidation of H1(0) histones in chromatin of mammalian tissues. J Cancer Res Clin Oncol, 125, 182-186.

Lindner, H., Sarg, B. and Helliger, W. (2003) Capillary electrophoresis analysis of histones, histone variants, and their post-translationally modified forms: a review. J Capillary Electrophor, 8, 5967.

Lindner, H., Sarg, B., Meraner, C. and Helliger, W. (1996) Separation of acetylated core histones by hydrophilic-interaction liquid chromatography. J Chromatogr A, 743, 137-144.

Lindner, H., Wurm, M., Dirschlmayer, A., Sarg, B. and Helliger, W. (1993) Application of highperformance capillary electrophoresis to the analysis of $\mathrm{H} 1$ histones. Electrophoresis, 14, 480485.

Lo, W.S., Duggan, L., Emre, N.C., Belotserkovskya, R., Lane, W.S., Shiekhattar, R. and Berger, S.L. (2001) Snf1--a histone kinase that works in concert with the histone acetyltransferase Gcn5 to regulate transcription. Science, 293, 1142-1146.

Lo, W.S., Trievel, R.C., Rojas, J.R., Duggan, L., Hsu, J.Y., Allis, C.D., Marmorstein, R. and Berger, S.L. (2000) Phosphorylation of serine 10 in histone $\mathrm{H} 3$ is functionally linked in vitro and in vivo to Gcn5-mediated acetylation at lysine 14. Mol Cell, 5, 917-926. 
Lockshin, R.A. and Williams, C.M. (1964) Programmed Cell Death .2. Endocrine Potentiation of the Breakdown of the Intersegmental Muscles of Silkmoths. Journal of Insect Physiology, 10, 643649.

Luger, K., Mader, A.W., Richmond, R.K., Sargent, D.F. and Richmond, T.J. (1997) Crystal structure of the nucleosome core particle at 2.8 A resolution. Nature, 389, 251-260.

Luo, X., Budihardjo, I., Zou, H., Slaughter, C. and Wang, X. (1998) Bid, a Bcl2 interacting protein, mediates cytochrome $c$ release from mitochondria in response to activation of cell surface death receptors. Cell, 94, 481-490.

Ma, H., Baumann, C.T., Li, H., Strahl, B.D., Rice, R., Jelinek, M.A., Aswad, D.W., Allis, C.D., Hager, G.L. and Stallcup, M.R. (2001) Hormone-dependent, CARM1-directed, arginine-specific methylation of histone $\mathrm{H} 3$ on a steroid-regulated promoter. Curr Biol, 11, 1981-1985.

Mardian, J.K. and Isenberg, I. (1978) Yeast inner histones and the evolutionary conservation of histone-histone interactions. Biochemistry, 17, 3825-3833.

Marushige, Y. and Marushige, K. (1995) Disappearance of ubiquitinated histone H2A during chromatin condensation in TGF beta 1-induced apoptosis. Anticancer Res, 15, 267-272.

McBain, J.A., Eastman, A., Nobel, C.S. and Mueller, G.C. (1997) Apoptotic death in adenocarcinoma cell lines induced by butyrate and other histone deacetylase inhibitors. Biochem Pharmacol, 53, 1357-1368.

McGhee, J.D., Nickol, J.M., Felsenfeld, G. and Rau, D.C. (1983) Higher order structure of chromatin: orientation of nucleosomes within the $30 \mathrm{~nm}$ chromatin solenoid is independent of species and spacer length. Cell, 33, 831-841.

McKittrick, E., Gafken, P.R., Ahmad, K. and Henikoff, S. (2004) Histone H3.3 is enriched in covalent modifications associated with active chromatin. Proc Natl Acad Sci U S A, 101, 1525-1530.

Meier, P., Finch, A. and Evan, G. (2000) Apoptosis in development. Nature, 407, 796-801.

Merdes, A., Ramyar, K., Vechio, J.D. and Cleveland, D.W. (1996) A complex of NuMA and cytoplasmic dynein is essential for mitotic spindle assembly. Cell, 87, 447-458.

Milsted, A., Day, D.L., Pensky, J. and Cox, R.P. (1987) Phenotypes of HeLa S3 variant cell lines resistant to growth inhibition by sodium butyrate. In Vitro Cell Dev Biol, 23, 395-402.

Mimnaugh, E.G., Kayastha, G., McGovern, N.B., Hwang, S.G., Marcu, M.G., Trepel, J., Cai, S.Y., Marchesi, V.T. and Neckers, L. (2001) Caspase-dependent deubiquitination of monoubiquitinated nucleosomal histone $\mathrm{H} 2 \mathrm{~A}$ induced by diverse apoptogenic stimuli. Cell Death Differ, 8, 1182-1196.

Mullauer, L., Gruber, P., Sebinger, D., Buch, J., Wohlfart, S. and Chott, A. (2001) Mutations in apoptosis genes: a pathogenetic factor for human disease. Mutat Res, 488, 211-231.

Nagata, S. (1994) Apoptosis regulated by a death factor and its receptor: Fas ligand and Fas. Philos Trans $R$ Soc Lond B Biol Sci, 345, 281-287.

Nagata, S. and Golstein, P. (1995) The Fas death factor. Science, 267, 1449-1456.

Naismith, J.H. and Sprang, S.R. (1998) Modularity in the TNF-receptor family. Trends Biochem Sci, 23, 74-79.

Nakayama, J., Rice, J.C., Strahl, B.D., Allis, C.D. and Grewal, S.I. (2001) Role of histone H3 lysine 9 methylation in epigenetic control of heterochromatin assembly. Science, 292, 110-113. 
Nathan, D., Sterner, D.E. and Berger, S.L. (2003) Histone modifications: Now summoning sumoylation. Proc Natl Acad Sci U S A, 100, 13118-13120.

Nevins, J.R. (1987) Isolation and analysis of nuclear RNA. Methods Enzymol, 152, 234-241.

Nishioka, K., Chuikov, S., Sarma, K., Erdjument-Bromage, H., Allis, C.D., Tempst, P. and Reinberg, D. (2002) Set9, a novel histone H3 methyltransferase that facilitates transcription by precluding histone tail modifications required for heterochromatin formation. Genes Dev, 16, 479-489.

Nowak, S.J. and Corces, V.G. (2000) Phosphorylation of histone H3 correlates with transcriptionally active loci. Genes Dev, 14, 3003-3013.

Nowak, S.J. and Corces, V.G. (2004) Phosphorylation of histone H3: a balancing act between chromosome condensation and transcriptional activation. Trends Genet, 20, 214-220.

Oberhammer, F.A., Hochegger, K., Froschl, G., Tiefenbacher, R. and Pavelka, M. (1994) Chromatin condensation during apoptosis is accompanied by degradation of lamin $A+B$, without enhanced activation of cdc2 kinase. J Cell Biol, 126, 827-837.

Olins, A.L. and Olins, D.E. (1974) Spheroid chromatin units (v bodies). Science, 183, 330-332.

Ornstein, L. (1964) Disc Electrophoresis. I. Background and Theory. Ann N Y Acad Sci, 121, 321-349.

Orth, K., Chinnaiyan, A.M., Garg, M., Froelich, C.J. and Dixit, V.M. (1996) The CED-3/ICE-like protease Mch2 is activated during apoptosis and cleaves the death substrate lamin A. J Biol Chem, 271, 16443-16446.

Osheroff, N. (1989) Biochemical basis for the interactions of type I and type II topoisomerases with DNA. Pharmacol Ther, 41, 223-241.

Osheroff, N., Zechiedrich, E.L. and Gale, K.C. (1991) Catalytic function of DNA topoisomerase II. Bioessays, 13, 269-273.

Osley, M.A. (2004) H2B ubiquitylation: the end is in sight. Biochim Biophys Acta, 1677, 74-78.

Oudet, P., Gross-Bellard, M. and Chambon, P. (1975) Electron microscopic and biochemical evidence that chromatin structure is a repeating unit. Cell, 4, 281-300.

Pantazis, P. and Bonner, W.M. (1982) Butyrate-induced histone hyperacetylation in human and mouse cells: estimation of putative sites of histone acetylation in vivo. J Cell Biochem, 20, 225-235.

Panyim, S. and Chalkley, R. (1969a) The heterogeneity of histones. I. A quantitative analysis of calf histones in very long polyacrylamide gels. Biochemistry, 8, 3972-3979.

Panyim, S. and Chalkley, R. (1969b) High resolution acrylamide gel electrophoresis of histones. Arch Biochem Biophys, 130, 337-346.

Pehrson, J.R. (1989) Thymine dimer formation as a probe of the path of DNA in and between nucleosomes in intact chromatin. Proc Natl Acad Sci U S A, 86, 9149-9153.

Perez-Soler, R., Glisson, B.S., Lee, J.S., Fossella, F.V., Murphy, W.K., Shin, D.M. and Hong, W.K. (1996) Treatment of patients with small-cell lung cancer refractory to etoposide and cisplatin with the topoisomerase I poison topotecan. J Clin Oncol, 14, 2785-2790.

Peters, A.H., Kubicek, S., Mechtler, K., O'Sullivan, R.J., Derijck, A.A., Perez-Burgos, L., Kohlmaier, A., Opravil, S., Tachibana, M., Shinkai, Y., Martens, J.H. and Jenuwein, T. (2003) Partitioning and plasticity of repressive histone methylation states in mammalian chromatin. Mol Cell, 12, 1577-1589.

Peterson, C.L. and Laniel, M.A. (2004) Histones and histone modifications. Curr Biol, 14, R546-551. 
Pilch, D.R., Redon, C., Sedelnikova, O.A. and Bonner, W.M. (2004) Two-dimensional gel analysis of histones and other H2AX-related methods. Methods Enzymol, 375, 76-88.

Polioudaki, H., Markaki, Y., Kourmouli, N., Dialynas, G., Theodoropoulos, P.A., Singh, P.B. and Georgatos, S.D. (2004) Mitotic phosphorylation of histone H3 at threonine 3. FEBS Lett, 560, 39-44.

Prigent, C. and Dimitrov, S. (2003) Phosphorylation of serine 10 in histone H3, what for? J Cell Sci, 116, 3677-3685.

Pruss, D., Bartholomew, B., Persinger, J., Hayes, J., Arents, G., Moudrianakis, E.N. and Wolffe, A.P. (1996) An asymmetric model for the nucleosome: a binding site for linker histones inside the DNA gyres. Science, 274, 614-617.

Radic, M., Marion, T. and Monestier, M. (2004) Nucleosomes are exposed at the cell surface in apoptosis. J Immunol, 172, 6692-6700.

Rathmell, J.C. and Thompson, C.B. (2002) Pathways of apoptosis in lymphocyte development, homeostasis, and disease. Cell, 109 Suppl, S97-107.

Redon, C., Pilch, D., Rogakou, E., Sedelnikova, O., Newrock, K. and Bonner, W. (2002) Histone H2A variants H2AX and H2AZ. Curr Opin Genet Dev, 12, 162-169.

Reed, J.C. (1998) Bcl-2 family proteins. Oncogene, 17, 3225-3236.

Reed, J.C. (2002) Apoptosis-based therapies. Nat Rev Drug Discov, 1, 111-121.

Rice, J.C., Briggs, S.D., Ueberheide, B., Barber, C.M., Shabanowitz, J., Hunt, D.F., Shinkai, Y. and Allis, C.D. (2003) Histone methyltransferases direct different degrees of methylation to define distinct chromatin domains. Mol Cell, 12, 1591-1598.

Rich, T., Allen, R.L. and Wyllie, A.H. (2000) Defying death after DNA damage. Nature, 407, 777-783.

Richards, E.J. and Elgin, S.C. (2002) Epigenetic codes for heterochromatin formation and silencing: rounding up the usual suspects. Cell, 108, 489-500.

Richmond, T.J., Rechsteiner, T. and Luger, K. (1993) Studies of nucleosome structure. Cold Spring Harb Symp Quant Biol, 58, 265-272.

Riggs, M.G., Whittaker, R.G., Neumann, J.R. and Ingram, V.M. (1977) n-Butyrate causes histone modification in HeLa and Friend erythroleukaemia cells. Nature, 268, 462-464.

Rogakou, E.P., Boon, C., Redon, C. and Bonner, W.M. (1999) Megabase chromatin domains involved in DNA double-strand breaks in vivo. J Cell Biol, 146, 905-916.

Rogakou, E.P., Nieves-Neira, W., Boon, C., Pommier, Y. and Bonner, W.M. (2000a) Initiation of DNA fragmentation during apoptosis induces phosphorylation of $\mathrm{H} 2 \mathrm{AX}$ histone at serine 139. J Biol Chem, 275, 9390-9395.

Rogakou, E.P., Pilch, D.R., Orr, A.H., Ivanova, V.S. and Bonner, W.M. (1998) DNA double-stranded breaks induce histone H2AX phosphorylation on serine 139. J Biol Chem, 273, 5858-5868.

Rogakou, E.P., Redon, C., Boon, C., Johnson, K. and Bonner, W.M. (2000b) Rapid histone extraction for electrophoretic analysis. Biotechniques, 28, 38-40, 42, 46.

Rongen, H.A.H., Hoetelmans, R.M.W., Bult, A. and Vanbennekom, W.P. (1994) Chemiluminescence and Immunoassays. Journal of Pharmaceutical and Biomedical Analysis, 12, 433-462.

Roth, S.Y., Denu, J.M. and Allis, C.D. (2001) Histone acetyltransferases. Annu Rev Biochem, 70, 81120. 
Sabet, N., Volo, S., Yu, C., Madigan, J.P. and Morse, R.H. (2004) Genome-wide analysis of the relationship between transcriptional regulation by $\mathrm{Rpd} 3 p$ and the histone $\mathrm{H} 3$ and $\mathrm{H} 4$ amino termini in budding yeast. Mol Cell Biol, 24, 8823-8833.

Saitoh, Y. and Laemmli, U.K. (1993) From the chromosomal loops and the scaffold to the classic bands of metaphase chromosomes. Cold Spring Harb Symp Quant Biol, 58, 755-765.

Salgame, P., Varadhachary, A.S., Primiano, L.L., Fincke, J.E., Muller, S. and Monestier, M. (1997) An ELISA for detection of apoptosis. Nucleic Acids Res, 25, 680-681.

Salvesen, G.S. and Renatus, M. (2002) Apoptosome: the seven-spoked death machine. Dev Cell, 2 , 256-257.

Santos-Rosa, H., Bannister, A.J., Dehe, P.M., Geli, V. and Kouzarides, T. (2004) Methylation of H3 lysine 4 at euchromatin promotes Sir3p association with heterochromatin. J Biol Chem, 279, 47506-47512.

Santos-Rosa, H., Schneider, R., Bannister, A.J., Sherriff, J., Bernstein, B.E., Emre, N.C., Schreiber, S.L., Mellor, J. and Kouzarides, T. (2002) Active genes are tri-methylated at K4 of histone H3. Nature, 419, 407-411.

Saraste, A. and Pulkki, K. (2000) Morphologic and biochemical hallmarks of apoptosis. Cardiovasc Res, 45, 528-537.

Sarg, B., Helliger, W., Talasz, H., Koutzamani, E. and Lindner, H.H. (2004) Histone H4 hyperacetylation precludes histone $\mathrm{H} 4$ lysine 20 trimethylation. J Biol Chem, 279, 5345853464

Sartorius, U., Schmitz, I. and Krammer, P.H. (2001) Molecular mechanisms of death-receptormediated apoptosis. Chembiochem, 2, 20-29.

Savill, J.S., Wyllie, A.H., Henson, J.E., Walport, M.J., Henson, P.M. and Haslett, C. (1989) Macrophage phagocytosis of aging neutrophils in inflammation. Programmed cell death in the neutrophil leads to its recognition by macrophages. J Clin Invest, 83, 865-875.

Scaffidi, C., Fulda, S., Srinivasan, A., Friesen, C., Li, F., Tomaselli, K.J., Debatin, K.M., Krammer, P.H. and Peter, M.E. (1998) Two CD95 (APO-1/Fas) signaling pathways. Embo J, 17, 1675-1687.

Schalch, T., Duda, S., Sargent, D.F. and Richmond, T.J. (2005) X-ray structure of a tetranucleosome and its implications for the chromatin fibre. Nature, 436, 138-141.

Schneider, R., Bannister, A.J., Myers, F.A., Thorne, A.W., Crane-Robinson, C. and Kouzarides, T. (2004) Histone H3 lysine 4 methylation patterns in higher eukaryotic genes. Nat Cell Biol, 6 , 73-77.

Schotta, G., Lachner, M., Peters, A.H. and Jenuwein, T. (2004a) The indexing potential of histone lysine methylation. Novartis Found Symp, 259, 22-37; discussion 37-47, 163-169.

Schotta, G., Lachner, M., Sarma, K., Ebert, A., Sengupta, R., Reuter, G., Reinberg, D. and Jenuwein, T. (2004b) A silencing pathway to induce H3-K9 and H4-K20 trimethylation at constitutive heterochromatin. Genes Dev, 18, 1251-1262.

Seligson, D.B., Horvath, S., Shi, T., Yu, H., Tze, S., Grunstein, M. and Kurdistani, S.K. (2005) Global histone modification patterns predict risk of prostate cancer recurrence. Nature, 435, 12621266. 
Senshu, T., Fukuda, M. and Ohashi, M. (1978) Preferential association of newly synthesized H3 and H4 histones with newly replicated DNA. J Biochem (Tokyo), 84, 985-988.

Sharp, P.A., Sugden, B. and Sambrook, J. (1973) Detection of two restriction endonuclease activities in Haemophilus parainfluenzae using analytical agarose--ethidium bromide electrophoresis. Biochemistry, 12, 3055-3063.

Shen, X., Yu, L., Weir, J.W. and Gorovsky, M.A. (1995) Linker histones are not essential and affect chromatin condensation in vivo. Cell, 82, 47-56.

Shi, Y., Sawada, J., Sui, G., Affar el, B., Whetstine, J.R., Lan, F., Ogawa, H., Luke, M.P. and Nakatani, Y. (2003) Coordinated histone modifications mediated by a CtBP co-repressor complex. Nature, 422, 735-738.

Shibahara, K., Verreault, A. and Stillman, B. (2000) The N-terminal domains of histones H3 and H4 are not necessary for chromatin assembly factor-1- mediated nucleosome assembly onto replicated DNA in vitro. Proc Natl Acad Sci U S A, 97, 7766-7771.

Simpson, R.T. (1978) Structure of the chromatosome, a chromatin particle containing 160 base pairs of DNA and all the histones. Biochemistry, 17, 5524-5531.

Slee, E.A., Adrain, C. and Martin, S.J. (2001) Executioner caspase-3, -6, and -7 perform distinct, nonredundant roles during the demolition phase of apoptosis. J Biol Chem, 276, 7320-7326.

Slee, E.A., Harte, M.T., Kluck, R.M., Wolf, B.B., Casiano, C.A., Newmeyer, D.D., Wang, H.G., Reed, J.C., Nicholson, D.W., Alnemri, E.S., Green, D.R. and Martin, S.J. (1999) Ordering the cytochrome c-initiated caspase cascade: hierarchical activation of caspases-2, -3, -6, -7, -8, and -10 in a caspase-9-dependent manner. J Cell Biol, 144, 281-292.

Smith, R.M. and Rill, R.L. (1989) Mobile histone tails in nucleosomes. Assignments of mobile segments and investigations of their role in chromatin folding. J Biol Chem, 264, 10574-10581.

Smith, S. and Stillman, B. (1989) Purification and characterization of CAF-I, a human cell factor required for chromatin assembly during DNA replication in vitro. Cell, 58, 15-25.

Snow, C.M., Senior, A. and Gerace, L. (1987) Monoclonal antibodies identify a group of nuclear pore complex glycoproteins. J Cell Biol, 104, 1143-1156.

Sobel, R.E., Cook, R.G., Perry, C.A., Annunziato, A.T. and Allis, C.D. (1995) Conservation of deposition-related acetylation sites in newly synthesized histones $\mathrm{H} 3$ and $\mathrm{H} 4$. Proc Natl Acad Sci U S A, 92, 1237-1241.

Standring, R. and Williams, A.F. (1978) Glycoproteins and antigens of membranes prepared from rat thymocytes after lysis by shearing or with the detergent Tween-40. Biochim Biophys Acta, 508, 85-96.

Stedman, E. (1950) Cell specificity of histones. Nature, 166, 780-781.

Strahl, B.D. and Allis, C.D. (2000) The language of covalent histone modifications. Nature, 403, 41-45.

Struhl, K. (1998) Histone acetylation and transcriptional regulatory mechanisms. Genes Dev, 12, 599606.

Sun, Z.W. and Allis, C.D. (2002) Ubiquitination of histone H2B regulates H3 methylation and gene silencing in yeast. Nature, 418, 104-108. 
Tagami, H., Ray-Gallet, D., Almouzni, G. and Nakatani, Y. (2004) Histone H3.1 and H3.3 complexes mediate nucleosome assembly pathways dependent or independent of DNA synthesis. Cell, 116, 51-61.

Taimen, P. and Kallajoki, M. (2003) NuMA and nuclear lamins behave differently in Fas-mediated apoptosis. J Cell Sci, 116, 571-583.

Takahashi, A., Alnemri, E.S., Lazebnik, Y.A., Fernandes-Alnemri, T., Litwack, G., Moir, R.D., Goldman, R.D., Poirier, G.G., Kaufmann, S.H. and Earnshaw, W.C. (1996a) Cleavage of lamin A by Mch2 alpha but not CPP32: multiple interleukin 1 beta-converting enzyme-related proteases with distinct substrate recognition properties are active in apoptosis. Proc Natl Acad Sci U S A, 93, 8395-8400.

Takahashi, A., Musy, P.Y., Martins, L.M., Poirier, G.G., Moyer, R.W. and Earnshaw, W.C. (1996b) CrmA/SPI-2 inhibition of an endogenous ICE-related protease responsible for lamin A cleavage and apoptotic nuclear fragmentation. J Biol Chem, 271, 32487-32490.

Talasz, H., Helliger, W., Sarg, B., Debbage, P.L., Puschendorf, B. and Lindner, H. (2002) Hyperphosphorylation of histone H2A.X and dephosphorylation of histone $\mathrm{H} 1$ subtypes in the course of apoptosis. Cell Death Differ, 9, 27-39.

Talasz, H., Sapojnikova, N., Helliger, W., Lindner, H. and Puschendorf, B. (1998) In vitro binding of H1 histone subtypes to nucleosomal organized mouse mammary tumor virus long terminal repeat promotor. J Biol Chem, 273, 32236-32243.

Tamburini, B.A., Carson, J.J., Adkins, M.W. and Tyler, J.K. (2005) Functional Conservation and Specialization among Eukaryotic Anti-Silencing Function 1 Histone Chaperones. Eukaryot Cell, 4, 1583-1590.

Tanimoto, Y., Onishi, Y., Hashimoto, S. and Kizaki, H. (1997) Peptidyl aldehyde inhibitors of proteasome induce apoptosis rapidly in mouse lymphoma RVC cells. J Biochem (Tokyo), 121, $542-549$

Thiriet, C. and Hayes, J.J. (2005) Chromatin in need of a fix: phosphorylation of H2AX connects chromatin to DNA repair. Mol Cell, 18, 617-622.

Th'ng, J.P. (2001) Histone modifications and apoptosis: cause or consequence? Biochem Cell Biol, 79, 305-311.

Thoma, F. and Koller, T. (1977) Influence of histone H1 on chromatin structure. Cell, 12, 101-107.

Thoma, F., Koller, T. and Klug, A. (1979) Involvement of histone H1 in the organization of the nucleosome and of the salt-dependent superstructures of chromatin. J Cell Biol, 83, 403-427.

Thornberry, N.A. and Lazebnik, Y. (1998) Caspases: enemies within. Science, 281, 1312-1316.

Thorne, A.W., Kmiciek, D., Mitchelson, K., Sautiere, P. and Crane-Robinson, C. (1990) Patterns of histone acetylation. Eur J Biochem, 193, 701-713.

Tse, C., Georgieva, E.I., Ruiz-Garcia, A.B., Sendra, R. and Hansen, J.C. (1998a) Gcn5p, a transcription-related histone acetyltransferase, acetylates nucleosomes and folded nucleosomal arrays in the absence of other protein subunits. J Biol Chem, 273, 32388-32392.

Tse, C., Sera, T., Wolffe, A.P. and Hansen, J.C. (1998b) Disruption of higher-order folding by core histone acetylation dramatically enhances transcription of nucleosomal arrays by RNA polymerase III. Mol Cell Biol, 18, 4629-4638. 
Turner, B.M. (2000) Histone acetylation and an epigenetic code. Bioessays, 22, 836-845.

Turner, B.M. (2002) Cellular memory and the histone code. Cell, 111, 285-291.

Ura, S., Masuyama, N., Graves, J.D. and Gotoh, Y. (2001a) Caspase cleavage of MST1 promotes nuclear translocation and chromatin condensation. Proc Natl Acad Sci U S A, 98, 1014810153.

Ura, S., Masuyama, N., Graves, J.D. and Gotoh, Y. (2001b) MST1-JNK promotes apoptosis via caspase-dependent and independent pathways. Genes Cells, 6, 519-530.

Utley, R.T., Lacoste, N., Jobin-Robitaille, O., Allard, S. and Cote, J. (2005) Regulation of NuA4 histone acetyltransferase activity in transcription and DNA repair by phosphorylation of histone $\mathrm{H} 4$. Mol Cell Biol, 25, 8179-8190.

Vakoc, C.R., Mandat, S.A., Olenchock, B.A. and Blobel, G.A. (2005) Histone H3 lysine 9 methylation and HP1gamma are associated with transcription elongation through mammalian chromatin. Mol Cell, 19, 381-391.

van Holde, K. and Zlatanova, J. (1995) Chromatin higher order structure: chasing a mirage? J Biol Chem, 270, 8373-8376.

van Nieuwenhuijze, A.E., van Lopik, T., Smeenk, R.J. and Aarden, L.A. (2003) Time between onset of apoptosis and release of nucleosomes from apoptotic cells: putative implications for systemic lupus erythematosus. Ann Rheum Dis, 62, 10-14.

Vandenabeele, P., Declercq, W., Beyaert, R. and Fiers, W. (1995a) Two tumour necrosis factor receptors: structure and function. Trends Cell Biol, 5, 392-399.

Vandenabeele, P., Declercq, W., Vanhaesebroeck, B., Grooten, J. and Fiers, W. (1995b) Both TNF receptors are required for TNF-mediated induction of apoptosis in PC60 cells. J Immunol, 154, 2904-2913.

Varga-Weisz, P.D., Wilm, M., Bonte, E., Dumas, K., Mann, M. and Becker, P.B. (1997) Chromatinremodelling factor CHRAC contains the ATPases ISWI and topoisomerase II. Nature, 388, 598-602.

Vaux, D.L., Cory, S. and Adams, J.M. (1988) Bcl-2 gene promotes haemopoietic cell survival and cooperates with c-myc to immortalize pre-B cells. Nature, 335, 440-442.

Vaux, D.L. and Korsmeyer, S.J. (1999) Cell death in development. Cell, 96, 245-254.

Vermes, I. and Haanen, C. (1994) Apoptosis and programmed cell death in health and disease. Adv Clin Chem, 31, 177-246.

Verreault, A., Kaufman, P.D., Kobayashi, R. and Stillman, B. (1996) Nucleosome assembly by a complex of CAF-1 and acetylated histones H3/H4. Cell, 87, 95-104.

Verreault, A., Kaufman, P.D., Kobayashi, R. and Stillman, B. (1998) Nucleosomal DNA regulates the core-histone-binding subunit of the human Hat1 acetyltransferase. Curr Biol, 8, 96-108.

Walia, H., Chen, H.Y., Sun, J.M., Holth, L.T. and Davie, J.R. (1998) Histone acetylation is required to maintain the unfolded nucleosome structure associated with transcribing DNA. J Biol Chem, 273, 14516-14522.

Wang, D., Hara, R., Singh, G., Sancar, A. and Lippard, S.J. (2003) Nucleotide excision repair from site-specifically platinum-modified nucleosomes. Biochemistry, 42, 6747-6753. 
Wang, H., Cao, R., Xia, L., Erdjument-Bromage, H., Borchers, C., Tempst, P. and Zhang, Y. (2001a) Purification and functional characterization of a histone H3-lysine 4-specific methyltransferase. Mol Cell, 8, 1207-1217.

Wang, H., Huang, Z.Q., Xia, L., Feng, Q., Erdjument-Bromage, H., Strahl, B.D., Briggs, S.D., Allis, C.D., Wong, J., Tempst, P. and Zhang, Y. (2001b) Methylation of histone H4 at arginine 3 facilitating transcriptional activation by nuclear hormone receptor. Science, 293, 853-857.

Wang, H., Wang, L., Erdjument-Bromage, H., Vidal, M., Tempst, P., Jones, R.S. and Zhang, Y. (2004) Role of histone H2A ubiquitination in Polycomb silencing. Nature, 431, 873-878.

Wang, X. (2001) The expanding role of mitochondria in apoptosis. Genes Dev, 15, 2922-2933.

Waring, P., Khan, T. and Sjaarda, A. (1997) Apoptosis induced by gliotoxin is preceded by phosphorylation of histone $\mathrm{H} 3$ and enhanced sensitivity of chromatin to nuclease digestion. $J$ Biol Chem, 272, 17929-17936.

Weaver, V.M., Carson, C.E., Walker, P.R., Chaly, N., Lach, B., Raymond, Y., Brown, D.L. and Sikorska, M. (1996) Degradation of nuclear matrix and DNA cleavage in apoptotic thymocytes. J Cell Sci, 109 ( Pt 1), 45-56.

Weeks, I., Beheshti, I., Mccapra, F., Campbell, A.K. and Woodhead, J.S. (1983) Acridinium Esters as High-Specific-Activity Labels in Immunoassay. Clinical Chemistry, 29, 1474-1479.

Widlak, P., Kalinowska, M., Parseghian, M.H., Lu, X., Hansen, J.C. and Garrard, W.T. (2005) The histone $\mathrm{H} 1 \mathrm{C}$-terminal domain binds to the apoptotic nuclease, DNA fragmentation factor (DFF40/CAD) and stimulates DNA cleavage. Biochemistry, 44, 7871-7878.

Widom, J., Finch, J.T. and Thomas, J.O. (1985) Higher-order structure of long repeat chromatin. Embo J, 4, 3189-3194.

Widom, J. and Klug, A. (1985) Structure of the 300A chromatin filament: X-ray diffraction from oriented samples. Cell, 43, 207-213.

Wolffe, A.P. and Hayes, J.J. (1999) Chromatin disruption and modification. Nucleic Acids Res, 27, 711-720.

Wolffe, A.P. and Pruss, D. (1996a) Deviant nucleosomes: the functional specialization of chromatin. Trends Genet, 12, 58-62.

Wolffe, A.P. and Pruss, D. (1996b) Hanging on to histones. Chromatin. Curr Biol, 6, 234-237.

Wolffe, A.P., Urnov, F.D. and Guschin, D. (2000) Co-repressor complexes and remodelling chromatin for repression. Biochem Soc Trans, 28, 379-386.

Woodcock, C.L., Frado, L.L. and Rattner, J.B. (1984) The higher-order structure of chromatin: evidence for a helical ribbon arrangement. J Cell Biol, 99, 42-52.

Woodcock, C.L. and Frank, J. (1984) Nucleosome mass distribution using image averaging. J Ultrastruct Res, 89, 295-302.

Woodhead, S. (1995) Chemiluminescence Immunoassay - a Review. Journal of Clinical Ligand Assay, 18, 49-53.

Worcel, A. (1978) Molecular architecture of the chromatin fiber. Cold Spring Harb Symp Quant Biol, 42 Pt 1, 313-324.

Worcel, A., Han, S. and Wong, M.L. (1978) Assembly of newly replicated chromatin. Cell, 15, 969-977. 
Workman, J.L. and Abmayr, S.M. (2004) Histone H3 variants and modifications on transcribed genes. Proc Natl Acad Sci U S A, 101, 1429-1430.

Wu, D., Ingram, A., Lahti, J.H., Mazza, B., Grenet, J., Kapoor, A., Liu, L., Kidd, V.J. and Tang, D. (2002) Apoptotic release of histones from nucleosomes. J Biol Chem, 277, 12001-12008.

Wyce, A., Henry, K.W. and Berger, S.L. (2004) H2B ubiquitylation and de-ubiquitylation in gene activation. Novartis Found Symp, 259, 63-73; discussion 73-67, 163-169.

Wyllie, A.H., Beattie, G.J. and Hargreaves, A.D. (1981) Chromatin changes in apoptosis. Histochem J, 13, 681-692.

Wyllie, A.H., Kerr, J.F. and Currie, A.R. (1980) Cell death: the significance of apoptosis. Int Rev Cytol, 68, 251-306.

Wyllie, A.H., Morris, R.G., Smith, A.L. and Dunlop, D. (1984) Chromatin cleavage in apoptosis: association with condensed chromatin morphology and dependence on macromolecular synthesis. J Pathol, 142, 67-77.

Yang, C.H., Lambie, E.J. and Snyder, M. (1992) NuMA: an unusually long coiled-coil related protein in the mammalian nucleus. J Cell Biol, 116, 1303-1317.

Ye, J., Ai, X., Eugeni, E.E., Zhang, L., Carpenter, L.R., Jelinek, M.A., Freitas, M.A. and Parthun, M.R. (2005) Histone $\mathrm{H} 4$ lysine 91 acetylation a core domain modification associated with chromatin assembly. Mol Cell, 18, 123-130.

Zhou, Y.B., Gerchman, S.E., Ramakrishnan, V., Travers, A. and Muyldermans, S. (1998) Position and orientation of the globular domain of linker histone H5 on the nucleosome. Nature, 395, 402405.

Zuzarte-Luis, V. and Hurle, J.M. (2002) Programmed cell death in the developing limb. Int J Dev Biol, 46, 871-876.

Zweidler, A. (1978) Resolution of histones by polyacrylamide gel electrophoresis in presence of nonionic detergents. Methods Cell Biol, 17, 223-233. 


\section{Danksagung}

An dieser Stelle möchte ich mich bei allen denjenigen bedanken, die maßgeblich zum Gelingen dieser Arbeit beigetragen haben:

- Herrn Prof. Dr. D. Doenecke danke ich für die interessante Themenstellung und jede weitere wissenschaftliche Unterstützung beim Erstellen dieser Arbeit.

- Herrn Prof. Dr. R. Hardeland für die bereitwillige Übernahme des Korreferates.

- Besonders danken möchte ich vor allem auch Nicole Happel für ihre unermüdliche Unterstützung, ihre Diskussionsbereitschaft sowie ihren geduldigen Erklärungen und Lösungsvorschläge während der Arbeiten an der HPLC.

- Kristina Hänecke danke ich vor allem für die immer wiederkehrenden erheiternden Gespräche, ihren intensiven Arbeitseinsätzen an der Kapillarelektrophorese und vor allem für die tatkräftige Unterstützung in der Zellkultur.

- Danken möchte ich auch Christa Bode, die mir mit ihrem beinahe unerschöpflichen Pool an labortechnischen Tipps und Tricks äußerst hilfreich zur Seite gestanden hat.

- Des Weiteren möchte ich mich bei Wiebke für die unzähligen abendlichen Gesprächsrunden sowohl fachlicher als auch nicht-fachlicher Natur bedanken, vor allem aber für die gemeinsamen „(arbeits-)Druck“ ausgleichenden Tauchsportaktivitäten. Nicht umsonst heißt es wohl: „Nur unter Druck entstehen Diamanten“.

- Dank gilt natürlich auch Jörg, Sonja, Stefan und Julia für das angenehme Arbeitsklima, das vor allem durch die abendlichen „Diskussionsrunden“ im Aufenthaltsraum noch beträchtlich gesteigert wurde. Ein besonderes Dankeschön zusätzlich an Jörg und das „Taxi“ für den Feinschliff an dieser Arbeit bezüglich Formatierung, Layout und Korrekturlesen.

- Ganz besonderer Dank gilt meinen Eltern für jede Art von Unterstützung während meines gesamten Studiums einschließlich der Promotion. 


\section{Curriculum Vitae}

Name:

Vorname:

Geburtsdatum:

Geburtsort:

Staatsangehörigkeit:

Ausbildung:
Beisel

Nadine

$7 / 04 / 1975$

Göttingen

deutsch

1981-1985 Bonifatiusschule I, Grundschule; Göttingen

1985-1987 Bonifatiusschule II, Orientierungsstufe, Göttingen

1987-1994 Felix-Klein-Gymnasium, Göttingen

1994 Abschluss: Allgemeine Hochschulreife

1994-1995 Studium der Fächer Chemie / Englisch (LA Gym)

an der Carl von Ossietzky Universität, Oldenburg

1995-2001 Studium der Fächer Biologie / Englisch an der

Georg-August Universität Göttingen

WS 1996/97 Zwischenprüfung Englisch

SS 1997 Zwischenprüfung Biologie (Zoologie und Botanik) 1999-2000 DAAD Stipendium für einen Auslandsaufenthalt an der University of St Andrews

Fachbereiche: Biochemie / Molekularbiologie / Englisch 2000/2001 Staatsexamensarbeit am Institut für Hygiene und Humangenetik in der Abteilung Immunologie, Göttingen Thema: „Induktion und Expression des Komplementproteins Faktor $\mathrm{H}^{\prime \prime}$ 2000/2001 Staatsexamen für LA Gym in den Fächern Biologie und Englisch (Dezember 2001)

02/2002-09/2002 Wissenschaftliche Mitarbeiterin im Institut für Hygiene und Humangenetik (Universität Göttingen);

Abteilung: Bakteriologie 10/2002-10/2005 Doktorarbeit am Institut für Biochemie und Molekulare Zellbiologie in der Abteilung Molekularbiologie (Universität Göttingen); Thema: 'Patterns of post-translational histone modifications, chromatin condensation and DNA fragmentation during apoptosis'. 